\title{
Actividad eléctrica atmosférica en Sudamérica
}

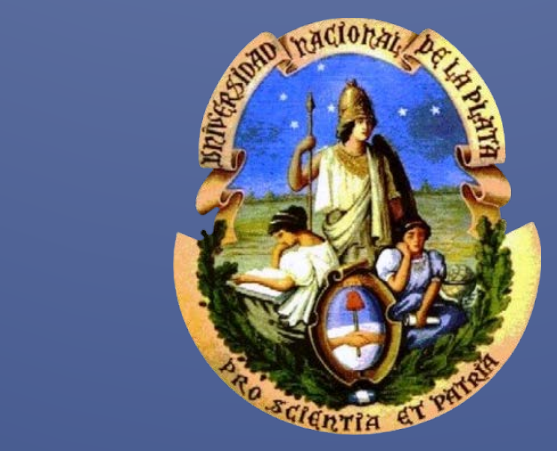

\section{Por María Gabriela Nicora}

Geofísica, Universidad Nacional de La Plata

Director: Dr. Rodrigo Exequiel. Bürgesser

Codirector: Dr. Pablo Luis Antico

Tesis presentada en cumplimiento de los requisitos para obtener el grado de Doctor en Geofísica en la

Facultad de Ciencias Astronómicas y Geofísicas

Universidad Nacional de La Plata

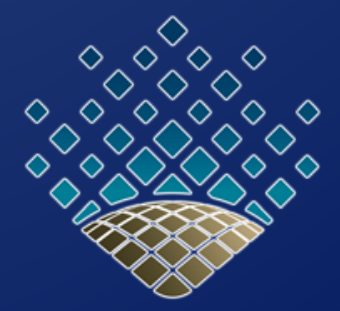




\section{Resumen}

La actividad eléctrica atmosférica (AEA), dada su relación con la microfísica y dinámica de las nubes de tormenta, es un parámetro relevante para el estudio del clima. El objetivo de la presente tesis consiste en realizar una caracterización de la AEA en América del Sur utilizando distintas escalas espaciales y temporales e investigar su relación con distintos eventos. Con miras de cumplir este objetivo se analizó la AEA detectada por dos sistemas independientes de detección, World Wide Lightning Location Network (WWLLN) y Lightning Imaging Sensor (LIS).

En la sección introductoria de la tesis presentamos la AEA dentro del circuito global, la física de las descargas, y parámetros de microfísica de nubes. Esta sección es seguida por la caracterización de la AEA a nivel global, en particular se estudiaron las regiones ubicada en la zona del Lago de Maracaibo (Venezuela) y la Cuenca del Congo (África) por ser éstas las regiones que presentan la mayor densidad de AEA a escala global. Si bien la Cuenca del Congo escapa al objetivo de la presente tesis, la caracterización de esta región permitió validar las bases de datos y los métodos de análisis utilizados en Sudamérica.

En una segunda parte de la tesis, se caracteriza la AEA en América del Sur, con énfasis en las regiones subtropical y extratropical del continente, en diferentes escalas temporales (diurna, estacional, e interanual). Se analizaron las regiones con AEA relevante y su relación con la actividad convectiva y la climatología local. Los resultados encontrados muestran que, en la región subtropical del continente, el ciclo diario de la AEA no presenta un tiempo de máxima actividad como consecuencia de la desestabilización de la capa límite debido a la radiación solar, sino que la AEA puede ocurrir en cualquier momento de día y que está fuertemente modelado por los sistemas convectivos de mesoescala.

Para el caso de la Argentina, se confeccionaron mapas isoceráunicos del territorio nacional. Éstos revelaron ciertas características, como por ejemplo el máximo encontrado en la región noroeste del país y cierta actividad eléctrica observada en la región patagónica de Chile, que no había sido reportado anteriormente. Estos mapas fueron utilizados para la actualización de las normas IRAM de protección contra descargas eléctricas atmosféricas en Argentina (IRAM 2184-11/AEA 92305-11).

Dada las observaciones de AEA en la región patagónica de Chile donde, en principio, la AEA debería ser irrelevante, se realizó un análisis de esta región y se propuso un modelo sinóptico para explicar los resultados encontrados.

La última parte de la tesis, presenta trabajos de aplicación de naturaleza operacional. En base a los mapas isoceráunicos, se realizó un estudio de la vulnerabilidad de la población frente a estos tipos de eventos y se confeccionó un mapa de riesgo para implementar medidas de protección de la población. También realizamos un estudio sobre la factibilidad de utilizar la AEA detectada por la WWLLN como marcador de eventos severos. Por último, se presenta un estudio sobre la AEA debido a la erupción volcánica del complejo volcánico Cordón Caulle, donde se relacionó la AEA observada con la altura de la pluma volcánica y la intensidad de la erupción. En este estudio se verificó que la AEA puede ser utilizada para emitir un alerta temprano a la comunidad ante la ocurrencia de este tipo de eventos. 


\section{Agradecimientos}

Deseo expresar mi agradecimiento a todas las personas que me acompañaron en este proceso. A mis papás que me permitieron hacer siempre lo que sentía sin ningún condicionamiento, a mis hermanos que me enseñaron el trabajo en equipo, a Adrián y a mis hijos Tomás, Bruno y Mateo, con su apoyo incondicional que sale del amor, a mis amigos de siempre que son mi apoyo.

También quiero agradecer a aquellas personas que fueron apareciendo en esta nueva etapa de mi vida, de manera "casual". Como dice Cortázar:"Andábamos sin buscarnos pero sabiendo que andábamos para encontrarnos"Elián y Jorge que han sido y son mis compañeros de ruta; el Dr. Quel, que junto con todos mis compañeros de la División, en especial Raúl, a Jacobo y Patricio, me han brindado todo su apoyo en este hermoso tema de trabajo; al Dr. Manzano, que desde el CEILAP apoyó la investigación; al Dr. Ávila que me acogió en su grupo y me permite pensar cosas nuevas, mi director Rodrigo el que ha sido el mejor director que pude haber tenido; mi codirector Pablo, que siempre acompaño con entusiasmo los resultados; a Jorge y al Ing. Arcioni que confiaron en las nuevas metodologías y a Rene y Paola que han sido maravillosos maestros, totalmente generosos y de los cuales aprendí muchísimo.

Deseo agradecer a las instituciones que financiaron o me facilitaron el acceso a las distintas fuentes de información utilizadas en este estudio. A la UNC (FAMAF) en especial al grupo de Física de la Atmosfera, a la red World Wide Lightning Location Network, al MINDEF (PIDDEF 14/12), al Servicio Meteorológico Nacional, UMI, NASA/MSFC, y especialmente a la División LIDAR del CEILAP, CITEDEF, en cuyas instalaciones se realizó este trabajo. Por haberla recibido y apoyado el tema de tesis, suministrándome fondos propios y facilitándome los medios necesarios básicos para iniciar y llevar adelante mis investigaciones, y apoyando mi ingreso al RPIDFA, y por haber colaborado en el sostenimiento y expansión de la red WWLLN en la Argentina. 


\section{Índice}

Resumen III

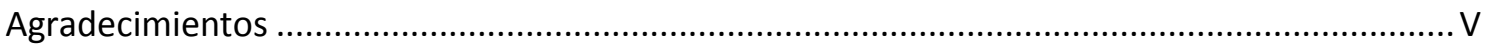

Aporte original y Objetivos del Trabajo ............................................................................... 2

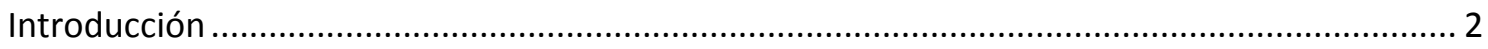

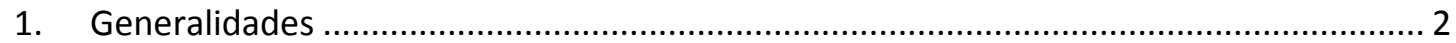

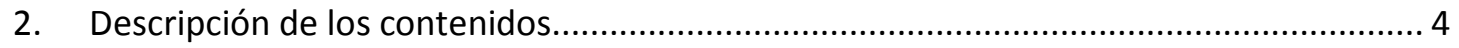

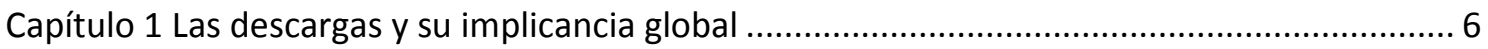

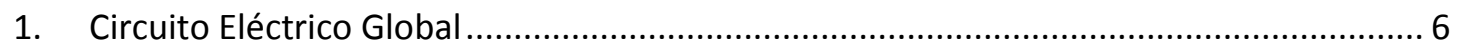

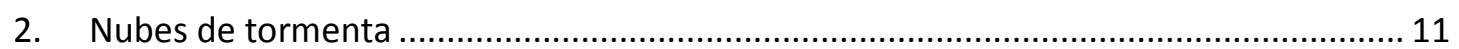

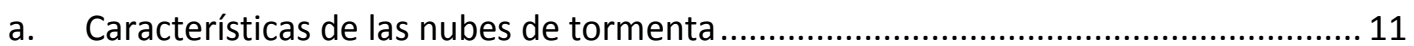

b. Estructura eléctrica en las nubes de tormentas......................................................... 12

c. Modelos de electrificación de nubes de tormenta ................................................... 15

Teoría precipitativa no inductiva .............................................................................. 16

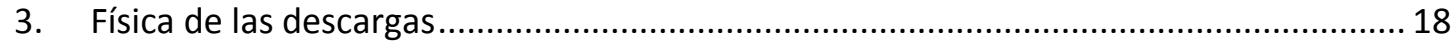

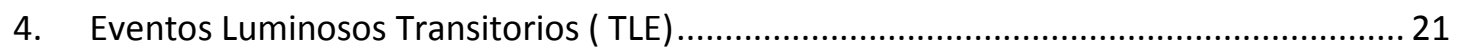

5. Implicancia global de las descargas y los componentes del Circuito Global.....................24

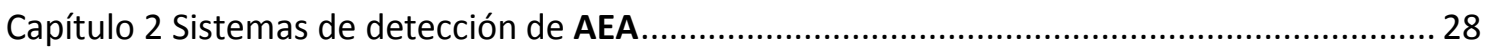

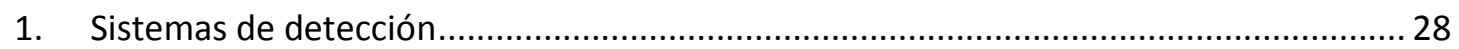

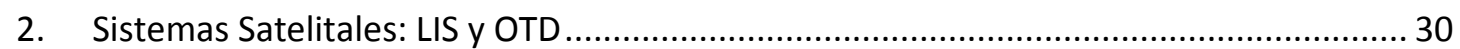

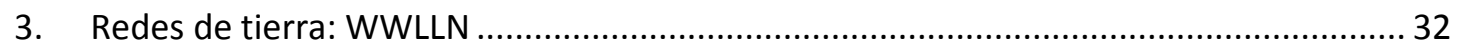

4. Comparación entre las bases de datos ........................................................................... 35

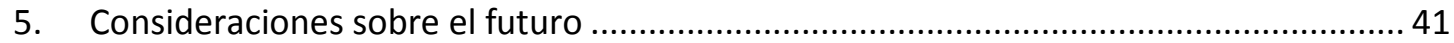

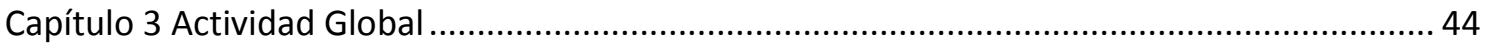

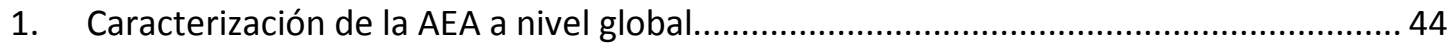

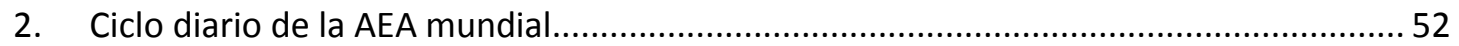

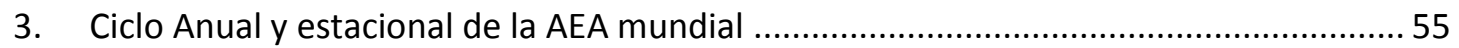

Capítulo 4 Estudio de dos Máximos de AEA a nivel global ........................................................6 60

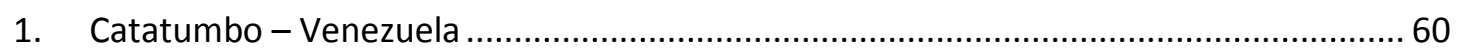

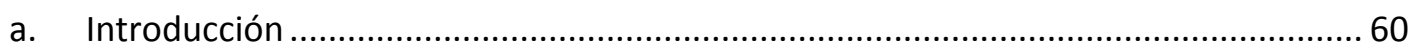

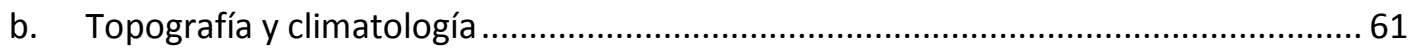

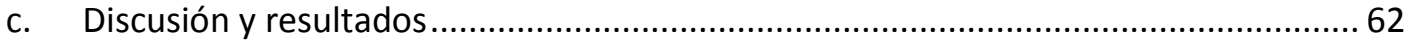

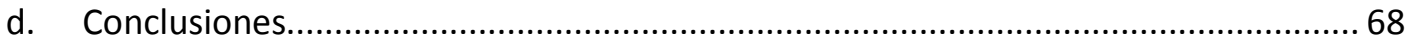




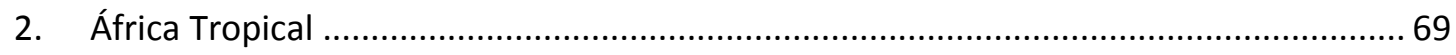

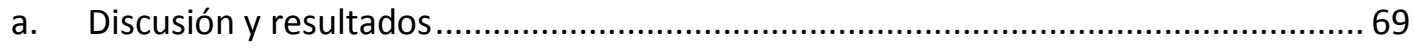

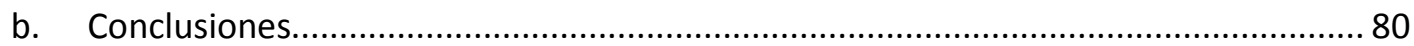

Capítulo 5 Mapas isoceráunicos de la República Argentina - Días de tormenta .......................... 82

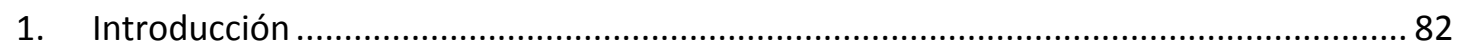

2. Estudio de días de Tormentas usando datos de la Red WWLLN - Metodología...............87 87

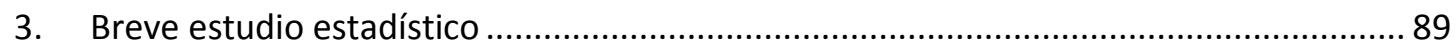

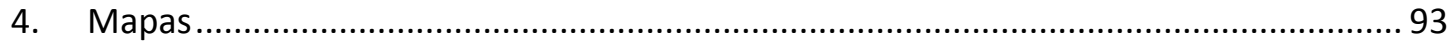

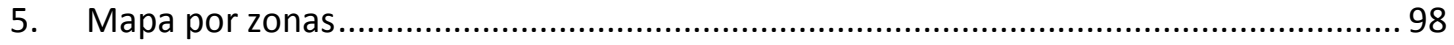

Capítulo 6 Actividad Eléctrica Atmosférica en el Sur de Sudamérica ....................................... 100

1. Caracterización del Clima Medio en el Sur de América del Sur ..................................... 100

2. Caracterización de la AEA Media en el Sur de Sudamérica......................................... 103

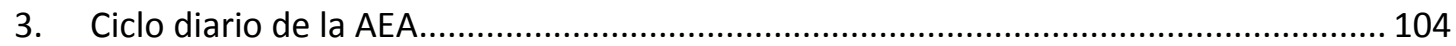

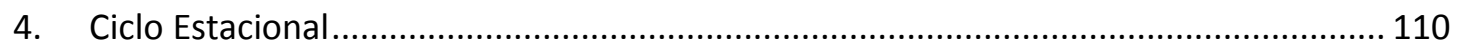

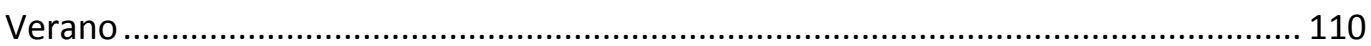

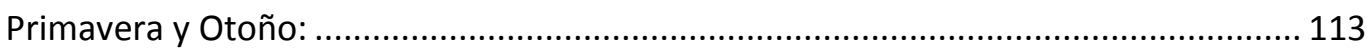

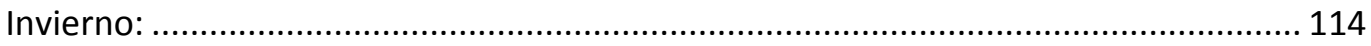

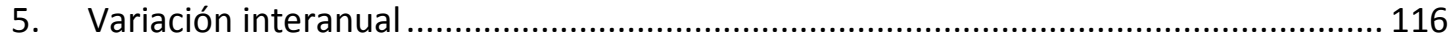

Capítulo 7 Actividad eléctrica atmosférica en la Patagonia Occidental.................................. 120

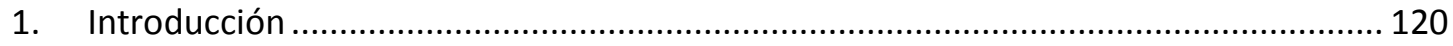

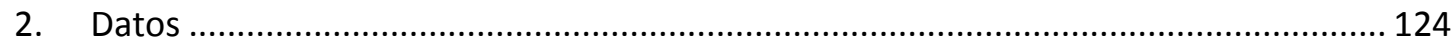

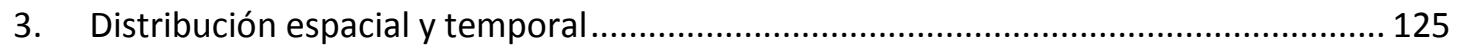

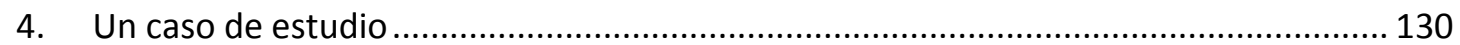

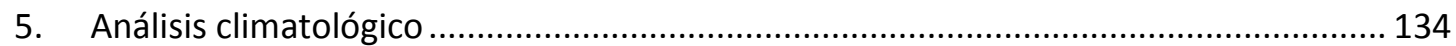

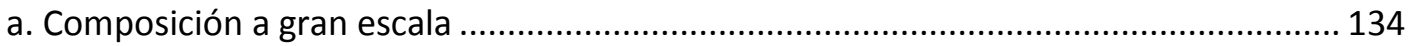

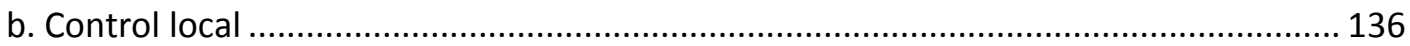

6. Modelo conceptual y observaciones finales ............................................................... 139

Capítulo 8 Estudio de muertes por acción de descargas ......................................................... 142

1. Antecedentes de trabajos ...................................................................................... 142

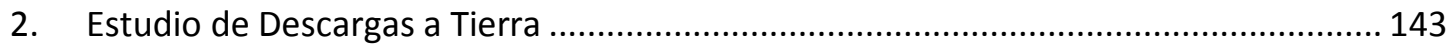

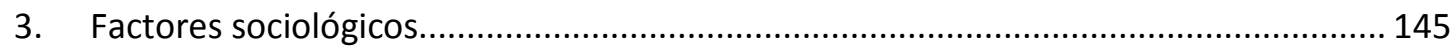

4. Modelo de la muerte por acción de Descargas eléctricas atmosféricas a tierra (Rayos) 147

5. Rayos a tierra y sus posibles daños a personas expuestas 


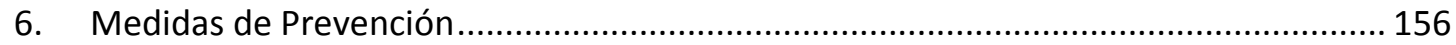

Capítulo 9 Descargas eléctricas como marcadores de eventos severos.................................... 158

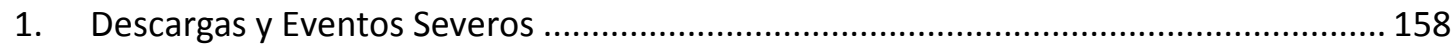

2. Estudio de las posibilidades de detección y pronóstico de eventos severos en Argentina

- Tormenta del 18 de Abril del 2010 ......................................................................................... 162

a. Características meteorológicas del día en estudio..................................................... 162

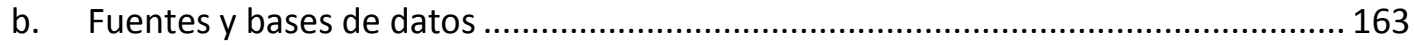

c. Metodología: de comparación entre descargas totales y eventos severosC. Schultz et.

al. (2011) - Universidad de Alabama ................................................................................. 163

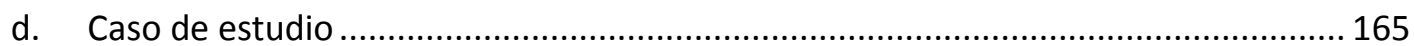

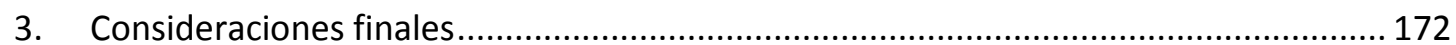

Capítulo 10 Actividad Eléctrica asociada a erupciones volcánicas - Un caso de estudio ......... 174

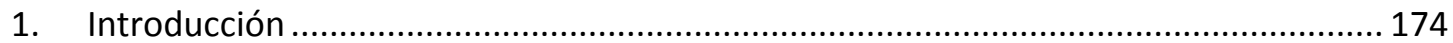

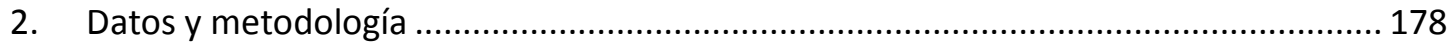

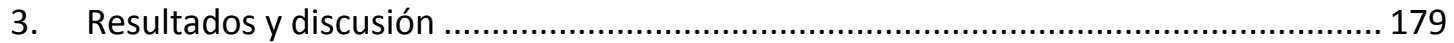

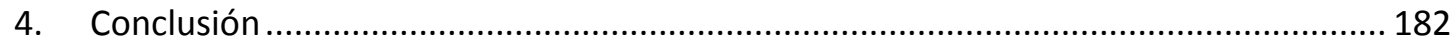

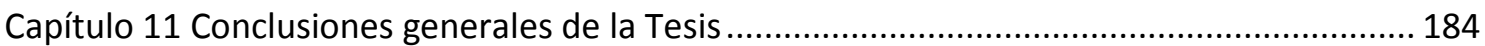

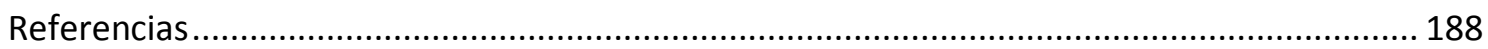

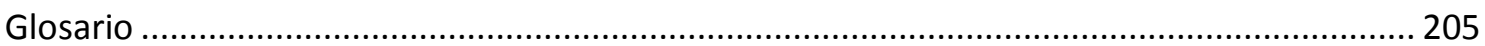




\section{Aporte original y Objetivos del Trabajo}

Debido a la escasez de trabajos relacionados con la Actividad Eléctrica Atmosférica sobre Sudamérica y a la falta de una investigación sistemática de este fenómeno en la Argentina, es que el estudio realizado aportará numerosos avances originales en el tema, los cuales se detallan en el capítulo 11. Especialmente queremos recalcar nuestro aporte en las aplicaciones de la información obtenida, tanto en la protección de infraestructura a través de los mapas isoceráunicos realizados, como en el sector de protección civil por medio del estudio realizado sobre muertes por acción de rayos, los cual generan información fundamental para los tomadores de decisiones.

El objetivo primario de la presente tesis consiste en realizar una caracterización de la Actividad Eléctrica Atmosférica (AEA) en Sudamérica utilizando distintas escalas espaciales y temporales e investigar su relación con distintos eventos.

Para poder llevarla a cabo, necesitamos lograr objetivos específicos como la validación de la base de datos World Wide Lightning Location Network (WWLLN) para Sudamérica, la preparación de una base de datos de AEA en Argentina, la realización de estudios específicos en zonas de interés. A lo largo de la tesis fueron emergiendo otros objetivos, los cuales fueron fundamentales para el enriquecimiento del trabajo: estudiar la relación de AEA con procesos microfísicos para poder hacer estudios aplicados como pronostico a corto plazo, modelar la situación de Argentina respecto a la muerte por rayos y en base a esto, aplicar medidas de protección para la población, estudiar la actividad eléctrica asociada a erupciones volcánicas.

\section{Introducción}

\section{Generalidades}

Los rayos y relámpagos son fenómenos que siempre han tenido un gran impacto en los humanos, principalmente debido a su imprevisibilidad y a los daños que produce tanto a la vida humana, como a las infraestructuras. Además de daños en estructuras terrestres y en vehículos aéreos, de pérdida de líneas de alimentación eléctrica y de comunicaciones, las descargas son una de las fuentes principales de incendios forestales en el planeta.

Sin embargo, los rayos y relámpagos también contribuyen en mecanismos que ocurren en la atmósfera como la producción de trazas químicas que de otra manera no estarían presentes en la atmósfera, o al menos no en la cantidad que es observada. Un ejemplo de estos son los compuestos Ilamados NOx, (e.g., von Liebig, 1827; Noxen, 1976; Hill et al., 1980, 1984; Ko et 
al., 1986). Por ejemplo, Schumann and Huntrieser (2007) utilizando datos del Optical Transient Detector encontraron que una descarga eléctrica produce alrededor de 250 moles de NOx.

Asimismo, las descargas eléctricas también producen diferentes efectos en la ionósfera y magnetosfera terrestre (e.g., Rycroft, 1973; Helliwell et al., 1973;Kelley et al., 1984; Carpenter et al., 1984; Inan et al., 1985; Goldberg et al.,1986). Debido a que las descargas son fuentes de radiación electromagnética en el rango de frecuencia de unos pocos $\mathrm{kHz}$ a $\mathrm{MHz}$, las ondas electromagnéticas procedentes de descargas de rayos a menudo se propagan a través de las regiones ionizadas de la atmósfera hasta los cinturones de radiación. Las observaciones han indicado que las ondas electromagnéticas inyectadas por descargas atmosféricas pueden dispersar los electrones energéticos y hacer que se precipitan fuera de los cinturones de radiación. A este proceso se lo llama: "Precipitación de electrones inducidos por rayos (LEP)", y se han observado casos individuales (localizadas en el espacio / tiempo).

Los rayos y relámpagos son descargas eléctricas que ocurren en la atmósfera, siendo su fuente más común las nubes de tormenta. Estas nubes presentan en su interior regiones con cargas eléctricas de distintos signos, las cuales desarrollan campos eléctricos a gran escala dentro dela nube y entre la nube y tierra. Cuando estos campos alcanzan valores suficientemente altos, se produce la ruptura dieléctrica del aire, generándose las descargas.

Para explicar la electrificación de las nubes de tormenta, que finalmente produce las descargas eléctricas, se utiliza el mecanismo no inductivo (Reynolds et al., 1957; Takahashi, 1978;Saunders et al 1991, 2006; Avila and Caranti 1994; Pereyra et al. 2000). Este mecanismo asume que: (1) los cristales de hielo colisionan con granizos, los cuales tienen tamaños del orden de milímetros, y rebotan; (2) durante el breve contacto entre las partículas de hielo se separa carga eléctrica; (3) no es necesario un campo eléctrico para que ocurra la separación de carga;(4) las partículas de hielo cargadas son transportadas a diferentes regiones dentro de la nube por las corrientes de aire y la fuerza gravitatoria. Distintas mediciones de laboratorio han demostrado que la carga transferida durante la colisión de un cristal de hielo y un granizo acrecido puede ser suficiente para explicar la electrificación de las nubes de tormenta. Estos estudios revelaron que el signo y la magnitud de la carga transferida al granizo depende de la condiciones microfísicas de la nube como son la temperatura y el contenido de agua líquida (Takahashi, 1978; Saunders et al., 1991, 1999, 2001; Avila et al., 1995, 1996;Pereyra et al., 2000, 2008), de la distribución de tamaños de las gotas de nube (Avila et al.,1998; Avila and Pereyra, 2000), del tamaño de los cristales de hielo (Keith and Saunders 1990) y de la velocidad de impacto (Bürgesser et al., 2006). Se ha observado que se transfiere una carga significante solo cuando coexisten granizos, cristales de hielo, gotas de agua sobreenfriadas y vapor de 
agua, por lo tanto la zona de cargado en la nube se extiende desdelos 0 a los $-40^{\circ} \mathrm{C}$ (temperatura de glaciación). Además, se encontró que la carga transferida por colisión aumenta rápidamente con el tamaño de los cristales y con la velocidad de impacto. Por lo tanto, la actividad eléctrica de las nubes está relacionada a la frecuencia de colisiones entre las partículas de hielo dentro de la misma, la cual a su vez está relacionada a la dinámica de las nubes. De este modo, parece razonable suponer que las descargas eléctricas podrían ser un buen indicador para la detección de nubes de tormenta.

Existen distintos estudios que muestran que la actividad eléctrica a escala regional y global puede ser usada como herramienta para el estudio de clima terrestre. Por ejemplo, Williams (1994) correlacionó las anomalías de temperatura de bulbo húmedo con la resonancia de Schumann, la cual es una medida indirecta de la actividad eléctrica global. Reeve y Toumi (1999), utilizando datos satelitales, mostraron que existe un acuerdo entre la temperatura global y la actividad eléctrica. Price (2000) encontró una relación entre la variación del vapor de agua en la troposfera superior y la variación en la actividad eléctrica global. Peterson et al. (2005) utilizaron datos satelitales y observaciones de radar para estudiar la relación entre la masa de precipitación de hielo y la densidad de rayos. Ávila et al. (2010)mostraron que existe correlación entre la tasa de descargas eléctricas y el número de tormentas de convección profunda. Williams (1985) sugirió que la tasa de descargas eléctricas es una función de la altura de la tormenta basado en el trabajo de Vonnegut (1963). Yoshida etal. (2009) examinaron la correlación entre el número de descargas eléctricas por segundo por nube convectiva y la altura entre la isoterma de $0^{\circ} \mathrm{C}$ y el tope de la nube. Estos autores encontraron que la tasa de descargas es proporcional a la quinta potencia de dicha altura.

Todos estos resultados refuerzan la idea que las descargas eléctricas pueden ser utilizadascomo indicadores de tormentas severas.

Todo lo dicho anteriormente, afianza la idea de que todos estos complejos procesos entre la atmosfera, la biosfera, el circuito global, hacen que las descargas eléctricas sean unos de los elementos imprescindibles para la vida en el Planeta Tierra, y muestran la importancia del estudio sistemático de la AEA en nuestro territorio.

\section{Descripción de los contenidos}

Teniendo en cuenta el objetivo planteado y las tareas propuestas, la presentación delos contenidos del trabajo de Tesis ha sido estructurada en once Capítulos. 
En los primeros dos capítulos se afianzan las definiciones y los presentamos como introducción a la temática a presentar. El capítulo 1 presentamos la AEA dentro del circuito global, la física de las descargas, y parámetros de microfísica de nubes. El capítulo 2 presentaremos los distintos sistemas de detección de AEA y las distintas bases de datos que hemos utilizado para hacer el análisis de la Actividad Eléctrica Atmosférica en América del Sur.

Esta sección es seguida por la caracterización de la AEA a nivel global. En el capítulo 3 se presentan las características principales de la AEA en el mundo para así poder entender los procesos que rigen esta actividad en Sudamérica. En particular, en el capítulo 4, se estudiaron las regiones ubicada en la zona del Lago de Maracaibo (Venezuela) y la Cuenca del Congo (África) por ser estas las regiones que presentan la mayor densidad de AEA a escala global.

En una segunda parte de la tesis, se caracteriza la AEA en América del Sur, con énfasis en las regiones subtropical y extratropical del continente, en diferentes escalas temporales (diurna, estacional, e interanual). En el capítulo 5, se presentan las metodologías para la confección de mapas isoceráunicos del territorio nacional. El estudio de los días de tormentas nos ayuda a poder reconocer las diferentes áreas de AEA. Esta información se profundiza en el capítulo 6 donde se analizaron las regiones con AEA relevante y su relación con la actividad convectiva y la climatología local. El capítulo 7, tiene como originalidad, el análisis de la actividad eléctrica observada en una región que, en los conocimientos previos, se tenía como irrelevante, como es la AEA en la Patagonia.

La última parte de la tesis, presenta trabajos de aplicación de naturaleza operacional, poniendo hincapié en la importancia del estudio de la AEA en aplicaciones relacionadas a la seguridad y la protección. En base a los mapas isoceráunicos, se realizó un estudio de la vulnerabilidad de la población frente a estos tipos de eventos y se confeccionó un mapa de riesgo para implementar medidas de protección de la población, dicho trabajo se presenta en el capítulo 9. En el capítulo 10 realizamos un estudio sobre la factibilidad de utilizar la AEA detectada por la WWLLN como marcador de eventos severos. Por último, en el capítulo 10 se presenta un estudio sobre la AEA debido a la erupción volcánica del complejo volcánico Cordón Caulle, donde se relacionó la AEA observada con la altura de la pluma volcánica y la intensidad de la erupción. En este estudio se verificó que la AEA puede ser utilizada para emitir un alerta temprano a la comunidad ante la ocurrencia de este tipo de eventos.

Finalmente, en el capítulo 11 se presentan las conclusiones del trabajo de Tesis. 


\section{Capítulo 1 Las descargas y su implicancia global}

Los rayos y relámpagos son descargas eléctricas que ocurren en la atmósfera, siendo su fuente más común las nubes de tormenta. Estas nubes presentan en su interior regiones con cargas eléctricas de distintos signos, las cuales desarrollan campos eléctricos a gran escala dentro dela nube y entre la nube y tierra. Cuando estos campos alcanzan valores suficientemente altos, se produce la ruptura dieléctrica del aire, generándose las descargas. Sin embargo, una descarga eléctrica atmosférica no es un hecho aislado dentro de una tormenta eléctrica, sino que es parte de este vasto circuito mundial, que se extiende a lo largo de nuestra atmósfera en lo que se Ilama colectivamente el Circuito Eléctrico Global. La idea básica del circuito global fue presentada por Wilson en 1920 y hasta la actualidad, los científicos siguen interesados en entender cómo los campos eléctricos, las corrientes eléctricas y los campos magnéticos se redistribuyen a nivel mundial en respuesta a los diferentes componentes que conforman este sistema

El Circuito Eléctrico Global no tiene solo profundas implicaciones en el clima de la Tierra, sino además sobre la vida sobre ella. En este capítulo introductorio presentaremos las características del circuito global y de las descargas eléctricas, haciendo hincapié en las nubes de tormenta como componente principal en este circuito, para así poder entender los mecanismos que rigen la Actividad eléctrica atmosférica en el mundo.

\section{Circuito Eléctrico Global}

Es sabido desde hace más de dos siglos que la Tierra sólida y su atmósfera gaseosa se encuentran casi permanentemente electrificadas. La superficie terrestre tiene una carga neta negativa, y hay una carga positiva de igual magnitud distribuida a lo largo la atmósfera por encima de la superficie. El valor del campo eléctrico de buen tiempo es típicamente entre 100 y $300 \mathrm{~V} / \mathrm{m}$ sobre la superficie; aunque este valor posee oscilaciones diurnas, estacionales, además de variaciones debido a la contaminación y a los aerosoles, entre otros factores.

La atmósfera posee una conductividad que aumenta con la altura. Esta conductividad se mantiene principalmente por ionización del aire debido a los rayos cósmicos galácticos. Cerca 
de la superficie de la Tierra, la conductividad es lo suficientemente grande para disipar toda su carga en un tiempo entre 5 y $40 \mathrm{~min}$ (dependiendo de las características de cada lugar), y por lo tanto, el campo eléctrico local debe mantenerse por alguna fuente de corriente casi continua.

Los científicos han estado interesados durante mucho tiempo en entender cómo los campos eléctricos, las corrientes eléctricas y los campos magnéticos se redistribuyen a nivel mundial en respuesta a los diferentes componentes que conforman este sistema, tratando de comprender de qué manera las descargas eléctricas atmosféricas, la cantidad de nubes electrificadas, las alteraciones en el espacio interplanetario y el entorno geoespacial se acoplan como diversas partes del Circuito Eléctrico Global. La Figura 1-1muestra algunos de los componentes del circuito eléctrico global y algunas de las interrelaciones entre los mismos.

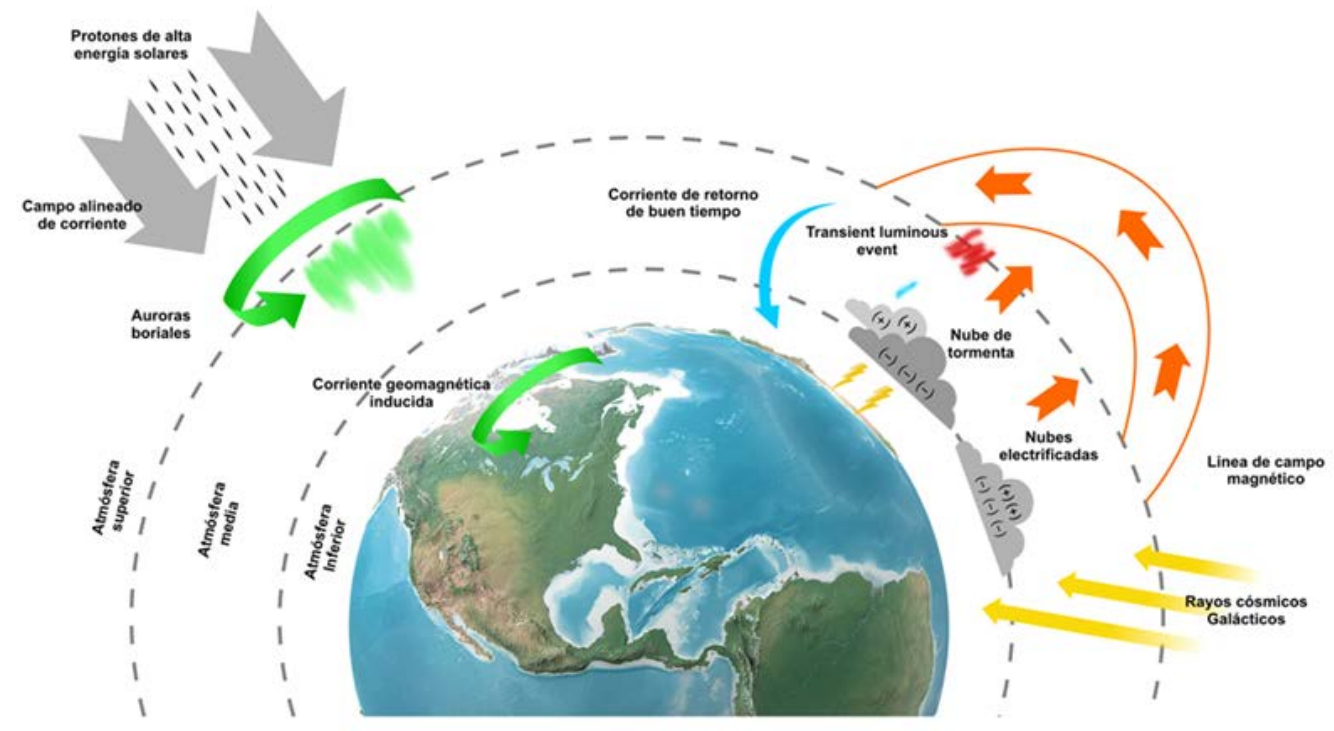

Figura 1-1 Esquema de componentes del circuito eléctrico global, en base de http://sisko.colorado.edu/FESD/

Dentro del circuito global llamaremos Actividad Eléctrica Atmosférica (AEA) a los procesos de intercambio de carga dentro de la troposfera (atmósfera inferior) y en particular, a las descargas eléctricas atmosféricas.

De 1909 a 1929, el yate Carnegie (Figura 1-2), perteneciente a la Institución Carnegie de Washington, dio numerosas vueltas al mundo (casi trescientas mil millas a través de sus océanos), para localizar y medir las entonces desconocidas influencias magnéticas en la atmósfera. Sus numerosos viajes eran parte del programa del Instituto Carnegie, que incluyó un ambicioso estudio de los campos eléctricos y magnéticos sobre la superficie de la tierra. 


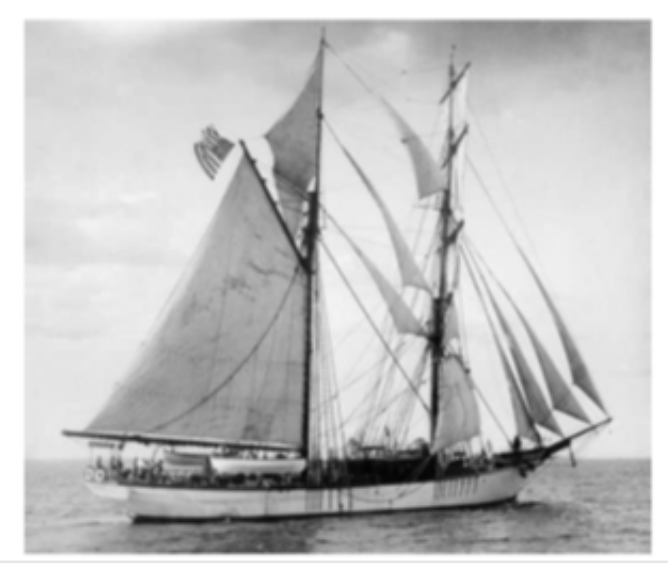

Figura 1-2 Uno de los barcos que realizaron a principios del siglo XX mediciones del circuito global

Gracias a estos trabajos, los científicos pudieron medir la variación característica y universal del campo eléctrico entre la atmósfera y la Tierra, que todavía se utiliza hoy en día, a la cual llamaron Curva de Carnegie.

En base a estas curvas, el circuito eléctrico global se puede establecer como una corriente que fluye entre dos conductores, la Tierra y la mesosfera/ionosfera, con una fina capa de aire aislante intercalada (nuestro ambiente) (por ejemplo, Roble y Tzur, 1986; Williams, 2009; Markson, 2007). Esta geometría es similar tanto a la de un condensador esférico de Corriente Continua (CC) con una diferencia de potencial entre la tierra y la ionosfera, como a una guía de ondas electromagnética de Corriente Alterna (CA) conformada por la resonancia de Schumann (Williams, 2009).

En el caso de la guía de onda en CA, la resonancia Schumann es un conjunto de picos en la banda ELF (frecuencia extremadamente baja, por sus siglas en inglés extremely low frequencies:) del espectro electromagnético de la Tierra. Las limitadas dimensiones terrestres provocan que esta guía de onda actúe como cavidad resonante para las ondas electromagnéticas en esta banda. La cavidad es excitada de manera natural por AEA global y forman parte del fondo del espectro electromagnético entre los 3 y $60 \mathrm{~Hz}$.

En la Figura 1-3 un esquema simple del circuito global con la corriente de pérdida (en condiciones de buen tiempo) y las nubes de tormentas con la AEA asociadas como batería de este circuito. 


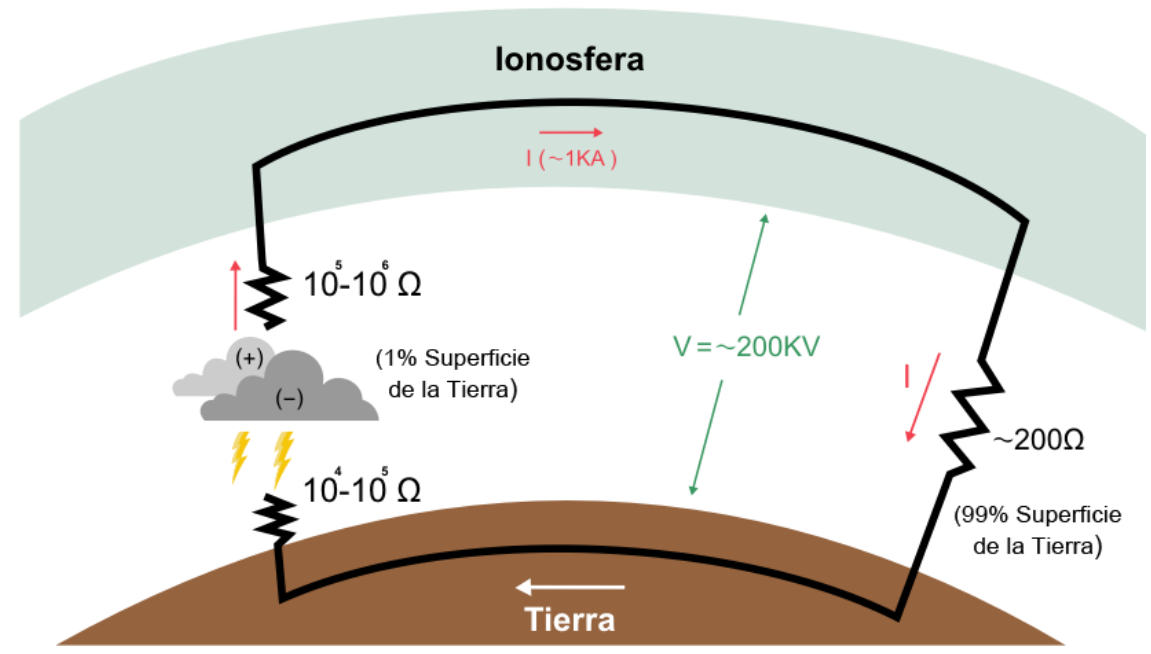

Figura 1-3Esquema del Circuito global

La diferencia de potencial entre la ionosfera y la Tierra de alrededor de $200 \mathrm{kV}$, medida por toda la superficie terrestre en buenas condiciones climáticas, es conocida como el campo eléctrico "de buen tiempo". Se cree que esta diferencia de potencial es impulsado por la AEA asociada a las tormentas (o también a las lluvias asociadas). Sin embargo, para que los resultados puedan ser interpretados correctamente, es importante entender qué se entiende exactamente por condición "de buen tiempo". La condición de buen tiempo, como el término lo indica, significa condiciones climáticas sin precipitación, poco viento, y sin tormentas cercanas. Ya que los aerosoles y la contaminación también pueden afectar a las mediciones, cambiando la resistencia de la atmósfera, es deseable también tener bajas concentraciones de contaminantes. Las observaciones durante las condiciones de buen tiempo se considera que son las mediciones del campo eléctrico atmosférico a escala mundial a pesar de que, a menudo, estas mediciones presentan efectos debido a la ubicación geográfica y sólo se aproximan a la curva de Carnegie después de un promedio a largo plazo.

Las similitudes entre la curva de Carnegie y la actividad global de AEA(medida como el área de la Tierra cubierta por nubes de tormenta)que se observan en la Figura 1-4, condujeron a la hipótesis de que son las tormentas eléctricas las que impulsan el potencial ionosférico. La actividad eléctrica, que se muestra en la Figura 1-4, fue obtenida de promedios de las estaciones meteorológicas mundiales. Es importante remarcar que el circuito es de escala mundial y que, en cada momento, en la Tierra las tormentas solo cubren alrededor del $1 \%$ de la superficie de la misma, mientras que el $99 \%$ está libre de tormentas eléctricas y es donde fluye la corriente de retorno (Ver Figura 1-3). 
El circuito mundial experimenta muchas variaciones complejas con la latitud y la longitud, la actividad en la ionosfera y la magnetosfera, y también debido a procesos ligados con la troposfera como la contaminación. Dado que el circuito mundial es sensible a la frecuencia de las tormentas, y también a la contaminación de la atmósfera, el estudio de los parámetros del circuito mundial permite la investigación del cambio climático (Williams, 2009).

En la Figura 1-4también se observa que existen diferencias entre la actividad eléctrica y la curva de Carnegie. Por ejemplo, en la curva de Carnegie no se observa el máximo a 14 UT que se observa en la actividad eléctrica dada por la región de África/Europa. Dos hipótesis se han formulados para explicar esta diferencia. La primera es la ubicación de las descargas eléctrica en América del Sur en relación con el ecuador magnético (Kartalec et al., 2006), y la segunda, que las tormentas eléctricas americanas contienen más agua de lluvia, que también puede generar un flujo de corriente entre la Tierra y la ionosfera (Williams et al., 2004). Por lo tanto, puede verse que el papel exacto de la actividad eléctrica, y de otras variables, todavía no es bien entendida, por lo cual, una mayor cantidad de estudios globales podrían ayudar a arrojar luz sobre estas cuestiones.

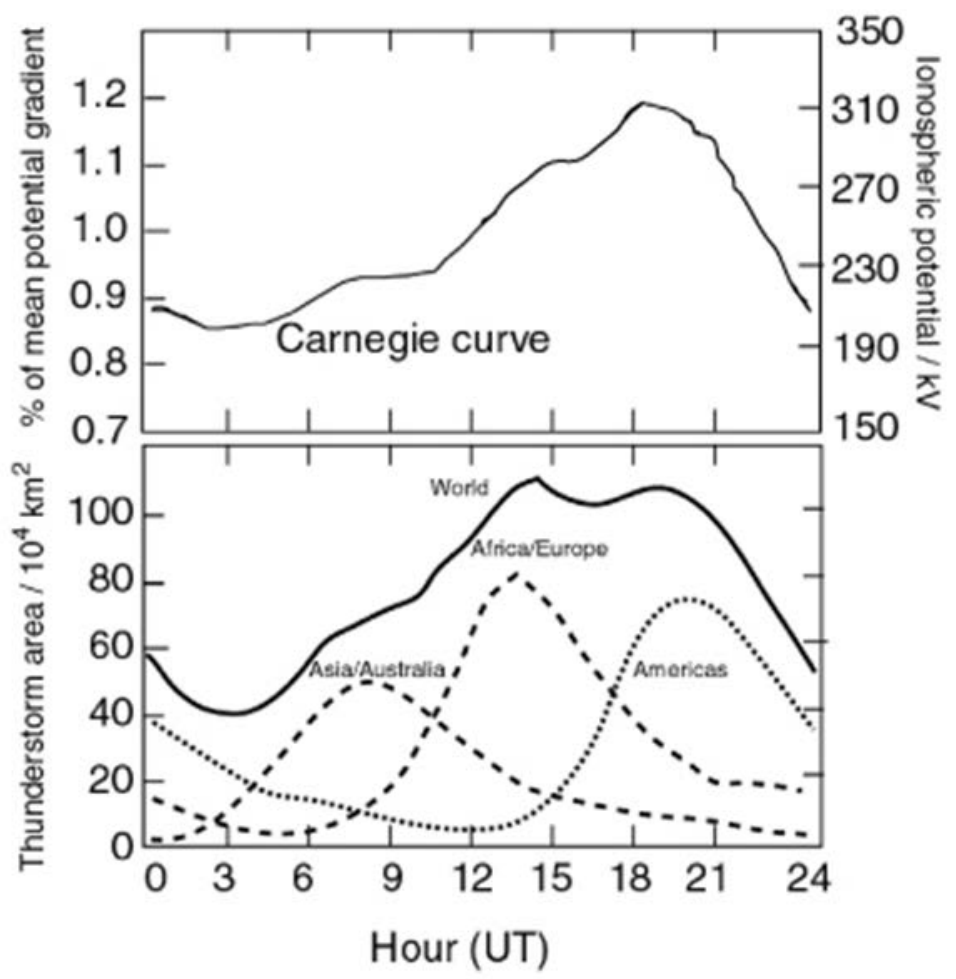

Figura 1-4Comparación entre las Curvas de Carnegie y la AEA diurna(Área de nubes de tormenta). Grafico extraído de Whipple y Scrase, 1936. 


\section{Nubes de tormenta}

Como se presentó anteriormente, diversos autores han propuesto a las nubes de tormentas como la fuente principal del Circuito Eléctrico Global. Para poder entender cómo las nubes de tormenta pueden ser el motor del Circuito Eléctrico Global, presentaremos primero cual es la estructura de una nube de tormenta, su estructura eléctrica, y por último los mecanismos que generan esta estructura eléctrica.

\section{a. Características de las nubes de tormenta}

Existe una sorprendente variedad de condiciones meteorológicas que son favorables para producir las descargas eléctricas: nubes de tormenta de verano ordinarias, nubes de tormentas severas, huracanes, nubes de tormentas de invierno, convecciones oceánicas y sistemas convectivos de mesoescala. La característica común a todas estas situaciones es una región con mezcla de fase.

Las nubes con mezcla de fase en la atmósfera están compuestas de partículas de agua líquida y de hielo y por vapor de agua, y se forman donde el aire está localmente sobresaturado de vapor de agua y contiene un abundante número de núcleos de condensación. La condición de sobresaturación de vapor de agua se alcanza, generalmente, a través de un proceso de elevación de una parcela de aire subsaturada de vapor de agua.

En el ascenso, la parcela se expande adiabáticamente y se enfría, y en consecuencia aumenta la humedad relativa. La altura a la cual se alcanza la condición de sobresaturación, y se empieza a formar la nube, es llamado nivel de condensación por ascenso ( $L C L$, del inglés Lifted Condensation Level). En general, el LCL está alrededor de los 1.000 metros sobre la superficie terrestre. Esta altura está por debajo de la altura correspondiente a la isoterma de $0^{\circ} \mathrm{C}$, la cual típicamente se encuentra entre 3.000 y 4.000 metros sobre el nivel del suelo. Debido a esto, la gran mayoría de las nubes se forman a temperaturas mayores a la temperatura de fusión del agua y están compuestas enteramente por gotas de agua líquida (nubes calientes). Las observaciones muestran que este tipo de nubes no están fuertemente electrificadas y raramente producen descargas eléctricas.

Por otro lado, numerosas observaciones, en diferentes ubicaciones geográficas, revelan que las nubes deben extenderse al menos 2-3 km por sobre la isoterma de $0^{\circ} \mathrm{C}$ antes de que se observe la primera descarga eléctrica. Estas nubes de desarrollo vertical pueden tener fuertes corrientes ascendentes, y se elevan muy por encima de sus bases. Este tipo de nubes generalmente se categorizan dentro del género Cumulonimbus. 
Estas observaciones son consistentes con el mecanismo más favorecido para explicar la separación de carga eléctrica que lleva a la descarga eléctrica: la colisión entre granizos y cristales de hielo. Por lo tanto, la presencia de este tipo de partículas requiere de nubes con mezcla de fase.

\section{b. Estructura eléctrica en las nubes de tormentas}

Dos científicos británicos, G. C. Simpson y C. T. R. Wilson, de forma independiente y utilizando métodos distintos, fueron los primeros en descubrir la estructura de carga eléctrica en una nube de tormenta. Sin embargo, estos científicos mantuvieron, durante más de dos décadas, posiciones opuestas sobre la polaridad del momento dipolar de las nubes de tormenta. Simpson (1909) midió la carga transportada por las gotas de lluvia debajo de las nubes de tormenta. A su vez, Wilson $(1916,1920)$ midió el cambio en el campo electrostático debido a las descargas eléctricas. El desacuerdo entre Wilson y Simpson fue resuelto mediante una serie de sondeos del campo eléctrico hechos por Simpson y Scrase (1937), y Simpson y Robinson (1941). Estos científicos identificaron una estructura electrostática tripolar en las nubes de tormenta: una región de carga positiva superior, una región de carga negativa principal a alturas medias, y una región de carga positiva más pequeña a bajas alturas.

La región de carga negativa principal se encuentra localizada entre las isotermas de -10 y $25^{\circ} \mathrm{C}$, y se encuentra distribuida verticalmente con una extensión de aproximadamente $1 \mathrm{~km}$. Su extensión horizontal es de varios kilómetros y tiene una densidad de carga entre 1 y $10 \mathrm{C}$ $\mathrm{km}^{3}$. La región de carga positiva superior es más difusa y puede extenderse verticalmente por varios kilómetros hasta el tope de la nube. La magnitud de la carga eléctrica que almacena es del mismo orden que la región de carga negativa principal, aunque su densidad de carga es menor. Las regiones superior positiva y negativa principal están usualmente separadas por una zona cuasi neutral.

La región inferior de carga positiva es típicamente más pequeña y su carga es un orden de magnitud menor que las otras dos regiones, y puede extenderse por debajo de la isoterma de $0^{\circ} \mathrm{C}$.

Generalmente existe una cuarta región de carga en el contorno superior de la nube de tormenta. Esta región tiene una polaridad negativa y usualmente se explica como una capa de apantallamiento. 
Una teoría satisfactoria para explicar los mecanismos de electrificación de nubes de tormenta debe ser capaz de explicar todas las características eléctricas observadas en una nube de tormenta típica. Esta lista de características, que fue primero esbozada por Mason (1953) y luego extendida por Moore y Vonnegut (1977), es la siguiente:

a. Para que ocurra una descarga, la altura de la nube debe ser mayor a $3 / 4 \mathrm{~km}$.

b. Las nubes de tormenta muy altas producen una mayor frecuencia de descargas que una nube de altura ordinaria.

c. Aunque las descargas pueden ocurrir en nubes que no presentan fase de hielo, no se observa una electrificación fuerte a menos que la nube se extienda por sobre la isoterma de $0^{\circ} \mathrm{C}$.

d. Las regiones altamente electrificadas de las nubes de tormenta casi siempre coinciden con la coexistencia de hielo y agua sobreenfriada.

e. La electrificación fuerte ocurre cuando la nube exhibe una fuerte actividad convectiva con un rápido desarrollo vertical.

f. La generación de carga y los procesos de separación están asociados con el desarrollo de precipitación, probablemente en la forma de granizo.

g. Las descargas se originan generalmente en la cercanía de regiones de alta precipitación.

h. El primer intercambio de carga (stroke) ocurre generalmente entre los 12 y 20 minutos luego de la aparición de partículas de precipitación de tamaño detectable por el radar.

i. La tasa inicial de cargado de las nubes se mantiene constante durante dos minutos aproximadamente.

j. La duración promedio de la precipitación y de la actividad eléctrica de una celda simple de una nube de tormenta es de alrededor de 30 minutos.

k. La localización de los centros de carga parece estar determinado por la temperatura y no por la altura sobre el suelo. El centro de carga negativo principal está generalmente ubicado entre las isotermas de -10 y $-25^{\circ} \mathrm{C}$, con el centro de carga positiva principal unos kilómetros por encima. Hay una pequeña región de carga positiva por debajo de la región principal negativa, cerca de la isoterma de $0^{\circ} \mathrm{C}$, que parece estar asociada con la precipitación.

I. En el estado maduro de una nube de tormenta puede existir un campo eléctrico de hasta $400 \mathrm{kV} \mathrm{m}^{-1}$, dando lugar a una gran tasa de descargas por minuto. Esta tasa de descargas requiere una corriente de cargado promedio del orden de $1 \mathrm{~A}$.

m. La tasa de cargado requerida es de alrededor de $1 \mathrm{C} \mathrm{km}^{-3} \mathrm{~min}^{-1}$. 
n. El momento eléctrico promedio destruido en una descarga es de alrededor de $100 \mathrm{C}$ $\mathrm{km}$; siendo la carga correspondiente de 20 a $30 \mathrm{C}$.

o. En algunos casos, el dipolo destruido por la descarga puede apartarse de la vertical hasta $90^{\circ}$.

Estas características sugieren un rol fundamental de la precipitación, basada en hielo, en los mecanismos de electrificación de nubes de tormenta.

Stolzenburg et al. (1998a, b, y c, 2008) realizaron estudios de las regiones de carga en el interior de la nube utilizando radiosondeos, los cuales tienen la capacidad de muestrear todo el desarrollo vertical de las nubes en un tiempo razonablemente corto, lo que da una información valiosa acerca de la distribución vertical de las magnitudes eléctricas y su variación con respecto a la vertical, así como los cambios en la temperatura y las condiciones microfísicas dentro de las nubes de tormenta.

Sobre la base de estos sondeos, se identificó una estructura eléctrica básica en la zona de las corrientes convectivas ascendentes formadas por cuatro regiones de carga. Una región de carga positiva débil en la zona más baja, y por encima de esta la región principal de carga positiva y negativa superior a menudo descrita como el "dipolo principal" de la nube. La cuarta y más alta región encontrada tiene carga negativa y es por lo general de poca profundidad. Esta estructura de cuatro capas modifica esencialmente la estructura de carga tripolar anterior añadiendo una capa de carga negativa (una región de carga formada principalmente por la unión de iones (por ejemplo, Vonnegut, 1955) cerca del límite superior de la nube, lo cual ha sido demostrado en mediciones de laboratorio (Ávila et al., 2011).

Fuera de la corriente ascendente, pero siempre dentro de la región convectiva de la tormenta, normalmente hay al menos seis regiones de carga, alternando en polaridad pero con la región superior de carga negativa.

En sus trabajo, Stolzenburg et al. (1998c) derivaron un modelo conceptual (Figura 1-5) para ilustrar las estructuras básicas de las cuatro y de las seis zonas de cargas que fueron identificadas, en regiones de latitudes medias, para tormenta convectivas típicas en fase madura. Se han encontrado que las dos estructuras de este modelo pueden ocurrir, simultáneamente, dentro de convección madura (Stolzenburg et al., 2002; MacGorman et al., 2005).Las descargas eléctricas en la nube también pueden añadir complejidad a la estructura de carga durante envejecimiento de la tormenta. 


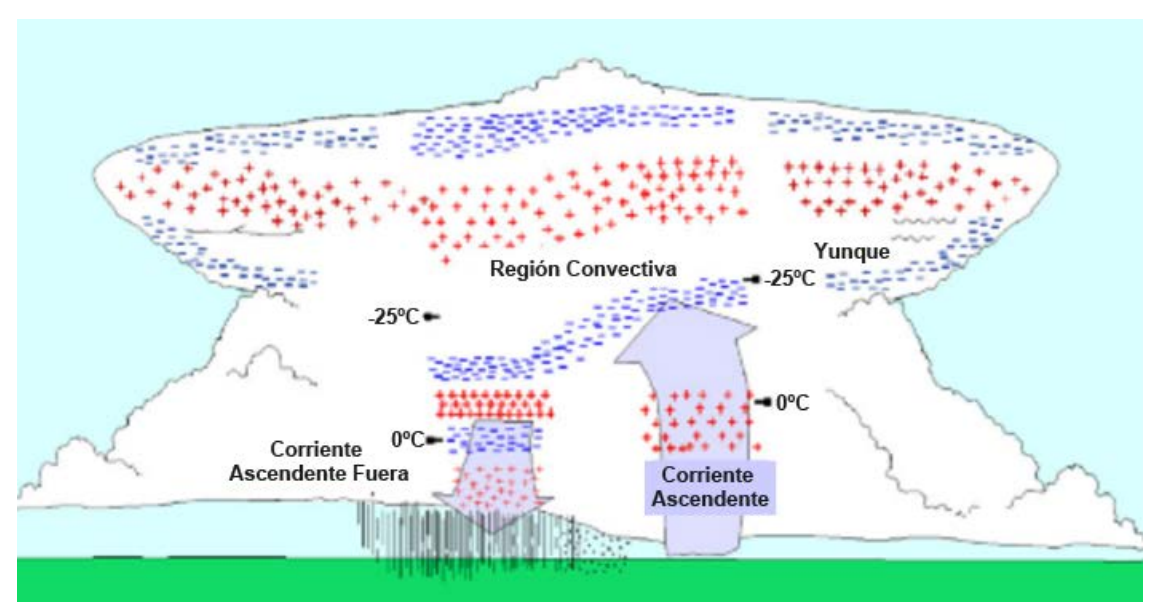

Figura 1-5 Modelo conceptual de cargas dentro de una nube de tormenta adaptada de los trabajos de Stolzenburg(1998c)

\section{c. Modelos de electrificación de nubes de tormenta}

Numerosos investigadores han propuesto distintas teorías para explicar las características eléctricas observadas en las nubes de tormentas.

Algunas de las teorías propuestas sugieren que las cargas eléctricas son suministradas por fuentes externas a las nubes, mientras que otras, en cambio, suponen que las partículas de nubes adquieren una carga eléctrica debido a la interacción entre ellas.

Las dos teorías de electrificación de nubes de tormentas más importantes son la teoría convectiva y la teoría precipitativa.

La teoría convectiva supone que las partículas de nube atrapan iones atmosféricos, y que estas partículas de nube cargadas son separadas por la diferencia entre sus velocidades de caída. En cambio, la teoría precipitativa supone que las partículas de nube adquieren una carga eléctrica debido a la interacción entre ellas.

La diferencia en la velocidad de las partículas, debido a la diferencia de tamaños, hace que las partículas colisionen $y$, esta teoría sugiere que, durante este contacto, las partículas intercambian una carga eléctrica. En esta teoría se puede identificar dos tipos de mecanismo, el mecanismo inductivo, el cual supone que la interacción entre las partículas de nube se produce en presencia de un campo eléctrico, y el mecanismo no inductivo, el cual supone que no es necesario la presencia de un campo eléctrico durante la interacción para que se produzca la transferencia de carga eléctrica entre las partículas interactuantes. 
En la actualidad se cree que la teoría precipitativa no inductiva es la más representativa de los procesos de electrificación observado en las nubes de tormentas, al menos en las etapas iniciales.

\section{Teoría precipitativa no inductiva}

Reynolds et al. (1957) realizaron el primer experimento de cargado de granizos creciendo por acreción en laboratorio. Para ello hicieron circular dos esferas de metal a través de una nube de gotas de agua sobreenfriadas y de cristales de hielo dentro de una cámara fría, la cual podía ser enfriada hasta $-25^{\circ} \mathrm{C}$. Las esferas tenían $4 \mathrm{~mm}$ de diámetro y seguían una trayectoria circular de $6 \mathrm{~cm}$ de radio a una velocidad de $10 \mathrm{~m} \mathrm{~s}^{-1}$. Las esferas adquirieron una carga eléctrica negativa para altos contenidos de agua líquida (el contenido de agua líquida se define como la masa de agua líquida por unidad de volumen de aire), y una carga positiva para bajos contenidos. En este último caso el signo de la carga transferida podía ser revertido si se calentaban las esferas. Además, ellos observaron que el signo de la carga se invertía, de negativo a positivo, a medida que se aumentaba la concentración de cristales de hielo de valores entre $10^{2}$ y $10^{5} \mathrm{~L}^{-1}$ a valores entre $10^{4}$ y $10^{6} \mathrm{~L}^{-1}$. Un resultado importante obtenido por estos autores fue que, en ausencia de gotas de agua sobreenfriadas, la corriente de cargado es, al menos, un orden de magnitud menor que en la presencia de éstas. Entonces, estas observaciones establecen que la acreción (crecimiento del granizo por captura de gotas de agua) es una condición importante para el cargado del granizo.

Takahashi (1978) hizo circular un cilindro de $3 \mathrm{~mm}$ de diámetro y $4 \mathrm{~cm}$ de largo a través de una nube de gotas de agua sobreenfriada y de cristales de hielo crecidos por vapor de agua a una velocidad de $9 \mathrm{~m} \mathrm{~s}^{-1}$. Estos experimentos mostraron que el signo y la magnitud de la carga adquirida por el cilindro estaban controlados por la temperatura del aire y el contenido de agua líquida.

Jayaratne et al. (1983), en un estudio similar al realizado por Takahashi, utilizaron un granizo cilíndrico de $5 \mathrm{~mm}$ de diámetro y $30 \mathrm{~cm}$ de largo, y una velocidad de impacto de 3,6 $\mathrm{m}$ $\mathrm{s}^{-1}$. Ellos observaron que el granizo simulado, sujeto a interacciones con cristales de hielo, se cargaba de manera positiva para altas temperaturas y altos contenidos de agua de nube, y de manera negativa para bajas temperaturas y bajos contenidos de agua líquida. Para un valor del contenido de agua líquida de $1 \mathrm{gm}^{-3}$, estos autores encontraron que, para una temperatura de $-20^{\circ} \mathrm{C}$, se invertía el signo de la carga adquirida por el granizo. Esta temperatura se denomina temperatura de inversión de signo. 
Todas estas observaciones muestran que existe una transferencia de carga durante la colisión entre granizos y cristales de hielo en presencia de gotas de agua sobreenfriadas y en ausencia de un campo eléctrico. La carga eléctrica transferida depende de la temperatura, del contenido de agua líquida, del espectro de tamaños de las gotas de nube y de los cristales de hielo, y de la velocidad de impacto de los cristales de hielo sobre el granizo.

Estos resultados fueron utilizados para explicar, de una manera simplificada, como se forma la estructura de carga tripolar clásica presente en una nube de tormenta. Este proceso de electrificación simple, que se esquematiza en la Figura 1-6, se basa en la existencia de la temperatura de inversión para el signo de la carga transferida al granizo. Para temperaturas mayores a la temperatura de inversión, el granizo adquiere una carga positiva, y para temperaturas menores a la temperatura de inversión, adquiere una carga negativa. Entonces, en las regiones de la nube donde la temperatura es menor a la temperatura de inversión de signo, los cristales de hielo adquieren una carga neta positiva durante la colisión con los granizos y luego son transportados por las corrientes de convección a las regiones superiores de la nube, donde forman la región de carga positiva superior.

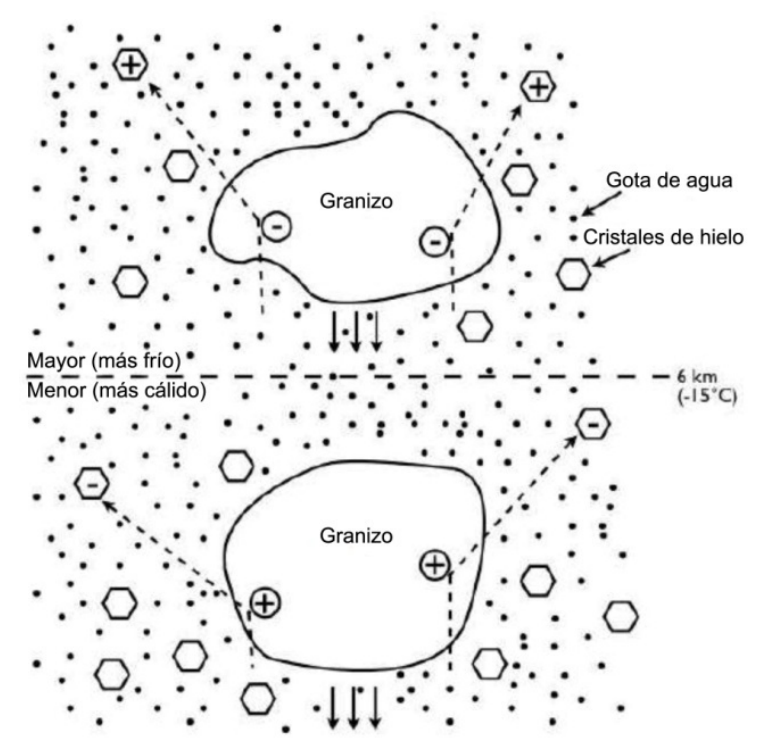

Figura 1-6Esquema de la transferencia de cargas entre los granizos para diferentes temperaturas. Para temperaturas mayores a la temperatura de inversión, el granizo adquiere una carga positiva, y para temperaturas menores a la temperatura de inversión, adquiere una carga negativa. Adaptado de Rakov y Uman (2003).

En tanto, los granizos adquieren una carga neta negativa y, como no pueden alcanzar las regiones superiores de la nube debido a la fuerza gravitatoria, contribuyen a la región negativa 
principal. Aquellos granizos que caen relativos a las corrientes verticales de aire y cruzan laregión donde la temperatura es igual a la temperatura de inversión traen una carga neta negativa.

Las siguientes colisiones con los cristales de hielo descargan al granizo ya que en la región donde la temperatura es mayor a la temperatura de inversión los granizos adquieren una carga neta positiva y los cristales de hielo una carga neta negativa. Entonces, la magnitud de la carga transportada por los granizos será cada vez menor a bajas alturas. Por otro lado, los cristales de hielo, con una carga neta negativa, serán transportados por las corrientes de aire ascendentes y acrecentarán la región de carga negativa principal. En las regiones de la nube con temperaturas entre $-5^{\circ} \mathrm{C} y-8^{\circ} \mathrm{C}$, existe un máximo en la concentración de cristales de hielo debido al mecanismo de Hallet-Mossop, entonces la carga eléctrica transportada por el granizo puede invertirse debido a las múltiples colisiones con los cristales de hielo en esta región y formar la región de carga positiva inferior (Bateman et al., 1999).

Este modelo simplificado del proceso de electrificación de las nubes de tormentas sólo tiene en cuenta la dependencia del signo de la carga transferida con la temperatura pero aun así muestra que este mecanismo es capaz de explicar de manera satisfactoria la estructura de carga observada en las nubes de tormentas.

\section{Física de las descargas}

A consecuencia de la estructura eléctrica dentro de las nubes de tormentas, se forman campos eléctricos dentro de las nubes con valores típicos entre de 1 a $2 \times 10^{5} \mathrm{~V} / \mathrm{m}$ (el valor más alto medido fue de $4 \times 10^{5} \mathrm{~V} / \mathrm{m}$ ). Sin embargo, estos valores no llegan a tener los valores mínimos esperados para la ruptura dieléctrica convencional del aire, que es del orden de $10^{6}$ $\mathrm{V} / \mathrm{m}$, aunque se observa que el mecanismo se inicia. Por lo tanto, se han sugerido dos mecanismos (Rakov, 2012 TEA). Uno se basa en la emisión de streamers positivos (flujos de carga en forma de avalancha) desde los hidrometeoros cuando el campo eléctrico es superior a $9,5 \times 10^{5} \mathrm{~V} / \mathrm{m}$, y la otra implica que partículas de alta energía, como los rayos cósmicos, permiten que se produzca un campo crítico, que se presume alrededor $10^{5} \mathrm{~V} / \mathrm{m}$, a una altura de $6 \mathrm{~km}$. Cualquiera de estos dos mecanismos de iniciación, en principio, permite la creación de una región ionizada ("semilla relámpago") en la nube que es capaz de aumentar localmente el campo eléctrico en su extremidades. Es probable quetal aumento del campo sea el proceso principal que conduce a la iniciación de las descargas eléctricas. 


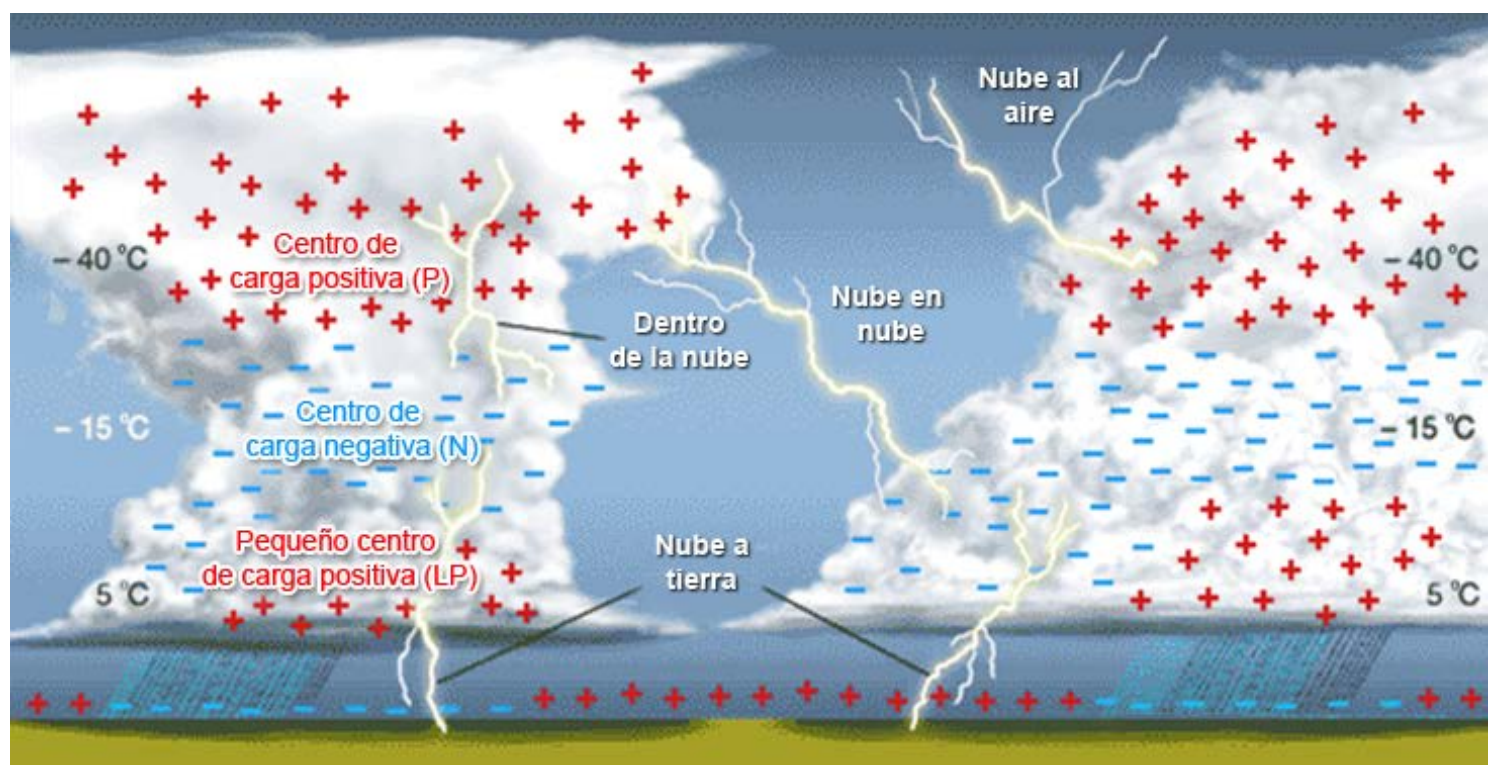

Figura 1-7 Diagrama de la localización de las regiones de carga y las diferentes AEA en el sistema. Adaptado de Enciclopedia Británica

Según la región de carga donde se inicia y termina la descarga eléctrica, las descargas eléctricas pueden clasificarse de distintas maneras como se muestra en la Figura 1-7.

Sin embargo, los tipos de descargas más importantes son:

- Intra- nubes (IC: Intra-Cloud), las cuales ocurren entre diferentes regiones de carga eléctrica de una misma nube o entre regiones de carga de nubes diferentes. En castellano estas descargas son denominan Relámpagos.

Estas descargas ocurren típicamente entre regiones con carga positiva y negativa dentro de las nubes y tienen una duración total de aproximadamente medio segundo. Este tipo de descarga eléctrica transfiere decenas de culombios de carga a través de una extensión espacial total de 5 a10 km.

- Nube a tierra (CG: Cloud to ground), las cuales ocurren entre alguna región con carga eléctrica de la nube y la tierra. Su duración total también es de aproximadamente medio segundo. En castellano se denominan Rayos.

A este último tipo de descarga eléctrica (CG) se pueden clasificar también según el signo de la carga eléctrica transferida desde la nube a la tierra y según su dirección de propagación, entonces los rayos pueden ser clasificados como negativos o positivos, y ascendentes 0 descendentes. Alrededor del $90 \%$ o más de los CG son descendentes negativos. Esto significa que la carga que se transporta eficazmente hacia el suelo es negativa y el proceso inicial comienza en la nube y se desarrolla en dirección a la tierra. Otros tipos de CG incluyen positivo descendentes, y negativo y positivo ascendentes. También hay descargas de rayos bipolares 
que transfieren secuencialmente a tierra tanto cargas positivas como negativas en la misma descarga eléctrica. Vale la pena señalar que las descargas nube a tierra constituyen sólo un25\% de la AEA y el restante $75 \%$ son IC. Sin embargo, dado la importancia para la vida humana y los daños causado en infraestructura, las descargas CG negativas descendentes han sido las más estudiadas.

En la Figura 1-8se ilustran los procesos que comprenden una descarga negativa nube a tierra (CG). Cada uno de los intercambios de carga entre la nube y la tierra se denominan strokes (carrera de retorno). Cada descarga o flash contiene típicamente de 3 a 5 strokes, aunque se ha observado entre 1 y 26 strokes en una misma descarga eléctrica. Hay dos procesos principales que comprenden un rayo, como se muestra en la Figura 1-8, el líder (precursor) y el/los stroke/s que se producen como una secuencia del líder.
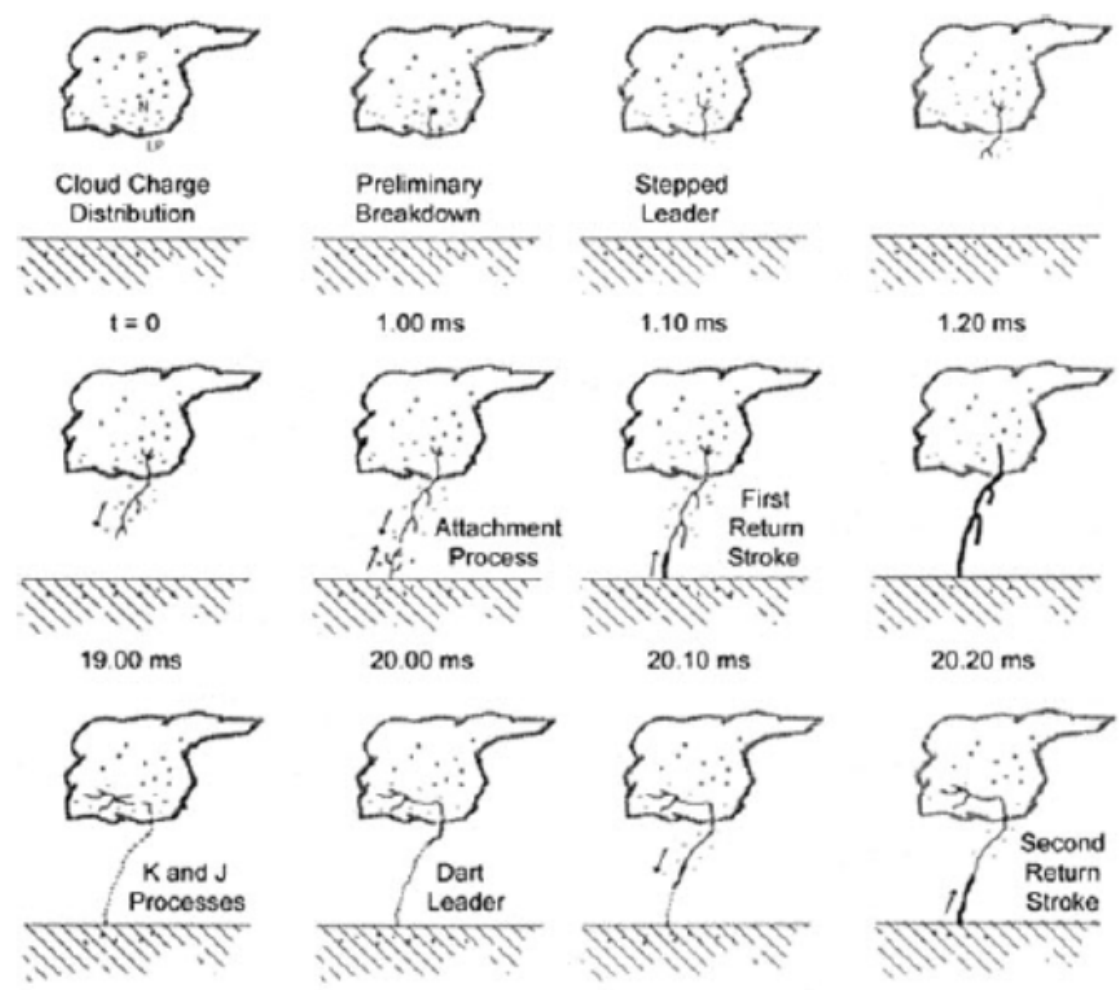

$40.00 \mathrm{~ms}$

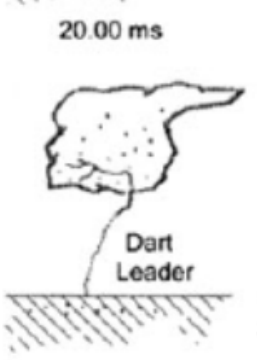

$60.00 \mathrm{~ms}$

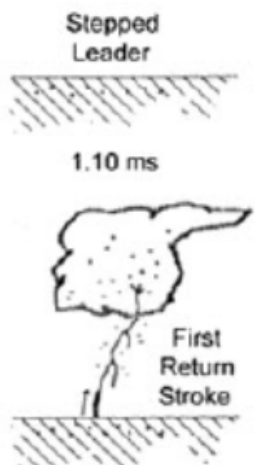

$20.10 \mathrm{~ms}$

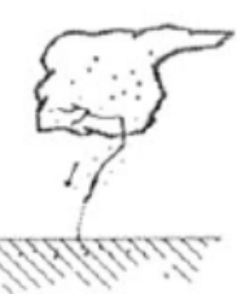

$61.00 \mathrm{~ms}$

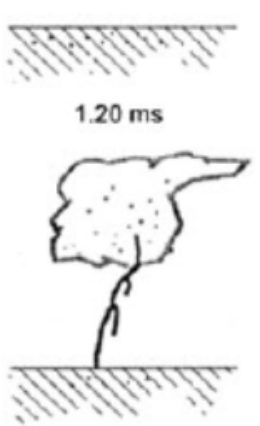

$20.20 \mathrm{~ms}$

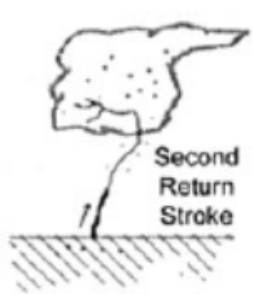

$62.05 \mathrm{~ms}$

Figura 1-8 Procesos en una descarga CG-, comenzando en $t=0$ con la distribución de las cargas. Tomado de Rakov y Uman (2003)

A partir de la semilla relámpago, el líder (o precursor escalonado descendente) se desplaza hacia la tierra, y al llegar al suelo se forma el canal y ocurre el primer stroke. Esta corriente de 
retorno tiene un pico de aproximadamente $30 \mathrm{kA}$, la cual se alcanza en algunos microsegundos, y luego decae a la mitad de ese valor en algunas decenas de microsegundos, produciendo que se reduzca eficazmente la magnitud de la carga originalmente depositada en el canal por el líder. Los sucesivos strokes presentan típicamente una corriente de pico de 10 a $15 \mathrm{kA}$. Los strokes calientan rápidamente el canal a una temperatura cercana a $30.000 \mathrm{~K}$ y crea una presión de canal de 10 atm o más, lo que resulta en la expansión del canal. Esta expansión genera una onda de choque que finalmente se convierte en el trueno que escuchamos a la distancia.

Los strokes generan radiación electromagnética en un amplio espectro de frecuencia que van desde los pocos $\mathrm{Hz}$ hasta cerca de $300 \mathrm{MHz}$, con un pico en el espectro de frecuencia entre los 5 y los $10 \mathrm{kHz}$ para descargas a una distancia mayor a $50 \mathrm{~km}$. Para valores de frecuencias mayores, la amplitud espectral de la radiación electromagnética es aproximadamente inversamente proporcional a la frecuencia hasta los $10 \mathrm{MHz}$ e inversamente proporcional a la raíz cuadrada de la frecuencia entre los $10 \mathrm{MHz}$ y los $10 \mathrm{GHz}$. Sin embargo la radiación electromagnética emitida por las descargas es aún detectable para frecuencias mayores, como por ejemplo, en las microondas, $300 \mathrm{MHz}$ a $300 \mathrm{GHz}$ y en el espectro visible, 1014 a $1015 \mathrm{~Hz}$. Siendo esta radiación la detectada por los principales sistemas de detección de AEA.

De esta manera, las nubes de tormentas, a través de la AEA y la carga transferida por las mismas, funcionarían como "batería" del circuito global eléctrico. Sin embargo, todavía falta saber de qué manera se cierra el circuito, y como la actividad eléctrica permite que fluya carga eléctrica hacia la ionosfera.

Las descargas eléctricas, y en particular los rayos, causan una variedad de fenómenos ópticos transitorios de baja luminosidad llamados, por sus siglas en inglés, TLEs. Estos fenómenos ocurren entre la parte superior de las nubes (a una altura de cerca de $20 \mathrm{Km}$ o menos) y la ionosfera inferior (alrededor de $60-90 \mathrm{~km}$, dependiendo de la hora del día) y representan el mecanismo para transferir la energía de las descargas eléctricas a la ionosfera inferior, como se explicará a continuación.

\section{Eventos Luminosos Transitorios ( TLE)}

Los Eventos Luminosos Transitorios (TLE: Transient Luminous Events) son eventos de muy corta duración que se emiten desde la atmosfera superior, por encima de las tormentas, a la ionosféra. Estos eventos son consecuencia de la actividad eléctrica de las tormentas y forman 
parte del acoplamiento entre la troposfera y la ionosfera (Sao Sabbas et al, 2011). En la Figura 1-9 se puede observar este acoplamiento por medio de los TLEs.

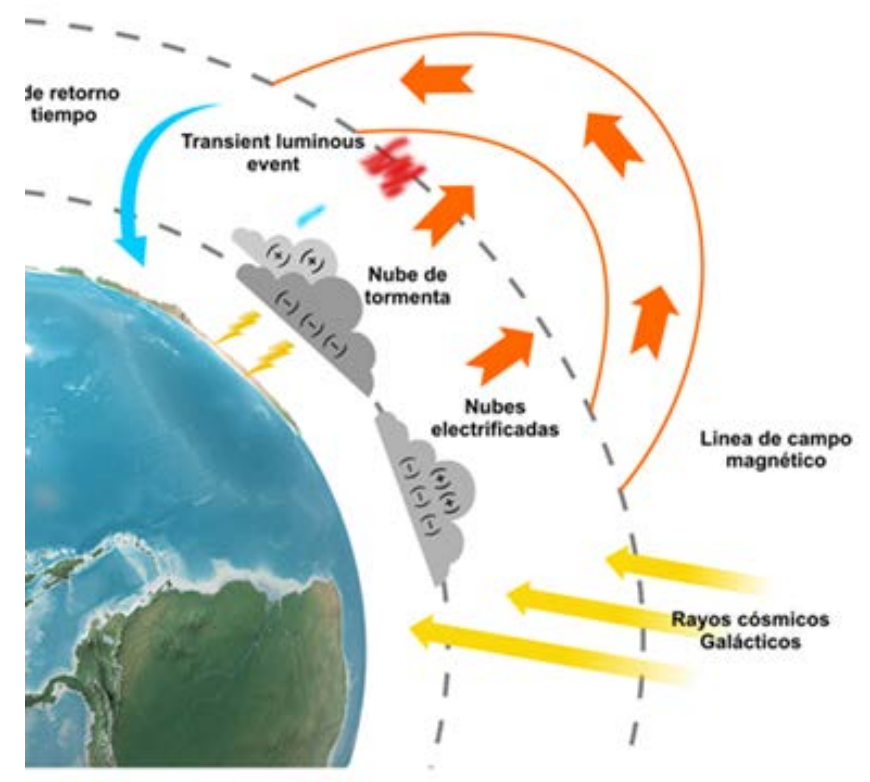

Figura 1-9 Detalle del Circuito global donde se puede apreciar el acoplamiento entre las nubes de tormenta y los TLES

La terminología TLEs en realidad involucra a un conjunto de eventos llamados Halos, Sprite Halos, Blue Jets, Gigantic Jets como se puede ver en el diagrama de la Figura 1-10. Es muy interesante señalar que estos eventos están fuertemente asociados con los Sistemas Convectivos de Mesoescala (MCSs) ${ }^{1}$ donde una muy fuerte convección lleva a una alta tasa en la actividad eléctrica.

Estos fenómenos ópticos atmosféricos superiores son un descubrimiento relativamente nuevo ya que se detallaron recién en la década de los 90. Los TLEs no son fáciles de ver a simple vista ya que se encuentran ocultos por encima de tormentas eléctricas y tienen baja luminosidad. Sin embargo, los astronautas y pilotos de gran altitud han realizado informes sobre estos fenómenos desde hace más de 40 años.

Poco se sabe todavía sobre los TLEs ya que se producen en una región que es demasiado alta para que la mayoría de los aviones y demasiado baja para que la mayoría de los satélites puedan realizar un estudio. Por ser un descubrimiento relativamente nuevo en física

\footnotetext{
${ }^{1}$ Un sistema convectivo de mesoescala es un sistema nuboso que aparece compuesto de numerosas tormentas y que produce una zona continua de precipitaciones de extensión horizontal del orden de los 100 km o más
} 
atmosférica, su iniciación y su desarrollo aún no se entienden completamente, aunque numerosos grupos de trabajo alrededor del mundo, están estudiando sus características, que son resumidas a continuación.

Los Sprites pueden aparecer justo por encima de una tormenta eléctrica activa y se extienden hasta los 96 kilómetros desde la parte superior de una nube de tormenta. Poseen una débil intensidad lumínica pero de mucha envergadura vertical, y con una duración de unos pocos segundos. Muchas veces son descritos como parecido a las medusas y son de color rojo debido al nitrógeno (el principal elemento en el aire) que se ioniza por la fuerte campos eléctricos.

Blue Jets también son vistos saliendo de la parte superior de las nubes de tormenta y se extienden en conos estrechos a alturas de 15 a $22 \mathrm{~km}$, y duran sólo una fracción de segundo. A veces los pilotos de aerolíneas son testigos de estos eventos.

Elves son grandes regiones brillantes en forma de disco que pueden ser llegar a tener hasta 300 kilómetros de diámetro. Tienen una duración de menos de una milésima de segundo. Se necesitó una cámara de vídeo con poca luz en el transbordador espacial en 1992 para descubrir y verificar estos fenómenos. Estos eventos tienden a ocurrir luego de una descarga nube tierra positiva $(+C G)$ y se cree que son pulsos electromagnéticos energéticos que se extienden hacia la ionosfera, donde se encuentra una región de partículas cargadas por ionización debido a la radiación solar. En general, se extienden desde la capa superior de mesosfera hasta el espacio.

En la actualidad, aunque se investiga el rol de los TLEs en el Circuito Global Eléctrico de la Tierra, se cree que podrían ayudar a reducir la diferencia en la magnitud de la carga que se acumula entre la superficie y la ionosfera y cerrar el Circuito Global Eléctrico. 


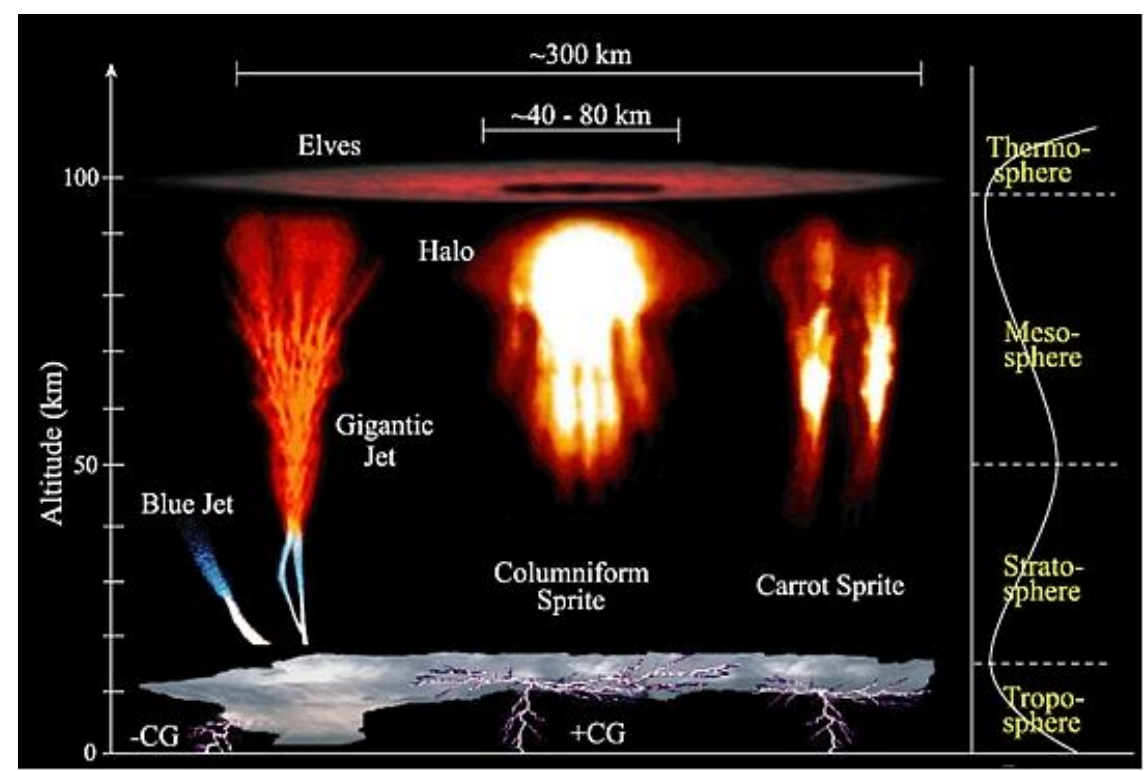

Figura 1-10 Diferentes tipos de TLE extraído de Pilipenko 2010

\section{Implicancia global de las descargas y los componentes del Circuito Global}

Como vimos anteriormente, a consecuencia de la estructura eléctrica dentro de las nubes de tormentas, se forman campos eléctricos dentro de las mismas que, por medio de diferentes mecanismos, pueden provocar un intercambio de cargas entre diferentes regiones por medio de descargas eléctricas y que estas están relacionadas con la microfísica y dinámica de las nubes.

Existen distintos estudios que muestran que la actividad eléctrica a escala regional y global puede ser usada como herramienta para el estudio de clima terrestre. Por ejemplo, Williams (1994) correlacionó las anomalías de temperatura de bulbo húmedo con la resonancia de Schumann, la cual es una medida indirecta de la actividad eléctrica global. Reeve y Toumi (1999), utilizando datos satelitales, mostraron que existe un acuerdo entre la temperatura global y la actividad eléctrica. Price (2000) encontraron una relación entre la variación del vapor de agua en la troposfera superior y la variación en la actividad eléctrica global. Peterson et al. (2005) utilizaron datos satelitales y observaciones de radar para estudiar la relación entre la masa de precipitación de hielo y la densidad de rayos. Ávila et al. (2010) mostraron que existe correlación entre la tasa de descargas eléctricas y el número de tormentas de 
convección profunda. Williams (1985) sugirió que la tasa de descargas eléctricas es una función de la altura de la tormenta basado en el trabajo de Vonnegut (1963). Yoshida et al. (2009) examinaron la correlación entre el número de descargas eléctricas por segundo en una nube convectiva y la altura entre la isoterma de $0^{\circ} \mathrm{C}$ y el tope de la misma. Estos autores encontraron que la tasa de descargas es proporcional a la quinta potencia de dicha altura.

Todos estos resultados refuerzan la idea que las descargas eléctricas pueden ser utilizadas como indicadores de tormentas severas. La actividad eléctrica asociada a las tormentas está directamente relacionada con los procesos microfísicos y dinámicos dentro de las nubes, los cuales se correlacionan debido a la liberación de calor latente durante el desarrollo de una tormenta.

Las tormentas a menudo siguen un ciclo regular de nacimiento, desarrollo, madurez, decaimiento y disipación (Figura 1-11). Este ciclo puede tardar alrededor de $1 \mathrm{~h}$, con las nuevas células de tormenta formándose en el límite del frente frío de las celdas anteriores.

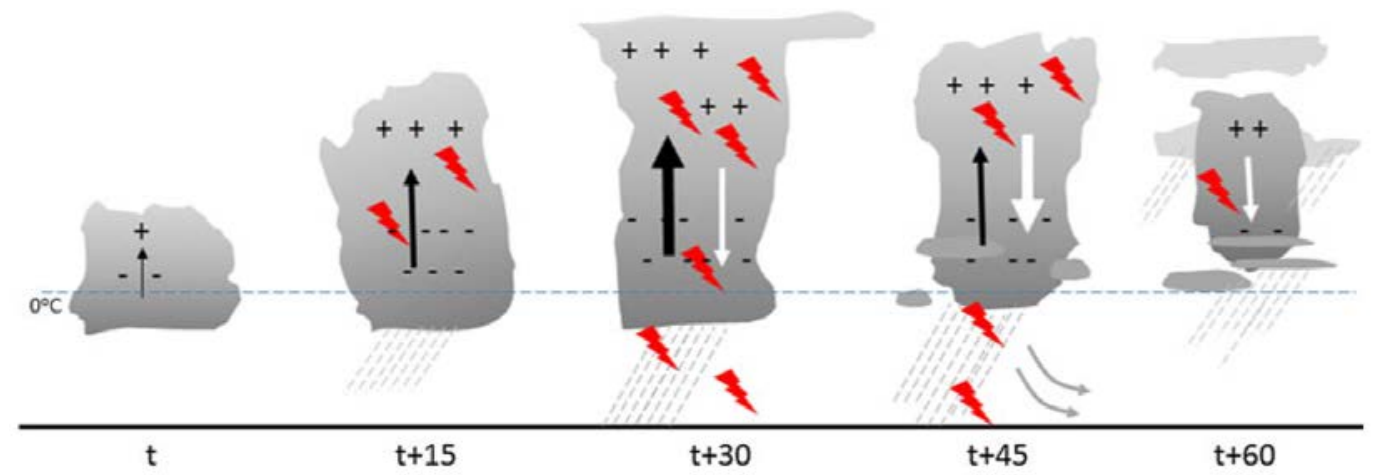

Figura 1-11Etapas de la actividad eléctrica asociada a las fases de una nube convectiva. (Figura extraída de Williams et al., 1989).El tiempo se muestra en minutos

Desde el nacimiento de la nube convectiva hasta su disipación, la nube se electrifica a diferentes niveles, y aunque sólo vemos la AEA durante las etapas de desarrollo, madurez y decadencia, la actividad eléctrica sigue un patrón específico. En los primeros momentos, la nube se caracteriza por una actividad eléctrica formada solo por descargas intranube (durante la fase de desarrollo), seguido por la generación de descargas nube-tierra durante la etapa de madurez (Williams et al. 1989). Ambos tipos de AEA pueden ocurrir durante la etapa de decaimiento. Además del cambio en los patrones de la AEA, la etapa de madurez se puede asociar con fuertes lluvias, granizo y tornados, mientras que la etapa de disipación es conocida 
por estar asociada con corrientes descendentes, microrráfagas y cortantes del viento (Williams, 2013).

Como se mencionó anteriormente, la AEA en las tormentas está fuertemente ligada a la microfísica y dinámica de las mismas y, por lo tanto, los cambios en la actividad eléctrica pueden indicarnos cambios en los procesos internos de las tormentas eléctricas. Tanto la tasa de las descargas, así como la polaridad de las mismas, se encuentran asociados con eventos severos específicos (Williams, 2001; Dotzek y Praice, 2009). La tasa de descargas pareciera estar relacionado con la intensidad de las corrientes ascendentes, que afecta la tasa de transferencia de carga y separación de las mismas. En cuanto a la polaridad de los CGs, pareciera depender más directamente con al cambio de temperatura en la región de carga o por cambios en el contenido de agua líquida (LWC) en la zona de carga (Takahashi, 1978; Saunders et al., 1991). 


\section{Capítulo 2 Sistemas de detección de AEA}

En este capítulo presentaremos los distintos sistemas de detección de AEA y las distintas bases de datos que hemos utilizado para hacer el análisis de la Actividad Eléctrica Atmosférica en la Argentina.

Se presenta los sistemas de detección de AEA World Wide Lightning Location Network (WWLLN, http://Wwlln.net), y los instrumentos satelitales Optical Transient Detector (OTD) y Lightning Imaging Sensor (LIS). Se discuten los distintos métodos de medición así como la información que son capaces de proveer los distintos sistemas Por último, se discute la eficiencia de detección y la precisión espacial y temporal de la WWLLN relativa a LIS, especialmente en la zona de trabajo de esta Tesis mostrando la variación de la eficiencia de detección de la WWLLN en los últimos años.

Al no contar el país con una red nacional de detección de descargas, la WWLLN ha permitido (y permite) poder realizar el estudio de la AEA en todo el país aun en latitudes altas, permitiendo poder realizar una climatología de nuestro territorio y de los países del Sur del continente.

\section{Sistemas de detección}

Existen distintos sistemas de detección de AEA pero en general todos estos sistemas se basan en la detección de la señal electromagnética y/o acústica (trueno) emitida por las descargas eléctricas.

Los sistema de detección actuales utilizan esencialmente el hecho que las descargas eléctricas atmosféricas son generadoras de radiación electromagnética en un espectro de frecuencia muy amplio, que incluye al rango visible. La Figura 2-1 muestra el espectro de frecuencia emitida por una descarga y los distintos intervalos de frecuencia (VLF, LF, VHF) que se utilizan para detectar a las mismas. Este rango de frecuencia es utilizado principalmente por las redes de detección de tierra. 


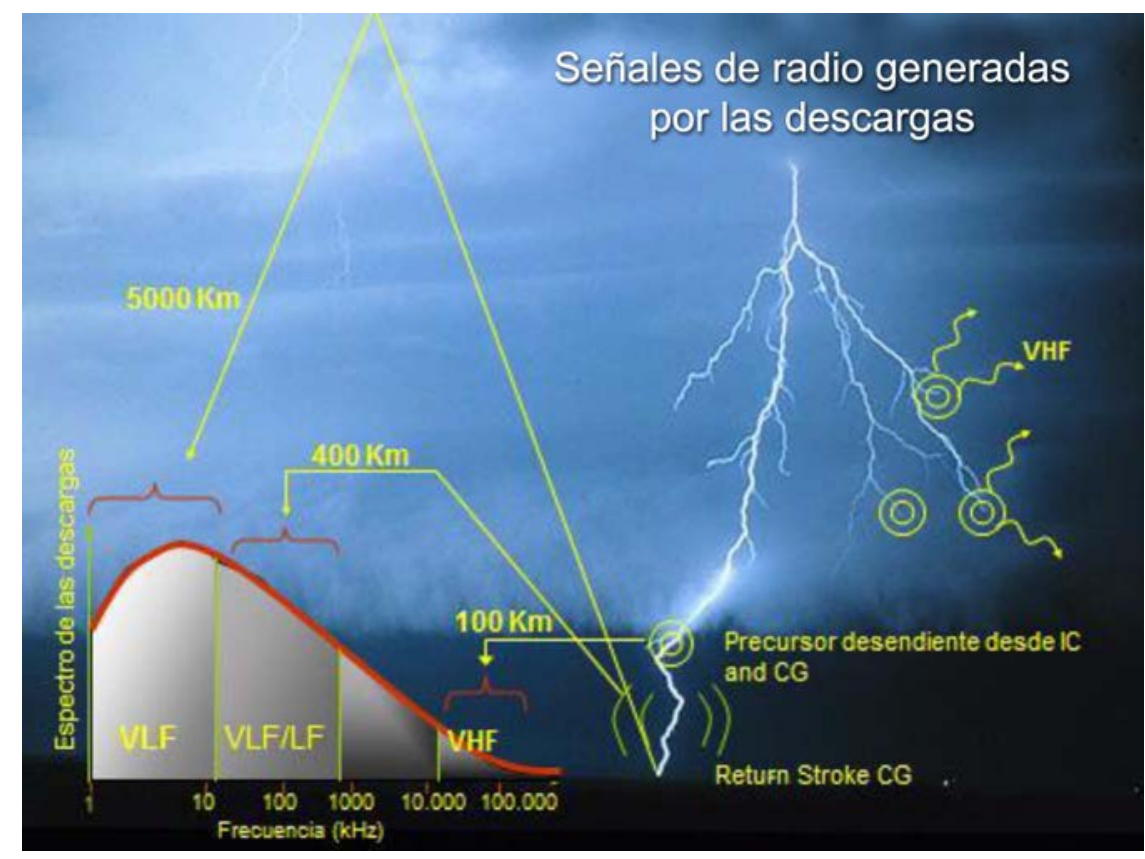

Figura 2-1 Espectro generado por las descargas eléctricas atmosféricas. Adaptado de Morales (2013)

Todos los sistemas de detección de AEA, sin importar el rango de frecuencia de trabajo, son capaces de informar la posición espacial y el tiempo de ocurrencia de la descarga. Sin embargo, según el rango de frecuencia, algunos sistemas son capaces de proveer información sobre la polaridad, tipo e intensidad de la descarga pero a costa de disminuir el alcance de detección.

Los sistema en el rango de frecuencias en VHF puede detectar descargas cercanas (hasta $\sim 100 \mathrm{~km}$ de distancia), y puede determinar su posición, e incluso la trayectoria del canal, en 3D $(\mathrm{X}, \mathrm{Y}, \mathrm{Z})$ con alta resolución tanto temporal como espacial. Estos sistemas son capaces de proveer información de la polaridad, tipo e intensidad de la descarga.

Los sistemas en el rango de frecuencias en LF detectan descargas a distancias intermedias ( 400 km) y puede determinar la posición geográfica de la descarga, en 2 dimensiones $(X, Y)$ con una buena resolución espacial y temporal, y proveen información del tipo y de la intensidad de la descarga. En estas frecuencias trabajan en general las redes nacionales y/o regionales de alta eficiencia.

Las redes que trabajan en VLF son en general redes globales que, aunque solo proveen información sobre la posición espacial y el tiempo de ocurrencia de la descarga eléctrica, tienen la ventaja de poder hacer un mapeo a escala global de AEA ya que las ondas de radio, 
en este rango de frecuencia, pueden ser detectadas a más de $4.000 \mathrm{~km}$ de distancia de la fuente.

Por otro lado, los sistemas satelitales detectan, principalmente, la radiación generada por las descargas en el espectro visible proveyendo información sobre la posición espacial y el tiempo de ocurrencia de la descarga a escala global pero son incapaces de proveer una cobertura continua en el tiempo de una dada región y de proveer información sobre el tipo y la polaridad de la descarga.

\section{Sistemas Satelitalles: LIS y OTD}

Se utilizó la base de datos de AEA procedente de los instrumentos satelitales Optical Transient Detector (OTD) y Lightning Imaging Sensor (LIS).

Los instrumentales OTD y LIS detectan la AEA durante el día y la noche con una eficiencia de detección entre (44 \pm 9)\% (OTD durante el día) y el (93 \pm 9) \% (LIS durante la noche), con una precisión espacial de $10 \mathrm{~km}$ para OTD y de $4 \mathrm{~km}$ para LIS, aunque puede presentar una pequeña variación espacial (Boccippio et al., 2002).

El instrumento OTD (Christian et al., 1999) fue puesto en órbita en abril de 1995 a bordo del satélite MicroLab-1 (más tarde rebautizado OV-1) y dejo de operar en marzo de 2000. El satélite tenía una inclinación de $70^{\circ}$, lo cual permite a OTD detectar AEA entre $\pm 75^{\circ}$ de latitud, aproximadamente.

El instrumento LIS, se puso en funcionamiento en Noviembre 1997 a bordo de la plataforma satelital Tropical Rainfall Measuring Mission (TRMM) (Kummerow et al., 1998; 2000). Esta plataforma se encuentra en una órbita con inclinación de $35^{\circ}$ y a $350 \mathrm{~km}$ de altitud (la cual fue elevada a 402 kilómetros en agosto de 2001), y su margen de detección se encuentra entre $\pm 38^{\circ}$ de latitud, aproximadamente.

LIS presenta una eficiencia de detección de $90 \%$ en el hemisferio norte (NH) y de $98,6 \%$ en el Hemisferio Sur (SH), aunque esta varía con la hora del día. Varios estudios (por ejemplo, Christian et al, 1999, 2003; Boccippio et al, 2002, b; Koshak et al, 2000; Cecil et al, 2014), que estudiaron la eficiencia de ambas bases de datos conjuntas, detallaron que la incertidumbre de estos datos son del orden del 10-15\% (Blakeslee et al., 2012).

Ambos sensores monitorean en $777,4 \mathrm{~nm}$, detectando los pulsos de luz producidos por las descargas eléctricas por encima de un nivel de luminosidad base. Ambos están (estuvieron) a 
bordo de satélites de orbitas bajas, y en cada paso visualizan una región de $580 \mathrm{~km}$ x $580 \mathrm{~km}$ de la tierra durante unos 3 min para el caso de OTD o durante 1,5 min en el caso de LIS.

Los archivos de los datos de cada órbita individuales están disponibles en el Centro Mundial de Recursos de Hidrología (GHRC, http://thunder.nsstc.nasa.gov/lightning_team.html), con 14 órbitas/día para OTD y 16 órbitas/día para LIS, con una resolución de $10 \mathrm{~km}$ para OTD y de 5 km para LIS.

Ambos instrumentos detectan la totalidad de las descargas sin diferenciar si son CG o IC, ya que ambos tipos de descargas producen pulsos ópticos que son visibles desde el espacio. En particular, los datos registrados por LIS incluyen la hora del evento, su energía radiante, y su ubicación.Asimismo, los datos de LIS poseen distintos subniveles donde las descargas detectadas son agrupadas según criterios espaciales y temporales dando lugar a distinta información:

- Background, cada una de las fotos que toma la cámara a bordo.

- Event, evento definido como la detección, en un solo píxel, de un valor superior al valor umbral de fondo durante un solo fotograma. En este punto vamos a señalar que en esta tesis en general la palabra evento (en español) la utilizaremos no con este significado, sino como cada uno de los registros detectados por al WWLLN.

- Group, debido a que una descarga a menudo ilumina más de un píxel durante un solo tiempo de integración, el resultado son dos o más eventos adyacentes en el mismo período de tiempo. Cuando estos eventos son múltiples adyacentes entre sí (comparten un lado o esquina), se los asigna en un solo grupo. La definición formal de un grupo es uno o más eventos simultáneos (es decir, los eventos que se producen en el mismo período de tiempo de integración) que se registran en pixeles adyacentes (vecinos o en diagonal) en la matriz de plano focal. Un grupo puede estar constituido por un solo evento o incluir muchos eventos.

- Flash, consiste de uno a múltiples pulsos ópticos que se producen en la misma tormenta de células dentro de un tiempo y a una distancia especificada. Un flash debe entonces corresponden a varios grupos relacionados en un área limitada. Para el algoritmo, definimos un flash como un conjunto de grupos secuencialmente separados en el tiempo por no más de 330 ms y en el espacio por no más de 5,5 km. El algoritmo utiliza la distancia euclídea ponderada (Hartigan, 1975). Un flash puede incluir tan sólo un grupo o puede consistir en muchos grupos, cada uno de los cuales puede contener uno o muchos eventos. En el caso de LIS se utiliza la 
definición de Flashpara esta categoría de datos, porque la resultante "flash" en general se corresponden a la definición aceptada para un relámpago (IC) o un rayo (CG).

- Área, las descargas eléctricas se produce en las células de tormenta que tienen dimensiones de aproximadamente $10 \mathrm{~km}^{2}$. Muchas tormentas, sin embargo, son multicelulares y pueden extenderse sobre grandes distancias y mantenerse durante muchas horas. Se define Área como una región contigua donde se han producidos descargas (que se define como un conjunto de flashes detectados por LIS) durante una sola órbita de la LIS. Un área definida de este modo consiste en un conjunto de flashes separados en el espacio por no más de 16,5 km(aproximadamente 3 píxeles). Se acepta que Área se corresponde a núcleo de una tormenta.

\section{Redes de tierra: WWLLN}

La World Wide Ligtning Location Network (WWLLN, http://wwlln.net)es una red de detección de tierra que se inició en 2003 con 11 sensores y en la actualidad está compuesta por 70 sensores instalados en todos los continentes y también en algunas islas (Hutchins et al., 2012; Virtz et al., 2013). La Figura 2-2muestra la ubicación de los sensores indicando su fecha de instalación y los sensores a instalarse en los próximos años (marcados por estrellas).Es importante señalar que este mapa llega hasta las estaciones del año 2012, a la fecha (año 2014) las estaciones en forma de estrella se encuentran en funcionamiento. Estos sensores detectan ondas de muy baja frecuencia (VLF) para identificar el tiempo de arribo de grupo (Time Of Group Arrival TOGA) para el paquetes de onda sferics $^{2}$ de descargas individuales (Dowden et al., 2002). Esta información es enviada a un procesador central, el cual combina los tiempo de arribos de los distintos sensores, y determina las ubicaciones de origen sobre la Tierra, considerada esférica. Se requieren al menos de cinco sensores para localizar una descarga en el espacio y en el tiempo con una precisión espacial y temporal de $\sim 5 \mathrm{~km}$ y $<10$ $\mu \mathrm{s}$, respectivamente. Esta red tiene una eficiencia de detección baja y favorece la detección de las descargas CG más energéticas (Abarca et al,. 2010) pero es capaz de determinar la ubicación de las descargas eléctricas que producen tormentas a escala global y en tiempo real (Jacobson et al., 2006).

\footnotetext{
${ }^{2}$ Sferic, o atmospheric: Señal de radio generada por cada una de los intercambios de carga entre dos centros de carga
} 
Cada sensor consta, básicamente, de un receptor de VLF y de un GPS, cuyas señales se digitalizan y se envían a la central de procesamiento cuando un evento es detectado. Los elementos que conforman el sensor y el mismo ya instalado se muestran en la Figura 2-3 y la Figura 2-4, respectivamente.

Como se puede observar de la Figura 2-2, la red cuenta con cuatro estaciones instaladas en la Argentina, la más antigua en la ciudad de Córdoba (FAMAF-UNC), otras dos ubicadas en la Patagonia (Universidad de la Patagonia en Trelew y en el Observatorio de la Patagonia Austral (OAPA) en Río Gallegos), y la más reciente en la División LIDAR perteneciente a CITEDEF (Villa Martelli), en las cercanías de la ciudad de Buenos Aires. A nuestro entender, estas estaciones, más las estaciones ubicadas en América del Sur (sumada a una nueva estación instalada en 2014 en Chile), proporcionan una buena cobertura de Sudamérica, y en particular, de todo el territorio argentino.

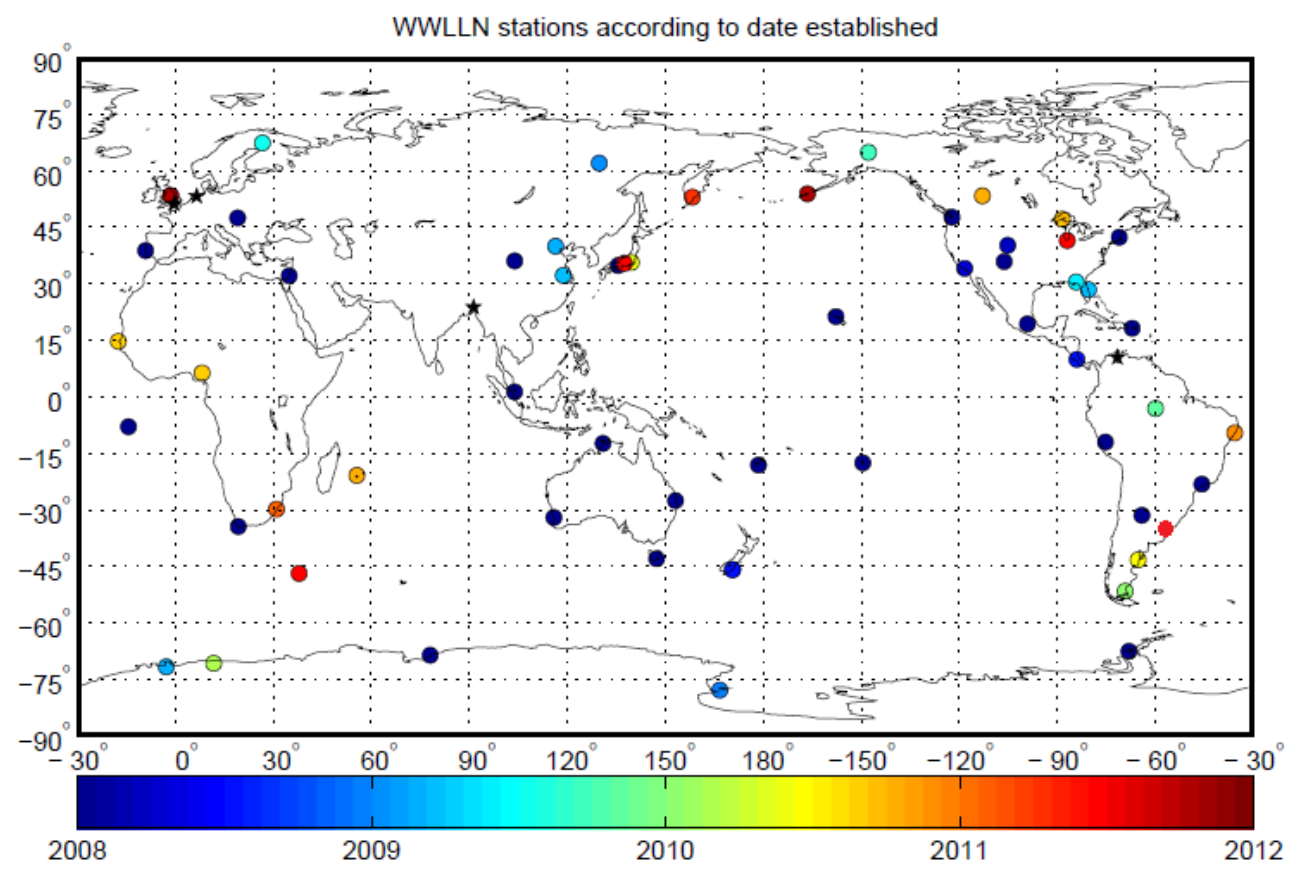

Figura 2-2 Estaciones de la WWLLN y fechas de su instalación 


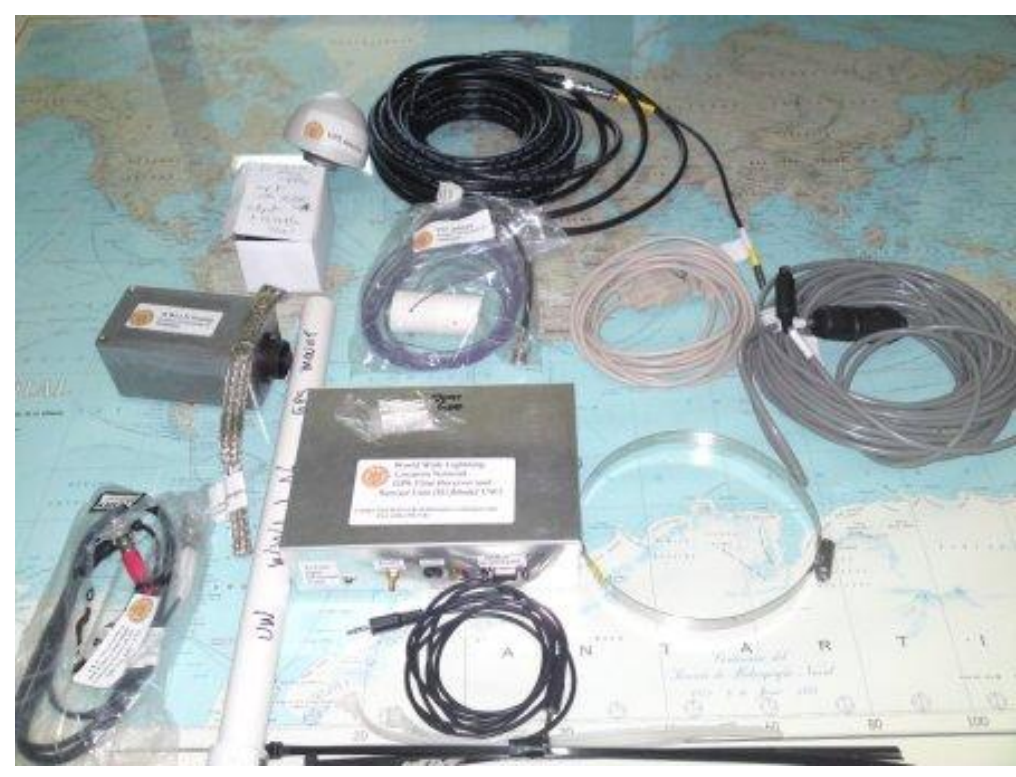

Figura 2-3 Partes delsensor de la WWLLN

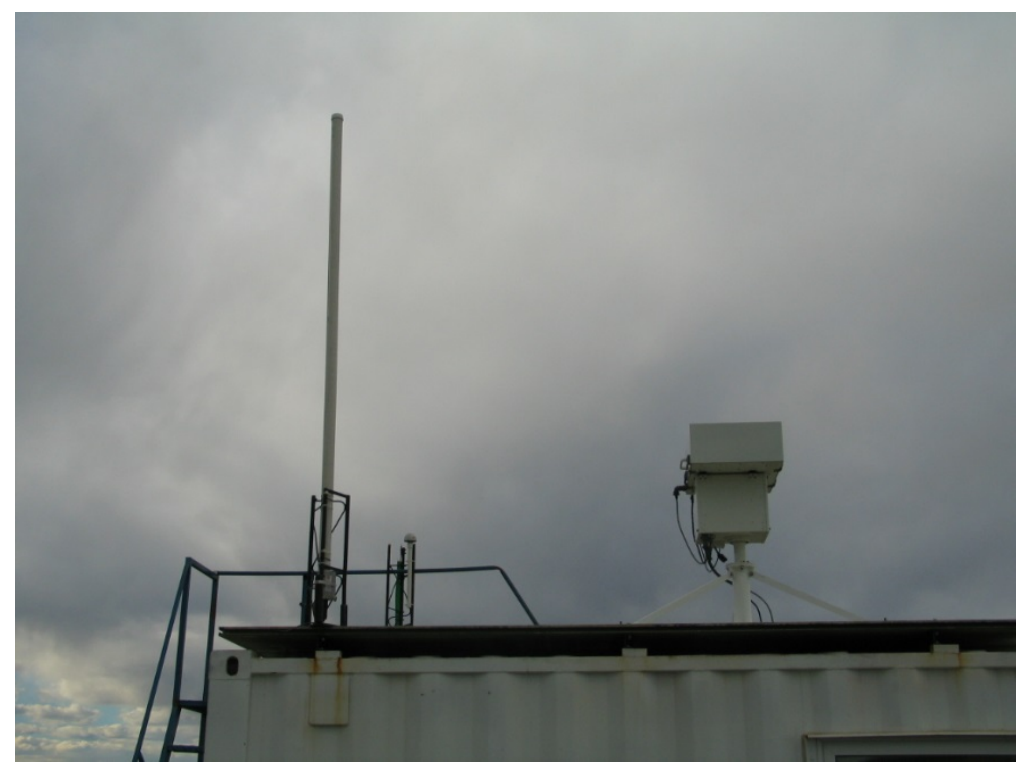

Figura 2-4 Antena instalada en Rio Gallegos

La Figura 2-5 muestra, a modo de ejemplo, un espectro típico de la señal detectada por un solo sensor, en este caso la estación ubicada en Córdoba, para el día 8 de Febrero de 2014 a las 11:00 hs UTC. En el eje horizontal está representado el tiempo en segundos, en el eje vertical el rango de frecuencia de detección y las líneas verticales corresponden a los sferics detectados donde la escala de color representado la intensidad (dB) de los mismos. 


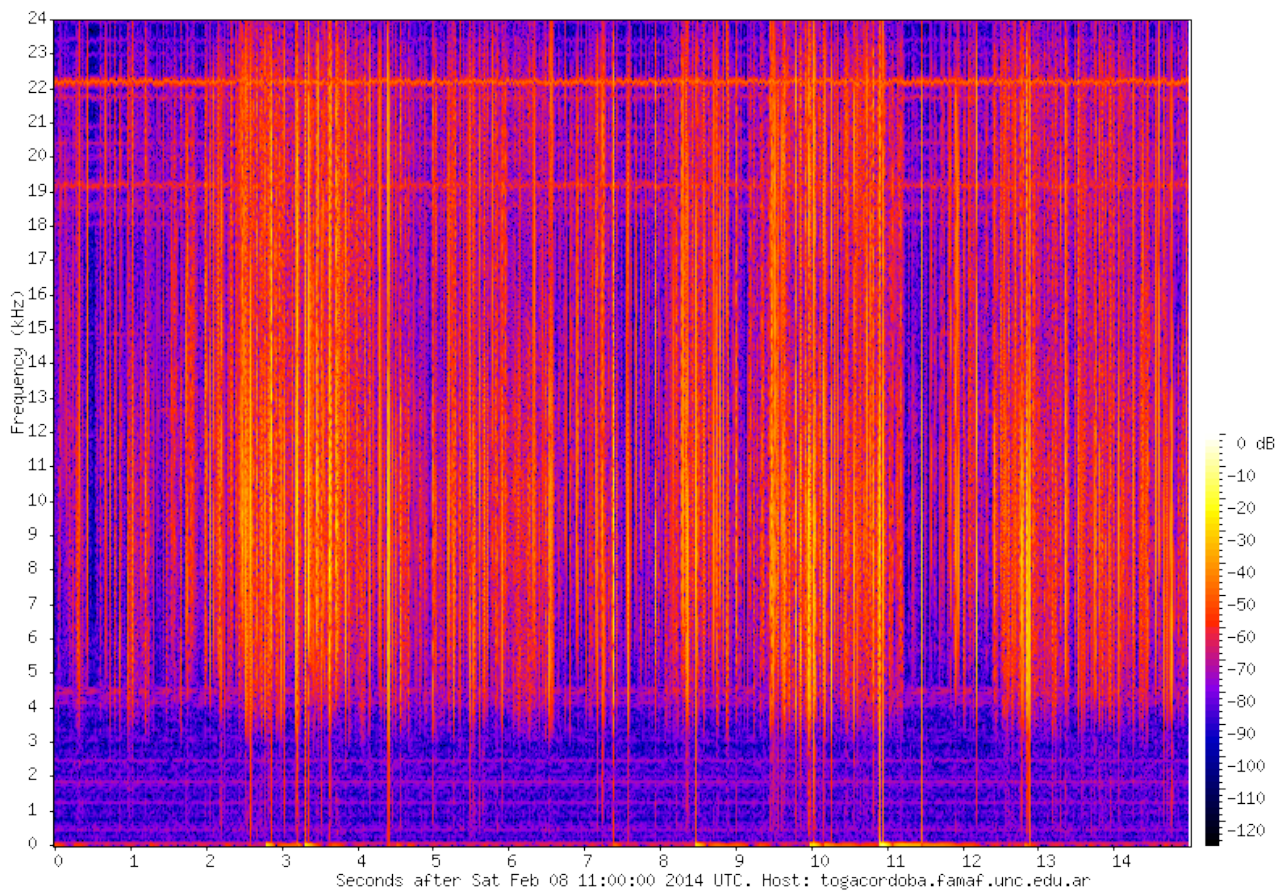

Figura 2-5 Espectrograma de las estaciones WWLLN

\section{Comparación entre las bases de datos}

LIS y OTD detectan cambios momentáneos en el brillo de una nube causados por una descarga eléctrica, y aquellos destellos que se encuentran agrupados espacial y temporalmente son registrados en un evento referido como flash (Christian et al., 2000).Por el contrario, la WWLLN detectan sferics que se han propagado en la guía de onda de la Tierraionosfera y que son capturados totalmente dentro de una ventana de 1 ms en cada estación (Dowden et al. 2002). Por lo tanto, la WWLLN detecta preferentemente descargas CG, con una corriente de pico de 30kA o más, y rara vez detecta y localiza múltiples descargas en un solo flash. Esto se debe a que las formas de onda dispersas se superponen o porque hay una gran diferencia en la energía total radiada por cada stroke (lo que significaría que no llegan a ser detectadas) (Rodger et al., 2004; 2005; Jacobson et al., 2006). Por lo tanto, los eventos detectados por WWLLN pueden considerarse como flashes. De ello se deduce que la comparación de climatologías entre los strokes detectados por la WWLLN y los flashes detectados por LIS/OTD es posible.

En la Figura 2-6, tomada del trabajo de Virts et al., (2013), se puede observar la climatología de la AEA generadas por ambas bases de datos. Los datos de la WWLLN corresponden a los valores medios anuales del periodo comprendido entre 2008 y 2011, y los datos LIS/OTD son 
los valores medios anuales para el período 1995-2011 (aproximadamente 5 años de datos OTD y 13 años de LIS).

Los periodos comprendidos en las bases de datos es un punto fundamental al comparar las mismas. Como explicamos anteriormente, el sistema LIS-OTD se encuentran a bordo de satélites de orbitas bajas, y en cada paso visualizan una pequeña región de la tierra durante algunos minutos, esto significa que, aunque su eficiencia de detección es muy alta, no están monitoreando en cada momento todo el planeta. Por lo tanto, es necesario una base de datos a largo plazo para obtener una climatología promedio de la AEA, pero a su vez no permite conocer las variaciones interanuales, así como realizar un seguimiento de eventos específicos.

De las Figura 2-6 a y b se observa que las dos climatologías son cualitativamente similares, ambos muestran una concentración de descargas sobre los continentes, en particular sobre las regiones tropicales, destacándose África, el sureste de Asia y Australasia (Continente Marítimo), América Central y América del Sur. También se observan fuertes gradientes cerca de las costas y en regiones con importantes cadenas montañosas (Los Andes, Himalaya, etc.). De las figuras también se observa la diferencia en el valor de la AEA detectada por los dos sistemas, siendo la AEA detectada por LIS/OTD, en general, diez veces mayor que la detectada por WWLLN.

Esta diferencia se observa en la razón entre las dos climatologías que se ilustran en la Figura 2-6 c. Los valores menores a uno indican proporcionalmente más descargas detectadas por la WWLLN que por LIS/OTD. En general, LIS/OTD presenta una mayor eficiencia de detección que la WWLLN, sin embargo, sobre los océanos, la detección de la WWLLN es mayor que LIS/OTD, y esto pareciera indicar que las descargas sobre los océanos serían más energéticas que sobre tierra dado que la WWLLLN tiende a detectar con mayor eficiencia este tipo de descargas.

La eficiencia de detección de la WWLLN, relativa a LIS/OTD, para América del Norte y América del Sur se puede observar en la Tabla 2-1 (Rudolsky y Shea, 2013). En general se observa un aumento en la eficiencia a través de los años debido a la expansión de la red y también que la eficiencia de detección de la WWLLN es el doble sobre América del Norte $(10,7 \%)$ que sobre América del Sur (4,9\%). Sin embargo es importante señalar que la mejora en el rendimiento es más pronunciado sobre América del Sur, con una mejora de hasta un $100 \%$, que en América del Norte (de $25 \%$ ). Esta diferencia podría ser debido a que en América del Sur hay menos sensores que en América del Norte, y por lo tanto, el agregado de una estación incrementa la eficiencia notablemente (Virts et al., 2013). 

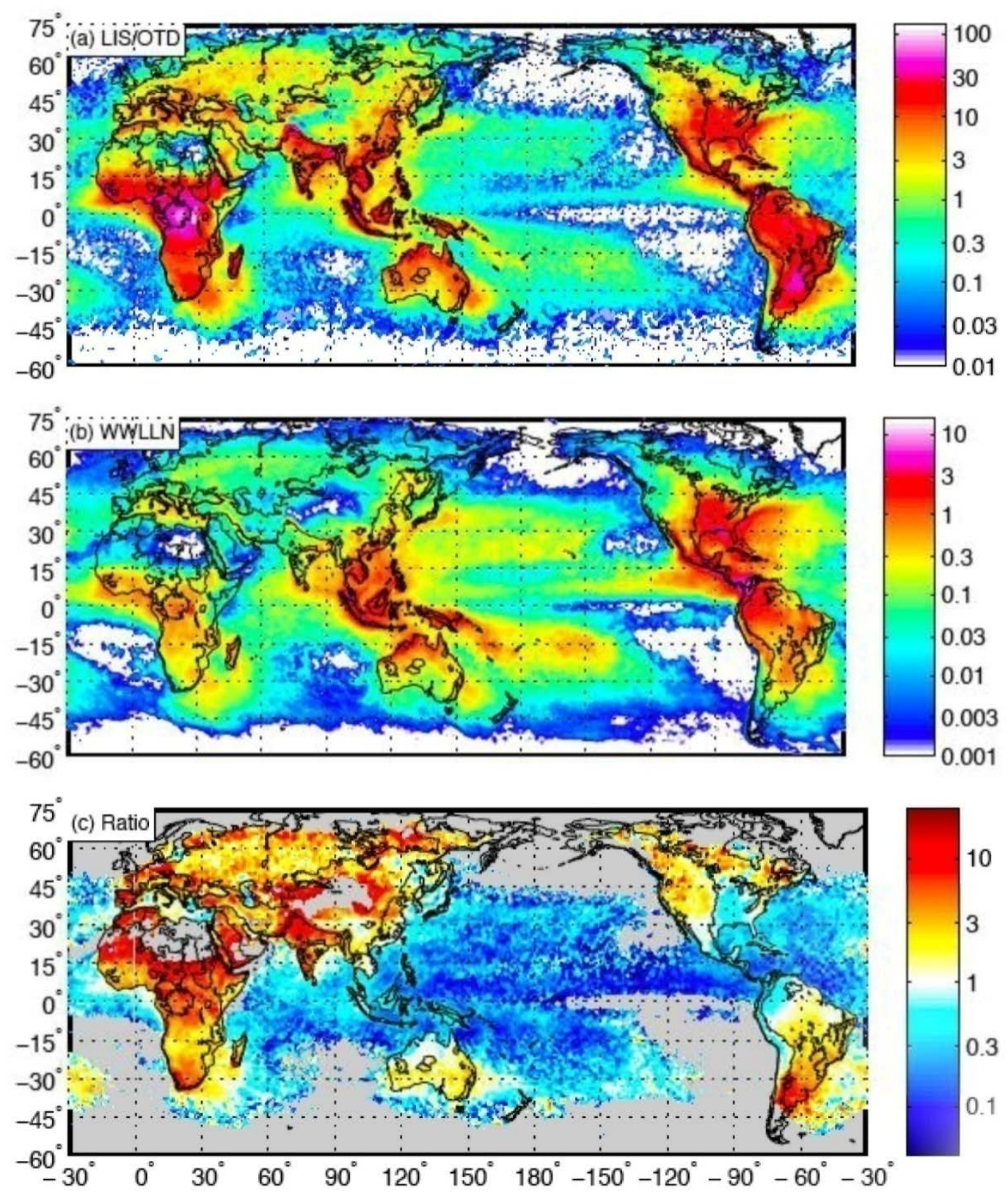

Figura 2-6 Figura extraída de Virts, 2013 en donde se observa la densidad de descargas detectadas por LIS (2-6a) WWLLN (2-6b) [fI Km $\mathrm{Kn}^{-2} \mathrm{n}^{-1}$ y la relación de eficiencia entre ambas (2-6c)

En su trabajo Rudolsky y Shea (2013) también estudiaron el error espacial de la WWLLN, relativo a los datos de LIS/OTD, y encontraron que la mediana de las distancias entre las posiciones de las descargas detectadas por ambas bases de datos tiene un valor entre 10 y 11 km como se puede observar en la Figura 2-7 


\begin{tabular}{|lccccc|} 
& Overall & Land & Ocean & Noth America & South America \\
\hline 2009 & 6.0 & 4.0 & 12.3 & 8.0 & 2.3 \\
2010 & 6.8 & 4.8 & 13.9 & 7.6 & 4.1 \\
2011 & 8.1 & 5.8 & 15.2 & 8.7 & 4.8 \\
2012 & 9.2 & 6.4 & 17.3 & 10.7 & 4.8 \\
$2009-2012$ & 7.5 & 5.2 & 14.7 & 8.7 & 4.0 \\
\hline
\end{tabular}

Tabla 2-1 Eficiencia de la WWLLN para diferentes períodos y disposiciones espaciales. Extraída de Rudolskyy Shea, 2013

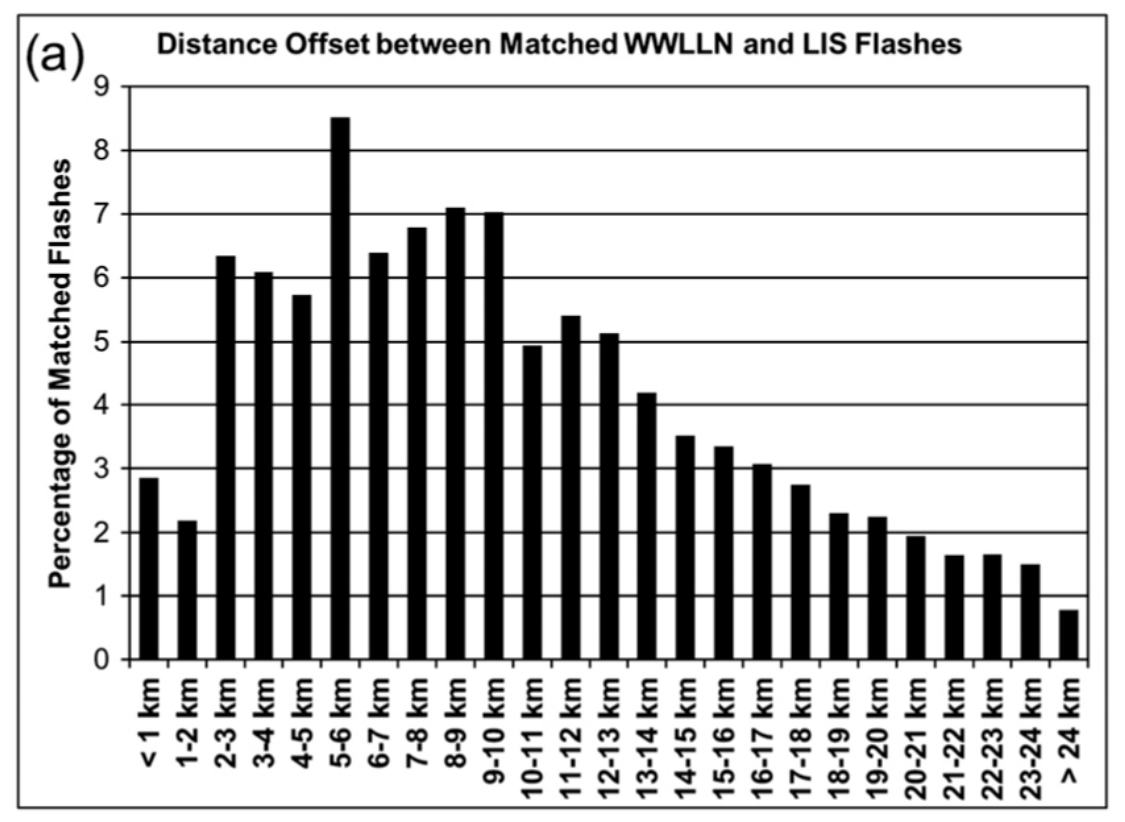

Figura 2-7 Error espacial de la WWLLN en referencia a LIS. Extraída de Rudolsky,y Shea, 2013

Para el caso de nuestra zona principal de trabajo que es el Sur de Sudamérica realizamos los mapas de densidad de descargas ${ }^{3}$ sobre el área de trabajo a partir de los sistemas de detección de descargas independientes LIS/OTD y WWLLN, la Figura 2-8 (a) muestra la densidad de descargas derivada de la Red WWLLN entre 2008 y 2012. Y la Figura 2-8 (b) muestra la densidad de descargas derivado de LIS-OTD entre enero de 1995 y diciembre de 2012. Se utilizó una resolución espacial de $0,5^{\circ} \times 0,5^{\circ}$ para ambos conjuntos de datos.

Parte de nuestra zona de trabajo se encuentra en el margen de detección del sistema LIS ($38^{\circ}$ de latitud, aproximadamente) por lo que los datos para latitudes mayores son en su mayoría provisto por el sistema OTD que dejo de operar en el año 2000, por lo que la comparación entre las dos bases de datos se dificulta para latitudes mayores a los $-40^{\circ}$.

\footnotetext{
${ }^{3}$ Descargas detectadas (flash) por una red de detección por $\mathrm{Km}^{2}$ por año $\left[\mathrm{fl} \mathrm{Km}^{-2}\right.$ año ${ }^{-1}$ ]
} 

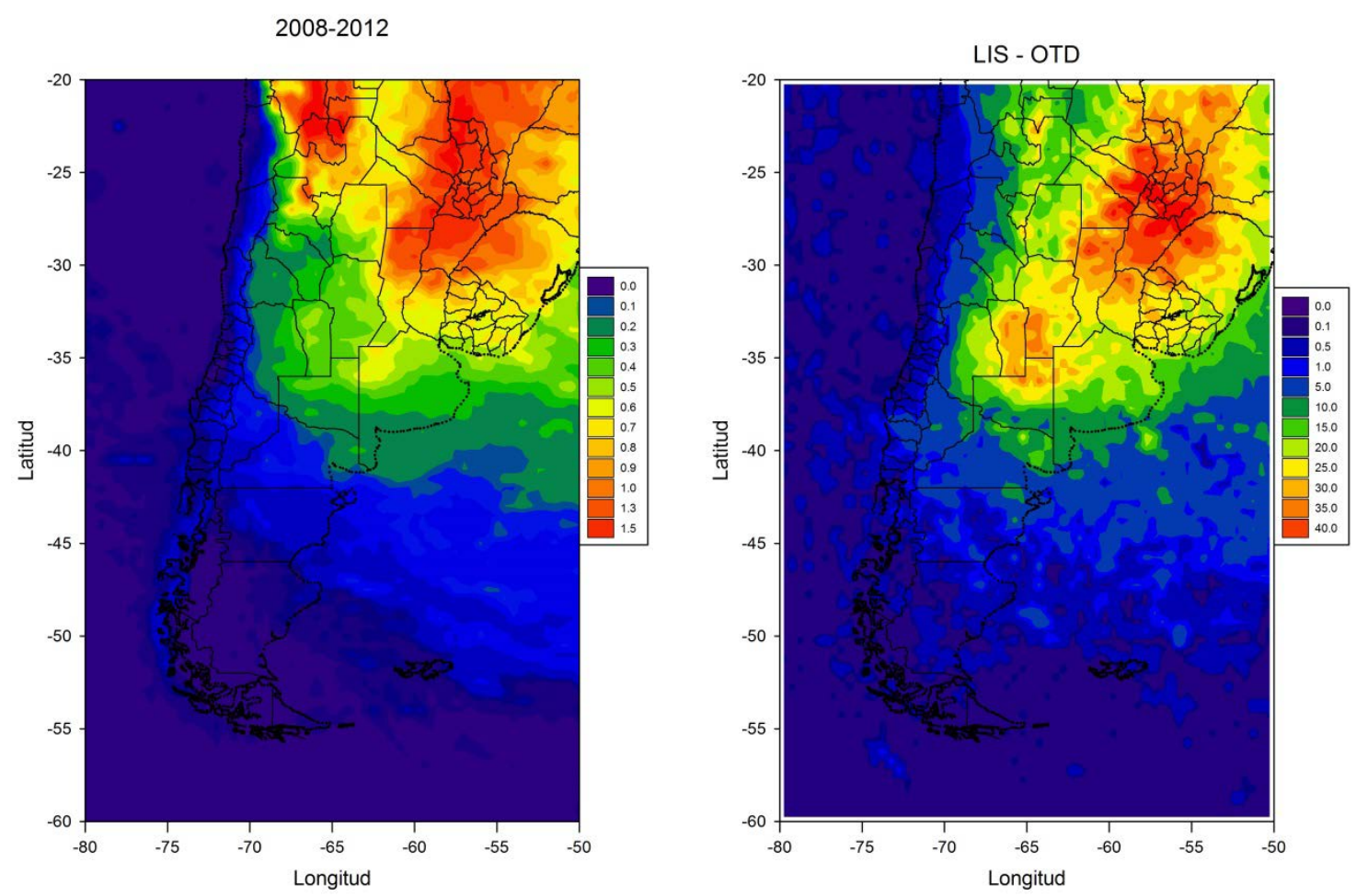

Figura 2-8 (a) densidad de descargas derivada de la Red WWLLN entre 2008 y 2012. (b)densidad de descargas derivado de LIS/OTD entre enero de 1995 y diciembre de 2012.

Claramente, la densidad de descargas detectado por LIS/OTD es mayor que la detectada por WWLLN para esta zona en concordancia a los trabajos presentados anteriormente. No obstante la baja eficiencia en la detección de WWLLN, ambos mapas de densidad de descargas muestra una distribución espacial similar con un máximo en la AEA en la región Mesopotamia y una disminución progresiva de la AEA con la latitud.

Aunque el patrón espacial es similar con dos zonas de máxima AEA, una en la zona del NOA (Noroeste Argentino, Salta, Jujuy Tucumán)y el otro máximo en la zona en la Mesopotamia argentina, sur de Brasil y Paraguay, existe una diferencia sobre la intensidad relativa entre esas zonas. Mientras que la WWLLN sitúa el máximo de AEA en la zona del NOA (Noroeste Argentino, Salta, Jujuy Tucumán),LIS-OTD lo marca sobre la región de la cuenca del Plata (LPB:[-20 -40 $]^{\circ}$ de latitud y $[-50-65]^{\circ}$ de longitud), con una continuación sobre las sierras de Córdoba y San Luis. Aunque la WWLLN no detecta la zona de las sierras como un máximo en la densidad de descargas, si mostro un máximo de actividad ceráunica (días de tormentas) que presentaremos en el Capítulo 5. 
Esta mayor intensidad observada por la WWLLN en comparación con LIS-OTD sobre NOA pareciera ser debido a la diferencia de eficiencia de detección sobre esa zona que presenta la WWLLN en el periodo 2009-2012 (Rudloskyy Shea, 2013). Mientras que en toda Argentina y Países limítrofes la eficiencia es de 1-5\% en referencia a LIS, en la zona de la cordillera, la WWLLN presenta una eficiencia de entre el 5-10\%(Rudloskyy Shea, 2013) como se observa en la Figura 2-9. (Por lo tanto, dado que la WWLLN es una red en continuo mejoramiento y con variaciones espaciales en la eficiencia de detección es que no es posible obtener valores absolutos de la AEA, sino que trataremos de identificar las zonas de AEA relevante para su estudio y para poder tener un mejor entendimiento de los procesos asociados a la AEA en dichas zonas.)

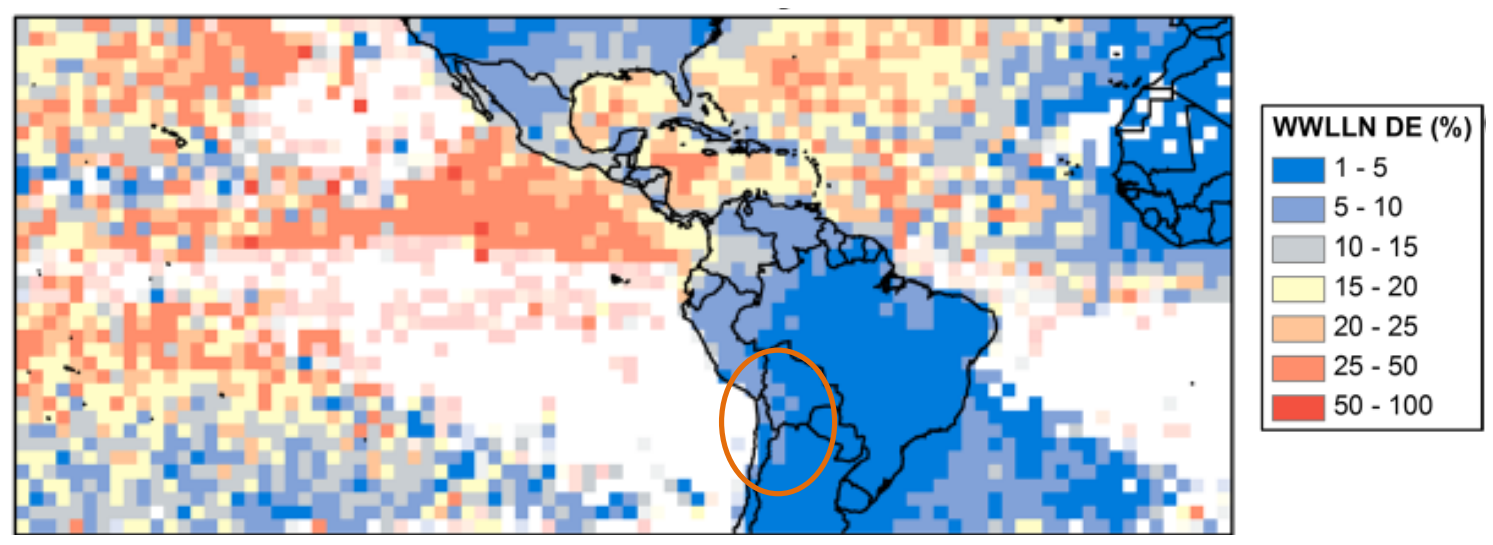

Figura 2-9 Eficiencia de detección de la WWLLN en función de LIS-OTD en el periodo 2009-2012 (Rudloskyy Shea, 2013).

A modo de ejemplo de la variación de la eficiencia de la WWLLN en los últimos años, presentamos la densidad de descargas de la WWLLN en el periodo 2008-2012 y lo comparamos con los valores de densidad del año 2012. Aunque el patrón es similar, es muy importante destacar que los valores absolutos del año 2012 llegan a ser el doble que en el promedio 2008-2012, lo que muestra los cambios fuertes en la eficiencia de la red en los últimos años, lo cual sumado a la nueva estación que entró en operación en Chile en los primeros meses del 2014 y a la futura estación en la Isla de Pascua hacen prever una aumento todavía mayor de la eficiencia en nuestra región de estudio. 

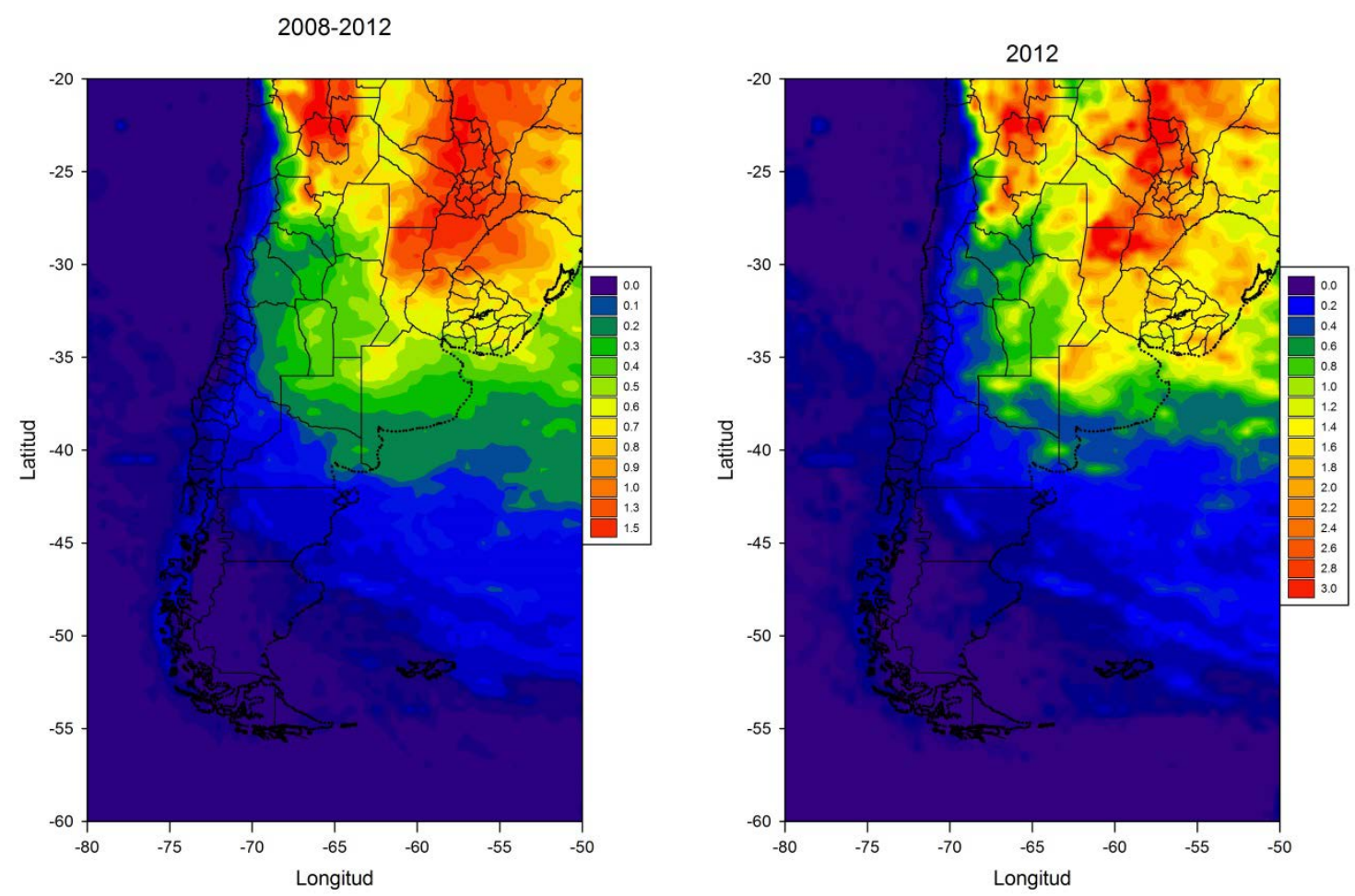

Figura 2-10 Densidad de descargas de la WWLLN en el periodo 2008-2012 y densidad del año 2012

\section{Consideraciones sobre el futuro}

El crecimiento de la red WWLLN no tan solo con mayor eficiencia, sino con nuevos productos (polaridad de descargas, energía irradiada, etc), y el uso de LIS, no son las únicas bases de datos que esperamos contar a futuro para poder ampliar los conocimientos en este tema.

La red "Sferics Timing And Ranging NETwork (STARNET)"es otra red de tierra que opera desde el año 2006 en Brasil y es operada por la Universidad de San Pablo. En el año 2013 se instaló una estación en la estación de Trelew lo que detecta también descargas dentro de nuestro país, las cuales están siendo evaluadas para poder utilizarlas en futuros trabajos de investigación

The Geostationary Operational Environmental Satellites - R Series (GOES-R) es la próxima generación de satélites meteorológicos geoestacionarios, prevista para el primer lanzamiento a principios de 2016. Los satélites de la serie GOES-R proporcionará imágenes continuas y mediciones atmosféricas de Hemisferio Occidental y en el espacio de monitoreo del clima de la Tierra para proporcionar crítico atmosférico, hidrológico, los datos oceánicos, climáticas, solares y de espacio. Este satélite constara de un instrumento The Geostationary Lightning 
Mapper que medirá la actividad total de la AEA continuamente a lo largo de las Américas y las regiones oceánicas adyacentes con resolución espacial uniforme cerca de aproximadamente $10 \mathrm{~km}$. GLM proporcionará las primeras predicciones de tormentas y la intensificación de los fenómenos meteorológicos extremos. También proporcionará datos para estudios climáticos a largo plazo. Este será un gran avance para el estudio de la AEA en nuestro País. 


\section{Capítulo 3 Actividad Global}

En el mundo cada segundo se producen 50 descargas (Price, 2013), generadas por aproximadamente 1.800 tormentas activas. Debido a su gran corriente (aprox. $20 \mathrm{kA}$ ), y sus altas temperaturas (aprox. $30.000^{\circ} \mathrm{K}$ ) dentro del canal, las descargas eléctricas son unos de las mayores peligros tanto a nivel infraestructura como para las personas. Por otro lado la AEA es considerada el generador y el encargado de mantener el circuito global generando un potencial ionosférico de $250 \mathrm{kV}$, que se traduce en un gradiente de potencial de $130 \mathrm{Vm}^{-1}$ (Yair, 2012).

La convección atmosférica se produce en condiciones atmosféricas inestables, ya sea debido al calentamiento de la capa límite por la radiación solar durante el día o por la mezcla de masas de aire de diferentes densidades. Por lo tanto, la tasa de descargas está relacionada con las regiones de mayor inestabilidad atmosférica de la Tierra.

Estas regiones de inestabilidad no se producen al azar en todo el planeta, tienen un patrón organizado relacionado con el clima de la Tierra, que es impulsada por el calentamiento diferencial de la superficie de la Tierra por el sol, debido a su eje de inclinación y a las diferencias físicas entre océanos y continentes.

En este capítulo presentaremos las características principales de la AEA en el mundo para así poder entender los procesos que rigen la AEA en el Sur de Sudamérica

\section{Caracterización de la AEA a nivel global}

En la última década hemos aprendido mucho sobre la distribución espacial y temporal de los patrones de la AEA, tanto por la información generada en datos satelitales, como desde estaciones terrenas. Después de años de observaciones, se ha obtenido una imagen clara de la distribución global de las tormentas eléctricas, y se observó que su distribución en el globo no es azarosa, sino que depende tanto de procesos microfísicos como de convección, como por ejemplo:la electrificación fuerte ocurre cuando la nube exhibe una fuerte actividad convectiva con un rápido desarrollo vertical, y la generación de carga y los procesos de separación de la misma están asociados con el desarrollo de precipitación, probablemente en la forma de granizo, como ha sido presentado en el Capítulo 1 
En la Figura 3-1 se muestra la distribución de la AEA, confeccionada con los datos de la WWLLN con una resolución espacial de $0.5^{\circ}$ para el período 2008-2011, junto con la suma de eventos medios en latitud (panel derecho) y en longitud (panel superior) donde se observa las características más significativas de su distribución:

- Se encuentra mayoritariamente en las zonas tropicales,

- Se encuentran especialmente sobre los continentes, esta característica se observa claramente en el panel superior en donde se diferencian las masas continentales;

- se observa una asimetría entre el hemisferio norte y sur, debida a la diferencias en las masas continentales entre ambos hemisferios;

- Se observa una mayor actividad sobre las zonas con presencia de cordones montañosos.

Esta distribución de la AEA, así como la distribución de las tormentas globales, está directamente relacionada con el clima de la Tierra, y más específicamente, con la circulación general de la atmósfera (Wallace y Hobbs, 2006). El máximo calentamiento solar de la superficie en los trópicos se traduce en la formación de térmicas y de mezcla vertical en la atmósfera. La región de aire ascendente que se produce a lo largo del ecuador térmico se conoce como la zona de convergencia intertropical (ITCZ,del inglés Intertropical Convergence Zone), debido a la convergencia de los vientos alisos de los hemisferios norte y sur. El ecuador térmico migra hacia el norte y hacia el sur del ecuador geográfico de acuerdo a las estaciones del año, con el ecuador térmico más al norte, en junio-agosto, durante el verano del hemisferio norte, y desplazándose hacia el sur en diciembre-febrero, durante el verano del hemisferio sur (Ver Figura 3-2). Debido a que las tormentas y las nubes convectivas se asocian generalmente con la ITCZ a lo largo del ecuador térmico, esta migración de la ITCZ se traduce en una migración estacional de la AEA global. 

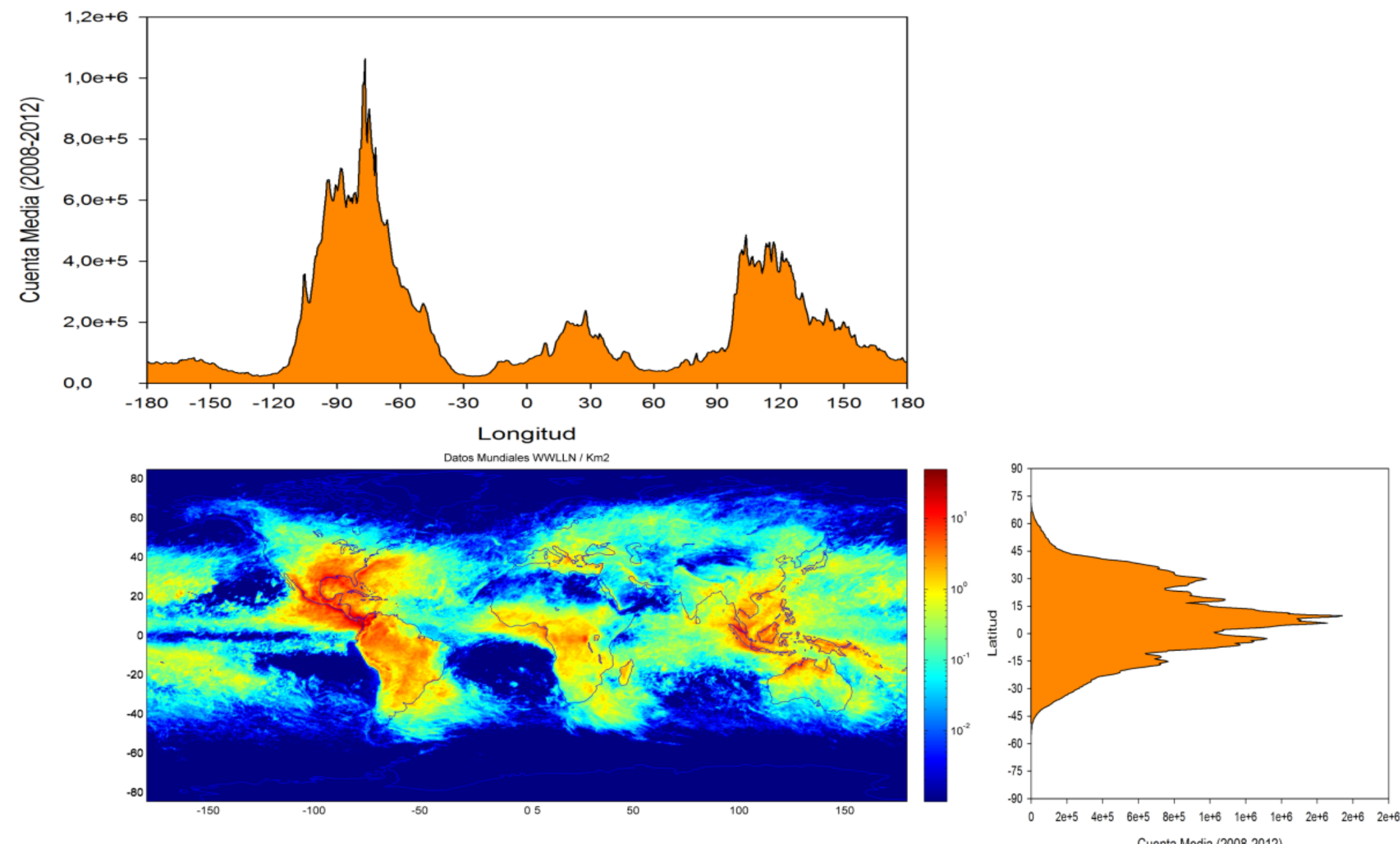

Figura 3-1Densidad de AEA confeccionada con los datos de la WWLLN con una resolución espacial de $0.5^{\circ}$ para el período 2008-2011. Escala de colores en flashes $\mathrm{km} \mathrm{m}^{-2}$ año ${ }^{-1}$. Se grafica junto con la suma de eventos medios en latitud (panel derecho) y en longitud (panel superior) donde se observa las características más significativas de su distribución 


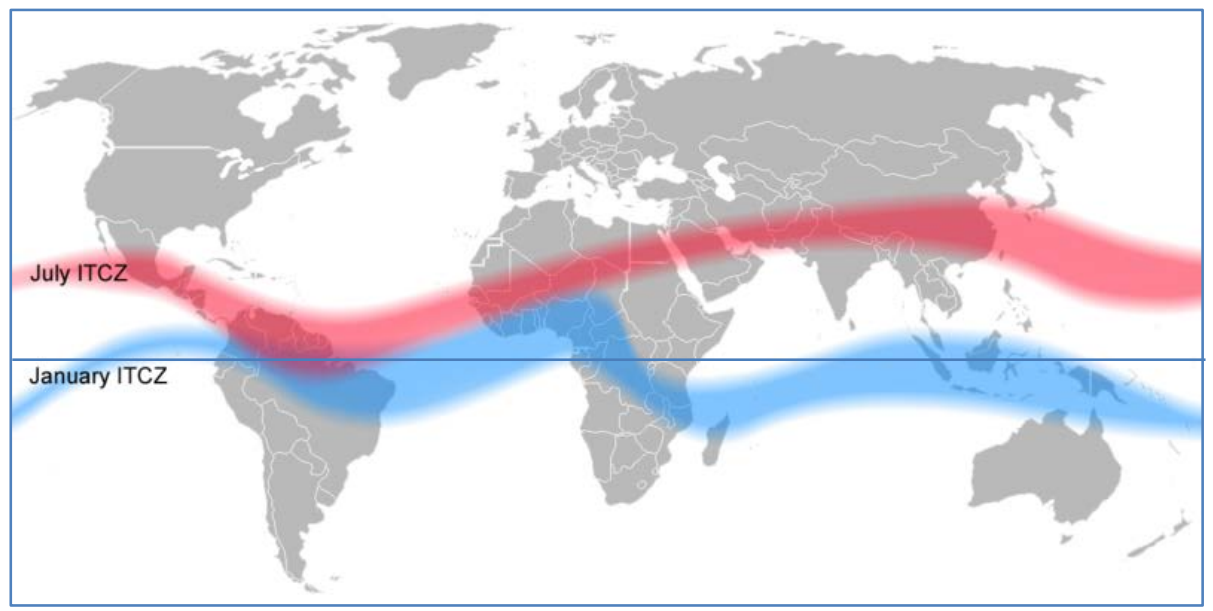

Figura 3-2 Mapa global mostrando la variación de la ITCZ extraído de http://www.srh.noaa.gov/jetstream//tropics/itcz.htm

No obstante lo anterior, debido a la diferente capacidad térmica de la tierra frente a la de los océanos, las regiones continentales se calentarán más rápidamente que los océanos, lo que resulta en diferencias longitudinales en la ubicación y del ancho de la ITCZ. Esto resulta en una diferencia significativa en la intensidad convectiva observada entre las regiones oceánicas y continentales en los trópicos (LeMone y Zipser, 1980; Jorgenson y Lemone, 1989). De hecho, esto se traduce en la diferencia de la AEA sobre la tierra y el océano que se observa en la climatología de descargas globales mostrada en la Figura 3-1.

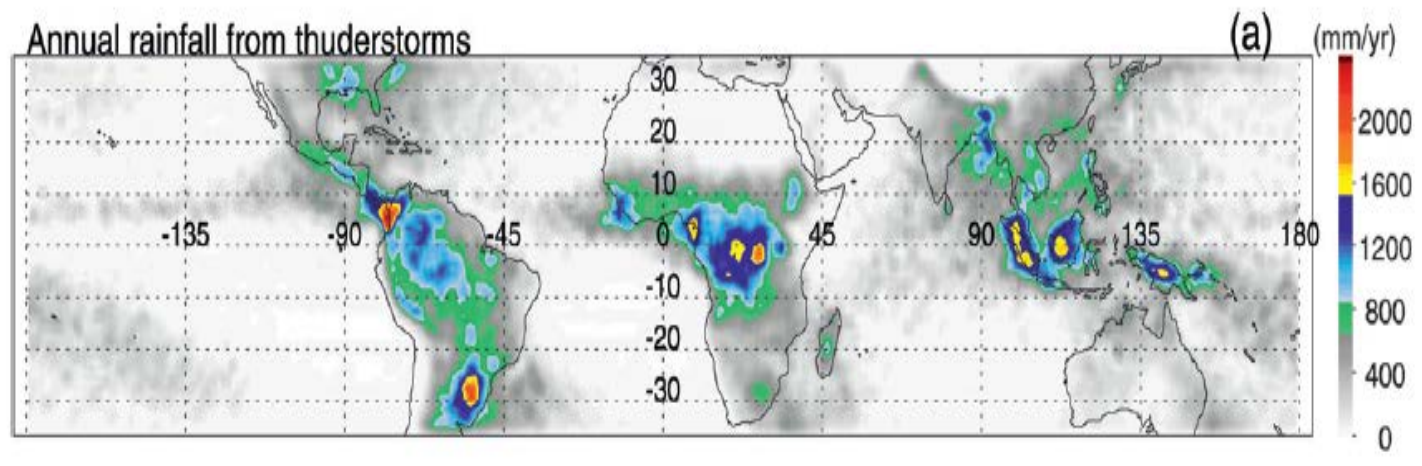

Figura 3-3 Zonas de mayor actividad de precipitación por acción de tormentas eléctricas. Figura extraída de Liu, 2010.

Esta característica sobre la diferencia de la AEA en los océanos y en los continentes fue evaluada por diferentes autores. Por ejemplo un estudio que refuerza también esa diferencia, es el estudio de Liu et al.(2010) (Figura 3-3), en donde se puede observar que las tormentas 
eléctricas aportan una gran cantidad de precipitación sobre los continentes, incluyendo algunas regiones de lluvias fuertes sobre el centro de África, Argentina, Panamá y el Continente marítimo ( $\mathrm{MC}$, del inglés Maritime Continent). Estas tormentas electrificadas contribuyen al 0,34\% de la precipitación continental frente al 0,19\% en los océanos.

Por otro lado, Ávila et al. (2010) encontraron que, en el verano de ambos hemisferios, la AEA en las tormentas convectivas profundas continentales es más intensa que en aquellas convectivas sobre los océanos en un factor de entre 7 y 10. Esta diferencia de escala se puede observar tanto en las figuras Figura 3-4 y Figura 3-5, en donde las escalas verticales dan una idea de estos parámetros. Por ejemplo, al comparar la Figura 3-4a con la Figura 3-4b se ve que durante el periodo de estudio la AEA sobre el mar, tuvo valores máximos de 15 flashdia $^{-1}$ por celda de estudio, en cambio sobre los continentes la actividad llega a valores cercanos a 300 flashdia ${ }^{-1}$.

Otra característica interesante de la actividad global reportada por Ávila et al. (2010) es que, en promedio, la tasa de descargas diarias para el hemisferio sur ( $\mathrm{SH}$ ) es aproximadamente un $20 \%$ mayor que la del hemisferio norte $(\mathrm{NH})$, lo que puede atribuirse a una mayor cobertura fraccional de nubes de convección profunda en el SH. Se pueden ver esta diferencia entre laFigura 3-4 a y la Figura 3-5 a y entre la Figura 3-4 b y la Figura 3-5 b, respectivamente.
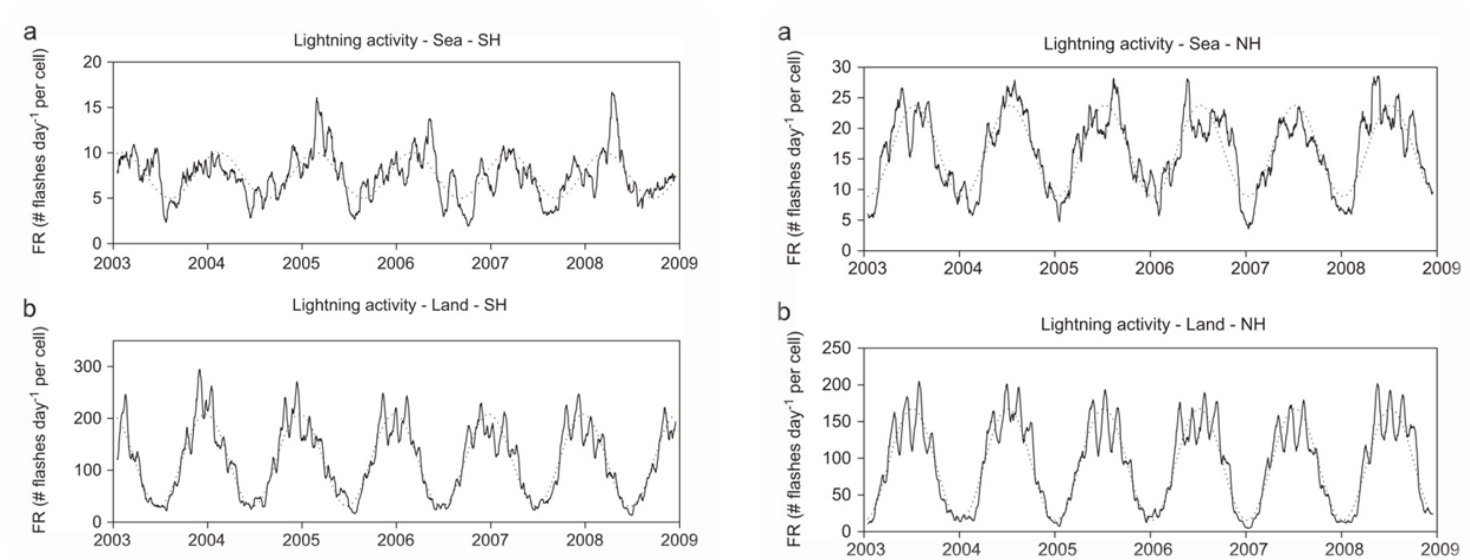

Figura 3-4 Densidad de actividad para América del Sur. El panel a muestra la AEA sobre los océanos y el panel b sobre las masas continentales. Extraído de Ávila e. al., 2010

Figura 3-5Densidad de actividad para América del Norte. El panel a muestra la AEA sobre los océanos y el panel $b$ sobre las masas continentales. Extraído de Ávila e. al., 2010

La hipótesis tradicional postula que la diferencia de la AEA observada se debe a la diferencia de velocidades en las corrientes ascendentes en las tormentas. Las velocidades de 
las corriente ascendente en las tormentas oceánicas pueden llegar a un máximo de $10 \mathrm{~ms}^{-1}$ mientras que, en las regiones continentales, las corrientes ascendentes pueden alcanzar valores de $50 \mathrm{~ms}^{-1} \mathrm{o}$ mayores (Price y Rind, 1992; Williams y Stanfill, 2002; Williams et al, 2004).Dado que la intensidad de dichas corrientes juega un papel importante en las frecuencias de electrificación de las tormentas (Baker et al, 1995; 1999), esta diferencia en la dinámica de las tormentas eléctricas resulta en una actividad eléctrica sobre los océanos de un orden de magnitud inferior en comparación con las generadas sobre los continentes.

Sin embargo, según Williams y Chan (2004), el origen físico del contraste tierra-océano no puede ser solo explicado por esta hipótesis. Williams et al. (2002) sugirió que la diferencia puede deberse a los procesos microfísicos que involucran a los aerosoles. La diferencia de concentración de núcleos de condensación de nubes (CCN) sobre la tierra y el océano, (existe una diferencia de alrededor de un orden de magnitud en la concentración de núcleos de CCN entre los continentes y los océanos), conduce a la formación de gotas de nubes más pequeñas y numerosas sobre las regiones continentales que sobre el océano, suprimiendo así el proceso de coalescencia de lluvia cálida, y permitiendo acceder a estas gotas de agua a alturas mayores dentro de la nube. Entonces, estas gotas alcanzan la región de fase mezcla y participan del proceso de electrificación. Esto no sucedería en las nubes sobre los océanos ya que las gotas de nube serían de mayor tamaño, favoreciendo la formación de gotas de precipitación, y por lo tanto, el mecanismo de electrificación no sería tan efectivo en este tipo de nubes.

Siguiendo con la estructura de circulación atmosférica, el aire que se eleva dentro de las tormentas convectivas tropicales a lo largo de la ITCZ, finalmente alcanza la tropopausa (entre 15 y $20 \mathrm{~km}$ de altitud) y la estratosfera estable, y luego se ve obligado a fluir desde el ecuador hacia los polos. Este movimiento del aire se ve influido por la fuerza de Coriolis, dando como resultado la desviación de los vientos hacia el este, en ambos hemisferios (Price, 2006). Este aire continúa irradiando calor al espacio y por lo tanto se enfría en este transporte noreste sureste desde las zonas ecuatoriales del hemisferio norte ( sur). El aire finalmente desciende alrededor de $30^{\circ}$ de latitud norte y sur, resultando de este proceso las zonas más desérticas de nuestro planeta, y mostrando una disminución de la AEA a nivel global como se puede observar en la Figura 3-1. (Panel derecho).Sin embargo, esta es una característica global y no siempre es así a escala local. Por ejemplo, existen zonas donde encontramos alta AEA como el centro de nuestro país. (Figura 3-1 y Figura 3-3)

La subsidencia, tal como se define al movimiento descendiente del aire a gran escala, está asociada con el calentamiento del aire a por compresión adiabática (resultando en una baja 
humedad relativa), y con la estabilización de la atmosfera, dando lugar al mínimo de precipitación observado en estas regiones. Este patrón de circulación meridional, junto con el movimiento ascendente a lo largo de la ITCZ y subsidencia en las zonas subtropicales, se conoce como la circulación de Hadley, y es extremadamente importante en la redistribución del calor y la humedad en todo el planeta (Figura 3-6).

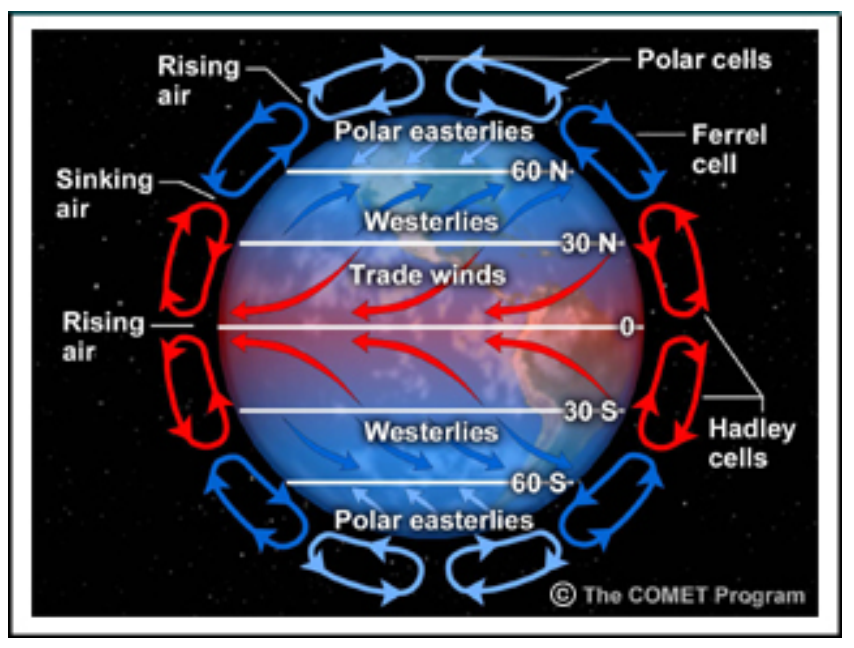

Figura 3-6Modelo de circulación global

Cerca de la superficie, la circulación de Hadley conecta las regiones subtropicales y la ITCZ a través de los vientos alisios que soplan entre $\pm 30^{\circ}$ de latitud. Por lo tanto no es casualidad que las regiones de actividad eléctrica se encuentran adyacente a la ITCZ.

Además del flujo de retorno hacia el ecuador en la superficie, una parte del aire tropical que alcanza la superficie alrededor de $\pm 30^{\circ}$ de latitud se dirige hacia los polos, donde se encuentra con el aire frío y seco proveniente de las regiones polares. Esta zona adicional de convergencia, conocido como frente polar, es otra zona de ascenso forzado de aire $y$, por tanto, nuevamente este patrón de circulación refuerza el desarrollo de nubes generadoras de tormentas eléctricas. Estas tormentas eléctricas frontales se producen a lo largo de la superficie (frontal) que separa masas de aire de origen polar (aire frio) y tropical ( aire caliente). Cuanto mayor sea la diferencia de densidad entre las masas de aire (temperatura y humedad) mayores serán las inestabilidades atmosféricas que se desarrollan, y por lo tanto mayor es la intensidad de estas tormentas.

Las superficies frontales suelen girar en torno a un centro de baja presión (en sentido anti horario en el hemisferio norte y en sentido horario en el hemisferio sur) denominado ciclón 
extratropical. A su vez, estos ciclones sufren un desplazamiento hacia el este debido al flujo del oeste que domina la circulación global en latitudes medias (30-60 grados de latitud)

Al igual que con la ITCZ, el frente polar también migra con las estaciones ubicándose en 5060 grados de latitud durante el verano, y en 30 a 40 grados en el invierno. Estas son las bandas de latitud de los sistemas de tormentas de latitudes medias, asociados con los frentes fríos y cálidos, los cuales provocan tormentas eléctricas. Estas regiones están asociadas principalmente con la actividad de tormenta de verano sobre los continentes de latitudes medias, aunque también pueden producir tormentas en invierno. A medida que avanzamos hacia el polo nos encontramos con las celdas polares de circulación meridional, donde se observan la ocurrencia de tormentas eléctricas aunque de manera poco frecuente.

Las situaciones de gran inestabilidad en la atmósfera suelen conducir a la formación de grandes sistemas convectivos de mesoescala (MCSs, del inglés Mesoscale Convective Systems), los cuales son prolíficos productores de tormentas (Lyons et al, 2003). Si regresamos a la Figura 3-3, se puede observar la zona norte de Argentina como unas de las zonas con mayor precipitación generada por tormentas eléctricas. Estas tormentas son ejemplos de MCS generadoras de grandes precipitaciones y elevadas tasa de descargas eléctricas atmosféricas.

Por lo tanto, las tormentas globales pueden ocurrir en ambientes muy diferentes. Aquellas resultantes del calentamiento diario de la superficie de la Tierra que se producen principalmente en las regiones tropicales, pero también puede ocurrir durante los meses de verano en las latitudes medias donde las inestabilidades pueden desarrollar por las tardes en los días calurosos de verano. También encontramos AEA asociada a tormentas frontales que se presentan principalmente en latitudes medias y altas donde diferentes tipos de masas de aire interactúan y dan lugar a inestabilidades entre frentes fríos y cálidos. Las tormentas frontales pueden ocurrir a cualquier hora del día, con mayor frecuencia sobre los continentes que sobre los océanos, y especialmente durante el verano.

Sin embargo diferentes características orográficas pueden ser generadoras de AEA (lagos, líneas costeras y cadenas montañosas, entre otras). En el forzamiento orográfico (elevación sobre topografía), las cadenas montañosas e islas fuerzan al aire a fluir hacia arriba y pueden iniciar inestabilidades que desencadenan la formación de precipitación y de tormentas eléctricas. Por ejemplo, Bürgesser et al. (2013) encontró un pico de la AEA debido al forzado orográfico en África como se observa en la Figura 3-7. 


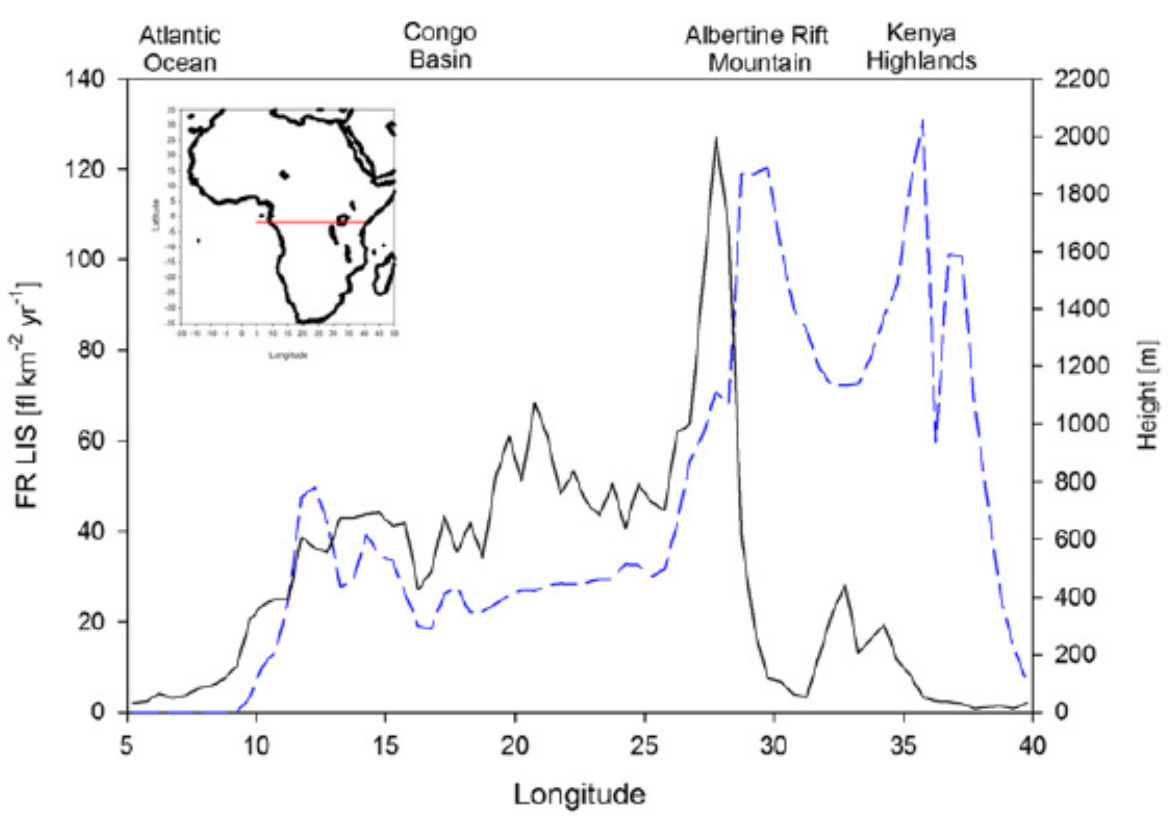

Figura 3-7Diagrama de descargas (negro) y topografía (azul), en donde se observa el aumento de la actividad en las laderas de las montañas

Sin embargo no todas las tormentas eléctricas continentales tropicales son intensas generadoras de rayos. Los períodos monzónicos tropicales se caracterizan por un flujo de aire oceánico húmedo hacia tierra, dando lugar a fuertes lluvias en el territorio continental. Sin embargo, estas tormentas presentan una baja tasa de AEA (Petersen et al, 2002; Williams et al., 2002). Esto ocurre generalmente en el monzón de la India, el monzón de África, el monzón brasileño y el monzón de Australia. Distintos autores señalan que la AEA intensa prefiere un ambiente un poco más seco que el observado durante los monzones. Esto puede ser corroborado durante el evento de El Niño de 1997/98 donde existió una fuerte condición de sequía a través de Indonesia mientras que la actividad eléctrica en esa región se incrementó en un 57\% (Betz et al, 2008, Capitulo 24.

\section{Ciclo diario de la AEA mundial}

El ciclo diario de la AEA a nivel global sobre los continentes está modulado especialmente por las descargas en las regiones tropicales ya que, como mostramos en climatología, el $75 \%$ de las mismas se dan en estas zonas, y estas muestra un pico de AEA claro en las horas de la tarde (tiempo local) (Figura 3-8). En contraste con esto, el ciclo diario de la AEA sobre las zonas oceánica es casi inexistente, con pequeñas variaciones a lo largo del día, de acuerdo con las 
pequeñas variaciones en la temperatura superficial del mar en la escala diaria (Betz et al, 2008).

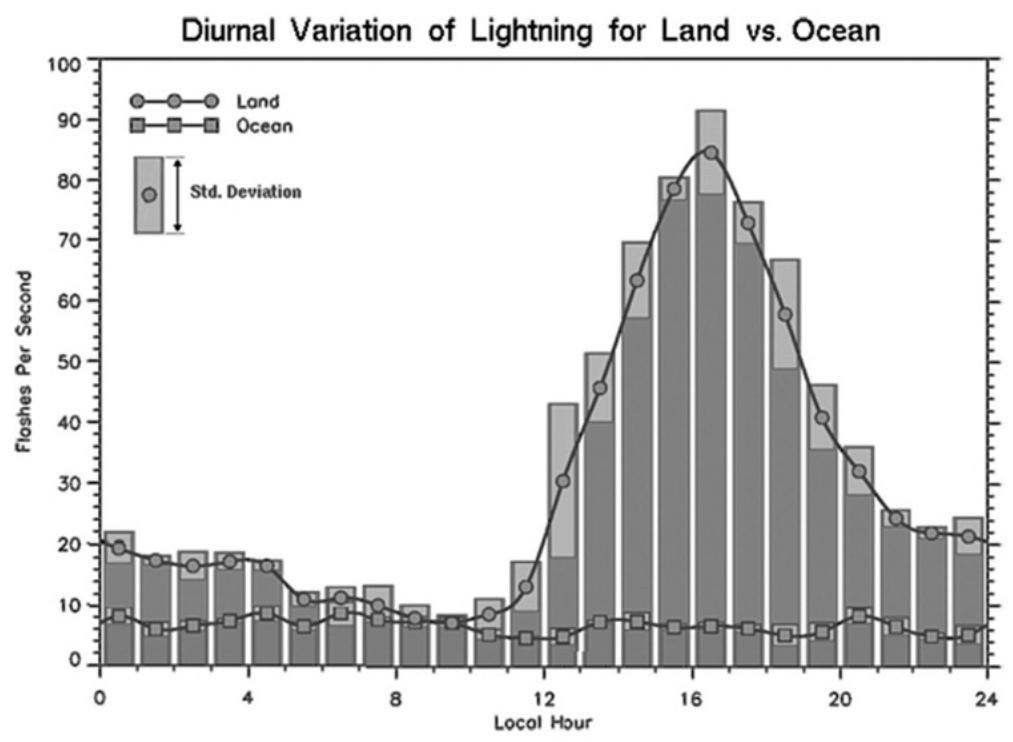

Figura 3-8variación diurna global sobre los continentes y los océanos. Extraído de http://thunder.msfc.nasa.gov

Esta variación diurna en la AEA sobre tierra ha sido relacionada con el mecanismo de creación de nubes de tormenta como resultado de la inestabilidades generadas por la radiación solar y con el máximo de precipitación observado en horas de la tarde (Wallace, 1975; Gray and Jacobson, 1977; Oki and Musiake, 1994; Dai et al., 1999; Dai, 2001; Nesbitt and Zipser, 2003).

Blakeslee et al. (2012), analizaron el conjunto de datos LIS/OTD. y determinaron la variación diurna anual mundial de AEA en las regiones continentales y oceánicas, tanto en tiempo universal (UTC, gráfico superior) como en tiempo local (LT, gráfico inferior) (Figura 3-9).Según los resultados encontrados, todos los continentes muestran una fuerte variación diurna, con un máximo en horas de la tarde, entre 15 y $17 \mathrm{LT}$, mientras que se presenta un mínimo de actividad en las últimas horas de la mañana entre las 09 y 11 LT. Las amplitudes diurnas son diferentes para los distintos continentes, con la mayor amplitud sobre África y la menor amplitud sobre Europa. 


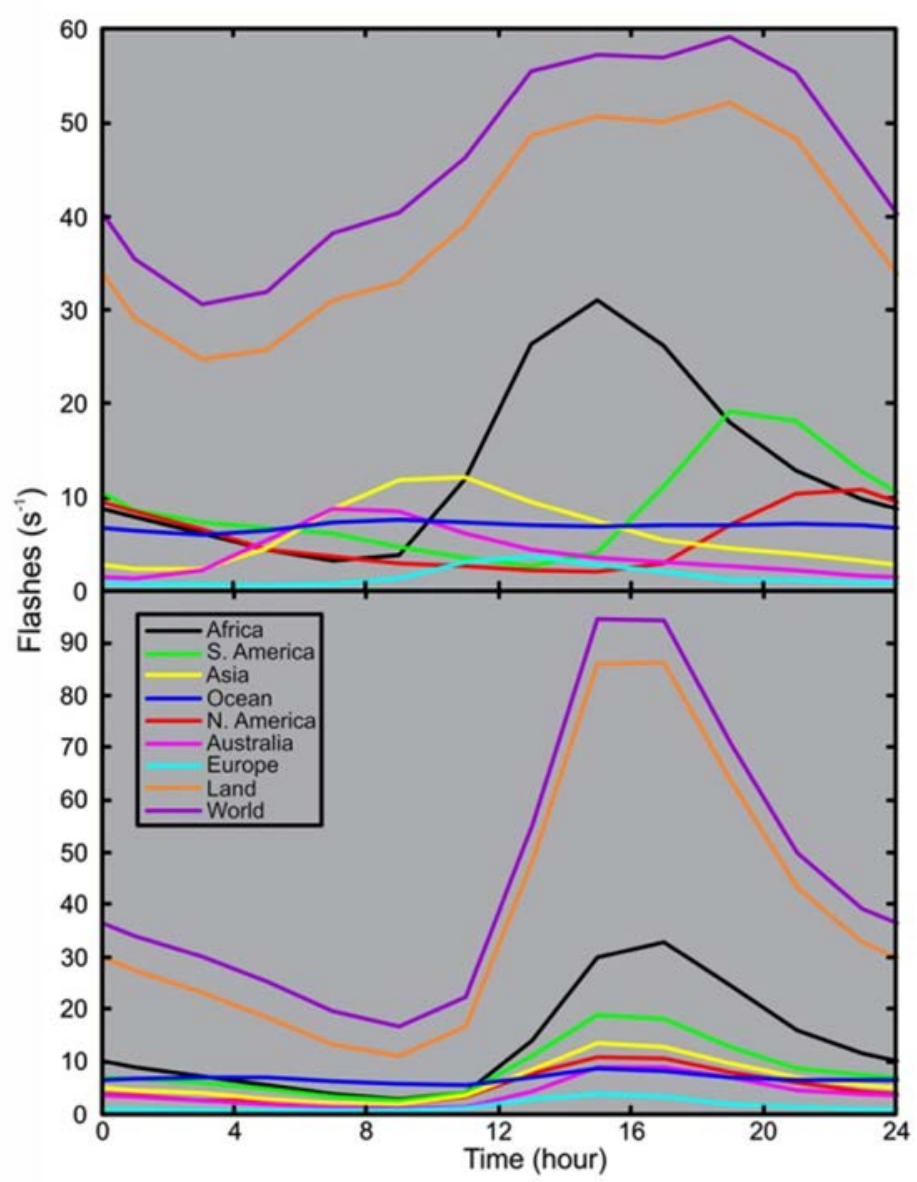

Figura 3-9 Cantidad anual de descargas detectadas por LIS/OTD en UTC en el panel superior y en LT en el panel inferior. Extraído de Blakeslee et. al., 2012

Las AEA sobre los océanos exhiben una mínima variación diurna, pero en horas de la mañana se puede observar un leve incremento en la AEA respecto a horas de la tarde. La distribución geográfica del pico de actividad diurna (en hora local) para la tierra y los océanos se muestra en la Figura 3-10. Sobre tierra se observa que el máximo de la AEA se da preferencialmente entre las 15 y 19 LT mientras que sobre los océanos no se observa un tiempo preferencial. También se observa que en las regiones del mundo dominadas por grandes sistemas convectivos de mesoescala, como son los EE.UU., Centroamérica, Argentina y África occidental, el pico de la curva diurnas desplaza hacia la noche o primeras horas de la mañana (Wallace,1975; Zipser et al., 2006; Ogawa y Komatsu, 2009). Esto estaría indicando que la radiación solar no sería el único mecanismo para la formación de las nubes en esas regiones. 

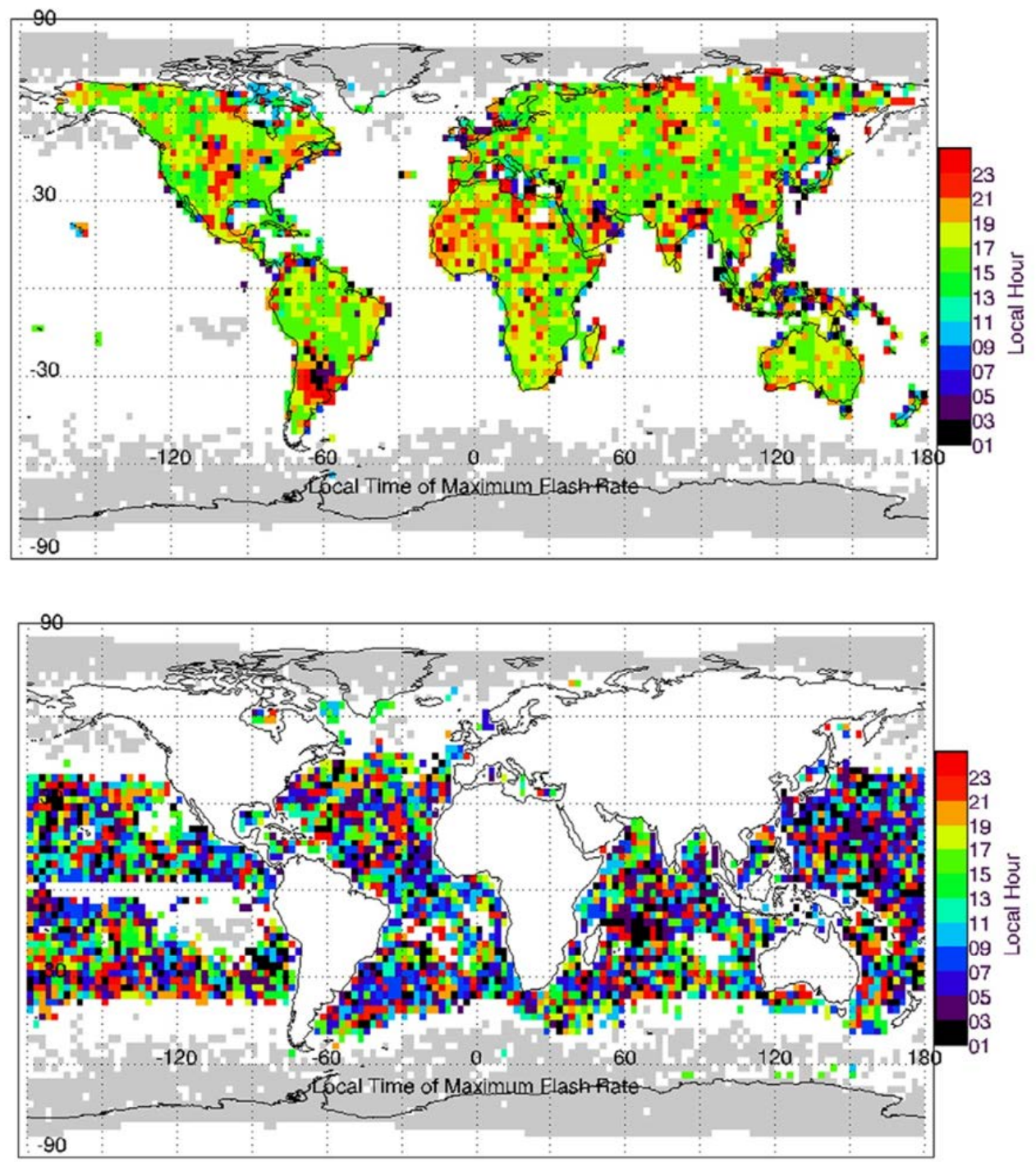

Figura 3-10 Distribución geográfica del pico de actividad diurna (en hora local) para la tierra (panel superior) y los océanos(panel inferior).Extraído de Blakeslee et. al., 2012

\section{Ciclo Anual y estacional de la AEA mundial}

Siguiendo con el análisis realizado por Blakeslee et al. (2012), la Figura 3-11muestra la comparación estacional de AEA para todo el mundo en UTC y LT. La mayor tasa de AEA se produce entre junio y agosto (JJA), que se corresponde al verano del hemisferio norte(HN), cuando se combinan la mayor actividad eléctrica atmosférica de América del Norte y Asia con la contribución (en todas las estaciones) de África.

El período de septiembre a noviembre (SON) excede al período de marzo a mayo (MAM) debido a la contribución de América del Sur que es mucho mayor durante los meses de SON 
que en el período MAM. El mínimo valor estacional se produce en diciembre-febrero (DEF) durante el verano en el hemisferio sur (HS), debido a que la masa continental de HS es mucho más pequeña que la del HN.

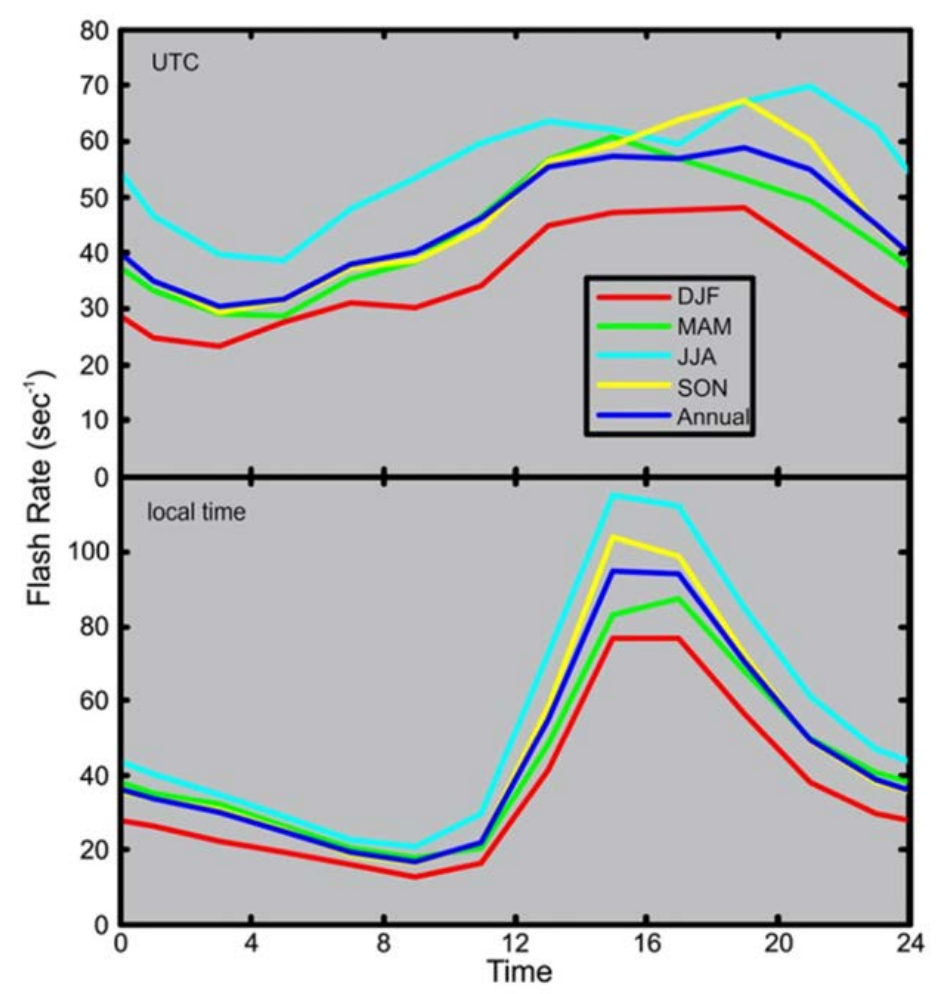

Figura 3-11comparación estacional de las tasas por hora de descargas eléctricas atmosféricas para todo el mundo en UTC( panel superior) y LT ( panel inferior). Extraída de Blakeslee et al. (2012),

En la Figura 3-13se muestra la contribución de las diferentes regiones del mundo a cada una de las curvas diurnas estacionales mostradas en laFigura 3-12.Como habíamos visto anteriormente, a lo largo de todas las estaciones, África proporciona la mayor contribución al ciclo diario. Esta contribución también se observa en el ciclo estacional. La contribución de las regiones oceánicas permanece relativamente constante y exhibe una respuesta diurna plana.

Durante JJA en el verano del HN (panel inferior izquierdo), una mayor actividad en América del Norte y Asia se une a la de África para contribuir igualmente a la frecuencia de descarga eléctrica atmosférica mundial total. Europa también contribuye con una mayor tasa durante este período, y aunque América del Sur presenta valores mínimos durante esta estación, todavía proporciona una contribución superior a la de Europa.

Durante la primavera en el HS (SON, panel inferior derecho) Sudamérica presenta gran AEA, con valores cercanos a la de África y Australia (junto con el continente marítimo) las cuales 
comienzan a elevar su AEA, mientras que las contribuciones de América del Norte y Asia disminuyen significativamente.

La contribución de Sudamérica siguen siendo prominente durante DJF en SH verano (panel superior izquierdo), aunque a un ritmo ligeramente inferior al observado durante SON, mientras que la tasa de descargas en Australia (junto con el continente marítimo) aumenta un $50 \%$ durante ese período.

Por último, durante el MAM (panel superior derecho), América del Sur disminuye su AEA a valores menores a la mitad del valor de AEA observado durante DJF, valores comparables con la contribución de Asia, mientras que la AEA de América del Norte comienza a aumentar.

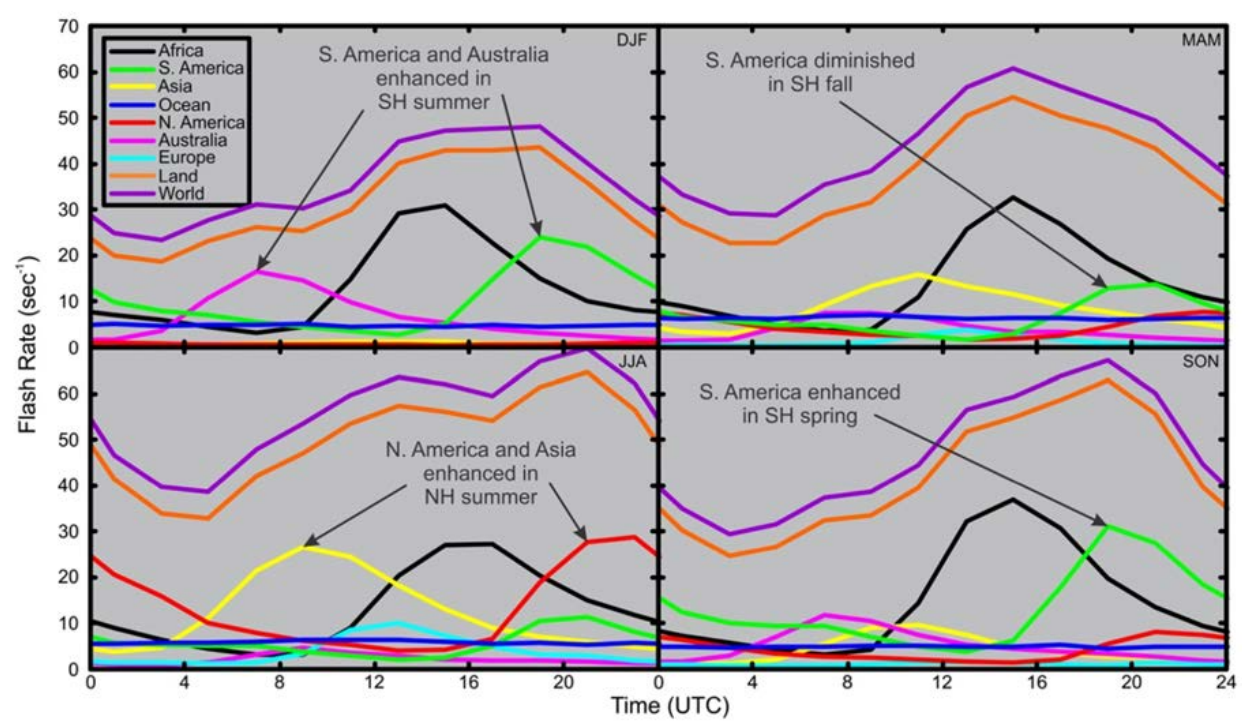

Figura 3-12 Ccontribución de las diferentes regiones del mundo a cada una de las curvas diurnas estacionales mostradas en la Figura 3-11 para cada estación mostrando para cada panel las características principales. Extraída de Blakeslee et al. (2012),

La AEA media sobre los continentes tiene su máximo valor en los meses de verano, luego le siguen en orden, los meses de primavera, otoño e invierno, pero existen regiones del planeta donde este patrón no se sigue.

Por ejemplo, en América del Sur, que en su mayoría se encuentra en el HS, la actividad durante la primavera (SON) supera ligeramente la actividad de verano (DJF). África, que está atravesada por la línea ecuatorial, exhibe una ciclo semianual pequeño en la tasa de descargas por segundo (que se manifiesta por un ligero aumento durante las temporadas de MAM e SON), pero como ya se ha señalado, la actividad sobre el continente africano tiene valores comparables en todas las temporadas. 
Según Blakeslee et al. (2012) la tasa máxima de descargas por segundo se produce durante JJA (verano del HN) con un valor de 55,7 flashes $\mathrm{s}^{-1}$ y el mínimo se produce en DJF (invierno de $\mathrm{HN}$ ) con una valor de 35,9 flashes $\mathrm{s}^{-1}$. Los meses de MAM y SON presentan valores de $47 f$ lashes $\mathrm{s}^{-1} \mathrm{y}$ de 44,1 flashes $\mathrm{s}^{-1}$, respectivamente.

La Figura 3-13muestra la distribución de la tasa de descargas para cada una de las estaciones, donde se pueden observar en conjunto todas las características detalladas anteriormente.

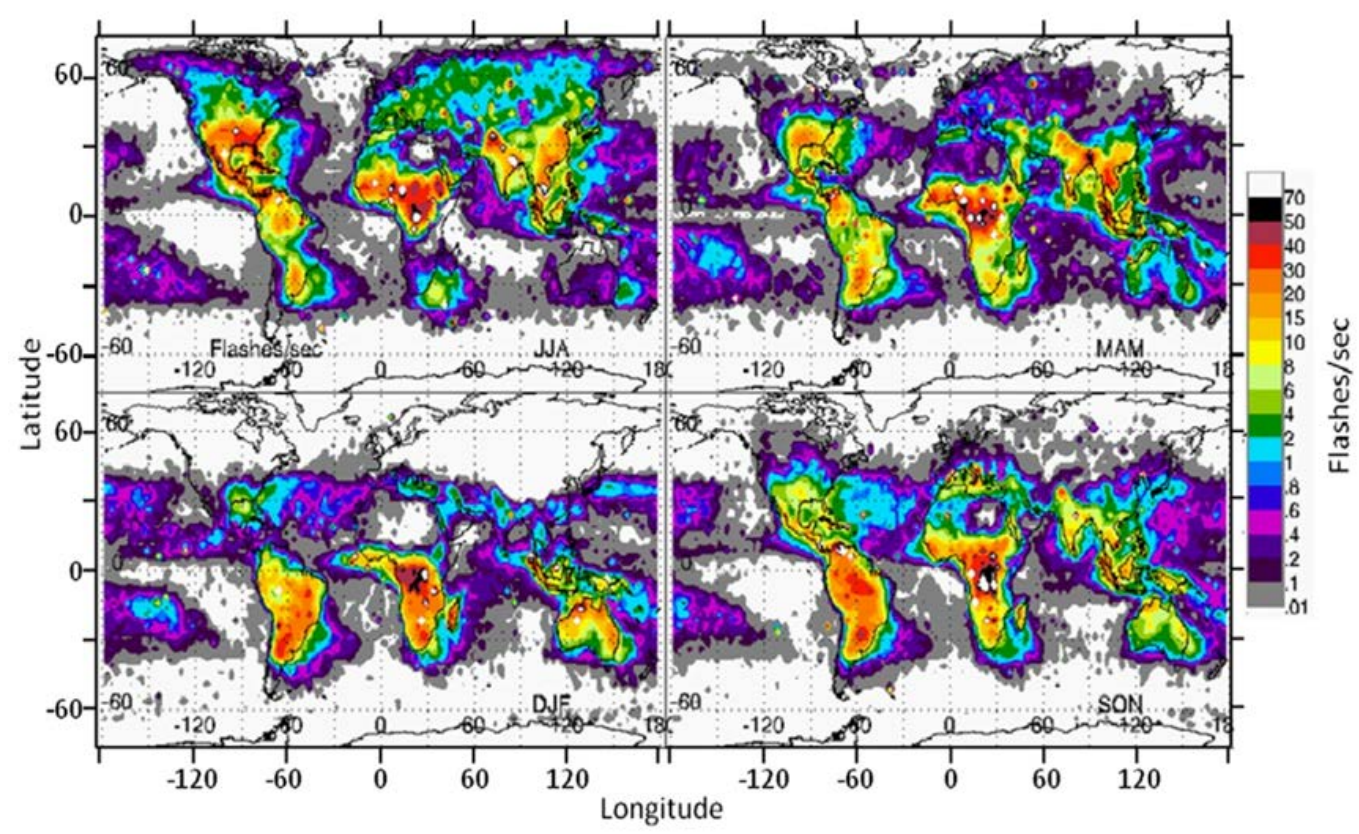

Figura 3-13 Tasa de descargas detectadas por LIS/OTD para cada periodo estacional. Extraído de Blakeslee et al. (2012)

La Figura 3-14muestra diferencia entre los valores de AEA de dos estaciones opuestas (panel superior derecho: JJA - DJF, panel superior izquierdo: DJF - JJA, panel inferior derecho: MAM-SON y panel inferior izquierdo: SON - MAM) donde se graficaron sólo los valores positivos. Esto permite observar qué estación del año (verano versus invierno, primavera versus otoño) y qué lugar de la Tierra tiene una mayor incidencia de AEA.

Como era de esperar, sobre tierra la AEA de verano domina la actividad sobre la de invierno, con valores en el hemisferio norte superiores a la que se encuentra en gran medida en el hemisferio sur, debido a su mayor masa de tierra. 
El análisis de las diferencias también revela que la AEA de primavera domina sobre las tasas de otoño en la mayoría de los lugares. Sin embargo, hay varias excepciones a este comportamiento incluyendo el centro de Canadá y la costa oeste de California y México. Las descargas durante primavera se manifiestan fuertemente sobre la región del Amazona en América del Sur.

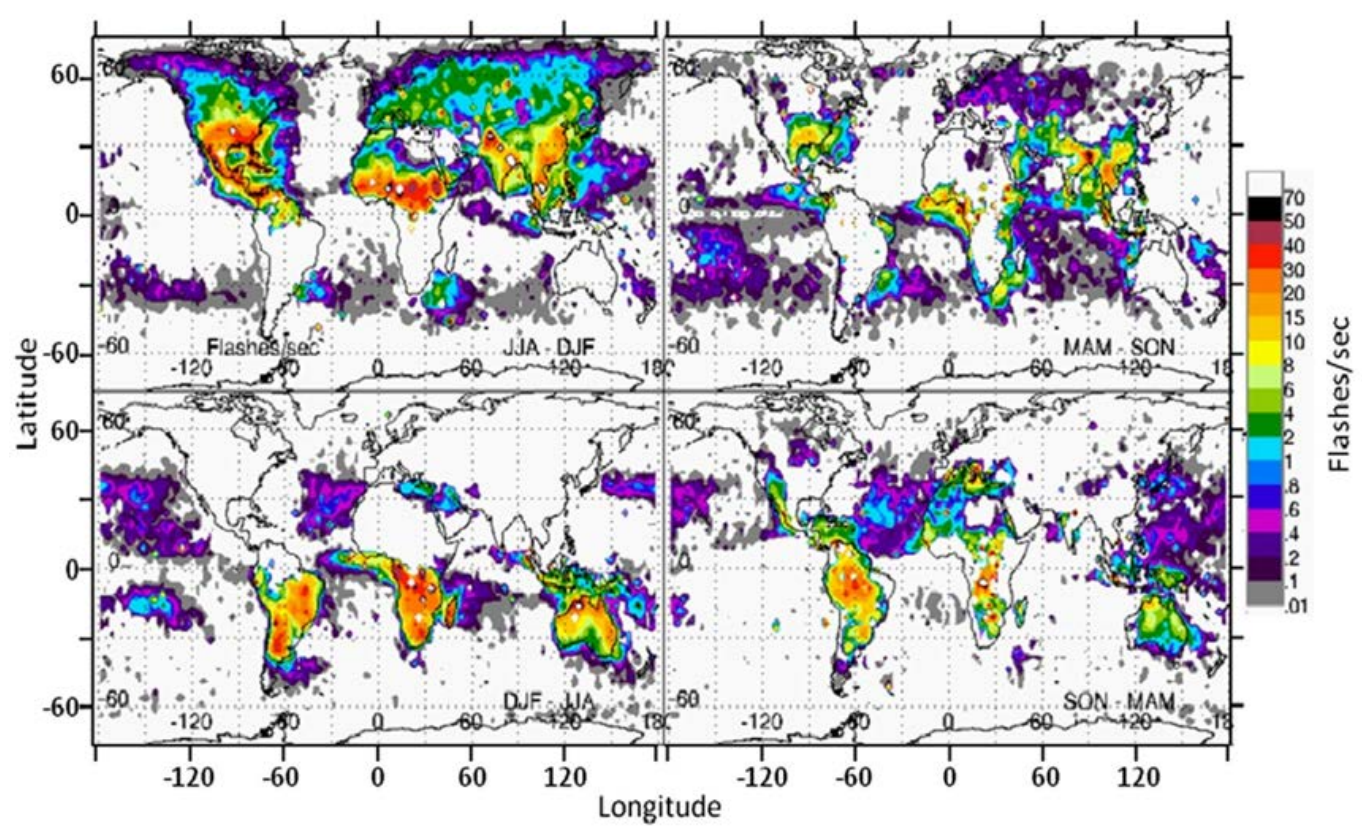

Figura 3-14mapas diferenciales entre dos estaciones opuestas (panel superior derecho: JJA - DJF, panel superior izquierdo: DJF - JJ, panel inferior derecho: MAM-SON y panel inferior izquierdo: SON - MAM) donde se graficaron sólo los valores positivos. Esto permite observar qué estación del año (verano versus invierno, primavera versus otoño) y qué lugar de la Tierra tiene una mayor incidencia de AEA

En contraste con lo observado sobre tierra, el análisis de la diferencias muestran que en las regiones oceánicas, la AEA en invierno y otoño tiende a ser superior a la AEA en verano y primavera, respectivamente. Esto sería el resultado de la alta capacidad calorífica del agua, dando lugar a una mayor inestabilidad convectiva sobre los océanos en invierno cuando el aire frío de los continentes pasa sobre las cuencas oceánicas relativamente cálidas. 


\section{Capítulo 4 Estudio de dos Máximos de AEA a nivel global}

Hasta ahora se presentó las características a nivel global de la AEA, pero en función de poder entender más detalladamente los procesos microfísicos y dinámicos que rigen la actividad eléctrica, se realizaron estudios sobre dos de las zonas más activas del planeta, los cuales presentamos en este capítulo por separado.

Las zonas elegidas son la región de Maracaibo en Venezuela (Bürgesser et al, 2012), y la zona de África tropical (Bürgesser et al, 2013), ambas señaladas como las zonas más activas de AEA en el planeta. Estas regiones son los mejores "laboratorios" para poder probar las bases de datos y metodología que utilizaremos en nuestro estudio de la AEA en la Argentina.

Distintos trabajos relacionados con la AEA sobre África han encontrado que la máxima actividad se concentra principalmente en la región tropical del continente y con menos intensidad hacia el sur, sobre Sudáfrica y hacia el norte, sobre la costa del mar Mediterráneo. En la región tropical, la cuenca del Congo muestra la más alta AEA teniendo una densidad máxima de 120 flashes $\mathrm{km}^{-2}$ año-1. Este centro es señalado como el segundo centro de actividad de AEA del mundo después del lago de Maracaibo que presenta 250 flashes $\mathrm{km}^{-2}$ año-1.

A continuación se presentan ambos estudios, mostrando los centros de máxima AEA en donde analizamos sus variaciones diarias, anuales e interanuales.

\section{Catatumbo - Venezuela}

En esta sección se presenta el trabajo Characterization of the lightning activity of “Relámpago del Catatumbo", Rodrigo E. Bürgesser, María G. Nicora, Eldo E. Ávila, 2012. Journal of Atmospheric and Solar-Terrestrial Physics77, 241-247.

a. Introducción

Al suroeste del Lago de Maracaibo en el estado Zulia, Venezuela, se encuentra una zona con frecuentes tormentas eléctricas. Este fenómeno es tan marcado que ya forma parte de la historia de la región y se conoce como el "Faro del Catatumbo" o "Relámpago del Catatumbo: la tormenta más persistente del mundo". Es visible casi a lo largo de todo del año en una 
región confinada, tiene una duración de hasta nueve horas por noche y se ha convertido en una parte fundamental de las tradiciones folclóricas del lugar. El poeta español Lope de Vega ya mencionó este fenómeno inusual en su clásico poema "La Dragontea" en 1597, que habla que las luces de rayos ayudaron a impedir el ataque del pirata inglés Sir Francis Drake en Maracaibo. Este fenómeno también fue observado por el famoso naturalista alemán Alexander von Humboldt.

\section{b. Topografía y climatología}

El noroeste de Venezuela es una zona con marcadas diferencia topográficas. Está constituida por la cuenca del Lago Maracaibo, la cual se encuentra rodeada por la Cordillera de la Costa con una orientación este-oeste y una altura aproximada de $1.500 \mathrm{~m}$, y la prominente Cordillera de Mérida de hasta 5.000 m de altura con una orientación suroeste-noreste. La Figura 4-1muestra la topografía de la región donde se encuentra la cuenca de Maracaibo. La escala de grises muestra la elevación del suelo de la región en metros sobre el nivel del mar. También están demarcadas la frontera nacional entre Venezuela y Colombia y las principales ciudades de la región. Se puede observar las dos ramas de la Cordillera de los Andes (Cordillera de la Costa y la Cordillera de Mérida) que rodean el Lago de Maracaibo. Los datos de elevación del suelo utilizados en la Figura 4-1provienen de Global Land One - kilometer Base Elevation (GLOBE,http://www.ngdc.noaa.gov/mgg/topo/globe.html).

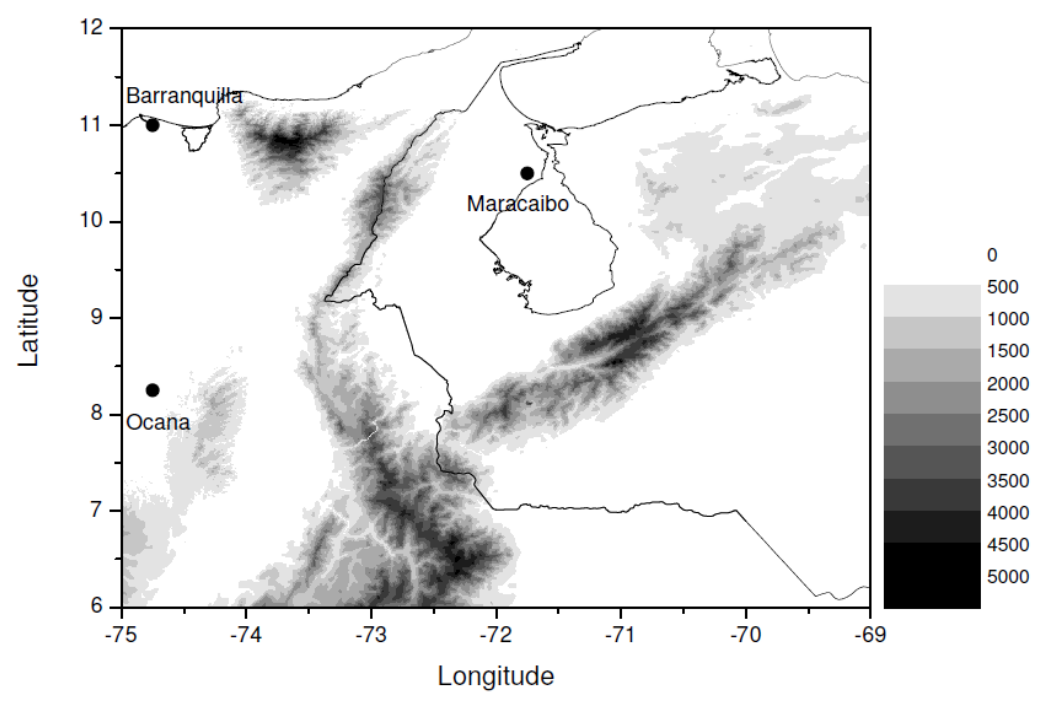

Figura 4-1Mapa de topografía. Base de (GLOBE, http://www.ngdc.noaa.gov/mgg/topo/globe.html). 
Esta topografía hace que el régimen de precipitación sea bastante complejo. La dirección en la cordillera norte-sur y la presencia de una importante fuente de humedad (Mar Caribe), producen condiciones climáticas muy particulares (Pulwarty et al., 1992) han demostrado que existe una Jet en capas bajas nocturno (nocturnal Low-Level Jet (NLLJ)) en el Lago de Maracaibo, que es parte del Jet en capas bajas del Caribe (LLJ) el cual se maximiza por la noche. Estos LLJs transportan humedad y calor, produciendo condiciones termodinámicamente favorable para la convección profunda (Beebe y Bates, 1955) y asimismo prolongan los tiempos de vida de la actividad convectiva.

Velásquez (2000) basándose en los regímenes de precipitación entre 1961 y 1999, encontró una distribución bimodal de la precipitación en la región noroeste de Venezuela. Negri et al. (2000) encontraron una tasa media de lluvia de más de 200 mm al mes de Lago de Maracaibo, con una estación seca entre diciembre y mayo. El Lago de Maracaibo presenta una tasa de precipitación media anual superior a 0,6 $\mathrm{mm} \mathrm{h}^{-1}$, con un pico entre 02:00-04:00 hora local. Negri et al., (2002)y Mapes et al. (2003) encontraron convección nocturna sobre el Lago de Maracaibo.

\section{c. Discusión y resultados}

Se calculó la actividad eléctrica para una ventana espacial de $\left[6^{\circ}-12^{\circ}\right] \mathrm{N}$ de latitud y $\left[75^{\circ}\right.$ $69^{\circ}$ ] $\mathrm{O}$ de longitud, como se muestra en la Figura $4-2$ con una resolución espacial de $0,1^{\circ} \mathrm{x}$ $0,1^{\circ}$.

Las descargas totales por año ( $F w[i, j])$ detectados por el WWLLN en cada punto de la malla centrada en [i,j] de latitud y longitud, respectivamente, se calculan para cada año entre 2005 y 2010. Debido a la variación de la eficiencia de detección a través de los años de la red WWLLN los valores de Fw[i, j] se normalizaron a los flashes totales en la ventana espacial para todo el año $\left(\sum_{\mathrm{i}} \sum_{\mathrm{j}} \mathrm{F}_{\mathrm{w}}[\mathrm{i}, \mathrm{j}]\right)$. Por lo tanto se define la variable $F_{w, n}($ year $)[i, j]$

$$
F_{w, n}(\text { year })[i, j]=\frac{F_{w}[i, j]}{\sum_{i} \sum_{j} F_{w}[i, j]} \quad \text { Ecuación 4-1 }
$$

Que será utilizada como un indicador de la AEA en cada punto de la cuadrícula. La Figura 4-2muestra la distribución espacial de $F_{w, n}$ entre 2005 y 2010. Donde se pueden observar dos centros muy bien localizados con alta actividad eléctrica para cada uno de los años analizados, un centro confinado entre los $\left[9^{\circ}\right.$ y $\left.10^{\circ} \mathrm{N}\right]$ de latitud y $\left[72^{\circ}\right.$ y $\left.71^{\circ} \mathrm{W}\right]$ de longitud sobre la región 
suroeste del Lago de Maracaibo, y otro centro alrededor de $\left[9^{\circ} \mathrm{N}, 73^{\circ} \mathrm{W}\right]$, cerca de la frontera entre Colombia y Venezuela. El primer centro coincide con las observaciones formuladas por Falcón et al. (2000).

La densidad de descargas en las ventanas espaciales $\left[6^{\circ}-12^{\circ}\right] \mathrm{N}$ de latitud y $\left[75^{\circ}-69^{\circ}\right] \mathrm{O}$ de longitud se calculó con datos de WWLLN y LIS con una resolución espacial de $\left[0,5^{\circ} \times 0,5^{\circ}\right]$. La Figura 4-3 a muestra la tasa de descargas utilizando los datos WWLLN (FRw) para el año 2010 y en la Figura 4-3 b muestra los resultados obtenidos por el uso de datos LIS (FRLis) entre los años 1998 y 2010.

Los resultados de los datos LIS también muestran dos regiones con alta actividad eléctrica coincidentes con las observadas por el uso de datos WWLLN. Ambos mapas muestran una muy buena correlación espacial con un coeficiente de Pearson de 0,86 ( $<<10-4)$, y también muestran un valor máximo de densidad de descargas centradas en [9.75N; 71.750] con 161 flashes $\mathrm{km}^{-2}$ año ${ }^{-1}$ detectada por LIS y 42 flashes $\mathrm{km}^{-2}$ año-1 detectada por WWLLN. Suponiendo que LIS tiene una eficiencia de detección de 0,85 (Boccipio et al., 2002), hemos estimado que la eficiencia en la detección de WWLLN en nuestra región de estudio es de alrededor de $20 \%$. Albrecht et al. (2011), utilizando una resolución espacial de $0,25^{\circ} \times 0,25^{\circ}$ encontraron en esta región una densidad de descargas de 250 flashes $\mathrm{km}^{-2}$ año-1. En nuestro caso utilizando la misma grilla de estudio que Albrecht et al. (2011) y datos de la WWLLN encontramos un máximo de 50flashes $\mathrm{km}^{-2}$ año-1 para el año 2010, por lo que tomando una eficiencia de detección de aproximadamente del $20 \%$. Esto hace que nuestros resultados concuerden con los encontrados por otros autores, y muestran que esta región es la zona de mayor AEA medida en el planeta. 

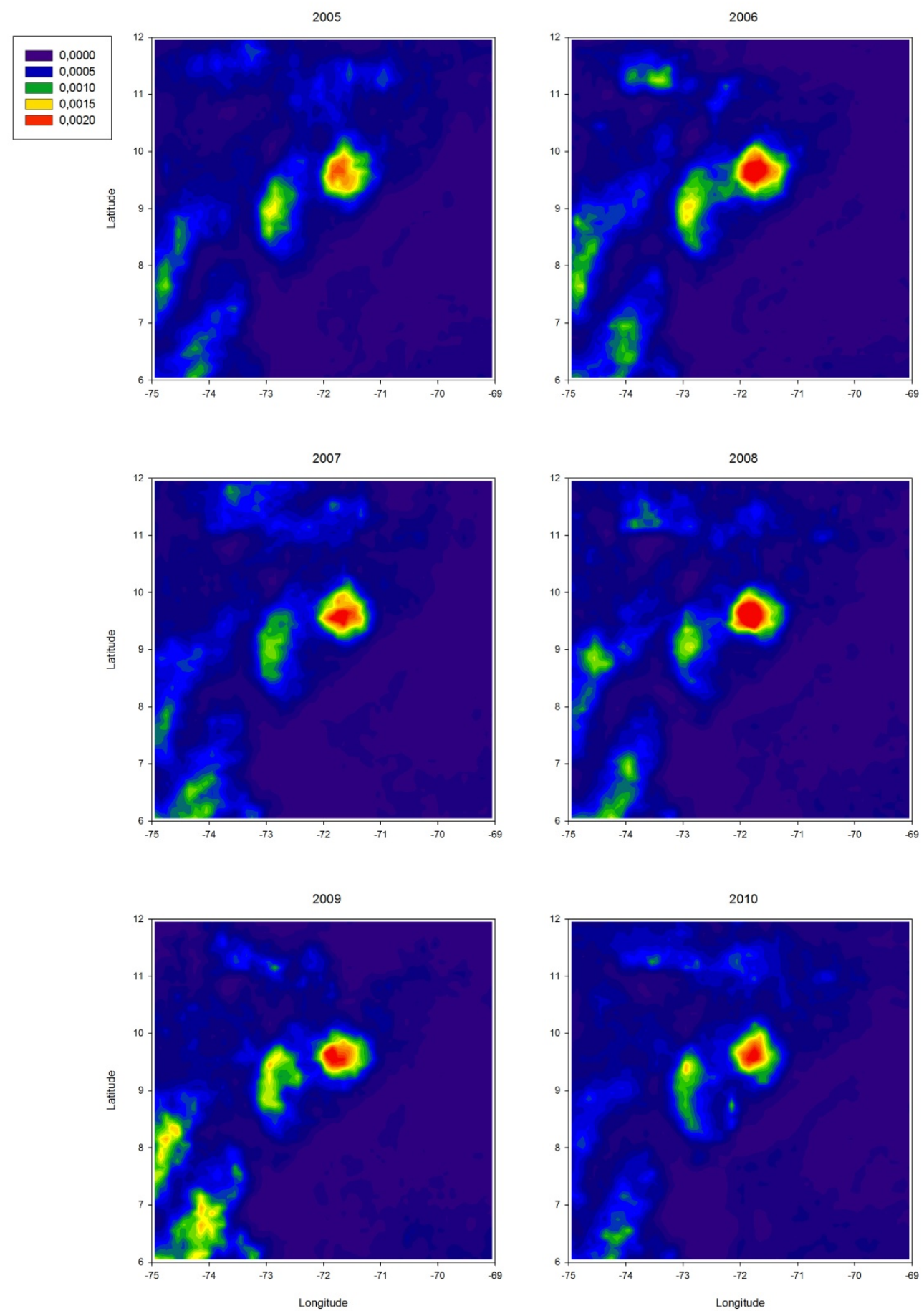

Figura 4-2Las descargas totales por año (FW $[i, j])$ detectados por el WWLLN en cada punto de la malla centrada en [i, j] de latitud y longitud, respectivamente, se calculan para cada año entre 2005 y 2010. 
FRw

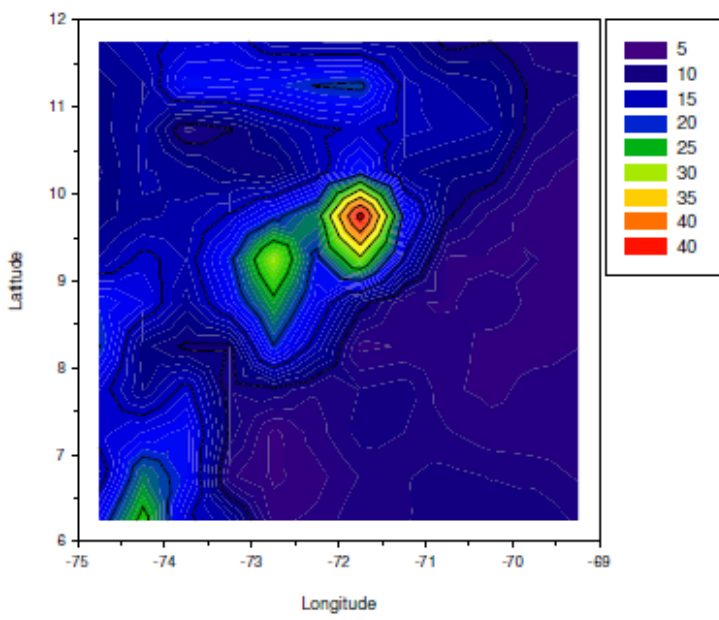

FRLis

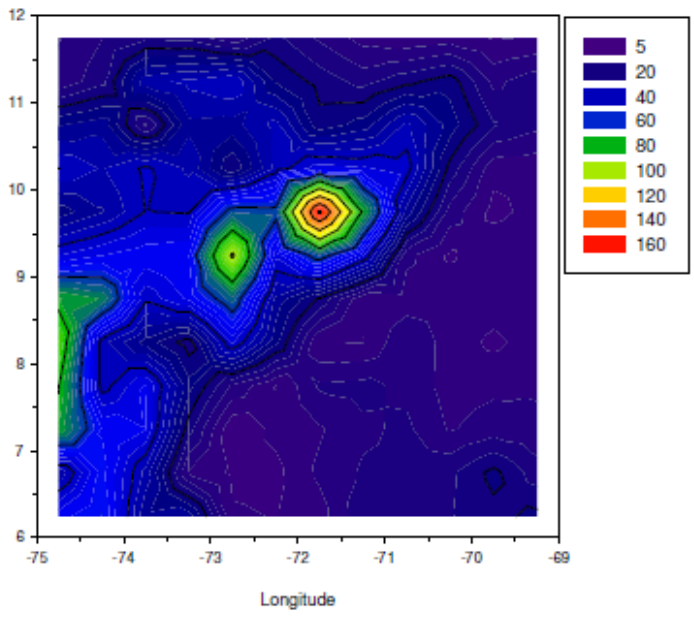

Figura 4-3 El panel izquierdo muestra la tasa de descargas utilizando los datos WWLLN (FRw) para el año 2010, y el panel derecho muestra los resultados obtenidos por el uso de datos LIS (FRLis) entre los años 1998 y 2010.

Con el fin de estudiar la evolución diaria de la actividad eléctrica del "Relámpago del Catatumbo", se calculó el valor diario de la cantidad de descargas $(f w, n)$ detectada por WWLLN para cada centro de alta AEA observada[9.5 $\left.\mathrm{N}, 71.5^{\circ} \mathrm{O}\right]$ (Primer centro) y $\left[9^{\circ} \mathrm{N}, 73^{\circ} \mathrm{O}\right]$ (Segunda centro) con una resolución espacial de $1^{\circ} \times 1^{\circ}$. Una vez más, con el fin de tener en cuenta la variación en la eficiencia de detección de la WWLLN, los valores fw se normalizaron al número total de descargas en el año. Por lo tanto se define la variable:

$$
f_{w, n}=\frac{f_{w}}{\sum_{\text {All year }} f_{w}}
$$

Ecuación 4-2

Que será usada como un indicador de la variación diaria de la AEA en cada punto de la cuadrícula. La Figura 4-4muestra la media móvil con 32 días de $\mathrm{f}_{\mathrm{w}, \mathrm{n}}$. Se puede observar que la actividad muestran una buena correlación con el tiempo un coeficiente de Pearson de 0,85 $\left(p<10^{-4}\right)$. Ambas regiones tienen un comportamiento semestral con dos máximos, uno en torno a mayo y otra en torno a octubre. Se observa que durante el período de la temporada seca, enero y febrero, la actividad se reduce. 


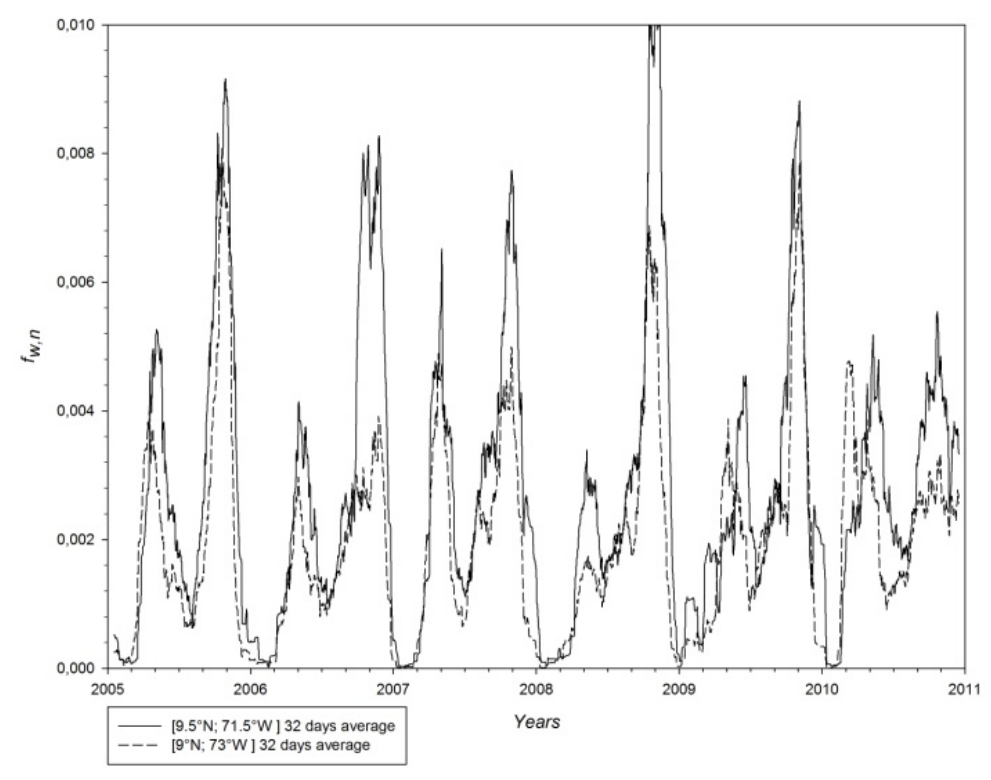

Figura 4-4 Media móvil con 32 días de fw, n.para el período 2005-2010

La climatología de la región del Lago de Maracaibo se ve afectada por varios factores, tales como la Zona de Convergencia Inter Tropical (ITCZ), el Jet en capas bajas nivel del Caribe (CLL) y la piscina caliente del hemisferio occidental (West Hemisphere Warm Pool). El CLL domina la circulación del Caribe y se asocia con la actividad convectiva y las características regionales de precipitación (Amador, 2008). El CLLJ tiene un ciclo anual con dos máximos de intensidad de viento, una en julio y otra en enero-febrero y tiene mínimos en mayo y octubre (Muñoz et al.,2008). Durante los máximos, la cortante vertical del viento en el Caribe alcanza su máximo, que es desfavorable para la convección. Este comportamiento semianual de CLL es coherente con el comportamiento semianual de la AEA diaria observada. El WHWP, contempera turas del agua mayores a $28.5^{\circ} \mathrm{C}$, tiene una superficie mínima en enero y febrero y alcanza su máxima área entre septiembre y octubre, cuando se expande hasta llegar a la costa norte de América del Sur (Wang y Enfield, 2001; 2002). Durante septiembre y octubre, el WHWP podría actuar de alimentación en forma de vapor y aumentar la convección.

La variación diurna de la $\mathrm{AEA}$ tomando una grilla de $1^{\circ} \times 1^{\circ}$ centrada en $\left[9.5^{\circ} \mathrm{N}, 71.5^{\circ} \mathrm{O}\right] \mathrm{y}$ en $\left[9^{\circ} \mathrm{N}, 73^{\circ} \mathrm{O}\right]$ se muestran en la Figura $4-5 a$ y $b$, respectivamente. La escala vertical representa la fracción de los descargas totales durante un año en función de la hora local, El ciclo diario del primer centro (Figura 5a) muestra una AEA escasa entre las 12:00-19:00 (hora local) con una densidad de descargas promedio de 7 flashes $\mathrm{km}^{-2}$ año-1. Además, el ciclo diario 
muestra una alta actividad entre las 23:00-09:00 (hora local) y el pico se produce entre 01:0003:00, con un valor superior a 200 flashes $\mathrm{km}^{-2}$ año-1. El segundo centro (Figura 4-5b) muestra un ciclo diario similar con una actividad escasa entre las 06:00-15:00 (hora local) y la mayor actividad se encuentra entre las 21:00-01:00 (hora local) con una densidad de descargas superior de 200 flashes $\mathrm{km}^{-2}$ año-1 a las 21:00 (hora local).

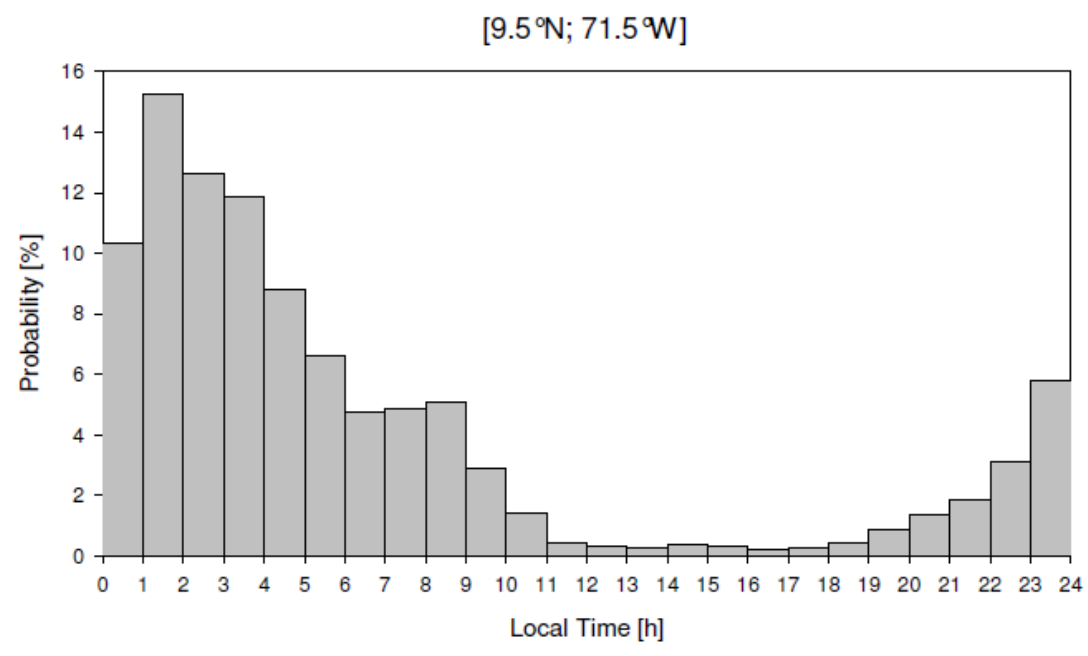

$\left[9^{\circ} ; 73^{q} \mathrm{~W}\right]$

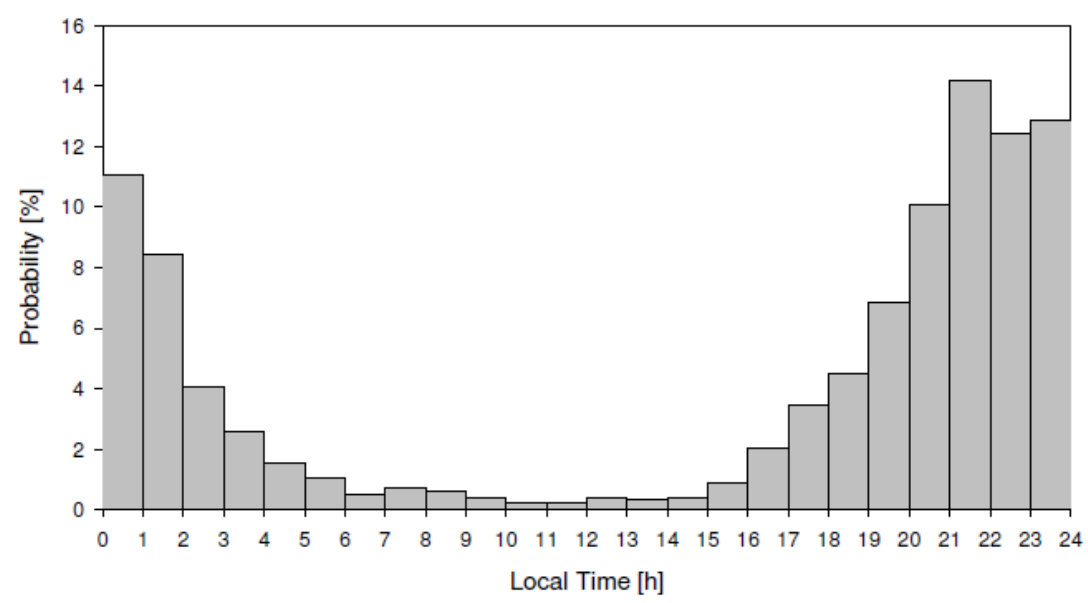

Figura 4-5variación diurna de la AEA tomando una grilla de $1^{\circ} \times 1^{\circ}$ centrada en $\left[9.5^{\circ} \mathrm{N}, 71.5^{\circ} \mathrm{W}\right]$ (panel superior) y en $\left[9^{\circ} \mathrm{N}, 73^{\circ} \mathrm{W}\right]$ (panel inferior). La escala vertical representa la fracción de las descargas totales durante un año en función de la hora local

El ciclo diario observado es coherente con la observación in situ en hecha por Falcon et al. (2000) y con la convección nocturna observada. Además, el valor máximo de la densidad de descargas se produce antes del pico de la lluvia (02:00-04:00 hora local) observado por Negri et al. (2002). Es importante tener en cuenta que la variación diurna de la AEA difiere apreciablemente de la ciclo diario típico de AEA. Probablemente, la compleja topografía local y 
las condiciones locales dinámicas y termodinámicas particulares son los responsables de la variación diurna particular de la AEA observada en esta región.

\section{d. Conclusiones}

La AEA en las ventana espacial de[6-12 $]^{\circ} \mathrm{N}$ de latitud y [75-69] $\mathrm{O}$ de longitud, perteneciente a la región de Maracaibo, se examinó mediante las bases de datos de la WWLLN y del LIS. Se detectaron dos centros muy bien localizadas con alta AEA. Uno de los centros se limita alrededor de $\left[9.5^{\circ} \mathrm{N}, 71.5^{\circ} \mathrm{O}\right]$ sobre la región suroeste del Lago de Maracaibo, y el otro es de alrededor de $\left[9^{\circ} \mathrm{N}, 7^{\circ} \mathrm{O}\right]$, cerca de la frontera entre Colombia y Venezuela.

Los dos centros muestran una importante AEA durante todo el año, excepto en los meses de enero y febrero. La AEA tiene un comportamiento semestral con máximo dos, uno en torno a mayo y otra en torno a octubre. Este comportamiento es consistente con la variación estacional de insolación sobre la región y con el ciclo anual CLLJ.

El ciclo diario de eventos de descargas muestra una actividad escasa al mediodía local y muestra una actividad significativa durante las horas nocturnas. La variación diurna es consistente con la convección nocturna y los regímenes de precipitación observada en la región.

La persistencia espacial y temporal de la AEA observada parece deberse a la compleja topografía de la región y a los efectos de los fenómenos climáticos globales regionales como la migración de la zona de convergencia intertropical, el Jet en capas bajas del Caribe y la piscina caliente del hemisferio occidental que produce unas condiciones climáticas particulares de la región.

El " Relámpago del Catatumbo " fue reportada como la región con la tasa más alta del flash del mundo con casi 250 flashes $\mathrm{km}^{-2}$ año $\mathrm{o}^{-1}$ (Albrecht et al., 2011). Este tipo de densidad de descargas es superior a la actividad observada en África, América del Sur y el continente marítimo, las tres zonas reconocidas como los principales componentes del circuito eléctrico global (Whipple, 1929). 


\section{2. África Tropical}

En esta sección se presenta eltrabajo Spatial and time distribution of the flash rate over tropical África, Rodrigo E. Bürgesser, María G. Nicora, Eldo E. Ávila 2013.Journal of Atmospheric and Solar-Terrestrial Physics, 94, 41-48.

\section{a. Discusión y resultados}

La cuenca del Congo se encuentra confinada en la zona tropical entre los $10^{\circ} \mathrm{N}$ y $10^{\circ} \mathrm{S}$ y se extiende por seis países: Camerún, República Centro africana, Congo , República Democrática del Congo, Guinea Ecuatorial y Gabón, y es bien conocido que tiene una de las tasas más altas de AEA en el mundo

La Figura 4-6 (panel superior-izquierdo) muestra la densidad de descargas derivado de los datos de LIS entre enero de 1998 y diciembre de 2011 sobre África. Se utilizó una resolución espacial de $0,5^{\circ} \times 0,5^{\circ}$. Esta figura muestra que la actividad principal de AEA está confinada en la zona tropical entre los $10^{\circ} \mathrm{N}$ y $10^{\circ} \mathrm{S}$, la que corresponde a la cuenca del Congo. La región presenta una AEA de base de 40 flashes $\mathrm{km}^{-2}$ año-1 y también muestra una distribución espacial de los centros de mayor AEA en el borde oriental de la región de la Cuenca del Congo y en la región central con actividades de más de 80 flashes $\mathrm{km}^{-2}$ año ${ }^{-1}$. La AEA en la zona tropical de África está delimitado por los desiertos del Sahel y el Sahara en la parte norte y por las altas elevaciones del terreno (> 1.000 metros) en el sur (Bie y la Meseta deKatanga) y en el este por las Albertine Rift Mountain como puede ser observado en la Figura 4-6 (panel superior derecha)en donde se muestra la topografía de la zona de estudio.

La Figura 4-6 también muestra la temperatura de tope nuboso CTT (Cloud Top Temperature) media anual (panel inferior izquierdo) y la temperatura superficial AST(Air Surface Temperature) media anual (panel inferior derecha) a lo largo de África. Los datos son de Atmospheric Infrared Sounder (AIRS). AIRS, instrumental a bordo del satélite Aqua (http://airs.jpl.nasa.gov/). La cuenca del Congo presenta la media anual más baja de CTT sobre África, con valores menores a $250^{\circ} \mathrm{K}$ y un AST medio anual mayor que $300^{\circ} \mathrm{K}$. El CTT es un buen indicador del desarrollo vertical de la nube y bajos valores de CTT suelen estar relacionados con convección profunda (Fue et al, 1990; Liu et al, 1995; Hong et al, 2005; Aumann et al, 2007). Numerosos estudios indican una fuerte correlación entre la producción de descargas y las características microfísicos y dinámicas de las nubes, en particular nubes de convección profunda (DCC). Se espera que la AEA en las DCC dependa de la intensidad del movimiento 
vertical del aire, que está estrechamente relacionado con la altura de la tormenta (Williams, 1985; Precio y Rind, 1992; Ushio et al, 2001; Avila et al, 2010). La cuenca del Congo parece tener las condiciones termodinámicas más favorables para la producción de la convección profunda, que son: alta humedad, altos valores de ASTy valores muy bajos de CTT, que puede conducir a una actividad significativa de AEA.
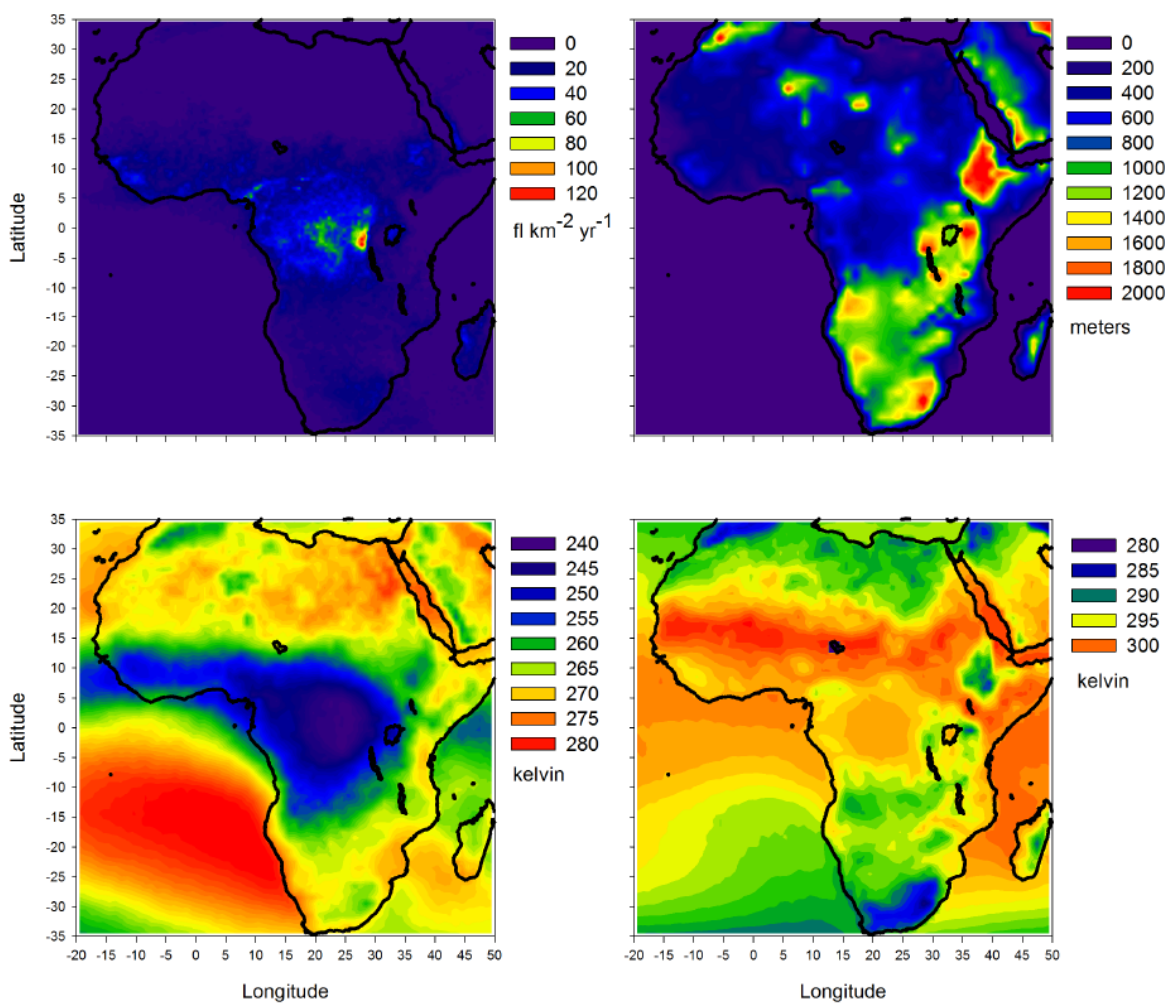

Figura 4-6 El panel superior-izquierdo muestra la densidad de descargas derivado de datos de LIS entre enero de 1998 y diciembre de 2011 sobre África. El panel superior - derecha se muestra la topografía de la zona de estudio. La temperatura de tope nuboso CTT media anual (panel inferior izquierdo) y la temperatura superficial AST media anual (panel inferior derecha) a lo largo de África

La Figura 4-7 muestra la densidad de descargas detectadas por LIS (FRLis, panel superior) entre 1998-2011 y por WWLLN durante 2011 (FRw, Panel inferior) para la ventana espacial entre $\left[-10^{\circ}, 15^{\circ}\right]$ de latitud y $\left[10^{\circ} ; 40^{\circ}\right]$ de longitud con una resolución espacial de $0,5^{\circ} \times 0,5^{\circ}$

Ambos mapas muestran también los contornos de elevación del suelo con la misma resolución espacial utilizada en los mapas de descargas. Como se puede observar, los dos mapas muestran una distribución espacial similar de las densidades de descargas con el centro de actividad. La WWLLN detecta una densidad de 4 flashes $\mathrm{km}^{-2}$ año-1 en el centro de mayor actividad y 1,5 flashes $\mathrm{km}^{-2}$ año-1en la región central, mientras LIS detectado 135 flashes km 
${ }^{2}$ año ${ }^{-1}$ y 60 flashes $\mathrm{km}^{-2}$ año ${ }^{-1}$, respectivamente. Asumiendo una eficiencia de detección de LIS de 0,85 (Boccipio et al., 2002), obtenemos una eficiencia de detección de WWLLN sobre la región de la Cuenca del Congo de 2-3\%. Claramente la baja eficiencia de detección de la WWLLN es una consecuencia del escaso número de estaciones WWLLN en África, lo que significa que sólo los GC con corrientes de pico muy altos son detectados en estas regiones. Sin embargo, a pesar de la baja eficiencia de detección de WWLLN, ambas bases de datos (WWLLN y LIS) muestran una buena correlación espacial con un coeficiente de Pearson de $0,69\left(p<10^{-4}\right)$ y la WWLLN parece ser capaz de detectar las principales características de la AEA en la distribución espacial sobre la cuenca del Congo.

La Figura 4-7 muestra a la vez que la región con mayor AEA está limitada por terrenos altos (> $1000 \mathrm{~m}$ ) en el sur y en el este de la cuenca del Congo. Los limites occidental y oriental se puede observar en la Figura 4-8 (panel superior), donde se muestran el perfil de la topografía (línea punteada azul) y la tasa de descargas (línea continua negra) detectada por LIS (FRLis) para una celda de la cuadrícula de $\left(0,5^{\circ} \times 0,5^{\circ}\right)$ centrada a $-1.75^{\circ}$ de latitud y entre $\left[5^{\circ}, 40^{\circ}\right]$ de longitud. El perfil muestra baja AEA en la longitud oeste $\left(<10^{\circ}\right)$, que se corresponde con el Océano Atlántico (elevación cero metros). Entre $\left[10^{\circ}, 25^{\circ}\right]$ de longitud (Cuenca del Congo) el continente africano presenta una elevación del terreno de $500 \mathrm{~m}$ con la actividad media de (40-60 flashes $\mathrm{km}^{-2}$ año-1). Hacia el este, se observa un aumento de la AEA que es coincidente con un aumento en la elevación del terreno. La densidad de descargas muestra un pico entre $\left[25^{\circ} ; 30^{\circ}\right]$ de longitud, que se corresponde con el centro de la actividad observada en las Figura 4-6 y Figura 4-7. Este pico se encuentra en el lado oeste de la Albertine Rift Mountain. Otro pico con 20 flashes $\mathrm{km}^{-2}$ año ${ }^{-1}$ también se puede observar entre el Albertine Rift Mountain y las tierras altas de Kenia, entre el $\left[31^{\circ} ; 35^{\circ}\right]$ de longitud, que pertenecen a la ubicación del Lago Victoria. 

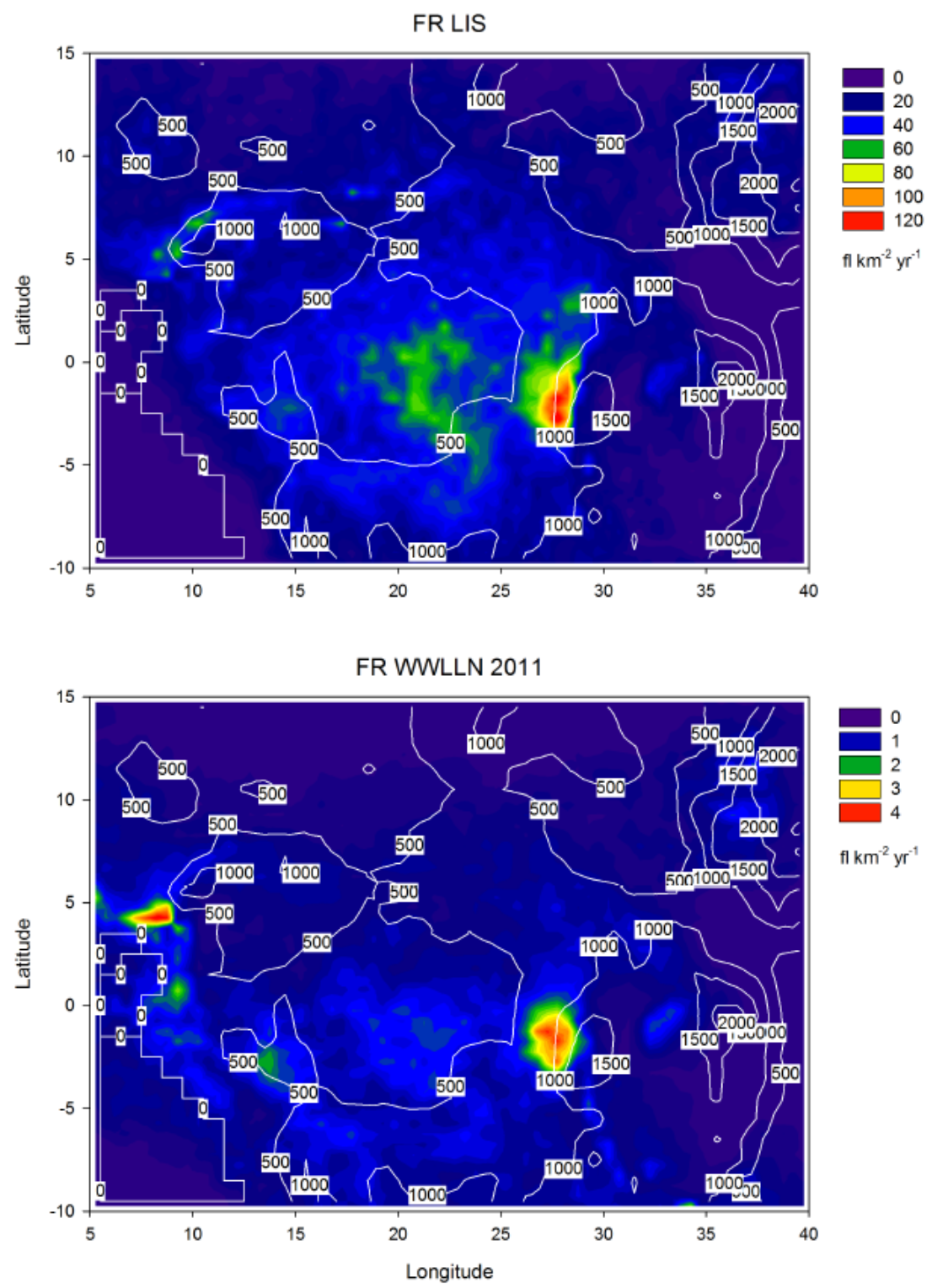

Figura 4-7densidad de descargas detectadas por LIS ( FRLis, panel superior ) entre 1998-2011 y por WWLLN durante 2011 ( FRw, Panel inferior). Se graficó también en color blanco la altura del terreno 

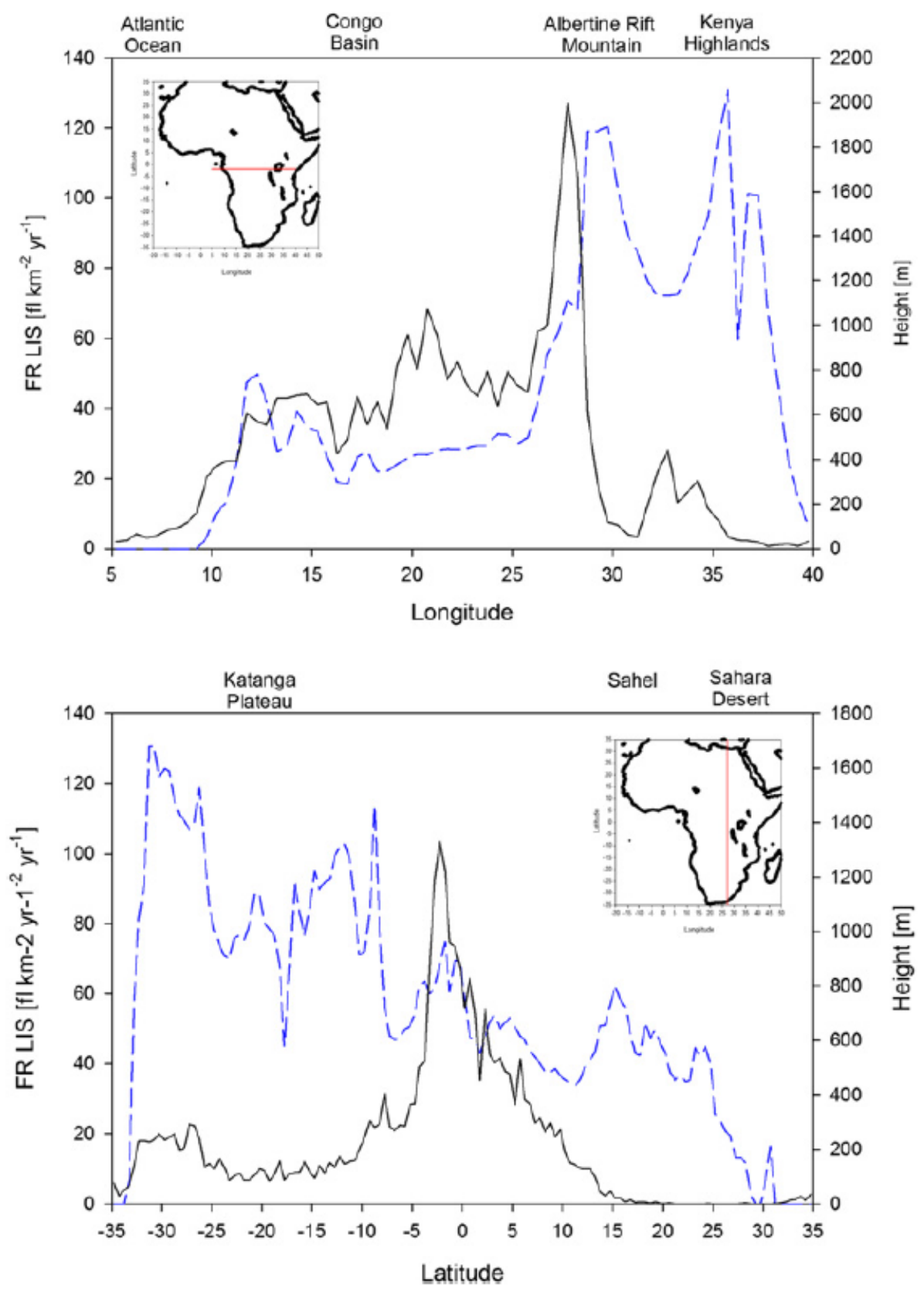

Figura 4-8 Perfil de la topografía (línea punteada azul) y la tasa de descargas (línea continua negra) detectada por LIS (FRLis) para una celda de la cuadrícula de $\left(0,5^{\circ} \times 0,5^{\circ}\right)$ centrada a $-1.75^{\circ}$ de latitud y entre $\left[5^{\circ}, 40^{\circ}\right]$ de longitud. (Panel Superior). El panel inferior muestra lo mismo que en el panel superior, pero para la celda de la cuadrícula de $\left(0,5^{\circ} \times 0,5^{\circ}\right)$ centrado en $27,25^{\circ}$ de longitud y entre $\left[-35^{\circ} ; 35^{\circ}\right]$ de latitud .

En el panel inferior de la Figura 4-8 se muestra lo mismo que en el panel superior, pero para la celda de la cuadrícula de $\left(0,5^{\circ} \times 0,5^{\circ}\right)$ centrado en $27,25^{\circ}$ de longitud y entre $\left[-35^{\circ} ; 35^{\circ}\right]$ de latitud. Para latitudes entre $-35^{\circ}$ y $-10^{\circ}$, la topografía muestra terrenos con altitudes superiores a los $1.000 \mathrm{~m}$ que corresponden a la meseta de Katanga. Estas latitudes muestran AEA de 
menos de 20 flashes $\mathrm{km}^{-2}$ año ${ }^{-1}$. Para latitudes entre $-5^{\circ}$ y $5^{\circ}$, AEA presenta un pico con más de 100 flashes $\mathrm{km}^{-2}$ año ${ }^{-1}$, que se corresponde con el centro observado previamente. Hacia el norte, la disminución de la AEA llega a valores cercanos a cero para latitudes superiores a $15^{\circ}$ que corresponden a los desiertos de Sahel y Sahara.

Para analizar la evolución anual de la distribución espacial de la AEA en la Cuenca del Congo, se calcularon para cada año entre 2005 y 2011,los flashes totales por año (Fw [i, j]) detectada por el WWLLN en cada punto de la malla centrada en [i, j] de latitud y longitud, con una resolución espacial de $\left[0,1^{\circ} \times 0,1^{\circ}\right]$. Estos valores se normalizaron por las descargas totales en la ventana espacial para todo el año. Por lo que se utilizó la variable $F_{w, n}(y e a r)[i, j]$ (Ecuación 4-1) presentada anteriormente

La Figura 4-9 muestra la distribución espacial de $\mathrm{F}_{\mathrm{w}, \mathrm{n}}$ en las ventana espacial entre $\left[-5^{\circ} ; 5^{\circ}\right]$ de latitud y $\left[20^{\circ} ; 30^{\circ}\right]$ de longitud. Para esta ventana, el coeficiente de Pearson entre la densidad de descargas detectado por LIS y por WWLLN durante 2011 es de $0,78\left(p<10^{-4}\right)$. Como se puede observar para cada uno de los años analizados, la región central de mayor actividad está presentes en cada año considerado. Este centro está confinado entre $\left[-3^{\circ} ; 0^{\circ}\right]$ de latitud y $\left[26^{\circ} ; 29^{\circ}\right]$ de longitud, mientras que la zona central presenta una distribución más dispersa de la densidad de descargas y no muestra un patrón de distribución espacial particular.

De manera similar a la Figura 4-9, la Figura 4-10muestra la actividad anual de descargas para la ventana espacia entre $\left[-3^{\circ} ; 1^{\circ}\right]$ de latitud y $\left[31^{\circ} ; 35^{\circ}\right]$ de longitud; la línea en blanco demarcada en la figura muestra la costa del Lago Victoria. Por cada año analizado, los resultados muestran que la AEA se limita en gran medida sobre el lago, con un máximo en la zona noreste, y con menos actividad sobre la región del sur del lago. Para esta región, el conjunto de datos de descargas para ambas bases de datos (LIS y WWLLN) dan una buena correlación espacial con un coeficiente de Pearson de $0,88\left(p<10^{-4}\right)$. 

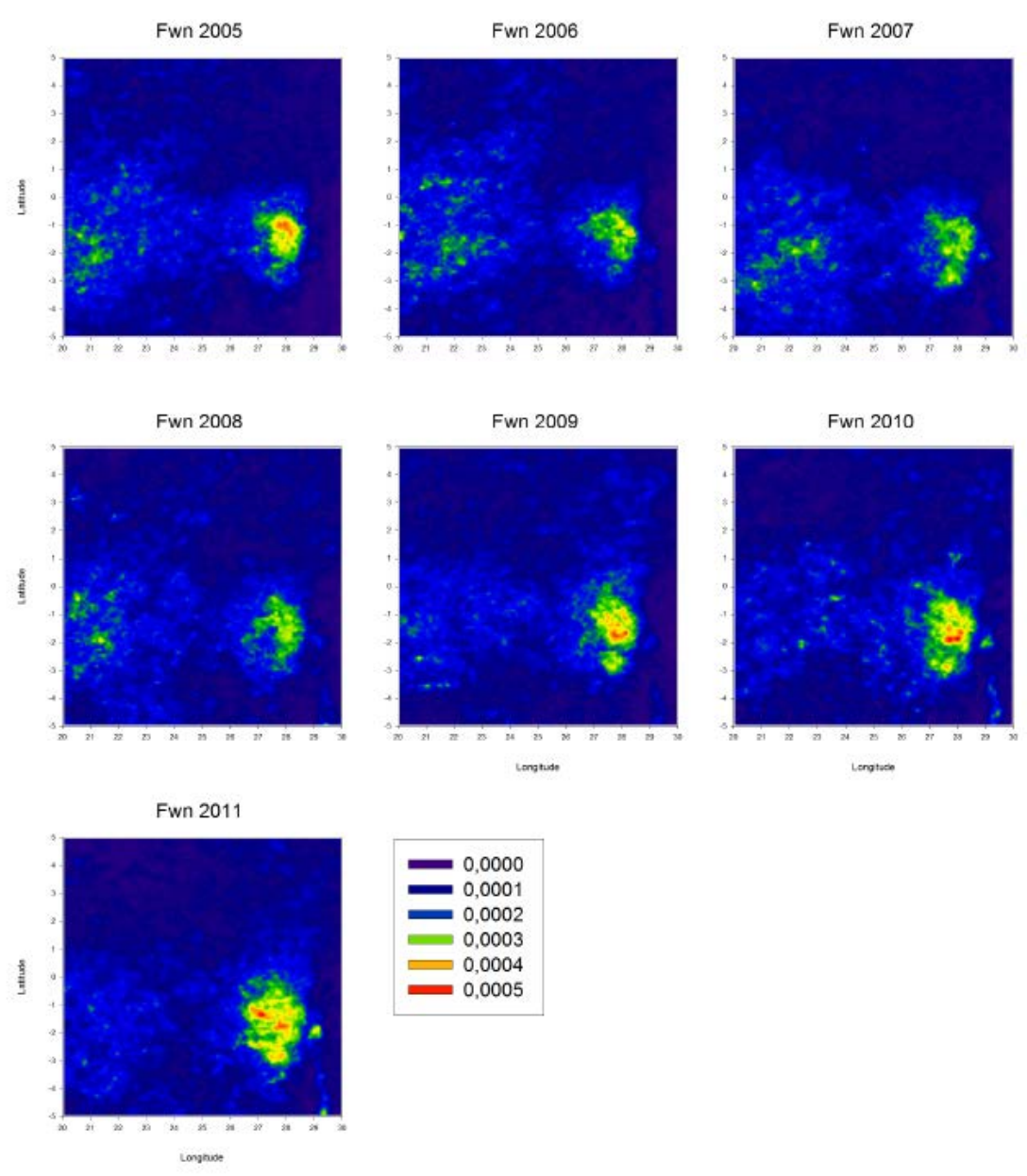

Figura 4-9 Distribución espacial de $F_{w, n}$ en las ventana espacial entre $\left[-5^{\circ} ; 5^{\circ}\right]$ de latitud y $\left[20^{\circ} ; 30^{\circ}\right]$ de longitud. Para el periodo 2005-2011

Mediante el uso de datos detectados por LIS/OTD, Collier y Hughes (2011a) estudiaron las climatologías de la AEA de la mayoría de los países africanos. La mayor actividad en el continente Africano se produce en la República Democrática del Congo, que se encuentra en su totalidad dentro de la cuenca del río Congo. Estos autores propusieron que la variación media anual de la AEA puede ser representada por componentes sinusoidales anuales y semestrales. La Figura 4-11 muestra la evolución diaria de la AEA de la Cuenca del Congo. Se calculó el valor diario de descargas normalizadas $(\mathrm{fw}, \mathrm{n})$ detectada por WWLLN dentro de la ventana espacial entre $\left[-10^{\circ}, 5^{\circ}\right]$ de latitud y $\left[15^{\circ}, 30^{\circ}\right]$ de longitud, como un indicador de la variación diaria de la AEA de la región. La Figura 4-11 muestra la media móvil de 32 días de $\mathrm{f}_{\mathrm{w}, \mathrm{n}}$ (línea continua negro) y el ajuste sinusoidal propuesta por Collier y Hughes (2011a) para la República Democrática del Congo (azul línea discontinua). 

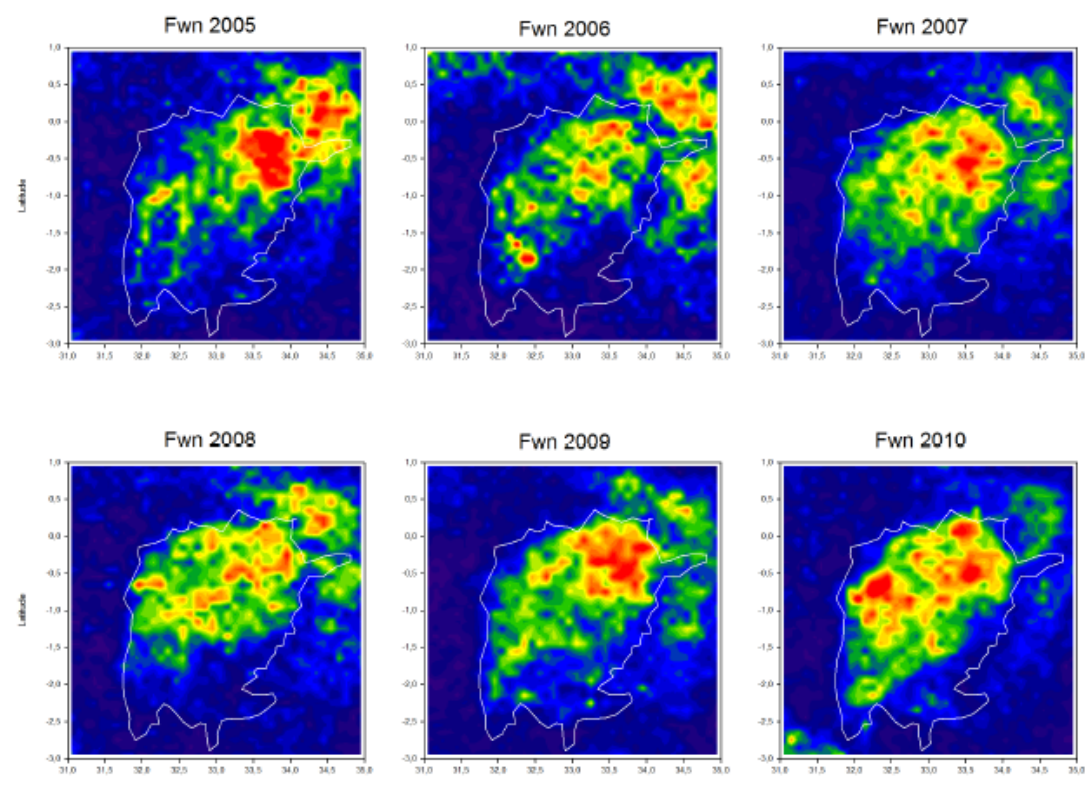

Fwn 2011
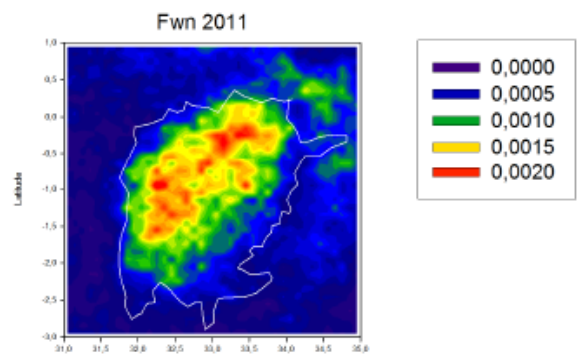

Langasta
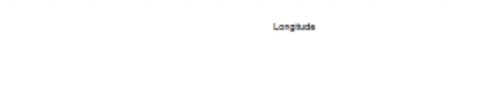


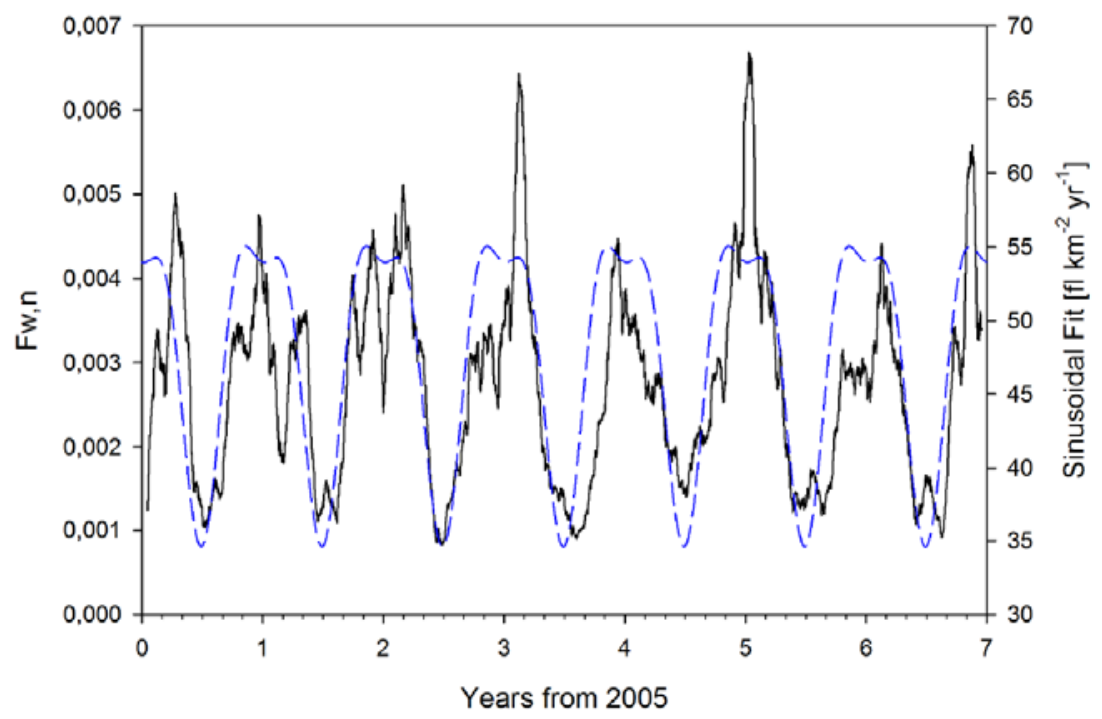

Figura 4-11muestra la media móvil de 32 días de $f_{w, n}$ (línea continua negro) y el ajuste sinusoidal propuesta por Collier y Hughes (2011a) para la República Democrática del Congo (azul línea discontinua).

También utilizamos la variable $\mathrm{El} \mathrm{f}_{\mathrm{w}, \mathrm{n}}$ para estudiar las características interanuales de tres regiones diferentes:

- el centro de alta actividad situado entre $\left[0^{\circ} ;-3^{\circ}\right]$ de latitud y $\left[27^{\circ} ; 29^{\circ}\right]$ de longitud ( Figura 4-12a),

- la región central delimitado por $\left[2^{\circ} ;-5^{\circ}\right]$ de latitud y $\left[20^{\circ}, 25^{\circ}\right]$ de longitud ( Figura $4-12 b)$,

- y para la región en el Lago Victoria (Figura 4-12c).

La Figura 4-12 muestra el valor medio de $\mathrm{f}_{\mathrm{w}, \mathrm{n}}$ con un promedio móvil de 32 días de estas tres regiones. Las tres regiones presentan variación anual similar con baja amplitud y con menos AEA, entre junio y agosto. El centro de alta actividad (Figura 4-12a) y la región central (Figura 4-12b) muestran una buena correlación en la variación $\mathrm{f}_{\mathrm{w}, \mathrm{n}}$ con un coeficiente de Pearson de $0,83\left(p<10^{-4}\right)$. La variación anual del Lago Victoria muestra coeficientes de Pearson de $0.66\left(p<10^{-4}\right)$ y $0.57\left(p<10^{-4}\right)$ con el centro de alta actividad y la región central, respectivamente. La principal diferencia en las variaciones de la AEA del lago Victoria y la Cuenca del Congo es el pico alrededor de marzo y abril observado sobre el Lago Victoria. 

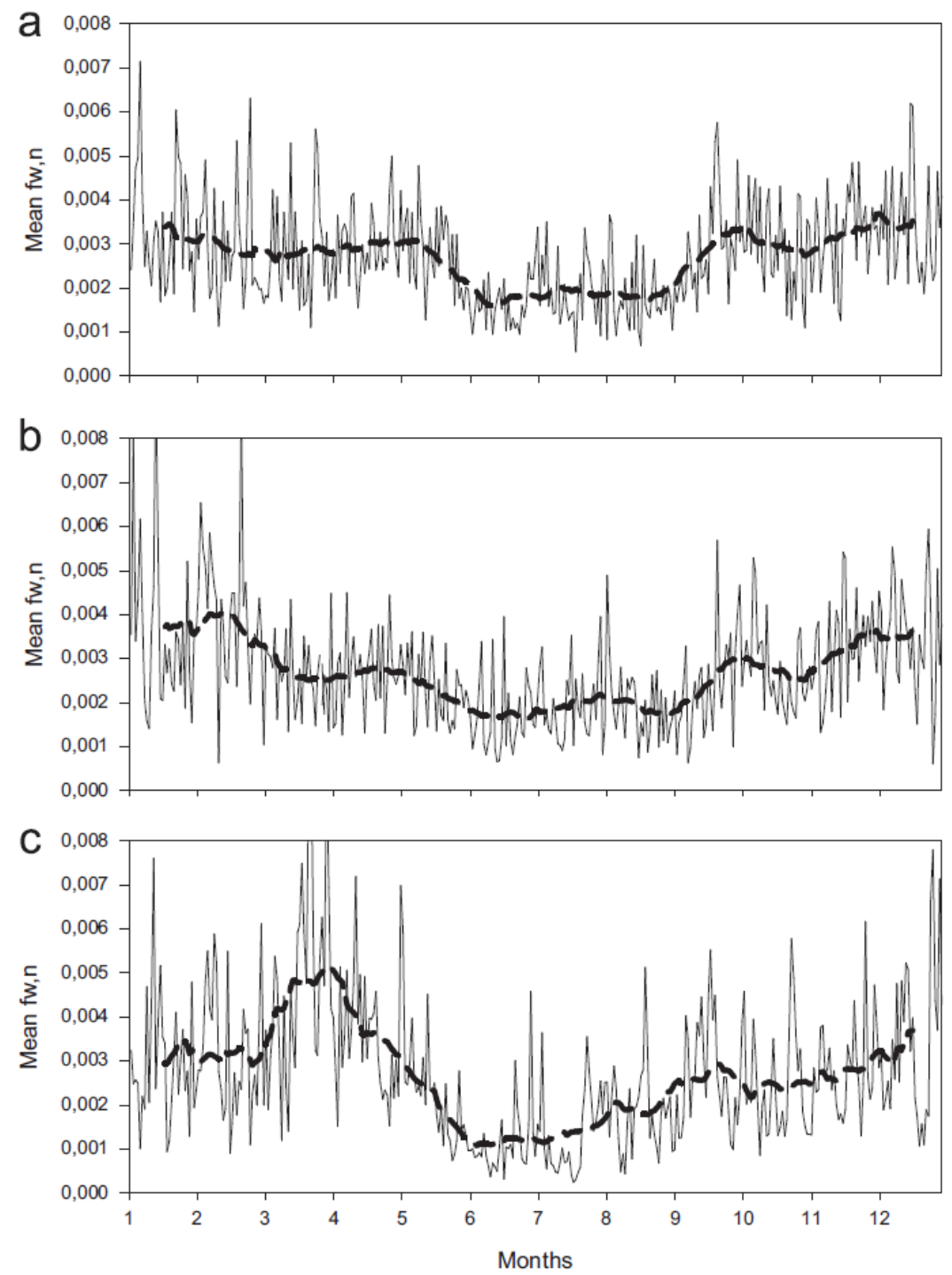

Figura 4-12Gráfico de la variable $f_{w, n}$ en tres regiones de máximos: el centro de alta actividad situado entre $\left[0^{\circ} ;-3^{\circ}\right]$ de latitud y $\left[27^{\circ} ; 29^{\circ}\right]$ de longitud ( Figura $4-12$ a) , la región central delimitado por $\left[2^{\circ} ;-5^{\circ}\right]$ de latitud y $\left[20^{\circ}, 25^{\circ}\right]$ de longitud ( Figura 4-12 b ), y para la región en el Lago Victoria (Figura 4-12c).

A lo largo del año, la cuenca del Congo presenta alta temperatura, con valores medios de $27^{\circ} \mathrm{C}$, y un rango anual de $\sim 6^{\circ} \mathrm{C}$ y una amplitud diurna entre $10^{\circ}$ y $15^{\circ} \mathrm{C}$ (Nicholson, 2001). En escala de tiempo corto, varios estudios encontraron una correlación positiva entre la AEA tropical y la temperatura superficial del aire (Price, 1993; Markson y Price, 1999; Price y Asfur, 2006). Por lo tanto, la baja amplitud de las variaciones observadas es coherente con el bajo rango en la variación de la temperatura anual de la región. Nicholson(2000)detalló una temporada de lluvias sobre la cuenca del Congo que dura entre 10 a 12 meses con una precipitación máxima en noviembre. La precipitación media anual es superior a $1.500 \mathrm{~mm}$, alcanzando $2.000 \mathrm{~mm}$ en la región central. 
El Lago Victoria presenta importantes precipitaciones que ocurren durante todo el año con una precipitación media anual de 1.200 mm (Nicholson, 2000; Asnani, 1993) encontraron una depresión casi permanente que persiste sobre el Lago Victoria debido a la convección inducida localmente, la influencia orográfica y el contraste térmico lago-tierra que tiende a favorecer la convección sobre el lago durante todo el año. Sin embargo, la precipitación estacional sobre el Lago Victoria muestra un régimen bimodal que está controlado principalmente por la migración norte-sur de la ITCZ a través de la región. Este ciclo estacional muestra una larga temporada de lluvias entre marzo y mayo, cuando se observa el valor máximo de las precipitaciones, y una estación corta de lluvias entre octubre y diciembre. Aunque la migración de la ITCZ parece ser el que controla las precipitaciones estacionales en las regiones, Collier y Hughes (2011b) encontraron una débil relación entre la AEA ecuatorial y la ITCZ sobre África. Esto parece ser debido a la asimetría en la humedad (vapor de agua) llevado por el aire que se mueve en la ITCZ desde el sur (Cuenca del Congo y el Golfo de Guinea) y del norte (Sahara).

La Figura 4-13 muestra la variación diurna de la AEA de las tres regiones analizadas en la Figura 4-12. Los valores verticales representan la fracción de las descargas durante todo un año como una función de la hora local; los recuentos se agrupan cada hora. El ciclo diario del centro de alta actividad y la región central (Figura 4-13a y b) Indicación de escasa actividad entre las 06:00-12:00 y un pico entre las 16:00-20:00 horas locales. El ciclo diario observado en el centro de alta actividad y la región central son consistentes con la observación mundial por LIS y OTD, que muestran que la AEA tropical tiene un pico diario claro en horas de la tarde locales (Williams et al, 2000).

Por otro lado, el ciclo diario de la AEA sobre el Lago Victoria (Figura 4-13c) muestra poca variación durante el día. Se pueden observar dos pequeños picos, uno de ellos entre las 15:0019:00 hora local y otro alrededor de las 23:00-05:00 hora local, las mínimas se encontraron entre las 11:00-13:00 hora local y entre las 20:00 y las 22:00 hora local. Ba y Nichoson (1998) estudiaron la actividad convectiva sobre los lagos del Rift Valley en África Oriental utilizando índices convectivos obtenidos por satélite y mediciones de lluvia. Encontraron un ciclo diario de la actividad convectiva sobre el Lago Victoria, con dos máximos para la convección, uno por la mañana y otro por la tarde. Fraedrich (1972), utilizando un modelo simple, encontró un pico de la circulación nocturna sobre el Lago Victoria, que se produce generalmente entre la medianoche y las primeras horas de la mañana cuando la superficie del lago es más caliente que la superficie circundante. Al final de la tarde y temprano en la noche, cuando la superficie del terreno contiguo es más caliente que la superficie del lago, se produce un pico en la brisa 
del lago. Song et al. (2004) demostraron que la región suroeste del lago es una fuente importante de agua caliente, ya que es relativamente menos profunda y se calienta mucho más rápidamente durante el día que el resto del lago. Esto da lugar a una distribución de la temperatura de la superficie del lago asimétrica que se modifica la circulación del viento por encima, que a su vez reduce la cobertura de nubes y precipitaciones.
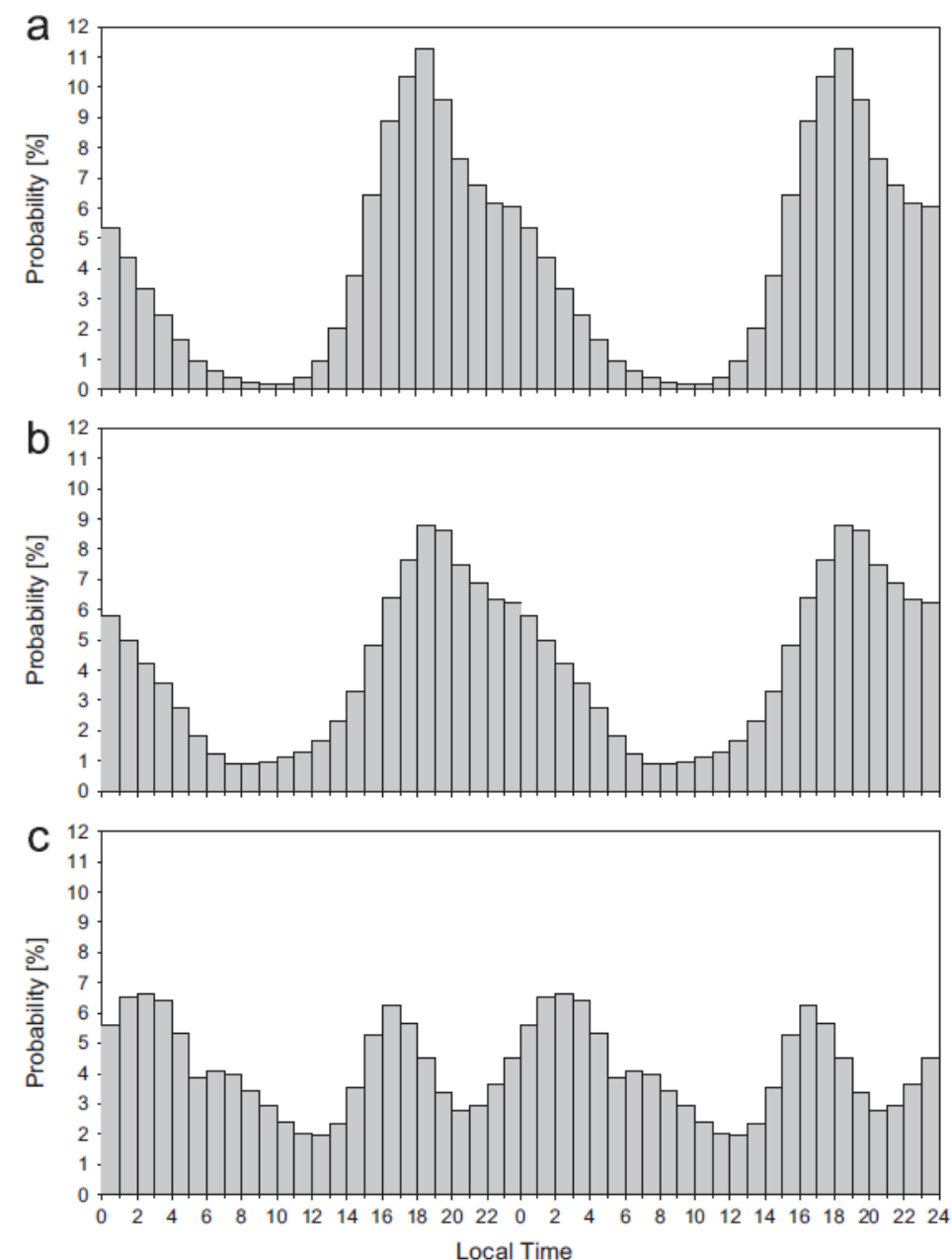

Figura 4-13muestra la variación diurna de la AEA de las tres regiones analizadas en la Figura 4-12.

\section{b. Conclusiones}

Los resultados LIS muestran que la cuenca del Congo en África tiene la más alta AEA a lo largo del año, con densidades de descargas resultantes de más de 50 flashes $\mathrm{km}^{-2}$ año ${ }^{-1}$. La AEA sobre esta región presenta un patrón con un centro localizado de alta actividad sobre la falda occidental del Rift Albertin. Este centro está situado entre $\left[0^{\circ} ;-3^{\circ}\right]$ de latitud y $\left[27^{\circ} ; 29^{\circ}\right]$ de longitud y llega a valores superiores a 100 flashes $\mathrm{km}^{-2}$ año ${ }^{-1}$. Los resultados parecen indicar 
que las fuerzas ascendentes topográficas mejora aún más el desarrollo de tormentas y pueden posteriormente dar lugar a un aumento de la AEA.

La cuenca del Congo muestra altas temperaturas del aire superficial, bajos valores de la temperatura de tope nuboso y precipitación anual sustancial. La baja amplitud de las variaciones anuales de la AEA es consistente con la baja variación anual de la temperatura de la región y con una estación lluviosa que dura casi todo el año. El ciclo diario observado es consistente con la observación global de la región tropical, con un pico en la densidad de descargas en horas de la tarde (hora local), consistente también con el ciclo diario de lluvia.

Valores altos de la AEA también se encontraron sobre el Lago Victoria, que presenta una variación diaria similar a las otras regiones pero sin un ciclo diario marcado.

La AEA está relacionada con la convección atmosférica que se produce debido al calentamiento de la capa límite por la radiación solar durante el día o por la mezcla de las masas de aire de diferentes densidades. También, el factor topográfico es fundamental para iniciar inestabilidades que desencadenan la formación de tormentas. 


\section{Capítulo 5 Mapas isoceráunicos de la República Argentina - Días de tormenta}

La medición o conteo de días de tormentas ha sido una de las primeras herramientas que ha utilizado la humanidad para poder realizar un monitoreo del clima; son fácil de cuantificar, nos dan una idea de que con qué frecuencia hay tormentas severas en el lugar de monitoreo, y nos muestran la variación estacional de dichos fenómenos. A su vez conociendo los días de tormentas, podemos inferir la cantidad de descargas a tierra (que son las más perjudiciales para las personas, animales y bienes personales), para poder realizar medidas de protección acordes a la actividad eléctrica del lugar.

Hasta la fecha, los mapas isoceráunicos de la República Argentina han sido confeccionados en base a datos obtenidos por observadores en estaciones meteorológicas. Sin embargo, la existencia de la WWLLN permite realizar un análisis más detallado, ya que permite trabajar con datos de todo el territorio, permitiendo una mayor precisión al momento de interpolación de los promedios anuales, y, debido a que cada una de las estaciones puede detectar ondas de VLF provenientes de varios miles de $\mathrm{km}$, se puede determinar la actividad eléctrica de regiones remotas, no habitadas y hasta inaccesibles para el hombre. Uno de los objetivos de la presente tesis fue poder confeccionar los mapas isoceráunicos en base a los datos de descargas eléctricas detectados por la WWLLN. En este capítulo se presenta el trabajo metodológico que llevó a la confección de los Mapas isoceráunicos de la República Argentina para el período 2005-2011.

\section{Introducción}

Varios siglos antes de Cristo, la cultura Caldeo Babilónica desarrolló un sistema de predicción de clima que incluía el conteo de truenos. En la Europa medieval se tiene conocimiento que hubo gente que rescató la práctica de Caldea y crearon calendarios de truenos. Estos fueron usados para hacer predicciones de clima, basados en registros históricos de truenos oídos en días específicos (Torres, 2010). 
En 1873, el Comité Meteorológico Internacional (International Meteorologica Committee ${ }^{4}$ ), reunido en Viena adoptó una unidad que denominó "Día con trueno oído" (Day with Thunder Heard), mediante una resolución que definía: "Para obtener resultados que permitan comparación, se recomienda contar solamente como días de tormenta eléctrica aquellos en los cuales se oye un trueno y la descarga es observada", esto se normalizó para prevenir el registro de tormentas muy lejanas.

Hacia finales del siglo 19 comenzaron a elaborarse mapas donde, mediante líneas, se conectaban sitios con iguales cantidad de días de tormentas. Estas líneas se llamaron líneas de igual número de truenos.

El término Isoceráunico se comenzó entonces a usar hacia 1920 y se refería a una línea o isograma de igual frecuencia de días de tormenta (Td) las cuales se consideraron como aquellos días en que el observador informa de una tormenta cuando escucha por lo menos un trueno, sin discriminar entre descargas nube - nube o nube a tierra. Los datos de días de tormentas basados en observaciones humanas permitieron la primera comparación cuantitativa de ocurrencia de tormentas para regiones de un país, durante diferentes épocas del año y para diferentes sitios alrededor del mundo.

En el año 1953 la Organización Meteorológica Mundial (WMO) realizó las primeras recopilaciones a nivel mundial de días de tormenta en un documento llamado WORLD DISTRIBUTION OF THUNDERSTORM DAYS. PART I: TABLES (WMO, 1953) en donde Argentina participó del estudio con 42 estaciones distribuidas en el país.

En la Tabla 5-1se presentan los datos referido al territorio argentino presentado en dicho documento. La tabla muestra: el nombre la estación, su latitud, longitud, altura sobre el nivel del mar, años de mediciones (N), Días de tormenta en el período marzo - mayo (I), Días de tormenta en el período Junio - agosto (II), Días de tormenta en el período Septiembre Noviembre(III), Días de tormenta en el período diciembre - febrero (IV), luego el total de los Td por año, y los valores de días de tormenta para cada uno de los 12 meses del año.

Este trabajo se completó con la publicación de WORLD DISTRIBUTION OF THUNDERSTORM DAYS.PART 2: Tables of Marine Data and World Maps del año 1956 (WMO, 1956). La Figura 5-1 muestra el mapa mundial confeccionado en dicho trabajo donde se observan las distintas isogramas de los días de tormenta.

\footnotetext{
${ }^{4}$ International MeteorologicaCommittee (1873-1951) fue la primera organización formada con el propósito de intercambiar información sobre el clima entre los países del mundo. Nació de la constatación de que los sistemas meteorológicos se desplazan a través de las fronteras del país y que, el conocimiento de los mismos son necesarios para la previsión meteorológica. De las bases de la IMC, en 1951, se fundó la Organización Meteorológica Mundial (WMO)la cual se convirtió en un organismo especializado de las Naciones Unidas. Los miembros de la OMM son representantes de sus respectivos países, no de sus servicios meteorológicos
} 
En Argentina, los datos de día de tormenta son suministrados por el Servicio Meteorológico Nacional (SMN), los cuales son registrados por los observadores desus estaciones. Este parámetro a nivel nacional se define como los días en los cuales el observador escucha por lo menos un trueno, sin discriminar entre descargas IC o CG (Bordon et al, 2009). El análisis de los días de tormenta fue continuado principalmente por dos grupos de investigación independientes. El primer grupo conformado por investigadores del Servicio Meteorológico Nacional (SMN), los cuales realizaron un trabajo metodológico en la preparación de mapas decenales comenzando con la década del 60 hasta el año 2000 (Hordij et al, 1996; Bordon et al, 2009) (Figura 5-7 c y Figura 5-8, respectivamente). También este tema fue investigado por el grupo de investigación de SEGBA a cargo del Ing. Juan Carlos Arcioni, el cual, en base a los datos del SMN, elaboró mapas isoceráunicos (Figura 5-7b) para poder realizar el cálculo de la probabilidad de caídas de rayos sobre tendidos de líneas eléctricas y para la elaboración de las normas de protección a estructuras (IRAM 2184-1/AEA 92305-1). En uno de los trabajos presentados en la Revista Ingeniería Eléctrica (Abril de 2006) hace una recopilación de estos trabajos con información de días de tormenta entre los años 1974 al 2000 (Arcioni, 2006).

En general los días de tormentas han sido monitoreados por observadores humanos en estaciones meteorológicas. Sin embargo, estas observaciones están sesgadas por las capacidades de los observadores y por la distribución de las estaciones meteorológicas y, en algunos casos, no existe información sobre este parámetro en lugares inhóspitos (desiertos, selva, etc) lo que obliga a realizar extrapolaciones que si bien pueden ser válidas no necesariamente se corresponde con la realidad. La existencia de la red WWLLN permite realizar un estudio más detallado y sistemático de la distribución de los días de tormenta. 


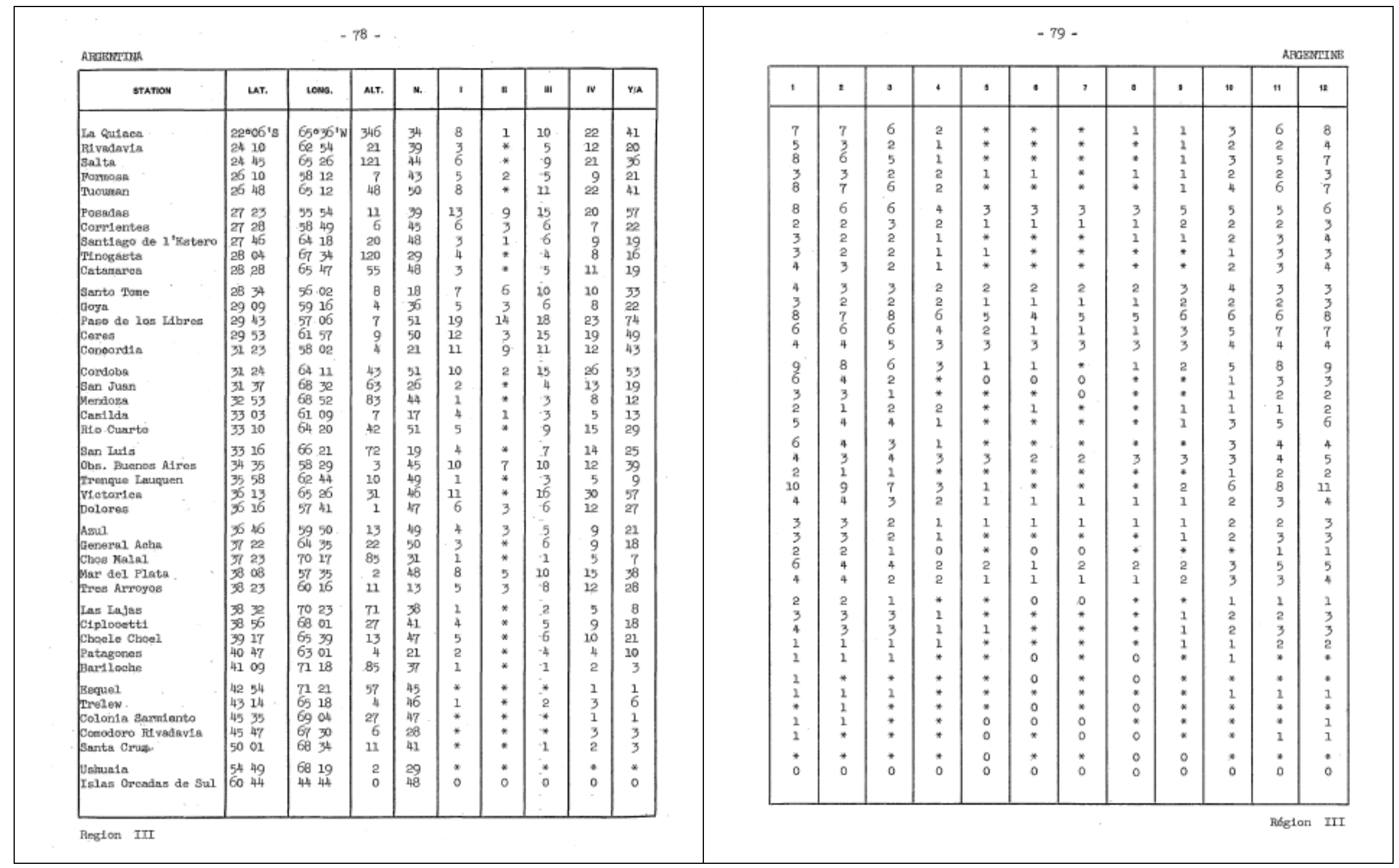

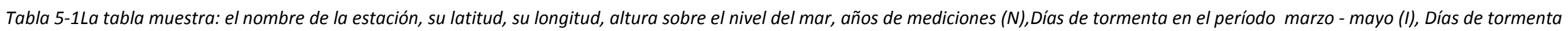
en el período Junio - agosto (II), Días de tormenta en el período Septiembre - Noviembre(III), Días de tormenta en el período diciembre - febrero (IV), luego el total de los Td por año, y los valores de días de tormenta para cada uno de los 12 meses del año. El símbolo* significa menor a medio día 


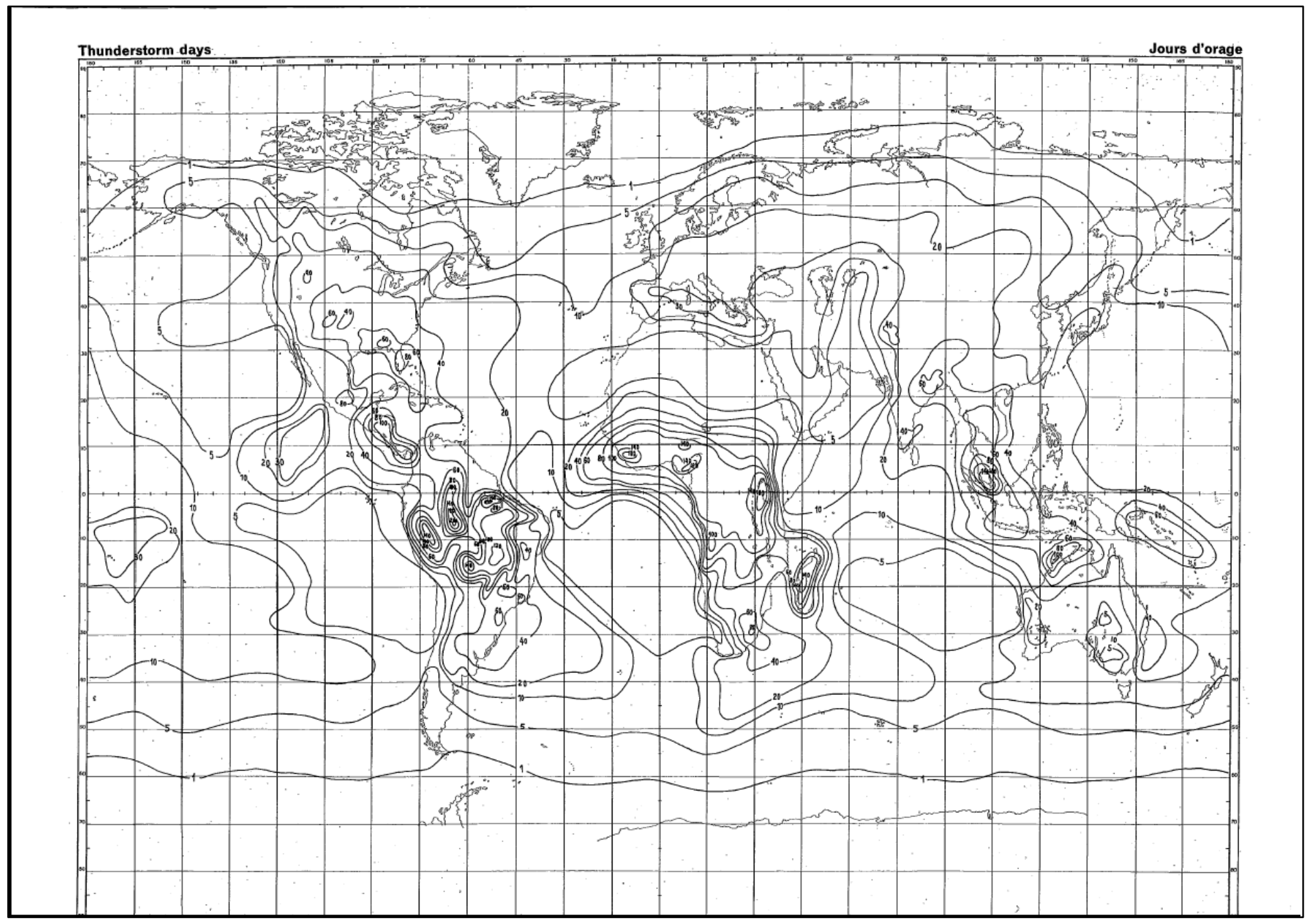

Figura 5-1Dias de tormenta Td anual mundial WORLD DISTRIBUTION OF THUNDERSTORM DAYS. PART 2: Tables of Marine Data and World Maps del año 1956. (WMO, 1956 


\section{Estudio de días de Tormentas usando datos de la Red WWLLN - Metodología}

Para la preparación de los Mapas isoceráunicos de la República Argentina utilizando los datos de la WWLLN, se definió como un día de tormenta Td a un día en el que la red detecta al menos un evento en un área determinada.

Para definir el tamaño de esta área, se realizó un análisis mediante el uso de diferentes resoluciones espaciales para determinar los valores de $\mathrm{Td}$ que mejor coincida con los días de tormenta proporcionados por el Servicio Meteorológico Nacional (SMN).

Cabe señalar que, aunque los métodos utilizados hasta el presente por el SMN para recabar información es por medio de observadores, la comparación con los datos de la red WWLLN es factible ya que en ambos casos no se discrimina entre descargas nube-nube o nube-tierra. A su vez presenta la ventaja de poder trabajar con los datos globales obtenidos por la red WWLLN, lo que permite poder utilizar una grilla igual espaciada en todo el territorio, permitiendo una mayor precisión en la interpolación de los promedios anuales.

Nuestro análisis se realizó sobre el periodo de datos 2005-2011. De todas las estaciones con datos de día de tormenta obtenidos por observadores del SMN, se eligieron solo las 15 estaciones que se encuentran dentro de aeropuertos nacionales o internacionales, más el Observatorio de Buenos Aires, para asegurar la calidad de los datos de Td reportados. A continuación se presentan el nombre y número de cada estación según el SMN: Ezeiza (87576), Salta (87047), Iguazú (87097), Córdoba (87344), Río Gallegos (87925), Observatorio de Buenos Aires (87585), Aeroparque (87582), Bariloche (87765), Posadas (87178), Paso de los Libres (87289), Tucumán (87121), Laboulaye (87534), Comodoro Rivadavia (87860), Santa Rosa (87623) y Bahía Blanca (87750).

Se calcularon los valores Td utilizando datos de la red WWLLN para distintas resoluciones espaciales. Para ellos, se calculó, sobre una celda centrada en cada una de estas 15 estaciones elegidas, y con área A dada por la Ecuación 5-1, (Figura 5-2) los días de tormenta para los diferentes años y se compararon con los datos suministrados por el SMN. Los tamaños $\Delta$ LatP y $\Delta$ LonP que se tomaron fueron $50 \mathrm{~km}\left(0.5^{\circ}\right)$, $25 \mathrm{~km}\left(0.25^{\circ}\right), 20 \mathrm{~km}\left(0.2^{\circ}\right)$ y $15 \mathrm{~km}\left(0.15^{\circ}\right)$.

$$
A=(2 \times \Delta \operatorname{Lat} P) \times(2 \times \Delta \text { Long } P)
$$

(Ecuación 5-1) 


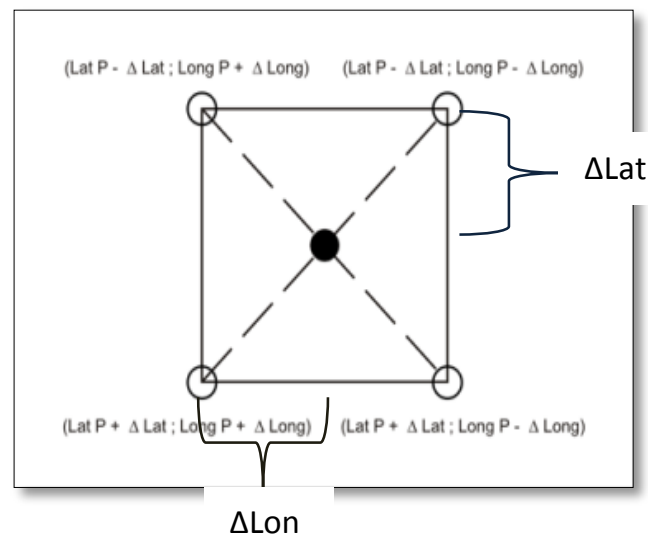

Figura 5-2 Diagrama explicativo de la sección tomada para la celda centrada en las estaciones del SMN

Ya que el estudio comparativo en todas las estaciones utilizadas dio resultados similares acerca del comportamiento relativo de los datos de la WWLLN y del SMN, es que presentamos tan solo los resultados de solo 6 de estas estaciones. Las estaciones elegidas fueron: Ezeiza como estación referente de la zona pampeana (Figura 5-3a), Salta de la zona del noroeste (Figura 5-3d), Paso de los Libres, Posadas e Iguazú (Figura 5-3 b, c, e) de la zona del litoral y Córdoba (Figura 5-3d) de la zona de las sierras centrales.

De los gráficos se observa que:

- todas las estaciones tienen igual comportamiento cualitativo, con un máximo en 2006-2007 y un mínimo en 2008;

- la grilla de $50 \mathrm{~km}$ tiene valores muy altos y estos no son representativos de los valores observados en las estaciones;

- desde el año 2008 se observa una tendencia positiva en los valores de los días de tormenta detectados por la WWLLN, esto pareciera deberse al aumento de la eficiencia de la red por la instalación de las estaciones (WWLLN) de Trelew y Rio Gallegos en el año 2009 y de Buenos Aires en el año 2011;

- la mejor resolución espacial es $25 \mathrm{~km}$, la cual coincide con la distancia estimada para que un observador puede detectar el sonido producido por las descargas eléctrica (este valor depende de varias características, entre ellos la topografía del lugar).

Por lo antedicho, luego del análisis comparativo entre las dos bases de datos en las 15 estaciones es que se realizaron los mapas isoceráunicos para el periodo 2005-2011 con una grilla de $25 \mathrm{Km}$, que corresponde a una grilla de $0.5^{\circ} \times 0.5^{\circ}$ 

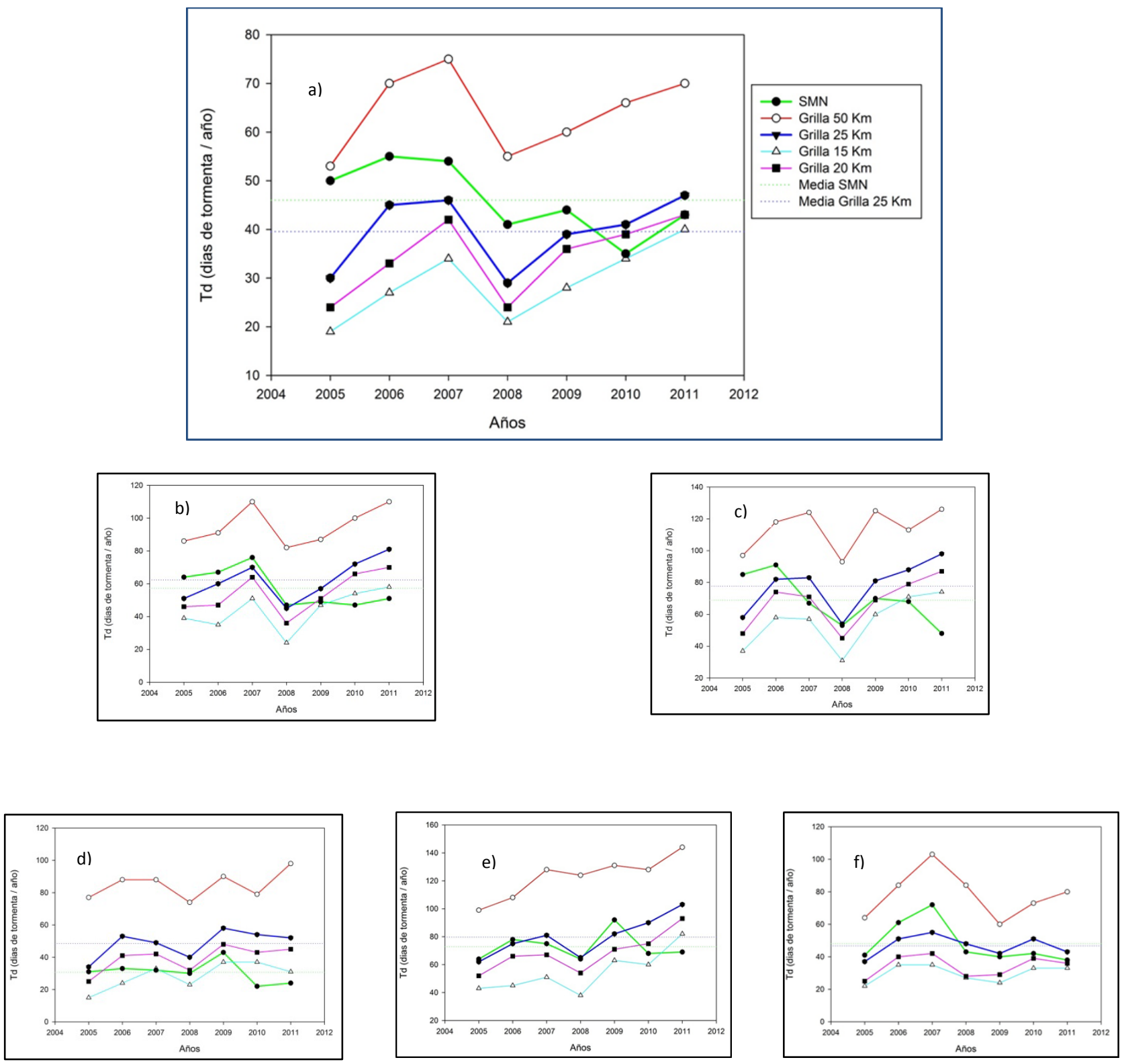

Figura 5-3. Comparación entre de valores de Td entre los datos del SMN (verde) y WWLLN para cuatro valores de grillas 50 km (línea roja), 25 km (azul), 20 km (lila) y 15 km (turquesa). Los gráficos muestran las estaciones de: a) Ezeiza, b) Paso de los Libres c) Posadas d) Salta, e) Iguazú y f) Córdoba

\section{Breve estudio estadístico}

Al hacer el estudio isoceráunico del territorio argentino con esta nueva metodología, es necesario validar los resultados obtenidos comparando con los resultados reportados por otros investigadores, y otras bases de datos.

Si bien no es posible realizar un estudio estadístico de largo plazo, ya que la red WWLLN está operando hace pocos años, en términos estadísticos, es posible realizar un estudio del rango de los valores decenales esperables siguiendo la probabilidad de Poisson en las 8 estaciones con datos del SMN cuya estadística sobre Td fue presentada por Bordon y otros (2009). 
La distribución de Poisson es un modelo estadístico para variables discretas (como el conteo de días de tormentas)que ocurren en un determinado intervalo de tiempo. Por lo tanto, aplicando el modelo probabilístico de Poisson, y del criterio de Petrov y D' Alessandro (Arcioni, 2014), los valores anuales medios esperables $\overline{T d d}$ se rigen por la siguiente ecuación:

$$
\overline{T d}=\overline{T d d} \pm k \sigma=\overline{T d d} \pm k \sqrt{T d d}
$$

\section{Ecuación 5-2}

Siendo:

- $\overline{T d}$ : Promedio anual (díasaño ${ }^{-1}$ ) extremos de días con tormentas eléctricas esperable

- $\overline{T d d}$ : Promedio anual (díasaño ${ }^{-1}$ ) de días con tormentas eléctricas tomados como valores medios anuales en cada decenio

- $\sigma=\sqrt{\overline{T d d}}$ es la desviación cuadrática media delos datos de $\overline{T d d}$

- $\quad k$ es un número natural que indica el número veces que se toma el valor de $\sigma$ para indicar la confiabilidad de la medida ( $k=1$ representa el 68,2\%; $k=2$ el 95,4\%; $k=3$ el $99.7 \%$ )

Siguiendo el estudio de Bordon et al. (2009) se presentan los datos para las estaciones estudiadas en dicho trabajo. En la Tabla 5-2 se observa los valores decenales para dichas estaciones para los periodos 1961/70, 1971/80, 1981/90, 1991/2000, y los valores promedios anuales extremos calculados por laEcuación 5-3en base a los datos de WWLLN.Las estaciones de Comodoro Rivadavia y Río Gallegos presentan muy pocos días de tormentas por lo que el estudio de Poisson podría no poder aplicarse

\begin{tabular}{|c|c|c|c|c|c|c|c|}
\hline Estación & $\begin{array}{c}1961 / 70 \\
\text { SMN }\end{array}$ & $\begin{array}{c}1971 / 80 \\
\text { SMN }\end{array}$ & $\begin{array}{c}1981 / 90 \\
\text { SMN }\end{array}$ & $\begin{array}{c}1991 / 00 \\
\text { SMN }\end{array}$ & $\mathrm{Td}+3 \sigma$ & $\mathrm{Td}-3 \sigma$ & $\begin{array}{l}\text { 2005-11 } \\
\text { (WWLLN) }\end{array}$ \\
\hline Comodoro Rivadavia & 3.7 & 3.6 & 3 & 6.2 & 10 & 0 & 4 \\
\hline Rio Gallegos & 1.9 & 1.9 & 2 & 7.7 & 8.8 & 0 & 2 \\
\hline Posadas & 64 & 79 & 77 & 90.1 & 104 & 51 & 89 \\
\hline Paso de los Libres & 37 & 50 & 65 & 65.5 & 76 & 32 & 70 \\
\hline Tucumán & 38.5 & 35.9 & 46.3 & 42.7 & 60 & 22 & 49 \\
\hline Salta & 33 & 46.2 & 54.3 & 50.2 & 66 & 26 & 58 \\
\hline Córdoba Aeropuerto & 45.5 & 50.3 & 55.9 & 61.9 & 75 & 31 & 52 \\
\hline
\end{tabular}

Tabla 5-3 Valores decenales para dichas estaciones para los periodos 1961/70, 1971/80, 1981/90, 1991/2000, y los valores promedios anuales extremos calculados por la Ecuación 5-2 y los datos promedios de la WWLLN para el periodo 2005-2011 
Para hacer el estudio estadístico, tomamos los valores de $\overline{T d d}$ del trabajo de Bordon et al ,2009) En la Figura 5-4 se graficaron los valores $\overline{T d d}$ escalonados para cada periodo, y aplicando la Ecuación 5-4, se calcularon los $\overline{T d}$ esperables (máximo esperable en línea continua roja y mínimo esperable en continua verde). También, y a modo de validación de datos, se graficó el valor aportado por las tablas de la WMO (Figura 5-1) como línea azul. Luego se graficaron los valores anuales de Td con los datos calculados de la WWLLN (puntos azules) y los aportados por el SMN (puntos negros).

Posadas

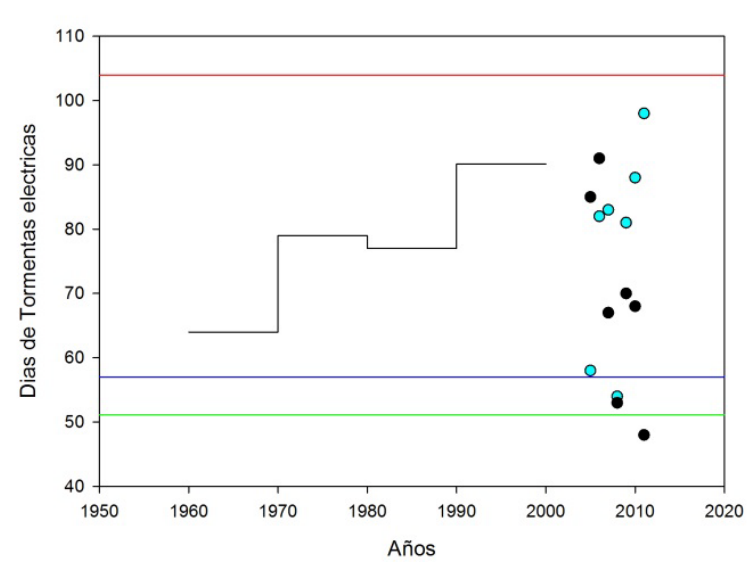

Tucuman

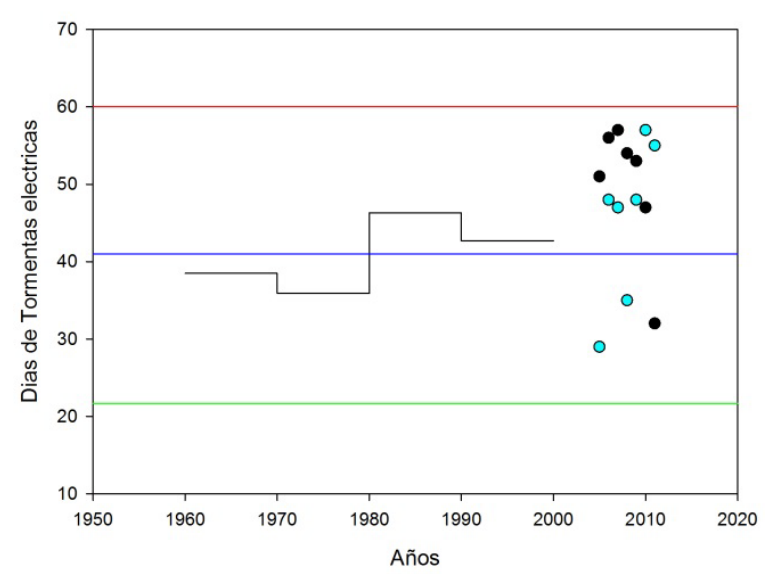

Paso de los Libres

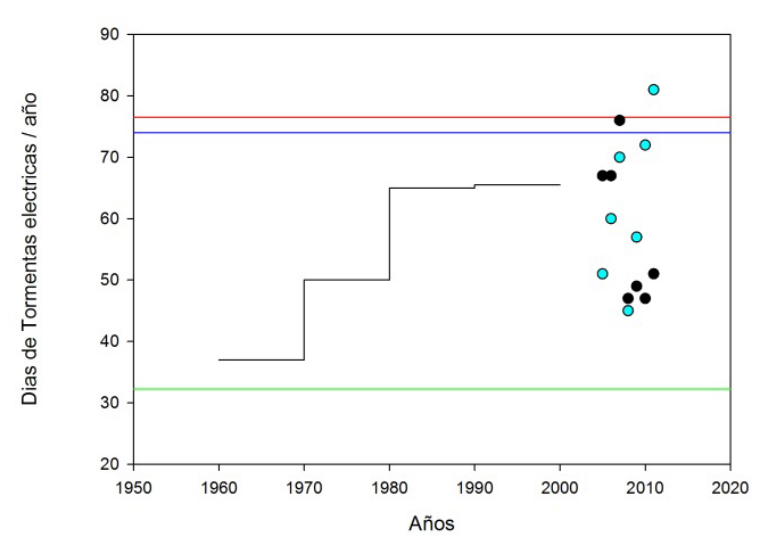

Salta

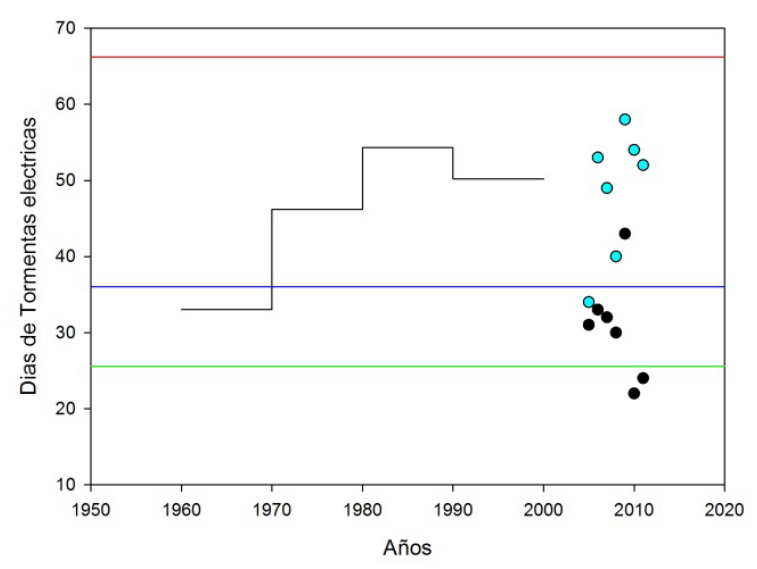


Cordoba

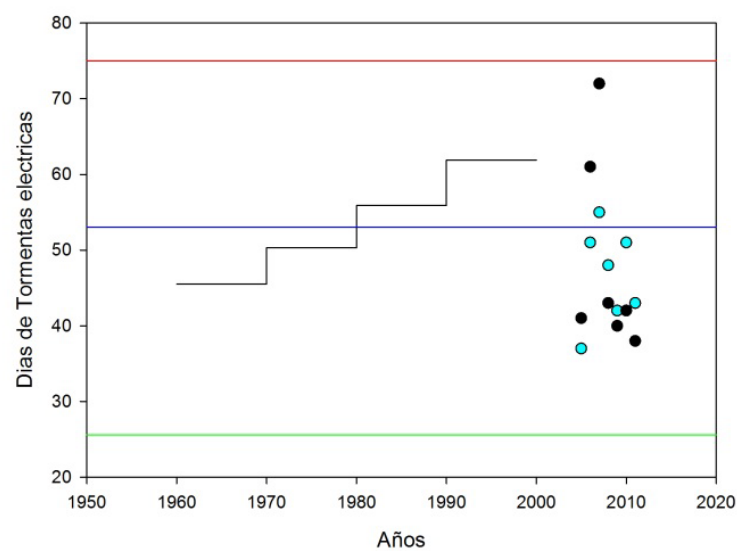

Figura 5-4T esperables (máximo esperable en línea continua roja y mínimo esperable en continua verde). valor aportado por las tablas de la WMO (Figura 5-1) como línea azul. valores anuales de Td con los datos calculados de la WWLLN (puntos azules) y los aportados por el SMN (puntos negros)

Se observa que en general los promedios decanales aumentan. Si se los compara con los datos de la WMO las estaciones de Córdoba, Salta y Tucumán, los valores de principio de siglo XX se encuentran dentro de los valores medios del periodo, en el caso de Posadas se observa un aumento marcado respecto a los valores de la WMO, pero en el caso de Pasos de los Libres llama mucho la atención que el promedio para principio de siglo XX es marcadamente mayor que los valores decanales 1960-2000

Sobre los datos del periodo 2005-2011, para ambas bases de datos, se observa que en algunos casos los valores reportados por el SMN poseen valores por debajo del mínimo esperado (caso de Posadas y Salta) y en el caso de Paso de los Libres se observa un valor por encima del máximo esperable reportado por la WWLLN.

En este punto volvemos a repetir que estos son estudios preliminares, pero sirven para poder aseverar que los datos de la WWLLN son factibles para poder analizar los días de tormenta en el territorio ya que los valores calculados en el periodo 2005-2011 están dentro del rango de +/- 3б. Estos estudios se seguirán realizando para poder en algún futuro analizar las variaciones interanuales y con esos datos poder inferir algún cambio significativo en la actividad eléctrica en el territorio nacional. 


\section{Mapas}

\section{i. Mapa Isoceráunico}

Siguiendo la metodología presentada se realizó el mapa isoceráunico de la República Argentina que se observa en lasFigura 5-5 y Figura 5-6. Este mapa ha sido incorporado a la IRAM 2184-11 /AEA 9230511Protección contra los rayos. Parte 11 - Guía para la elección de los sistemas de protección contra los rayos (SPCR) para usar en la República Argentina..

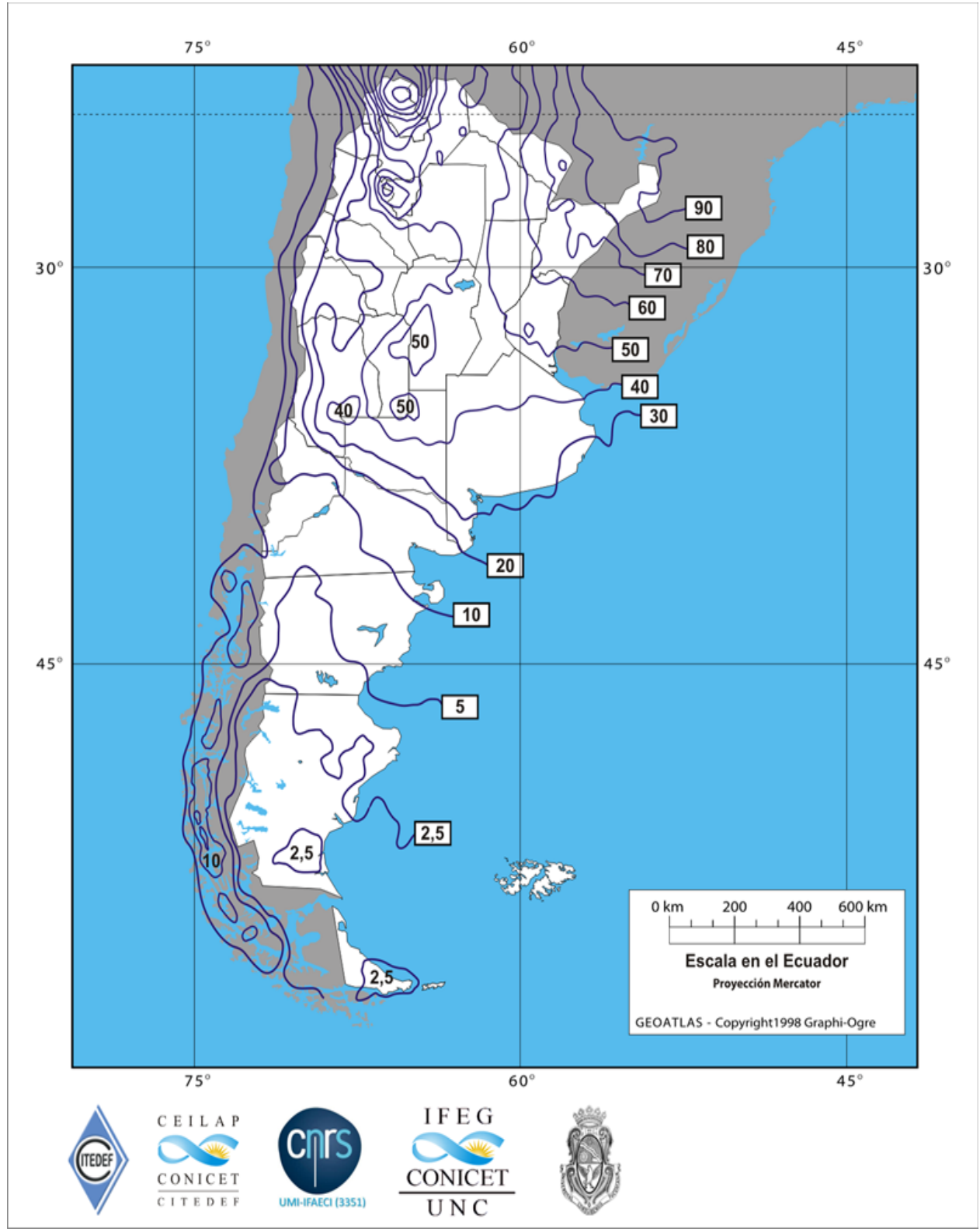

Figura 5-5Mapa Isoceráunico para el periodo 2005-2011 con datos de la WWLLN confeccionado con una grilla equiespacial de $0.5^{\circ}$. Se tomaron valores a intervalo de 10 días, salvo en la zona patagónica que se demarcaron las líneas de 5 y 2.5 días de tormentas por año 
En el trazado de las isogramas se incluyó el territorio Chileno a pesar que en el estudio no se incluyó ningún dato de Td de Chile. Sin embargo, esto permitió observar que la zona sur de Chile presentaba mayor número de Td en comparación con igual latitud en el territorio Argentino. Esta observación, nos llevó a estudiar esta zona con mayor profundidad, ya que hasta el momento no se había reportado ninguna AEA significativa en esta parte del continente. Dicho estudio se presenta en el Capítulo 7.

El mapa isoceráunico confeccionado permite una fácil identificación de las zonas con mayor actividad eléctrica atmosférica en el territorio e identificar distintas zonas interesantes a nivel ceráunico:

- Zona del Litoral: Se caracteriza por el aumento de la actividad eléctrica en dirección noreste, las líneas tienden a ser paralelas y con valores máximos mayores a 90 días de tormenta por año.

- Zona del Noroeste: Es muy interesante el contorno de las líneas en donde se muestra un "corredor" de actividad eléctrica. Se presenta una ampliación de este mapa en esta zona en Figura 5-6. Esta zona presenta valores mayores a 110 días/año, con una variación espacial muy fuerte, presentando grandes diferencia entre los valores de zonas cercanas. En esta zona de estudio es posible observar la ventaja que presenta la red por sobre los observadores, ya que poseen la suficiente precisión para poder captar las variaciones de actividad eléctrica en lugares remotos y con tasa de AEA muy variables.

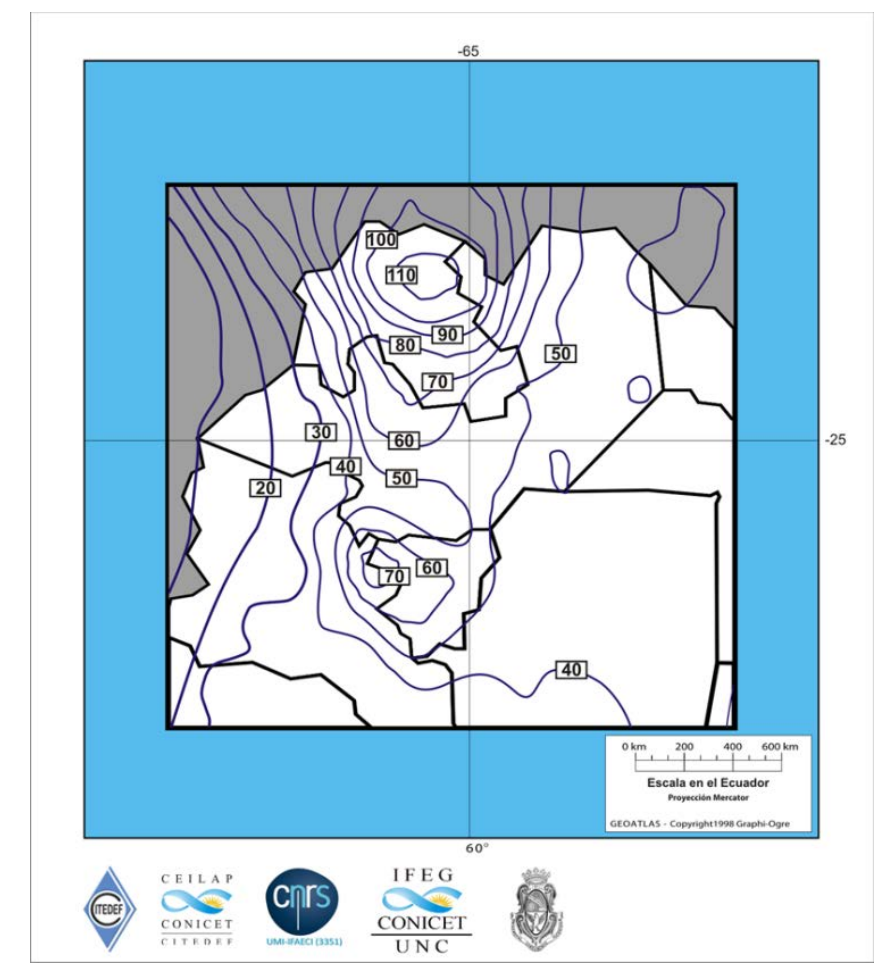

Figura 5-6Detalle del Mapa Isoceráunico periodo 2005-2011 para la zona del noroeste 
- Zona Central: Sierras de Córdoba y San Luis, con valores mayores a los 60 días es también una zona con valores altos en la AEA.

En la Figura 5-7 se presentan tres mapas isoceráunicos realizados por diferentes grupos de investigación. La Figura 5a es la confeccionada en base de datos de la WWLLN y presentada en este trabajo de Tesis, la 5b es el mapa confeccionado por el Ing. Arcioni (Arcioni, 2006) para el período decenal 1981/90, y la Figura 5c el mapa presentado por Bordon y otros (2009) para el período decenal 1991/2000, ambos últimos construidos según los registros climatológicos del Servicio Meteorológico Nacional.

Realizando una comparación visual de los tres mapas, aunque los períodos no son los mismos, analizaremos las tres zonas con mayor actividad detectada.

- Zona del Litoral: Se observan en los tres mapas las mismas características sobre la distribución de las isolíneas. Aunque la WWLLN detecta valores mayores a 90 días de tormenta por año, en comparación con Bordon (85 días) y Arcioni (70 días), es importante señalar que la variación espacial responde el mismo patrón y que los valores observados son uno de los valores más altos relativos a los valores observados en los tres mapas.

- Zona del Noroeste: Esta es una de las zonas en donde se observa una mayor diferencia en la estructura de las isolíneas. En el caso el trabajo del Ing. Arcioni, aunque el encuentra valores menores de Td (60 días), se puede ver que la variación espacial de las mismas es muy similar a la presentada en este trabajo. En cambio en el caso de los mapas confeccionados por Bordon muestra un aumento de la actividad ceráunica pero no logra detectar las cambios de los valore de Td para zonas muy cercanas

- Zona Central: Sierras de Córdoba y San Luis, los tres mapas muestran similitudes tanto en los valores como en la distribución de las isolíneas con un máximo en las zonas de altas cumbres ubicada entre las provincias de Córdoba y San Luis.

La Figura 5-8muestra la distribución espacial de líneas ceráunicas presentados por Bordon et. al. (2009) para el período decenal 1961/1970 (6a), 1971/1980 (6b), 1981/1990 (6c) y 1991/2000, construidos según los registros climatológicos del Servicio Meteorológico Nacional. En su trabajo los autores concluyeron que existe un aumento en los días de tormentas, aunque resaltan que en la comparativa de las cuatro décadas, los resultados espaciales son similares

Estos resultados concuerdan con el hecho de que la WWLLN reporte en general mayor número de días de tormenta que mapas confeccionados en periodos anteriores. 


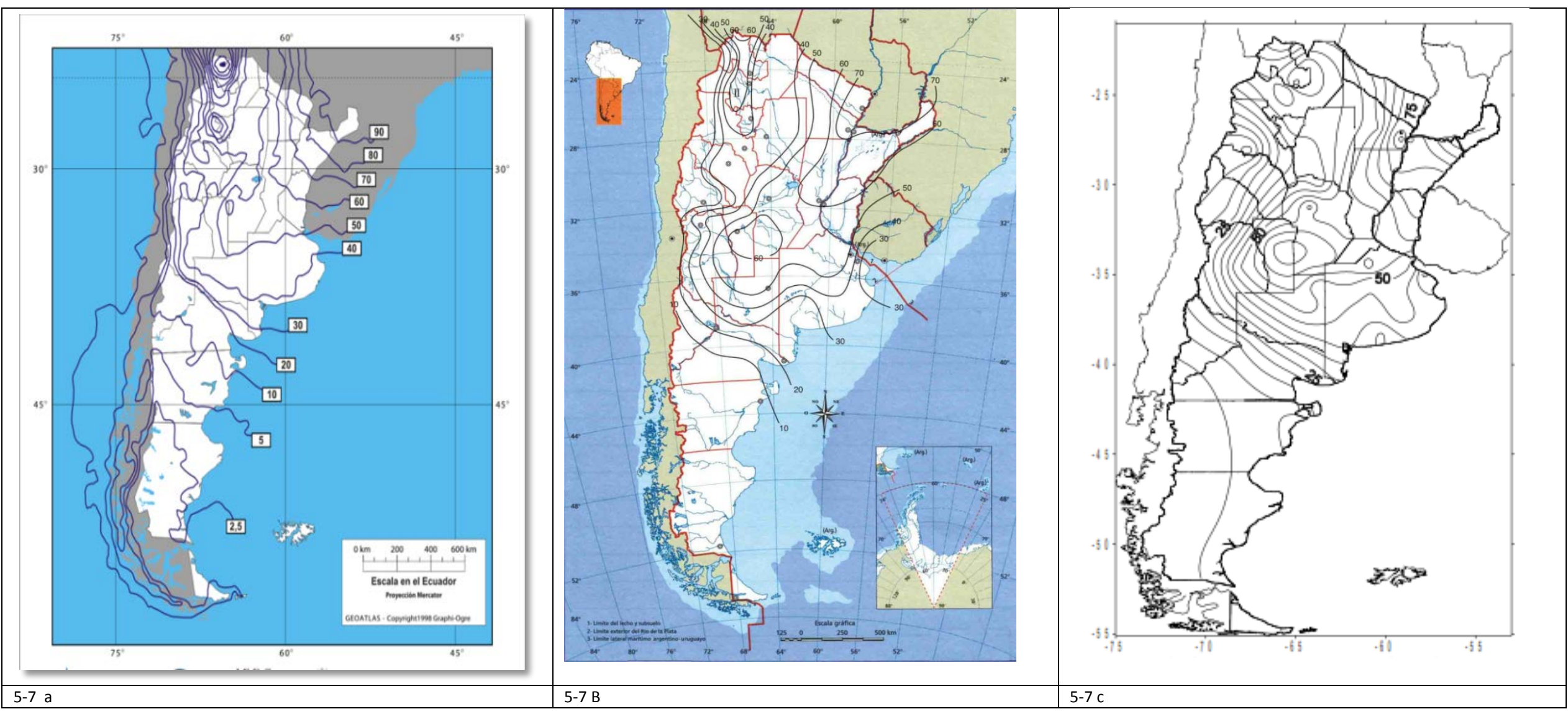

Figura 5-7Mapas isoceráunicos realizados por los diferentes grupos de investigación) en base de datos de la WWLLN y presentada en este trabajo de Tesis, b) mapa confeccionado por el In. Arcioni (Arcioni, 2006) para el período decenal 1981/90, y c) mapa confeccionado por Bordon et al( 2009) para el período decenal 1991/2000. Estos últimos construidos según los registros climatológicos del Servicio Meteorológico Nacional.

\section{Figura 5}




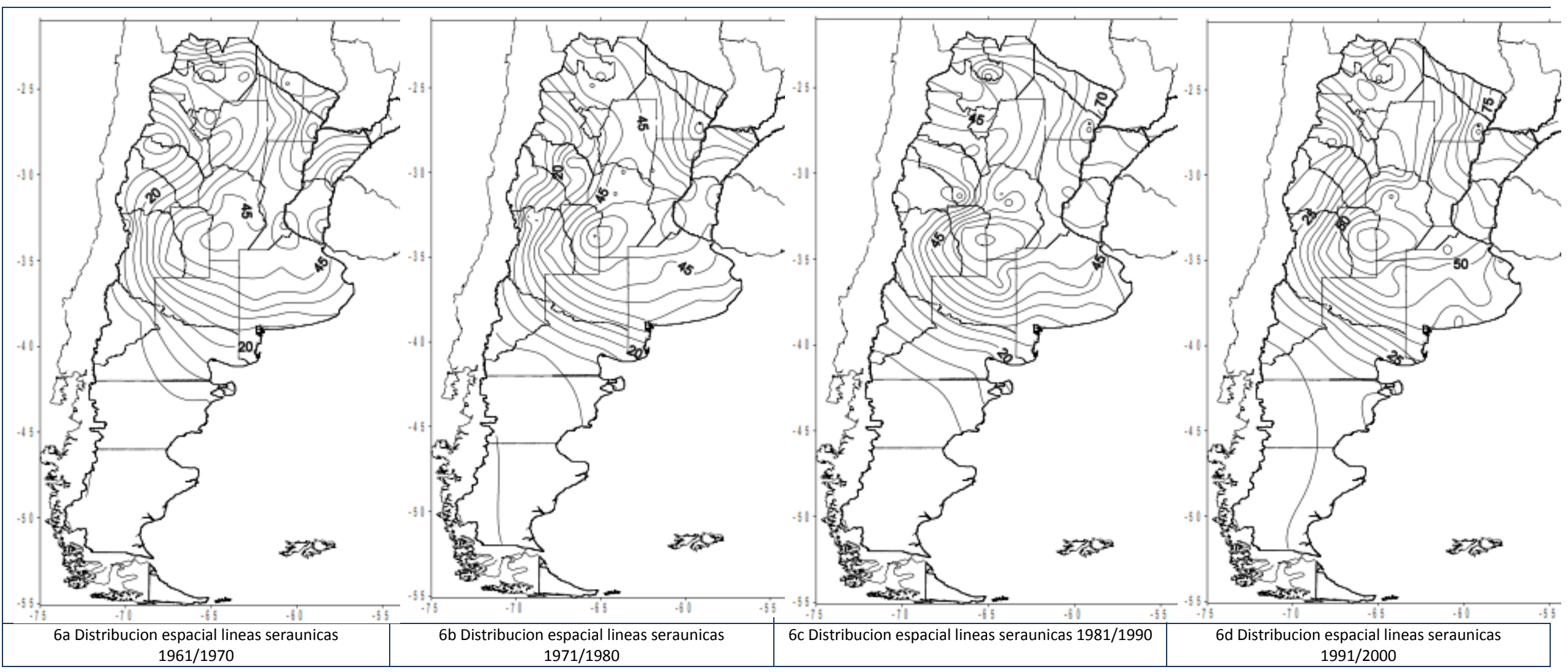

Figura 5-8Distribución espacial de líneas ceráunicas presentados por Bordon (Bordon et al, 2009) para el período decenal 1961/1970 (6 a), 1971/1980 (6b), 1981/1990 (6c) y 1991/2000, construidos según los registros climatológicos del Servicio Meteorológico Nacional. 


\section{Mapa por zonas}

Con el fin de tener un panorama más claro de la distribución espacial de la actividad de rayos, el territorio argentino se dividió en cuatro regiones según el número de días de ocurrencia de tormentas eléctricas. La Figura 5-9 muestra un mapa con las regiones con días de tormentas eléctricas según: 0 $<\mathrm{Td}<5$ (azul), $5<\mathrm{Td}<40$ (verde), $40<\mathrm{Td}<60$ (amarillo) y $\mathrm{Td}>60$ (rojo).

Si bien esta división es arbitraria, se tomó en función de los valores mundiales observado en el trabajo de la WMO (WMO, 1956) (Figura 5-1) en donde un valor de Td mayor de 60 días indican las zonas de mayor actividad ceráunica a nivel mundial, los valores deTd entre 40 y 60 días son representativos de las zonas intertropicales medias, Td entre 5 y 40 días se corresponden con valores de latitudes altas, y Td menores de 5 días representan zonas con muy baja actividad ceráunica.

Este mapa fue confeccionado con el propósito de divulgación, ya que muchas veces es importante conocer las regiones que presentan un alta AEA, al menos a nivel cualitativo, para poder promover conductas de educación y protección relativas a la AEA. 


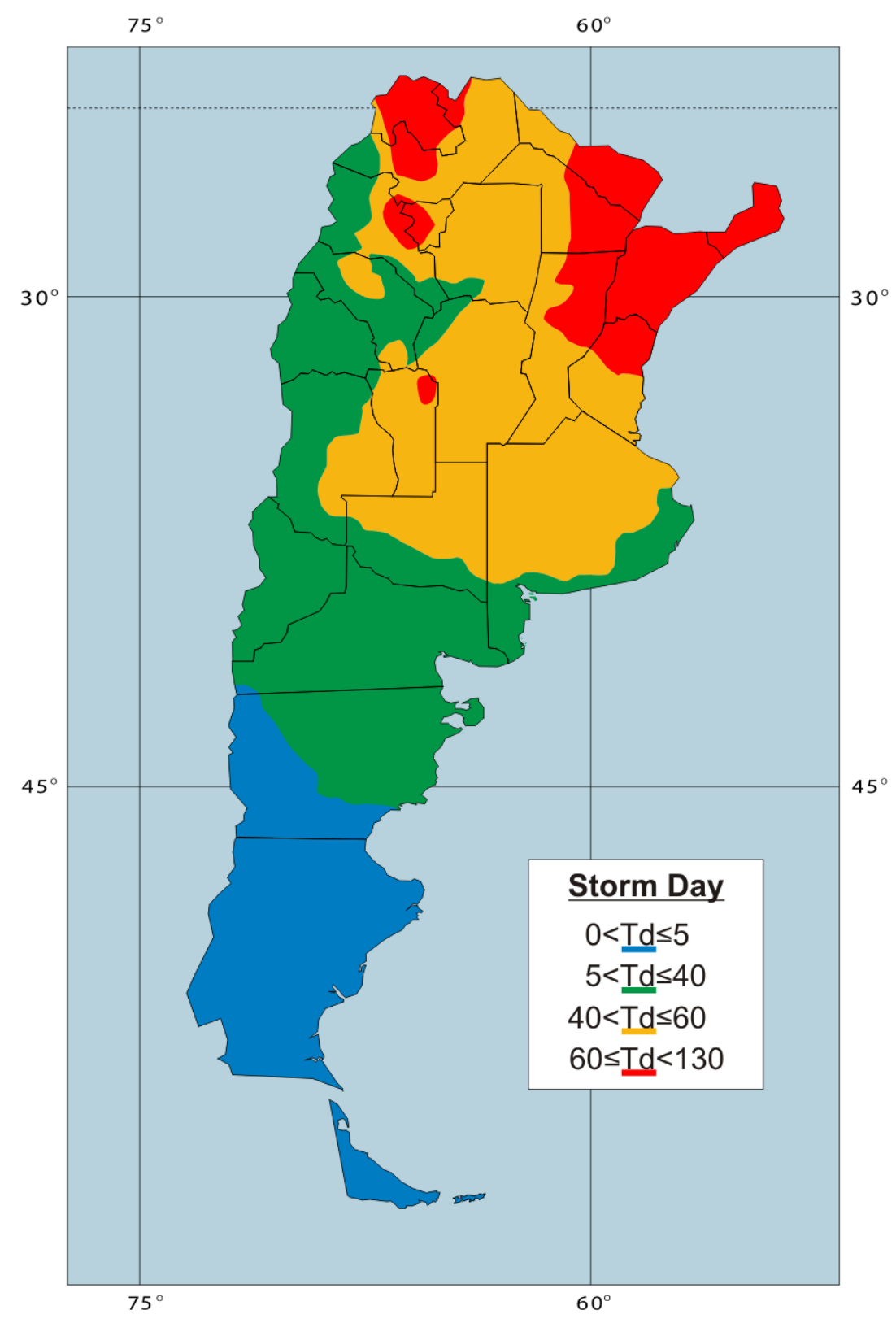

Figura 5-10Mapa zonal de regiones de Argentina con igual valor deTd. Los valores representados son los siguientes, :0 $<$ Td $<5$ (azul), $5<T d<40$ (verde), $40<T d<60$ (amarillo) y $T d>60$ (rojo). 


\section{Capítulo 6 Actividad Eléctrica Atmosférica en el Sur de Sudamérica}

En el capítulo anterior empezamos a conocer las regiones características de la República Argentina con relación a su actividad ceráunica, en el cual vimos que la Argentina presenta zonas de muy alta actividad, lo que la hace una zona muy atractiva de estudiar.

Llamaremos Sur de Sudamérica a la región comprendida entre $\left[20^{\circ}\right.$ y $\left.60^{\circ}\right] \mathrm{S}$ y entre $\left[50^{\circ}\right.$ y $80^{\circ} \mathrm{J}$ W y en este capítulo focalizaremos la actividad en las zonas comprendida al norte de $40^{\circ}$ $S$.

Numerosos trabajos han estudiado los sistemas precipitables en el Sur de Sudamérica los cuales demuestran que los sistemas de nubes convectivas producen la mayor parte de la precipitación y el mal tiempo en esta región, siendo algunos de características muy extremas (Rasmussen y Houze, 2011; Durkee et al., 2009; Romatschke y Houze, 2013, entre otros). En este capítulo desarrollaremos las características de la AEA en la Argentina y los Países limítrofes. Presentaremos su ciclo anual y diario, así como también sus variaciones interanuales. Mostraremos su relación con los sistemas convectivos precipitables y su importancia como componente principal en el estudio de la climatología sobre el Sur de Sudamérica.

Como se detalló en el Capítulo 2, una de las ventajas que presenta la WWLLN es tener una cobertura de la AEA en toda la región, aun para latitudes altas. Gracias a esta característica, es que se pudo evaluar la AEA, no solo en las zonas en donde se tenía conocimiento de que dicha AEA era significativa, sino que evaluamos en detalle otras zonas que, en general, no presentan una AEA considerable, aunque su actividad podía ser una interesante base de nuevos conocimientos.

\section{Caracterización del Clima Medio en el Sur de América del Sur}

Como pudimos ver en el Capítulo 5, los procesos más intensos de AEA en el territorio nacional se dan a al norte del Río Colorado con valores mayores a 20 días de tormentas, por lo cual vamos a centrar nuestra caracterización climatológica en la región al norte de los $-40^{\circ} \mathrm{S}$

Para poder entender los procesos que generan los patrones de AEA en la región, vamos a señalar algunas de las características del clima medio en el Sur de Sudamérica (parte de esta caracterización fue extraída de Barros et al., 2006).

La troposfera media y alta se caracteriza por un patrón de vientos del oeste (Oestes), y en particular durante el verano en la alta troposfera, la circulación es dominada por un centro de alta presión sobre 
Bolivia (Alta Boliviana) que afecta toda la región subtropical. La región de los Oestes intensos avanza hacia el norte en invierno y retrocede hacia el sur en verano.

Al norte de $40^{\circ} \mathrm{S}$, la circulación próxima a la superficie es dominada por los centros de altas presiones casi estacionarios del Pacífico y del Atlántico Sur. La mayor parte del año hay un centro de baja presión en el noroeste de Argentina y sur de Bolivia, originado por la interacción entre los Andes, los vientos del oeste en altos niveles y el calentamiento de la superficie. El campo medio de viento al este de los Andes aporta humedad desde la región tropical del continente debido a la circulación del noroeste que persiste durante la mayor parte del año, y desde el Océano por acción de los vientos del noreste durante el invierno. La circulación atmosférica en capa bajas se caracteriza por la continuación de los vientos que penetran a la región ecuatorial desde el Atlántico hasta los Andes, siendo el flujo bloqueado por la pendiente orográfica y desviado hacia el Sur, transportando vapor de agua desde el Amazonas hacia la mayor parte de la cuenca (Barros et al., 2006). La Figura 6-1 extraída de Grimm et al.,(2007) muestra los componentes principales descriptos anteriormente y el campo de vientos y precipitaciones.

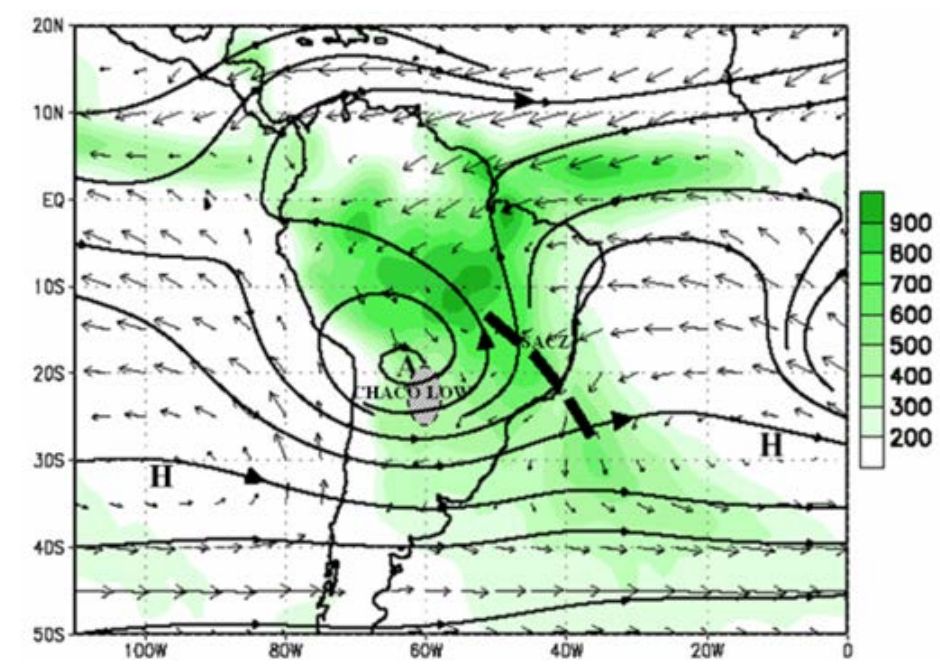

Figura 6-1Principales características del sistema monzónico. Media de diciembre a febrero (1979-1995) 925 hPa vector viento y $200 \mathrm{hPa}$ líneas de corrientes del archivo reanálisis NCEP / NCAR, Precipitación ( $\mathrm{mm}$, sombreado). La posición del Alto de Bolivia (A) y centros de alta presión de superficie $(H)$ el Atlántico subtropical y el Pacífico. El eje aproximado de la Zona de Convergencia del Atlántico Sur es indicado por la línea discontinua pesada (extraída de Grimm et al., 2007).

Al este de los Andes, hay solamente dos fuentes posibles de vapor de agua para el sudeste de América del Sur: el Océano Atlántico y la selva Amazónica, lo cual tiene un efecto importante sobre el ciclo anual de la precipitación. En el invierno, cuando el centro de alta presión del Atlántico Sur penetra sobre el continente, hay un transporte de humedad hacia el sur más intenso en torno de $60^{\circ} \mathrm{O}$, que se origina en el flujo del este proveniente del Océano Atlántico y está asociado con una región de máxima precipitación en la parte sur y este de la zona de estudio. 
Durante el verano, la Zona de Convergencia del Atlántico Sur (ZCAS) aparece como una extensión de la convección tropical del centro del Brasil hacia el Océano Atlántico, en la dirección nordeste-sudeste. El flujo de humedad que proviene de la selva tropical, se dirige hacia el sudeste en el subtrópico y converge en la ZCAS con el flujo marítimo de humedad conducido por los vientos alrededor de la Alta subtropical del Atlántico Sur. La convergencia de humedad favorece la abundante precipitación observada en esta región. Desde los subtrópicos, el flujo medio de humedad se dirige hacia el sudoeste, produciendo significativa precipitación también al sudoeste de la ZCAS, en la Argentina subtropical y en Paraguay. Por lo tanto, en el oeste de la región subtropical también predomina un ciclo anual pronunciado con un mínimo en el invierno y un máximo en el verano, cuando tanto el calentamiento de la superficie como la advección de vapor de agua del norte favorecen la convección.

Al norte de $20^{\circ} \mathrm{S}$, se presenta un típico régimen monsónico, con una estación lluviosa que se inicia en la primavera y termina en el otoño (principalmente abril) (Gan et al., 2004). El mismo régimen prevalece también al oeste de la región subtropical (al sur de $20^{\circ} \mathrm{S}$ ), en el oeste de Argentina y en la región del Chaco. En el este de la región subtropical, el vapor de agua está disponible todo el año, pero las condiciones baroclínicas ${ }^{5}$ más intensas ocurren en el invierno. Esta intensificación se debe al mayor gradiente latitudinal de temperatura en los subtrópicos favorecido por la mayor penetración de los frentes fríos en latitudes mayores. Por lo tanto, la actividad sinóptica ${ }^{6}$ es responsable por la mayor parte de la precipitación en esta estación del sudeste de América del Sur (Vera et al., 2002). Durante la estación estival, de octubre a abril, los complejos convectivos son frecuentes y responsables de gran parte de la precipitación total, especialmente en las estaciones de transición (Velasco y Fritsch, 1987; Laing y Fritsch, 2000). Además del invierno, también en las estaciones de transición hay frecuentes ciclogénesis (proceso de formación e intensificación de los centros de baja presión) en el este de la región subtropical (Gan y Rao, 1991; Rao et al., 1996). Entonces, el sur del Brasil, donde se encuentra parte de la cuenca del Plata (las cuencas del Uruguay e Iguazú), es una región de transición entre dos regímenes, el del monzón de verano y el de máximos de invierno. Este régimen de transición también se observa en el nordeste de Argentina y sudeste de Paraguay y está fuertemente influenciado por los sistemas convectivos de mesoescala (SCM) (Velasco y Fritsch, 1987; Silva Días, 1987).

Satyamurti et al., (1990), Gan y Rao (1991) y Vera y Vigliarolo (2000) hicieron estudios climatológicos sobre la ocurrencia de ciclogénesis en la América del Sur y mostraron que la costa sur de Brasil/Uruguay presenta una alta frecuencia de formación de ciclones, sobretodo en el invierno y primavera. Sin embargo, un número significativo de ciclones también se forma más al norte, en el Chaco, Paraguay y al

\footnotetext{
${ }^{5}$ Condición Baroclínica: La atmosfera es barolínica cuando existe un desfase en la vertical en loscampos de viento, presión, temperatura u otros. (Lo opuesto es la condición barotrópica en que todo está en fase).

${ }^{66}$ Actividad Sinóptica: Esta actividad se refiere a los fenómenos en la troposfera terrestre, los cuales tienen duraciones de 1-7 días y escalas espaciales de $1000-5000$ km
} 
oeste de Río Grande do Sul (cerca del 40\% del total de eventos, de acuerdo con Vera et al., 2002). El gradiente de temperatura de la superficie del mar (TSM) a lo largo de la costa sur de Brasil en el invierno puede influir en la intensificación y trayectoria de los ciclones (Saravia y Silva Días, 1996; Vera et al., 2001). Líneas de inestabilidad pueden también causar significativa precipitación en el sur del Brasil, Uruguay y noreste de Argentina (Silva Días, 1987).

Todas las características presentadas muestran que el clima medio en Sudamérica está gobernado por diferentes factores y que operan a diferentes escalas, interactuado entre sí.

\section{Caracterización de la AEA Media en el Sur de Sudamérica}

Habiendo ya evaluado la actividad ceráunica del territorio nacional (Capítulo 5) en este punto comenzaremos a evaluar la densidad de descargas (flashes $\mathrm{km}^{-2}$ año-1) en esta región. Para ello, se utilizaron las bases de datos de los sistemas de detección de descargas independientes LIS-OTD y WWLLN y se trabajó con una grilla de $0,5^{\circ} \times 0,5^{\circ}$ (Figura 6-2), la cual ya había sido presentada en el Capítulo 2 (Figura 2-8).
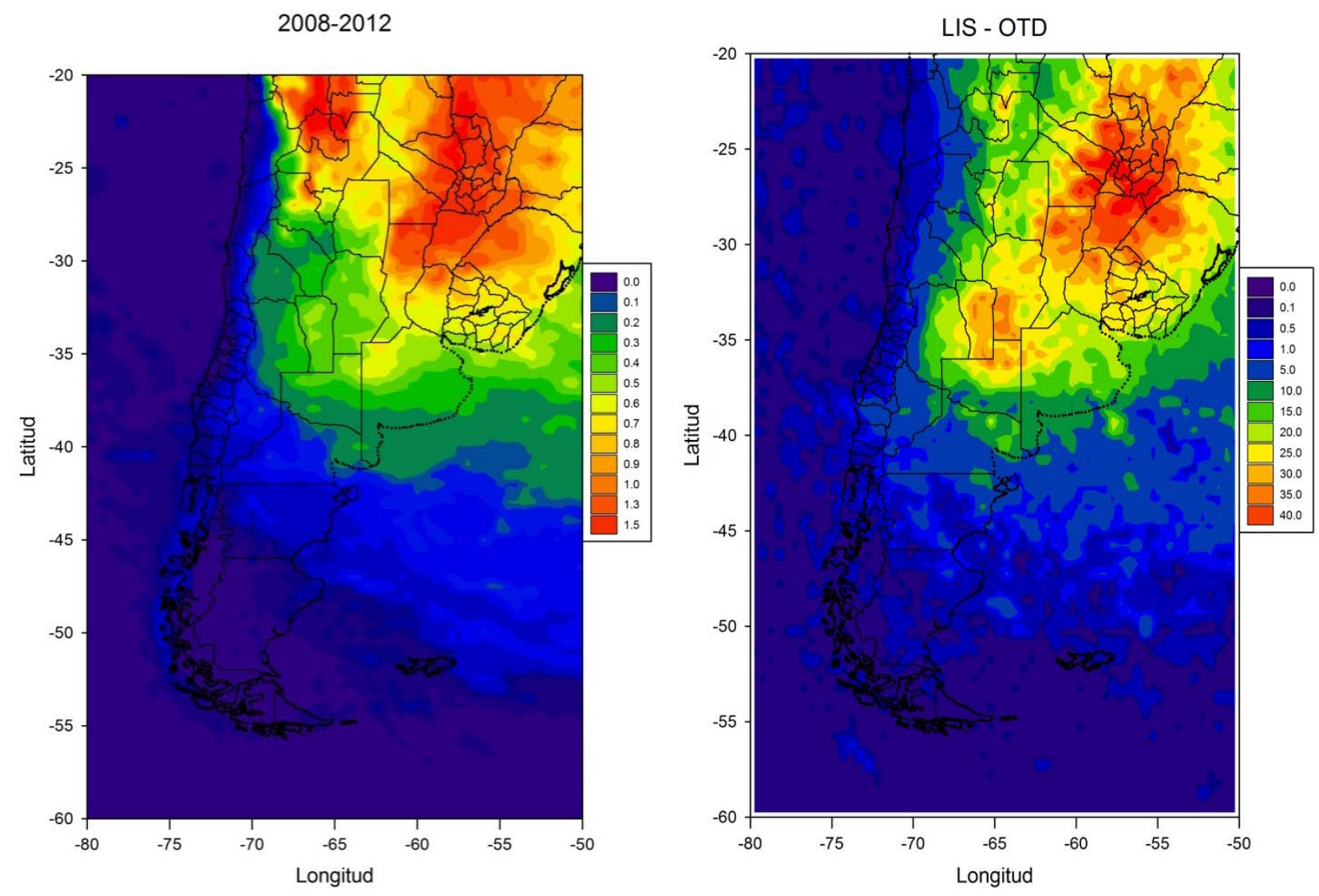

Figura 6-2 Mapas con densidad de descargas (flashes $\mathrm{km}^{-2}$ año ${ }^{-1}$ ) en esta región. Panel izquierdo datos de la WWLLN para el periodo 2008-2012 y panel derecho LIS-OTD y se trabajó con una grilla de 0,5 $\times 0,5$

El patrón de AEA medio anual mostrado está en concordancia con los procesos meteorológicos asociados especialmente a la precipitación. Esta característica fue mostrada por Liu et al. (2010) en su 
estudio sobre la distribución geográfica de las precipitaciones de nubes de tormentas, nubes electrificadas, y sin electrificar en el mundo. Estos autores encontraron que las precipitaciones generadas por nubes no electrificadas dominan la precipitación total sobre los océanos y el Amazonas en América del Sur, mientras que las nubes de tormentas aportan una gran cantidad de lluvia sobre los continentes, incluyendo algunas regiones de fuertes lluvias sobre el norte de Argentina. En particular, mostraron que casi todas las precipitaciones en el norte de Argentina y de la cuenca de La Plata son generadas por tormentas eléctricas. Por lo tanto el rol del sistema monsónico de Sudamérica (SAMS, South American Monsson System), la zona de convergencia del Atlántico Sur (ZCAS), el fenómeno de El Niño, el desplazamiento anual de la zona de convergencia intertropical (ITCZ), las fuentes de calor sobre el continente, principalmente en las zonas tropicales, las irrupciones de aire frío desde altas latitudes, la interacción con la cordillera de los Andes y el Altiplano, etc., son algunos de los elementos fundamentales en la distribución de la variabilidad de la precipitación sobre Sudamérica.

\section{Ciclo diario de la AEA}

El ciclo diario de la precipitación se ha investigado en diferentes regiones de América del Sur, debido a que este patrón y los patrones diarios de otros fenómenos meteorológicos tales como granizo, viento y AEA proporcionan información significativa sobre la actividad convectiva en la región.

Sin embargo, existen pocos estudios a nivel regional que hayan examinaron los patrones de la AEA en América del Sur. Por ejemplo, Williams et al. (2002) estudiaron el efecto de la contaminación atmosférica en la AEA en la cuenca del Amazonas; Naccarato et al. (2003) analizaron los efectos de los aerosoles sobre la densidad y la polaridad de los rayos de nube a tierra en áreas urbanas del sudeste de Brasil. Blakeslee et al. (2012), usando datos de OTD-LIS, estudiaron el ciclo anual diario para todo el mundo incluyendo las regiones continentales y oceánicas (Capítulo 3 de la presente tesis).

La variabilidad diurna de tormentas eléctricas se ha relacionado directamente con los mecanismos de forzamiento que provoca la creación de las mismas y a los patrones de las precipitaciones asociadas (Sterling, 1985). Como resultado de la desestabilización de la capa límite causada por la insolación de la tierra durante el día, la hora de máxima frecuencia de precipitación se observa en las horas de la tarde (Wallace, 1975; Gray y Jacobson, 1977; Oki y Musiake, 1994; Dai et al., 1999; Dai, 2001; Nesbitt y Zipser, 2003). Sin embargo, hay numerosos fenómenos sinópticos y meteorológicos de mesoescala, como son los Sistemas Convectivos de Mesoescala (SCM), por ejemplo, que pueden alterar o modificar el ciclo diario típico de una región determinada como ha sido señalado por Blakeslee et al. (2012).

Para estudiar el ciclo diario de la AEA se utilizaron los datos de LIS-OTD de la Climatología de Baja Resolución diurna (LRDC) basado en los datos de descargas detectados por LIS y OTD durante el período 
comprendido entre 1995 y 2012. Para ambas bases de datos, el número total de flashes detectados y el total de horas de observación se acumulan en $1 \mathrm{~h}$ (hora solar local) y en una grilla de $2,5^{\circ} \times 2,5^{\circ}$.

Con el fin de caracterizar y cuantificar el ciclo diario local de la AEA, se realizó un análisis armónico en cada cuadrícula de $2,5^{\circ} \times 2,5^{\circ}$. Para ello, el ciclo diario fue ajustado con una función sinusoidal con un período de 24 horas de la siguiente manera, (Ecuación 6-1)

$$
F R_{D C}(t)=a+b \sin \left(\frac{2 \pi}{24} t+c\right) \quad \text { Ecuación 6-1 }
$$

donde $\mathrm{FR}_{\mathrm{DC}}$ es la densidad de descargas medias por año (flashes $\mathrm{km}^{-2}$ año-1), $a$ es el valor medio de la actividad eléctrica en el período de 24 horas (flashes $\mathrm{km}^{-2}$ año-1 $), b$ es la amplitud de la oscilación en de la AEA en el período considerado (flashes $\mathrm{km}^{-2}$ año-1), y $c$ es la fase del ciclo diario (radianes), que es un indicador del momento del día en el cual se produce la máxima actividad eléctrica. Para obtener información sobre la forma de la distribución diurna, se calculó la amplitud normalizada (NA), que es la razón entre la amplitud y el valor medio (Ecuación 6-2), para cada celda de la cuadrícula y se utilizaron los siguientes criterios,

$$
N A=\frac{b}{a}
$$

Ecuación 6-2

- NA $<0,5$ indica la falta de un ciclo bien definido en la AEA o la existencia de un doble máximo,

- $0.5<\mathrm{NA}<1,0$ indica una tendencia a un ciclo diario con un máximo definido, y

- 1 <NA indica un ciclo diario bien desarrollado, con un máximo bien definido en el ciclo diario de la AEA en esa región.

Estos criterios fueron elegidos en base al análisis realizado por Easterly y Robinson (1985).

Como ilustración de los análisis de datos, la Figura 6-3 muestra en el panel izquierdo el análisis del ciclo diario para LIS / OTD en donde los colores muestran la intensidad del ciclo diario representada por el parámetro NA, junto con la hora local de máxima actividad eléctrica (gráfico vectorial).La dirección de la flecha indica la hora de máxima AEA. Las flechas que apuntan hacia el norte indican la máxima AEA a las 00:00 LT, aquellos que apuntan al este indican máxima AEA a las 06:00 LT, las que miran hacia el sur , indican máxima AEA a las 12:00 LT , y aquellos que apunta al oeste indican máxima AEA a las 18:00 LT.

En el panel derecho se muestran los detalles de los ciclos diarios que representan cuatro regiones diferentes. Los círculos azules y rojos simbolizan el número de descargas por $\mathrm{km}^{2}$ por año obtenidos de LIS / OTD y WWLLN, respectivamente. 


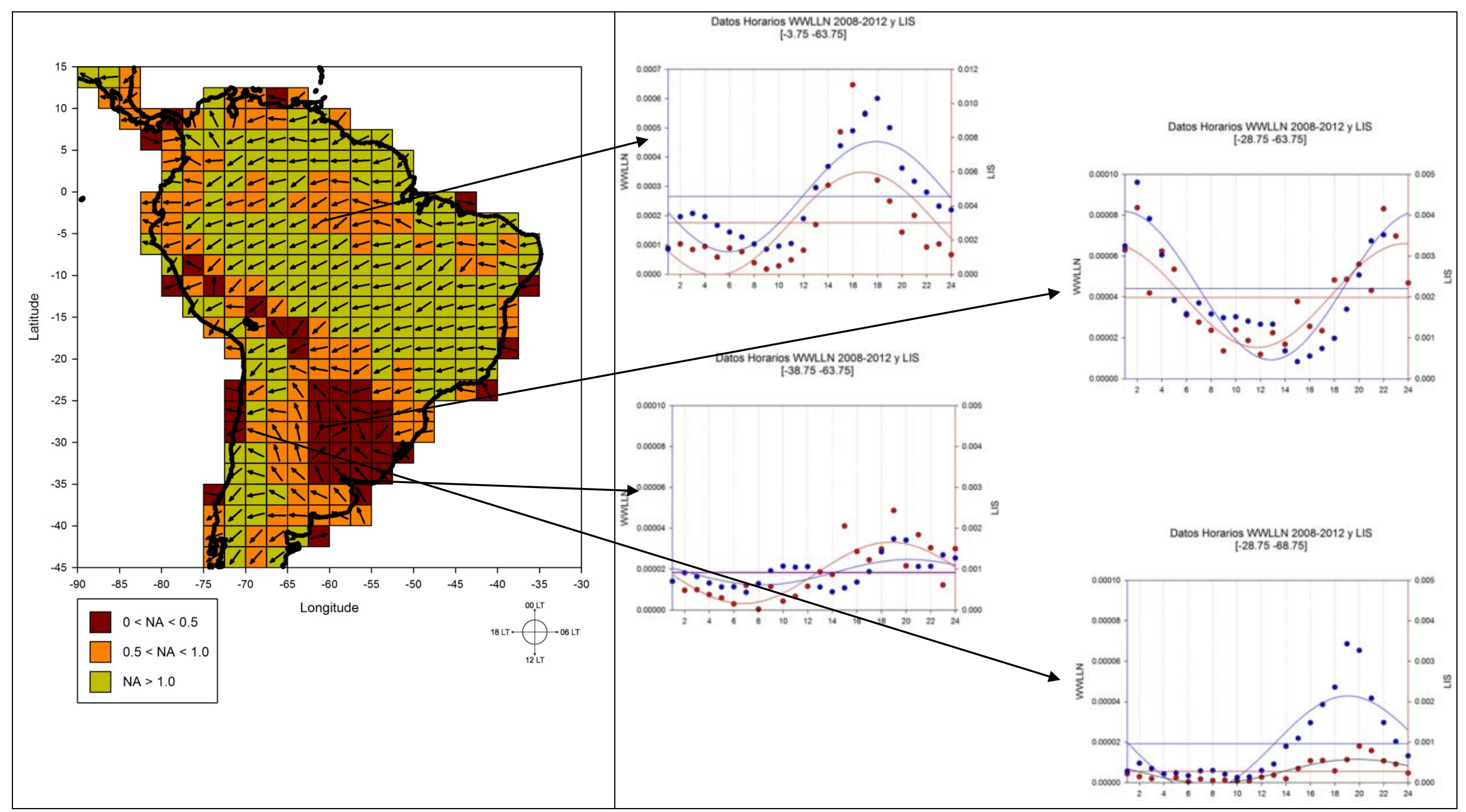

Figura 6-3 Ciclo diario de la AEA en la región tropical de Sudamérica (LIS/OTD) con detalle de la cantidad de descargas por hora en puntos para los datos y línea continua del ajuste WWLLN LIS/OTD (en azul y rojo correspondientes). 
La Figura 6-3muestra un ciclo diario marcado en la AEA en la región tropical del SA, con un pico de descargas17:00-19:00 LT. El segundo detalle muestra la variación diurna de la actividad eléctrica en la zona norte del país. El análisis sobre esta sección muestra el máximo marcadamente en horas de la media noche y primeras de la mañana. La tercera región representa la región pampean, se muestra muy poca amplitud diurna y una dispersión mayor de datos lo que implicaría que la AEA puede ocurrir en cualquier momento del día. La cuarta caja muestra la AEA en la zona de las laderas de los Andes Centrales, aunque la AEA en menor respecto a las otras zonas (ver escala) es muy interesante que su AEA se mantiene totalmente dentro de las horas de la tarde, siendo nula la actividad durante las otras horas del día.
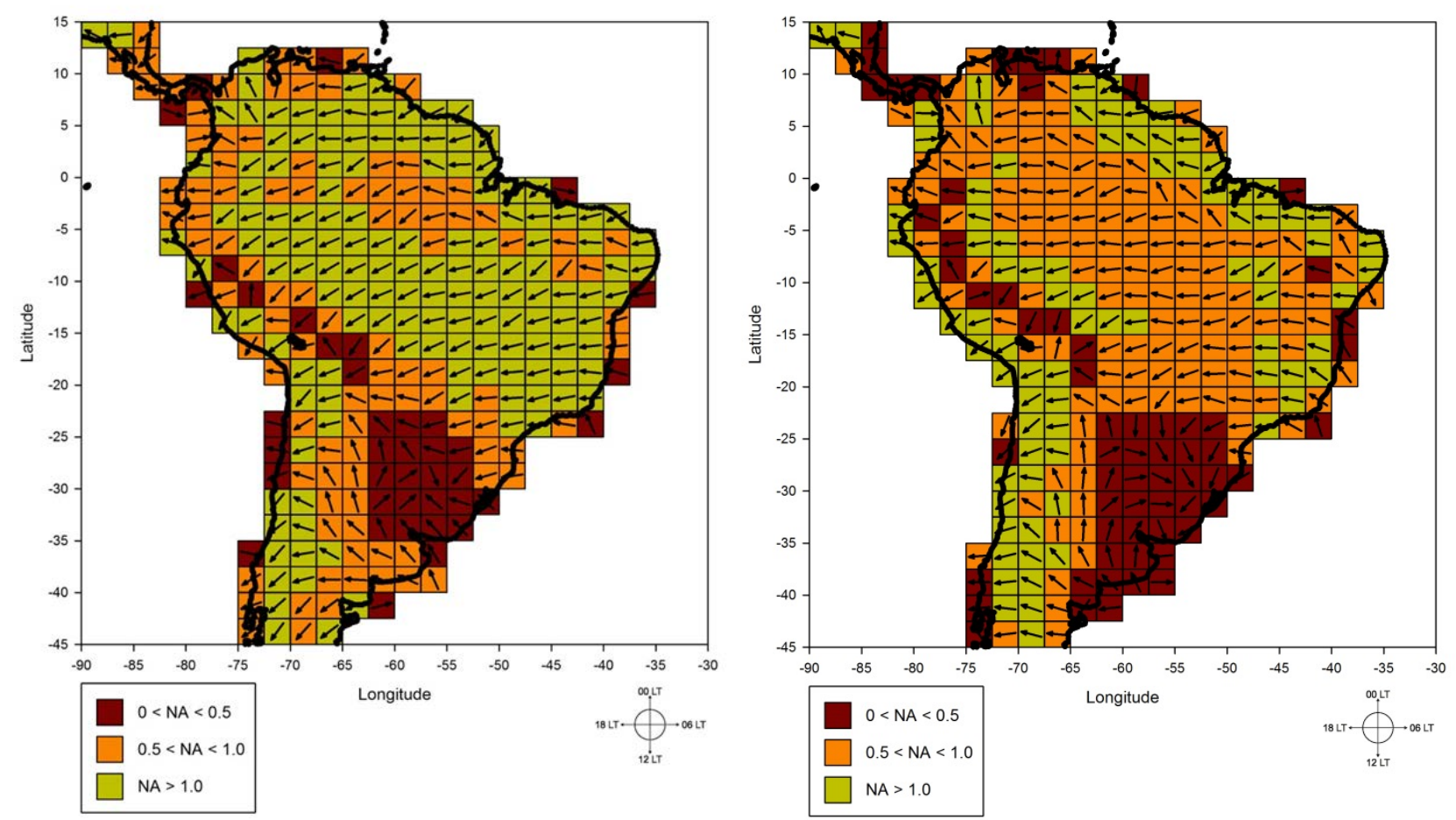

Figura 6-4mapas con el análisis del ciclo diario, junto con la hora local de máxima actividad eléctrica (gráfico vectorial) y la intensidad del ciclo diario representada por el parámetro NA, durante el ciclo diario de 24 horas para los datos de LIS-OTD (a) y WWLLN (b).

La Figura 6-4muestra los mapas comparativos del ciclo diario para las dos bases de datos independientes, junto con la hora local de máxima actividad eléctrica (gráfico vectorial), intensidad del ciclo diario está representada por el parámetro NA durante el ciclo diario de 24 horas para los datos de LIS-OTD (Figura 6-4 a) y WWLLN (Figura 6-4 b).

Los resultados de ambos conjuntos de datos se encuentran en concordancia y demuestran que la WWLLN es capaz de detectar el ciclo diario. Ambas figuras muestran que en las regiones del norte y centro de América del Sur, el momento de máxima actividad de AEA se concentró en horas de la tarde (17:00-19:00 LT) que puede ser asociado con el pico de la actividad convectiva local, asociada con el 
calentamiento de las grandes superficie en el continente. Curiosamente, en la zona limitada por [25\% $\left.40^{\circ}\right] \mathrm{S}$ y $\left[70^{\circ}, 50^{\circ}\right] \mathrm{W}$, incluyendo la cuenca de La Plata, el momento de máxima actividad se trasladó a horas nocturnas, extendiéndose desde cerca de la medianoche hasta horas tempranas de la mañana.

Al observar en mayor detalle sobre nuestra zona de trabajo (Figura 6-5) se observa que las áreas ubicadas en la ladera oriental de la Cordillera de los Andes (Andes Centrales) presentan valores de NA mayores que 1 , indicando la presencia de un máximo bastante bien definido de la actividad que se produce entre las 17:00-19:00 LT (panel inferior derecho de la Figura 6-3).

El noreste de Argentina, sur de Brasil y Uruguay (Cuenca del Plata o sus siglas en ingles LPB) muestran valores de NA inferiores a 0,5 lo que indica que no existe un ciclo definido en la actividad o la presencia de un doble máximo(segundo panel de la Figura 6-3). Es muy interesante observar los cambios bruscos entre áreas limítrofes teniendo picos de máxima actividad en horarios totalmente diferentes o desfasados en más de 12 horas. Un valor de NA bajo $(<0,5)$ en esas zonas indica que la amplitud, en relación con el valor medio, posee un valor muy pequeño, lo que se traduce en que la AEA se puede producir a cualquier hora del día, aunque el pico de actividad tiene a ser en horas nocturnas (medianoche y primera horas de la mañana)
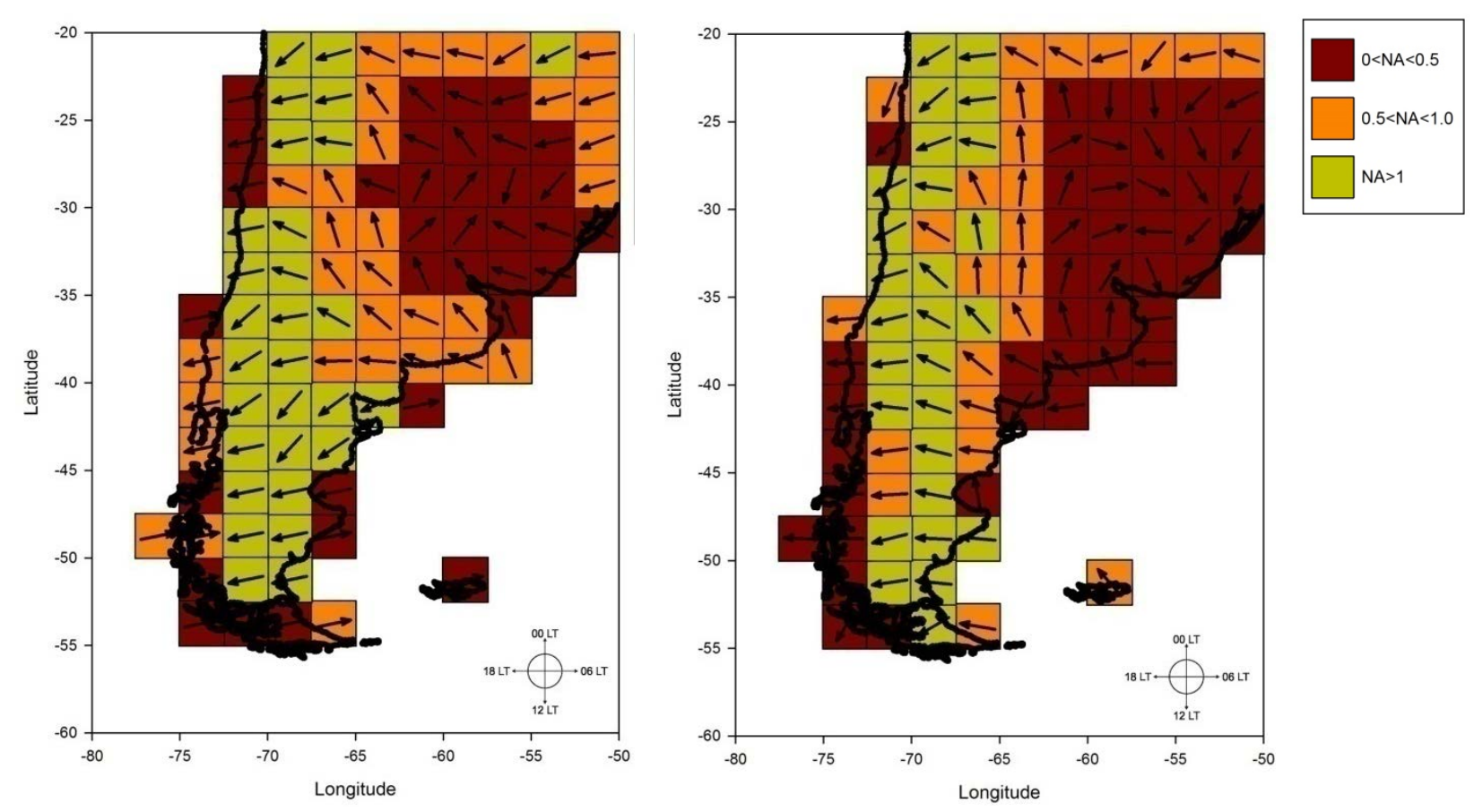

Figura 6-5 Similar a la .Figura 6-4Haciendo un zoom sobre nuestra zona de trabajo

Esta "deriva" de los máximos de AEA (desde horas de la tarde en la región oeste hacia horas de la mañana sobre la zona este), con la disminución en la intensidad de los mismos (NA pasa de valores mayores que uno a menores que 0,5 ) es una de la característica más importante de la AEA en el centro norte del país. 
Romatschke y Houze (2013) reportaron que, en las laderas de los Andes Centrales $\left[25^{\circ} ; 40^{\circ}\right] \mathrm{S}$, la mayor parte de la precipitación proviene de sistemas de pequeña dimensión horizontal, pero con células convectivas profundas, que aparecen primero en las laderas de los Andes durante horas de la tarde; en buen acuerdo con el tiempo máximo en la AEA encontrado en esta región (Figura 6-3 d). Se ha demostrado (Nicolini y Saulo 2006; Saulo et al., 2007; Matsudo y Salio, 2011; Rasmussen y Houze, 2011) que estos sistemas se mueven hacia el este sobre la región de la cuenca de La Plata, en asociación con una perturbación de latitudes medias, donde crecen como grandes sistemas con grandes regiones estratiformes. Estos sistemas son los responsables de las precipitaciones en esta zona con más del $80 \%$ de la precipitación total observada (S. W. Nesbitt, 2006), y pareciera que también son los responsables de la AEA observada en LPB. Estos sistemas son susceptibles de causar el momento de máxima AEA que ocurren durante las horas nocturnas en la región (Figura 6-3 b).

La segunda característica sobre la disminución en el valor de NA pareciera estar de acuerdo con el estudio de Salio et al. (2006) en donde se presenta que los SCMs subtropicales, en comparación con los SCMs tropicales, alcanzan una mayor duración y un rango de tamaños más amplio, con un valor extremo de $1,2 \times 10^{6} \mathrm{~km}^{2}$. Debido a esas grandes extensiones y la mayor duración temporal, es que AEA asociada a estos sistemas muestran un comportamiento disperso en el tiempo.

Diferentes estudios (Blakeslee et al., 2012; Zajac y Rutledge, 2001; Holle, 2012) han demostrado que el centro de EE.UU es también una región con las mismas características que se observan en LPB, Pico de la AEA en horas de la media noche y un leve ciclo nocturno, lo que demostraría que las tormentas podrían ocurrir a cualquier hora del día.

Por ejemplo, Zajac y Rutledge (2001) examinaron la actividad de las descargas tipo CG mediante la National Lightning Detection Network (NLDN) con datos del periodo 1995 a 1999, y encontraron un ciclo diario con un máximo de la AEA sobre las regiones sureste, este y occidental de EE.UU. entre las 15:0018:00 LT, mientras que sobre el centro de EE.UU. este análisis muestra una falta del ciclo diario bien definido con una máxima AEA durante la noche. Holle (2012), estudiando también la base de datos de rayos CG de NLDN, muestra que la región central de los EE.UU. presenta CG casi todo el día con un fuerte máximo entre la medianoche y las 02:00 LT.

Ambas regiones con actividad eléctrica nocturna y sin un ciclo diario marcado (LPB y el centro de EE.UU.) están dominados por grandes sistemas de mesoescala (Wallace, 1975; Zipser et al, 2006; Ogawa y Komatsu, 2009), ya que estas regiones muestran condiciones favorables para el desarrollo de tormentas severas: Jet en capas bajas llevando aire húmedo (del Golfo de México y de la Amazonía, respectivamente), un terreno elevado en el borde de la zona de estudio (Rocallosas y montañas de los Andes, respectivamente) elevación del aire de niveles bajos y la liberación de la inestabilidad convectiva, junto a una fuerte cortante de niveles bajos (Brooks et al, 2003; Zipser et al., 2006). 
Sobre la base de la medición de la polaridad de los flashes CG, diferentes estudios (Lyons et al, 1998; Carey y Buffalo, 2007; Villarini y Smith, 2013) han encontrado un aumento en la densidad de CG+ sobre el centro de EE.UU. durante el verano, que estaría relacionado con la región estratiforme de los SCM y con tormentas supercélulares. Además, la región del centro de EE.UU. es una región conocida de tormentas productoras de sprites. Este tipo de eventos se observa por lo general en las amplias áreas estratiforme de los SCMs (Lyons et al., 2008) que son productoras de CG+ (Singh et al., 2013). Por ejemplo, São Sabas et al. (2003) documentaron varios sprites sobre Kansas asociados a +CG ocurridos entre las 18:00-08:00 LT.

Lamentablemente, no hay información acerca de la polaridad de la AEA sobre Argentina. Sin embargo, las tormentas sobre el norte de Argentina son conocidas como las principales productoras de Eventos Luminosos Transitorios (TLE) de la Tierra (Thomas et al., 2007), y en base a las similitudes encontradas en la AEA, se podría apoyar la idea de AEA positiva sobre la región.

\section{Ciclo Estacional}

Para la realización de este estudio se trabajó solamente con la base de datos de la WWLLN, para el período 2008-2012, con una grilla de $0,5^{\circ} \times 0,5^{\circ}$. Para el periodo verano se tomaron los meses de diciembre, enero y febrero; para otoño: marzo, abril, y mayo; para invierno: junio, julio y agosto; y para primavera: septiembre, octubre y noviembre.

Las Figura 6-6 y Figura 6-7 muestran la actividad estacional para toda Sudamérica y para el Sur de Sudamérica respectivamente. Las unidades de estos gráficos son flashes $\mathrm{km}^{-2}$ periodo ${ }^{-1}$, dondeperiodo significa el tiempo de cada una de las estaciones presentadas. Por ejemplo en verano, un valor de 5 significa que se observan 5 descargas por $\mathrm{km}^{2}$ entre los meses de diciembre, enero y febrero. En cada grafico presentamos la actividad para toda Sudamérica para analizar las características regionales y luego analizamos con más detalle nuestro área de trabajo específica.

\section{Verano}

De las Las Figura 6-6 y Figura 6-7 se puede observar un patrón en la época estival similar a la presentada en los valores medios anuales de la AEA, con valores máximos en la zona del norte del país, tanto en la región este como en el oeste.

Los sistemas principales que actúan en el máximo de la AEA en la región son:

- la actividad asociada a los eventos máximos del SALL (South America Low Level Jet), provocando valores máximos en verano en la zona del NOA, alcanzando más de 110 días de tormentas por año en esta zona (centradas en las estaciones estivales); 
- la AEA asociados a los grandes sistemas convectivos MCS, los cuales fueron explicados en el apartado anterior, provocando intensa AEA en la zona centro norte del país, sur de Brasil y Paraguay;

- También otro elemento fundamental es la acción de la ZCAS como el encargado del transporte de humedad al continente, produciendo significativa precipitación al sudoeste de la ZCAS, en la Argentina subtropical y en Paraguay. Por lo tanto, en la parte oeste de la región subtropical también predomina un ciclo anual pronunciado con un mínimo en el invierno y un máximo en el verano, cuando tanto el calentamiento de la superficie como la advección de vapor de agua del norte favorecen la convección. 

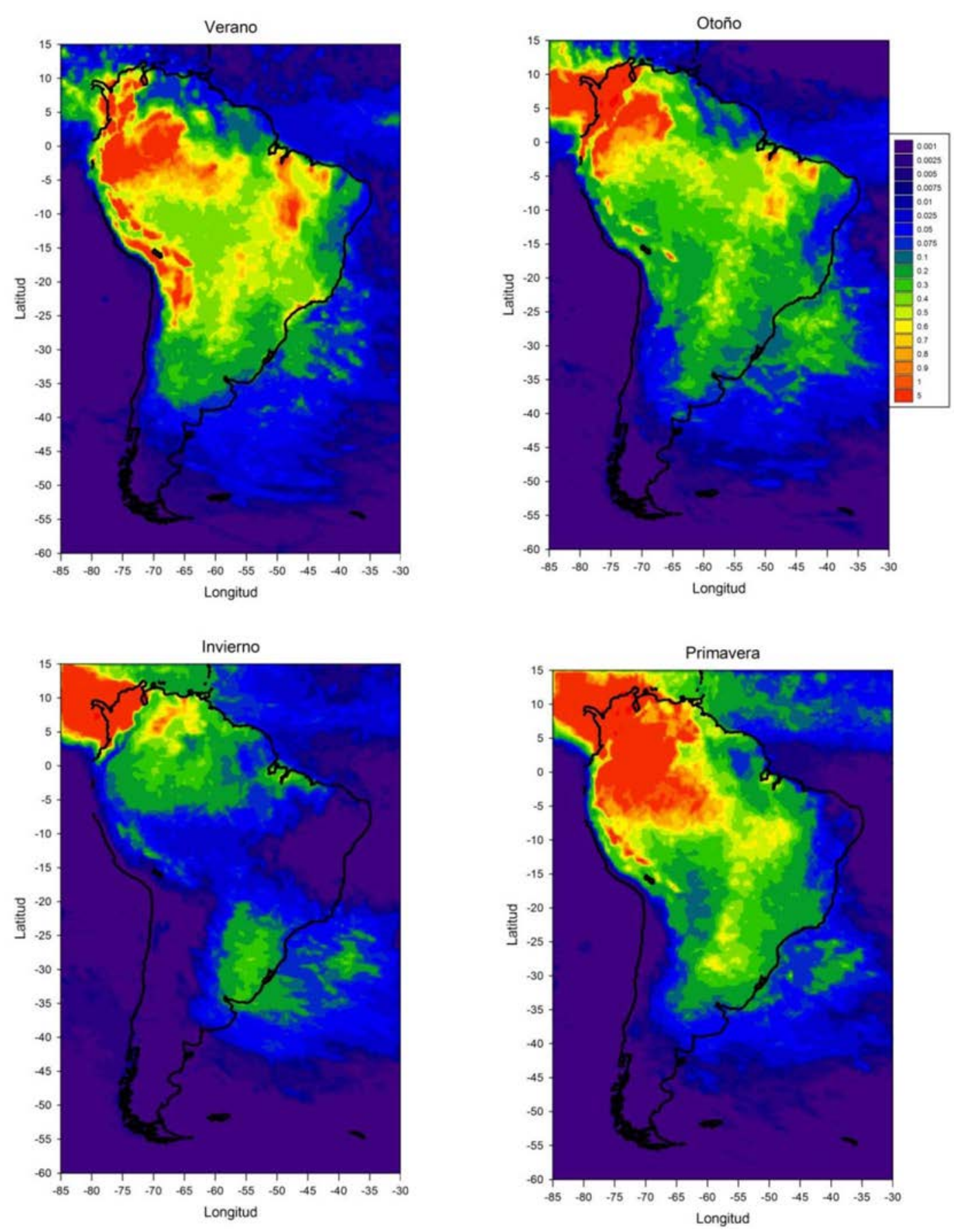

Figura 6-6 Actividad estacional para toda Sudamérica. Las unidades de estos gráficos son flashes $\mathrm{km}^{-2}$ periodo ${ }^{-1}$, dondeperiodo significa el tiempo de cada una de las estaciones presentadas 

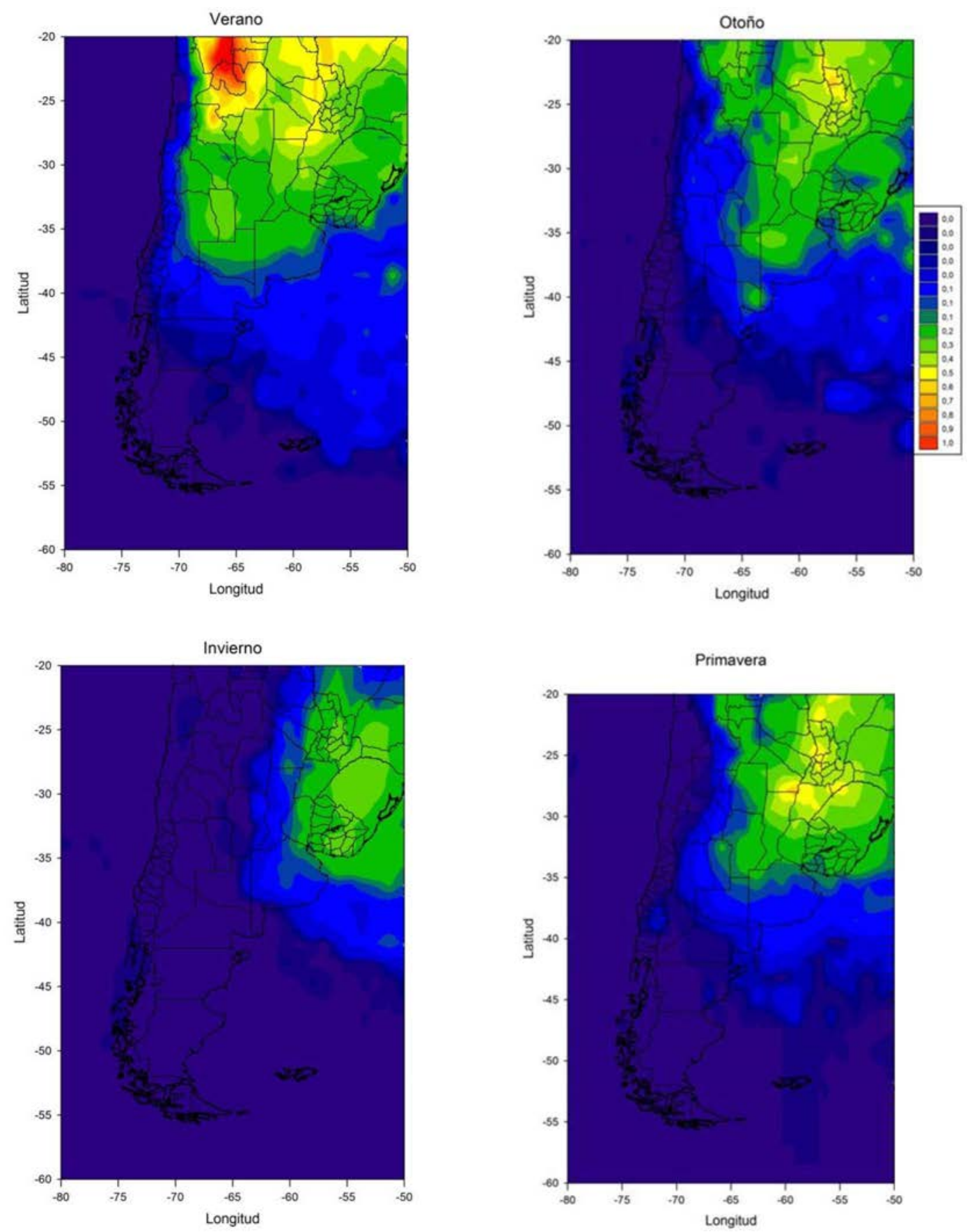

Figura 6-7 Actividad estacional para el Sur de Sudamérica. Las unidades de estos gráficos son flashes km-2 periodo-1, donde periodo significa el tiempo de cada una de las estaciones presentadas

\section{Primavera y Otoño:}

En primavera y otoño, la AEA se desplaza hacia el este respecto del verano. En los meses de otoño, el máximo se sitúa más al norte, sobre la zona de Paraguay y sur de Brasil, y en primavera sobre las provincias del noreste de Argentina. Resulta interesante destacar que los valores de AEA se mantienen 
estables para la zona de LPB con respecto a los valores de AEA en verano, diferencia de la región del NOA en donde la AEA decrece drásticamente con respecto al verano. (Figura 6-6 y Figura 6-7)

La disminución de la actividad en la zona del oeste se debe al debilitamiento de los procesos asociados al LLJ, y a la disminución de humedad disponible para el inicio de la convección.

Sobre la región al este de la región subtropical, el vapor de agua está disponible todo el año, pero, aunque las condiciones baroclínicas más intensas ocurren en el invierno, en las estaciones de transición hay frecuentes ciclogénesis (proceso de formación e intensificación de centros de baja presión) en el este de la región subtropical (Gan y Rao 1991; Rao et al., 1996). El sur de Brasil, el nordeste de Argentina y sudeste de Paraguay es una región de transición entre dos regímenes, el del monzón de verano y el de máximos de invierno, y está fuertemente influenciado por los sistemas convectivos de mesoescala (SCM) (Velasco y Fritsch, 1987; Silva Días, 1987).

\section{Invierno:}

Durante los meses de invierno se observa una característica única en la región sur de LPB. La AEA sobre las costas del litoral Argentino, Uruguay y Brasil presenta valores de AEA comparables con las otras estaciones (Figura 6-6 y Figura 6-7).

Estos niveles de AEA parecieran deberse a procesos de ciclogénesis ubicados cerca de la costa de Argentina, Uruguay y Sur de Brasil. Aunque invierno y verano son las temporadas que presentan la mayor cantidad de ciclones formados en esta región, invierno es la temporada con la máxima frecuencia de ciclones más profundos y con una intensificación de los ciclones extratropicales. A su vez, en esta estación los ciclones viajan mayores distancias en relación a las otras estaciones. Ambas características parecieran influir en la tasa de descargas (Mendes et. al., 2009).

Durante la formación de ciertos ciclones extratropicales, se produce un descenso de la presión en superficie muy notorio y muy rápido, del orden de un hectopascal por hora. El proceso que forma a este tipo de ciclones suele ser denominados "ciclogénesis explosiva". Seluchi y Saulo (1998) señalaron que los ciclones explosivos acompañados por lluvias importantes suelen causar inundaciones en las zonas densamente pobladas de la Argentina. Lim y Simmons (2002) encontraron que este tipo de ciclogénesis que se producen al este de Uruguay son más dominantes en los meses intermedios de invierno, como se puede observar en la Figura 6-8 (extraída de Lim, 2002).

Es importante señalar que hasta ahora la mayoría de los trabajos sobre ciclogenesis de invierno no trabajaron sobre la AEA asociada a estos procesos. El haber encontrado altos valores de AEA, en esta región y en esta época del año, estaría indicando la existencia de actividad convectiva vinculada con las ciclogénesis (Figura 6-7). 

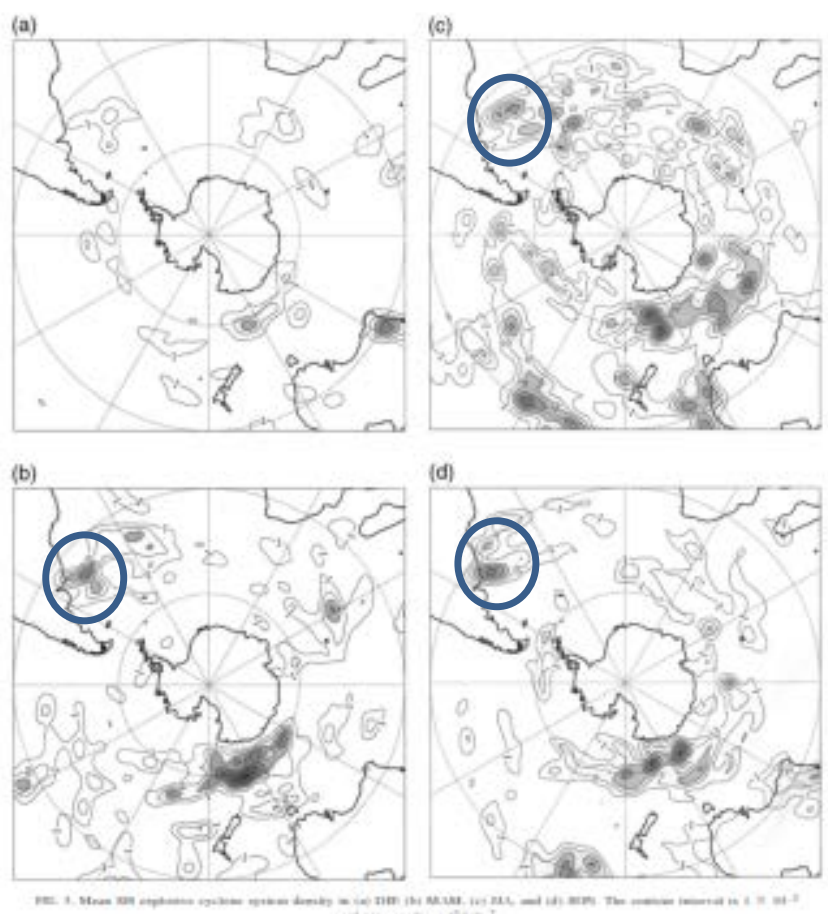

Figura 6-8SH densidad de ciclónes explosivo en el HSmedia en (a) DEF, (b) MAM, (c) JJA, y (d)SON. El intervalo de contorno es de $1 \times 10^{-5}$ ciclones explosivos lat ${ }^{-2}$ (extraído de Lim, 2002)

El ciclo anual de la AEA en la región ha sido estudiado por Collier et al. (2013.), en el cual, trabajando con datos LIS/OTD, se interpoló una función sinusoidal representando los ciclos anuales y semianuales para los distintos países de la región. En los gráficos de la Figura 6-9 se pueden observar la AEA sobre Paraguay, Uruguay y Argentina presentado por esto autores.
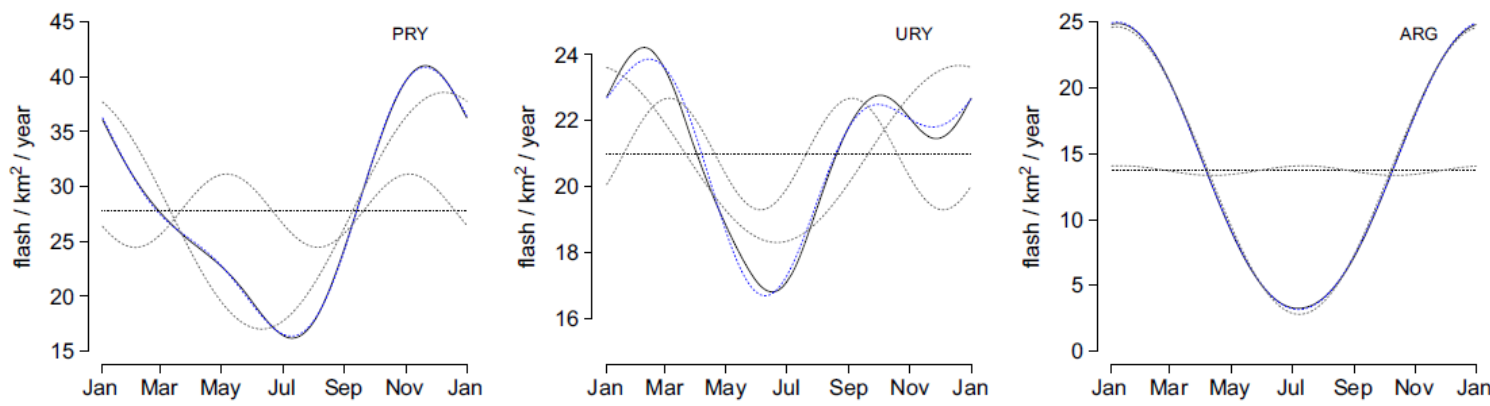

Figura 6-9 . Densidad de descargas construido a partir de 10 años de datos LIS / OTD),), Paraguay (PRY), Uruguay (URY) y Argentina (ARG). Las climatologías se representan como una curva de color negro sólido, los componentes anuales y semestrales de un ajuste sinusoidal se desvanecen en color gris, mientras que su suma es discontinua en azul. (Extraído de collier et. al. 2013)

Las características presentadas en su trabajo se encuentran en concordancia con nuestras observaciones. Se puede observar que Argentina presenta un ciclo anual muy marcado con un máximo en el mes de enero. Esta característica concuerda con el estudio realizado en este trabajo. Es 
interesante señalar que, aunque existe actividad sobre la Mesopotamia durante los meses de invierno, esta área es pequeña en relación a las dimensiones totales de Argentina, en donde una alta proporción del territorio presenta nula actividad en los meses de invierno.

En el caso de Uruguay se ve que el patrón no es tan simple, pero se observa que existe AEA durante casi todo el año. Esto se corresponde con las características observadas utilizando datos de la WWLLN. Por un lado, en los meses de veranos, tenemos la acción de los grandes sistemas precipitables MCS, pero a la vez Uruguay, y toda la zona costera aledañas a Brasil y Argentina, también presenta ciclogénesis a lo largo del año, aunque durante el invierno los ciclones extratropicales modifican notablemente el patrón esperable de AEA durante esos meses.

En Paraguay se observa actividad durante todo el año, pero presenta un ciclo con un mínimo marcado en julio y un máximo en noviembre

Dado que Paraguay y Uruguay poseen una extensión territorial mucho menor que la Argentina, la AEA en invierno es relevante en toda su superficie y, por lo tanto la actividad de invierno es importante y define fuertemente el ciclo anual de la AEA.

\section{Variación interanual}

Las descargas totales por año (Fw $[i, j])$ detectados por el WWLLN en cada punto de la malla centrada en [i,j] de latitud y longitud, respectivamente, se calculan para cada año entre 2005 y 2012 con una grilla de $0,5^{\circ} \times 0,5^{\circ}$.. A fin de tener en cuenta la variación de la eficiencia de detección, los valores de Fw $[i, j]$ se normalizaron a los flashes totales en la ventana espacial para todo el año $\left(\sum_{\mathrm{i}} \sum_{\mathrm{j}} \mathrm{F}_{\mathrm{w}}[\mathrm{i}, \mathrm{j}]\right)$ utilizando el análisis que ha sido presentado anteriormente. Por lo tanto la variable

$$
F_{w, n}(\text { year })[i, j]=\frac{F_{w}[i, j]}{\sum_{i} \sum_{j} F_{w}[i, j]} \times 1000
$$

se utiliza como un indicador de la AEA en cada punto de la cuadrícula y, en este caso, su valor representa la parte por mil del total de descargas en la zona de estudio por año. La Figura 6-10 muestra la distribución espacial de Fw,n para cada año entre 2005 y 2012. 

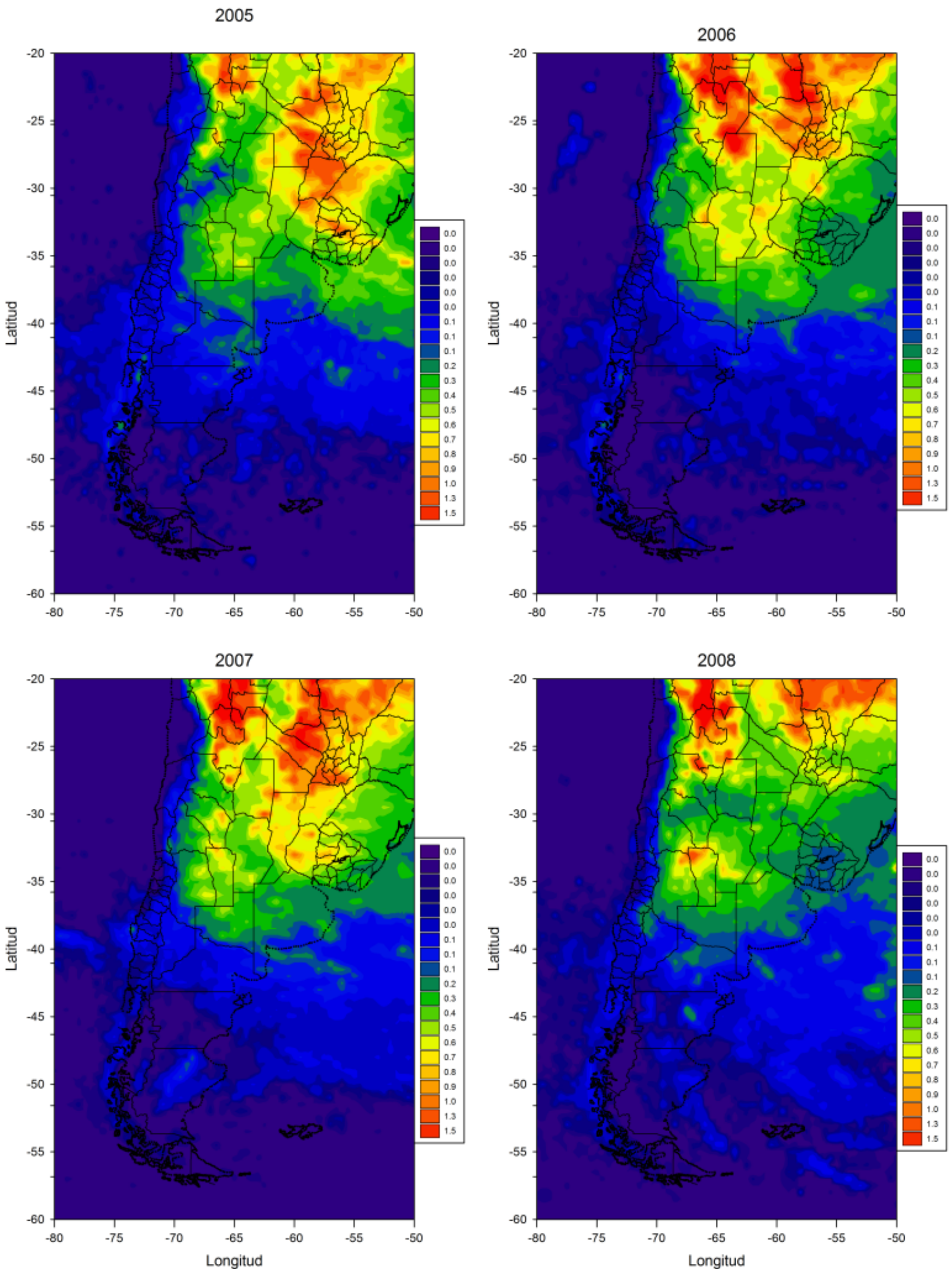
2009
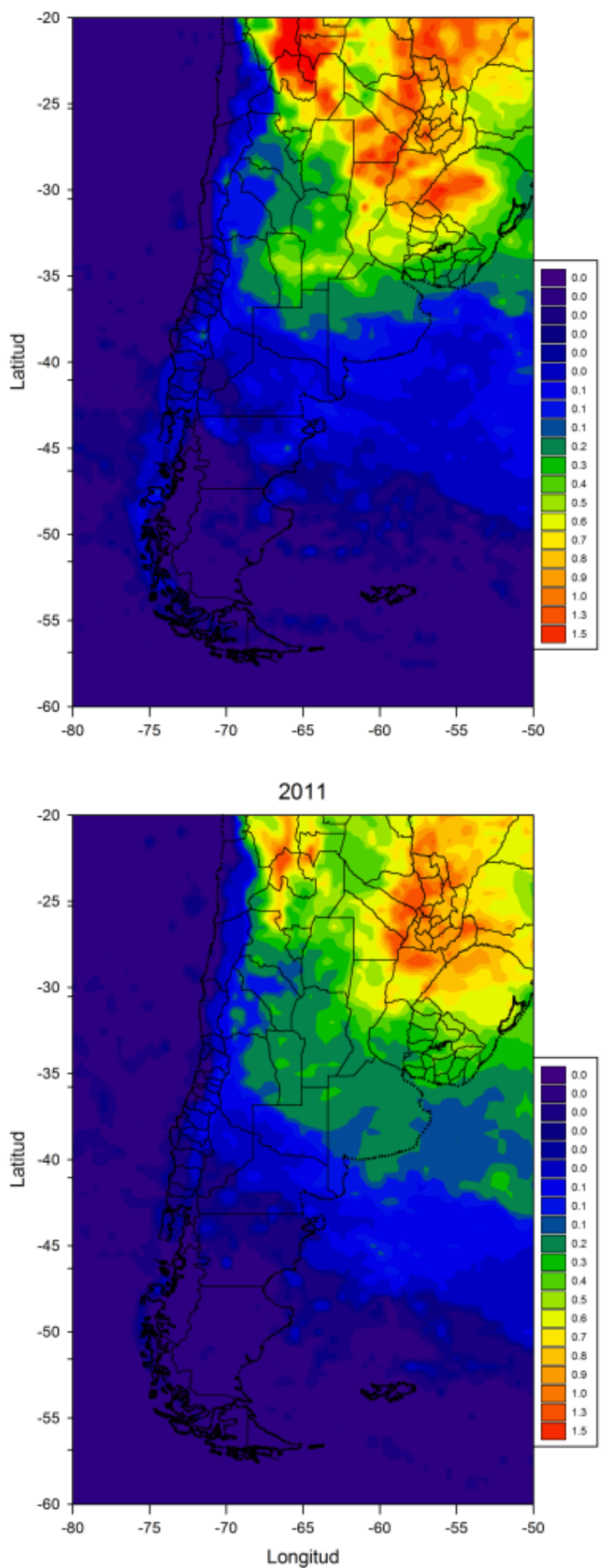
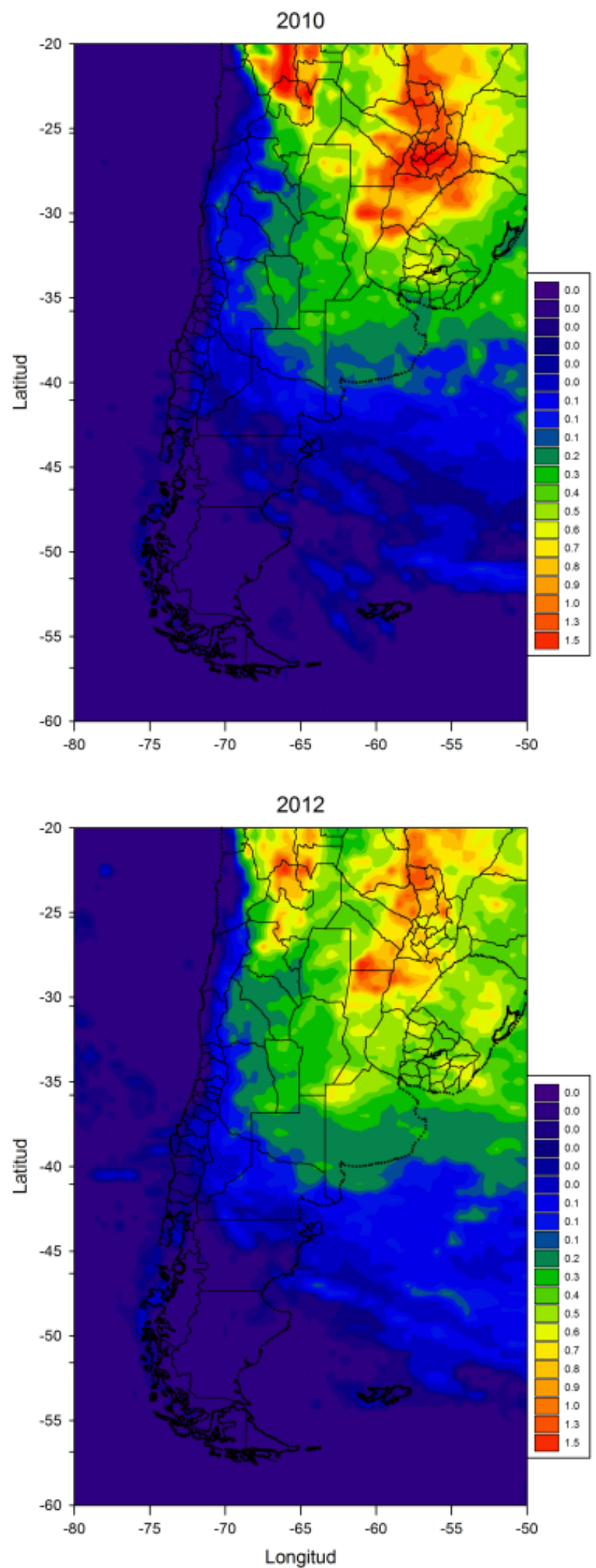
De los gráficos podemos ver que, si bien la eficiencia de la red cambio a lo largo de los años, los patrones espaciales de AEA se mantienen durante los diferentes años, aunque podemos enumerar algunas diferencias relevantes. En LPB se observa un máximo de AEA ubicado sobre Paraguay en los años 2006 y 2008y mientras que en los otros años, el máximo se sitúa más al sur, en la provincia de Corrientes. La zona del NOA tiene más localizado la zona de máxima AEA la cual presenta una persistencia notable años tras años. Esta característica pareciera tener una relación muy importante con la topografía. Mientras que en la NOA, la AEA posee una fuerte componente topográfica, manteniéndose junto a las laderas de la cordillera, y los sistemas que generan esta actividad son de tamaño reducidos, dando un patrón espacial mucho más marcado en comparación con la AEA observada en LPB. En esta última región, la AEA es más dispersa ya que LPB es una zona de planicies con grandes sistemas convectivos que generan esta actividad provocando un patrón espacial de mayores dimensiones (Romatschke y Houze, 2013).

Ya que la AEA se puede tomar como marcador de la severidad de una tormenta, estas diferencias interanuales, podrían ser una herramienta útil para entender los procesos microfísicos y convectivos en la formación de las nubes de tormentas, y en particular de los grandes SCMs.

Es muy importante destacar que el sur de América del Sur, es una estrecha cuña continental rodeada por inmensos océanos que la rodean, y por lo tanto la mayor parte del trabajo hecho para entender la variabilidad interanual del clima ha girado en torno a las condiciones de la TSM (Temperatura Superficial del Mar). La influencia de la TSM en la atmósfera se puede propagar a grandes distancias a través de ondas que dan lugar a patrones de teleconexiones. De esta forma, es como pueden manifestarse forzamientos remotos desde el Pacifico o el Atlántico sobre la cuenca del Plata y por ello, buena parte de la variabilidad climática en las escalas que van desde la ínter estacional a la decádica puede ser entendida a través de tales teleconexiones. (Barros et. al., 2006).

A su vez la ZCAS presenta fuertes variaciones en su intensidad en varias escalas de tiempo, de la sinóptica hasta la interdecadal, con una similar estructura espacial. Esta última es caracterizada por un dipolo en las anomalías de la lluvia, de forma que cuando la ZCAS es intensa (débil) sobre Brasil en alrededor de $20^{\circ} \mathrm{S}$ y por lo tanto hay fuertes lluvias, hay escasas o nulas (abundantes) precipitaciones hacia el sur, sobre Uruguay y el noreste de Argentina (Doyle y Barros, 2002). Esta característica concuerda con lo encontrado en nuestro estudio en la variación interanual del a AEA, en donde la máxima variación se encuentra en la zona más influenciada por la ZCAS.

Otra fuente de variabilidad climática en la escala interanual en la Cuenca del Plata es El NiñoOscilación del Sur (ENSO), cuyas fases extremas son conocidas como eventos El Niño (EN) y La Niña (LN), que son el principal modo de variabilidad interanual de la TSM en escala global. 


\section{Capítulo 7 Actividad eléctrica atmosférica en la Patagonia Occidental}

En este capítulo presentaremos un estudio detallado de la AEA en el Sur de la Patagonia Occidental, la cual es una síntesis del trabajo.Lightning in Western Patagonia, Garreaud, René, Nicora, M. Gabriela, Bürgesser, Rodrigo E., Ávila, Eldo E Journal of Geophysical Research: Atmospheres, DOI: 10.1002/2013JD021160.

En base a ocho años (2005-2012) de datos de descargas eléctricas atmosféricas (tiempo de ocurrencia y ubicación geográfica) provistos por la red WWLLN describiremos la distribución espacial y la variabilidad temporal de la AEA sobre la Patagonia Occidental. Esta región se extiende desde aprox. $40^{\circ} \mathrm{S}$ a $55^{\circ} \mathrm{S}$, a lo largo de la costa occidental de América del Sur, y está limitada al este por los Andes australes ubicados unos $100 \mathrm{~km}$ hacia el interior del continente. Se utilizaron reanálisis de alta resolución e imágenes satelitales para caracterizar el entorno sinóptico de las tormentas eléctricas que se producen en esta zona, ejemplificadas por un caso de estudio y generalizadas por un análisis de composición.

La densidad de AEA y la frecuencia de días de tormentas exhiben un fuerte máximo a lo largo de la costa del sur de Chile aunque también se observan descargas dispersas mar adentro, sobre el sur de Chile. Por el contrario, sobre la parte más austral de los Andes, donde la precipitación es máxima y hacia el este, sobre la Patagonia Argentina, las descargas son prácticamente inexistentes.

La AEA tiende a ocurrir cuando la Patagonia Occidental se encuentra inmersa en una masa de aire frío luego que un frente ha llegado a la costa alrededor de los $40^{\circ} \mathrm{S}$. Bajo estas condiciones, el enfriamiento a niveles medios se produce antes, y es más prominente, que el enfriamiento cerca de la superficie (donde este es amortiguado por el calor liberado por la superficie del mar) lo cual conduce a una condición post-frontal débilmente inestable. El ascenso forzado de los fuertes vientos del oeste que incide sobre las montañas puede desencadenar la convección y producir una AEA significativa. Mar adentro, ascensos de gran escala cerca del centro ciclónico, pueden forzar el ascenso de parcelas de aire superficiales, promoviendo convección poco profunda y una actividad eléctrica dispersa

\section{Introducción}

La deriva hacia el este de los ciclones frontales a lo largo de las trayectorias de las tormentas oceánicas es responsable de la mayor parte de la precipitación y las variaciones climáticas diarias en las 
regiones extra tropicales. Estas tormentas son dominadas por nubes y precipitación de naturaleza estratiforme (por ejemplo, Houze 1993, capítulo 9) con velocidades de aire verticales más pequeñas que la velocidad de caída de los cristales de hielo grandes ( $\leq 2 \mathrm{~m} \mathrm{~s}-1)$. Consistentemente con esta naturaleza estratiforme, las tormentas exhiben un AEA modesta en relación a los sistemas de convección profunda sobre las masas continentales. De hecho, las climatologías globales de descargas, construidas sobre la base de los datos de satélite (por ejemplo, Christian et al., 2003) y de redes de tierra (Virts et al., 2013), revelan que la densidad media del descargas sobre los océanos para latitudes mayores a $40^{\circ}$ es entre 50 y 500 veces menor que la densidad de descargas sobre las masas continentales tropicales/subtropicales. La densidad de descargas sobre los océanos extra tropicales es algo mayor en el este de Norteamérica y Sudamérica, Japón y Sudáfrica durante sus respectivas temporadas de invierno (por ejemplo, Virts et al. 2013, su Fig. 4), donde prevalecen las aguas cálidas y es frecuente la ciclogénesis (Hoskins y Hodges, 2002).

Análisis de eventos específicos sobre el Pacífico Norte (Pessi et al., 2009; Pessi y Businger, 2009a) y sobre el Atlántico Norte (Demetriades y Holle, 2005) revelan que la AEA se encuentra concentrada a lo largo del frente frío producido por las tormentas de latitudes medias, probablemente en conexión con la línea de convección forzada conocida como banda de lluvia frontal, angosta y fría (narrowcold-frontal rainband) (por ejemplo, Browning, 1986), así como cerca del centro del ciclón durante su fase de desarrollo. Pessi y Businger (2009a) también muestran un aumento logarítmico entre la tasas de precipitación convectiva con el aumento de las tasas de descargas, abriendo la posibilidad de utilizar las bases de datos de descargas para mejorar los pronósticos meteorológicos numéricos sobre las regiones oceánicas remotas (Pessi y Businger, 2009b). También han sido informadas descargas eléctricas en tormentas de invierno en regiones continentales de altas latitudes (Mäkelä et al., 2011). Recientemente, Mäkelä et al. (2013) estudiaron dos tormentas de invierno en el sur de Finlandia que tuvo efectos adversos en la aviación. Estos eventos, fuera de estación, ocurrieron en el sector de oclusión de un frente, sobre el mar libre de hielo y con casi cero energía convectiva disponible. Las tormentas de nieve con truenos (los llamados eventos thundersnow) son poco frecuentes pero han sido documentados, especialmente en América del Norte (Schultz, 1999; Mercado et al., 2002).

Aunque las tormentas de nieve de invierno tienen una altitud tan baja como $6 \mathrm{~km}$, estas pueden producir rayos y su evolución del cargado eléctrico es similar al observado en las tormentas de verano (Takahashi et al., 1999). Las observaciones sugieren que los cristales de hielo y los granizos son los principales portadores de carga y que el mecanismo no inductivo actúa como el proceso principal de separación de cargas en estos sistemas fríos. Ávila et al. (2013) estudiaron en el laboratorio el funcionamiento del mecanismo no inductivo en condiciones microfísicas similares a algunas de las que se producen en las tormentas de invierno. Sus resultados indican que este mecanismo de separación de 
cargas puede contribuir a los procesos de electrificación en las tormentas de invierno, a condición de que el tiempo de residencia del granizo en la nube sea suficientemente largo.

La AEA es notablemente baja a lo largo de la trayectoria de las tormentas en el hemisferio sur (Figura 7-1), la cual se ubica sobre el cinturón de vientos del oeste entre los $45^{\circ} \mathrm{S}$ y $55^{\circ} \mathrm{S}$ (por ejemplo, Hoskins y Hodges, 2005). La precipitación anual media en gran parte de los océanos del sur es de alrededor de 1000-1500 mm, pero este valor cambia drásticamente cuando la trayectoria de las tormentas intercepta la Patagonia en el extremo sur de América del Sur (por ejemplo, Garreaud et al., 2013).

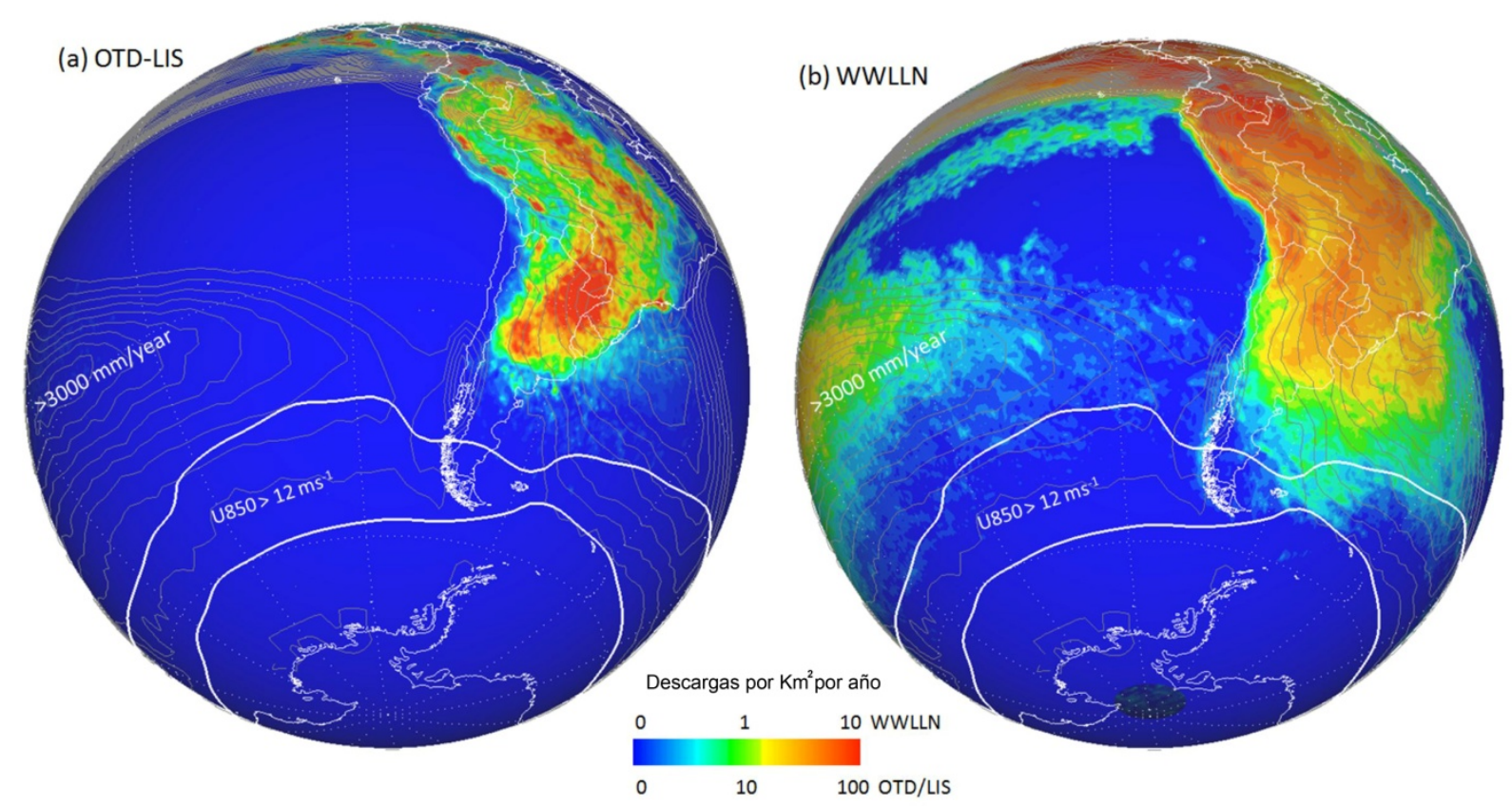

Figura 7-1Densidad media anual de rayos (flash por $\mathrm{km}^{2}$ por año) de (a) LIS / OTD (b) y WWLLN. También se muestra la precipitación media anual (contornos grises cada $300 \mathrm{~mm}$ ) y la velocidad del viento de $850 \mathrm{hPa}$ por encima de $12 \mathrm{~m} / \mathrm{s}$ (delimitadas por contornos blancos, de NCEP-NCAR) indicativas de la SH cinturón de vientos del oeste y la trayectoria de la tormenta.

Esta región se extiende hacia el sur, desde aproximadamente los $40^{\circ} \mathrm{S}$, y está dividida por los Andes australes; y las temperaturas de la superficie del océano (SST) sobre el océano Pacífico adyacente no superan los $10^{\circ} \mathrm{C}$. El forzado orográfico producido por las montañas genera una precipitación copiosa sobre la Patagonia Occidental (lado chileno). La distribución real de la precipitación es poco conocida debido a que la red de pluviómetros es pequeña en esta región extremadamente inaccesible, pero la

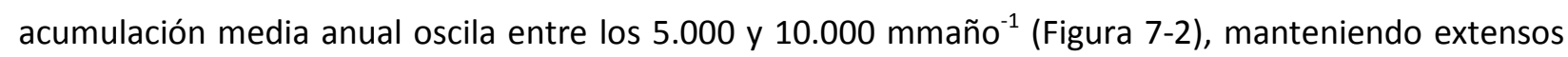
bosques, grandes ríos y los campos de hielo de la Patagonia norte y sur. La precipitación media disminuye a menos de $300 \mathrm{~mm}$ año ${ }^{-1}$ a sólo unas pocas decenas de kilómetros en dirección de la división continental, dando lugar a uno de los gradientes de precipitación más dramáticos de la tierra (Smith y Evans, 2007). 


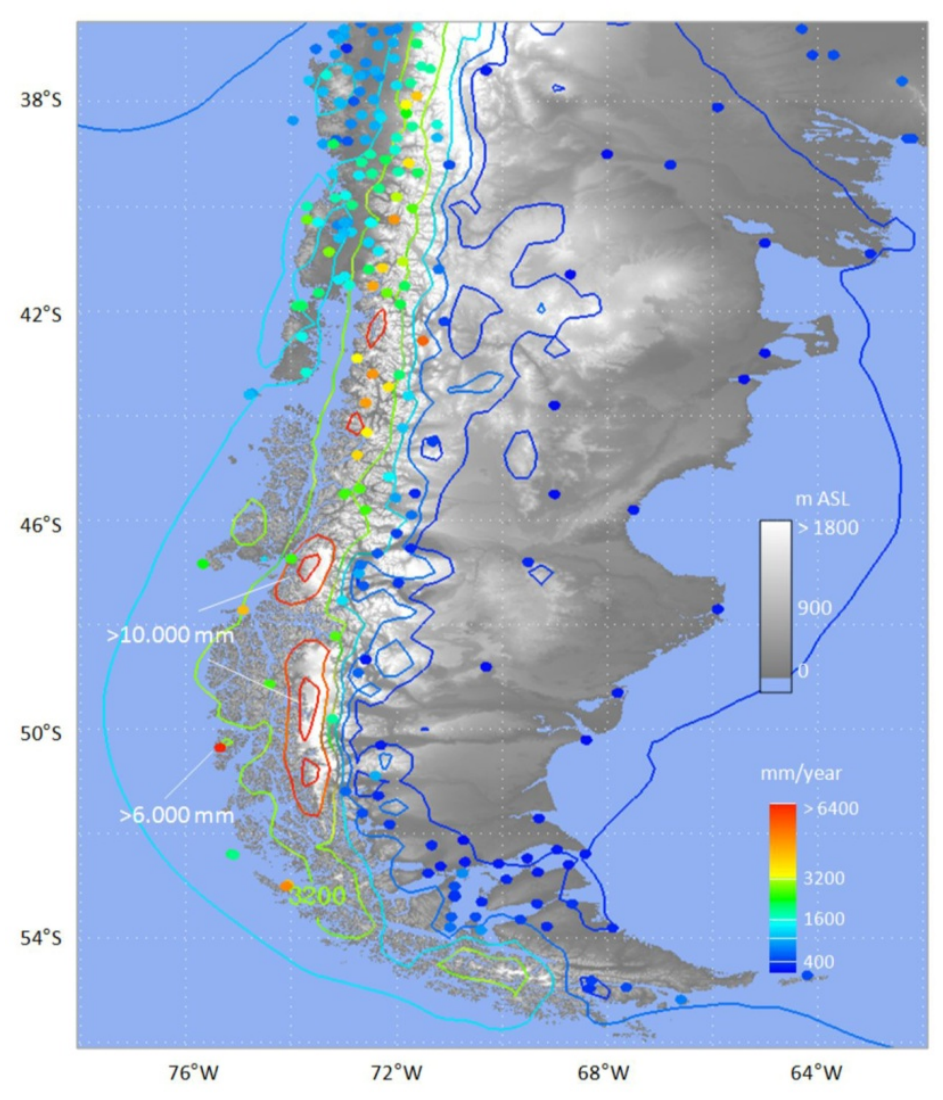

Figura 7-2 Pprecipitación media anual realizada con un modelo de simulación regional (PRECIS forced by ERA-40) contorneado en los niveles indicados en la escala de color y datos de la estación (círculos de colores, escala de la derecha. La elevación del terreno (escala de grises) es tomado desde the Shuttle Radar Topography Mission..

En base a los conocimientos y experiencias previas, se espera poca o ninguna AEA sobre la Patagonia occidental fría e híper-húmeda. Sin embargo, dos líneas de evidencia sugieren que se producen descargas eléctricas con bastante frecuencia en esa región. En primer lugar, la reconstrucción paleoambiental, sobre la base de muestras tomada de árboles y sedimentos lacustres, han documentado un aumento significativo, aunque variable, de los incendios forestales sobre la Patagonia Occidental durante el Holoceno (ver Holz y Veblen, 2011 para una revisión). Antes de la colonización euro-chileno (aprox. 200 años atrás), los incendios forestales en esta zona remota se han atribuido a la ignición por descargas eléctricas (Markgraf y Anderson, 1994; Moreno et al., 2001) durante los largos períodos con condiciones relativamente secas y cálidas (Holz y Veblen, 2011b). En segundo lugar, la red WWLLN realiza un monitoreo en tiempo real de AEA de aproximadamente 1700 volcanes con el objetivo de detectar la AEA generada por la nube de cenizas durante una erupción volcánica en curso (http://wwlln.net/volcanoMonitor.html). En los Andes meridionales se encuentran más de 33 volcanes activos pero con erupciones poco frecuente (por ejemplo, tres acontecimientos importantes en la última década, Sernageomin, 2012). Sin embargo, se observan advertencias de erupción volcánicas generadas 
por la red WWLLN 4-5 veces al mes sobre el sur de América del Sur, que fueron posteriormente interpretados como eventos meteorológicos.

Precisamente en este trabajo se estudia la AEA sobre la Patagonia Occidental, con énfasis en su distribución y en las condiciones meteorológicas relacionadas.

\section{Datos}

En este trabajo se han utilizado los datos de WWLLN de Enero 2005 a Diciembre de 2012, con énfasis en la AEA sobre la Patagonia Occidental y el Pacífico adyacente al sur de los $40^{\circ} \mathrm{S}$. La eficiencia de detección (ED) de WWLLN en esta región es desconocida y ha ido cambiado en el tiempo (no hay observaciones in-situ y los datos de LIS se limitan a $\pm 38^{\circ}$ de latitud), pero es probable que la ED se encuentre entre el 5-10\%, la cual es la eficiencia global estimada (Abarca et al., 2010; Rudlosky y Shea, 2013).

Para nuestro caso de estudio (30 de abril - 03 de mayo 2012) también se utilizaron la AEA detectada por la Sferics Timing And Ranging NETwork (STARNET, http://www.zeus.iag.usp.br/). Esta red está compuesta por 8 sensores de tierra ubicados en Brasil y en el Atlántico adyacente (todos ellos al norte de los $25^{\circ} \mathrm{S}$ ) para monitorear la AEA sobre las regiones tropicales. También hemos utilizado los registros históricos de días de tormenta en un puñado de estaciones en la Patagonia compilados por la Organización Meteorológica Mundial (WMO 1953).

La circulación atmosférica y las condiciones termodinámicas durante las tormentas eléctricas se caracterizaron utilizando el Climate Forecast System Reanalysis (CFSR) elaborado por los Centros Nacionales de Predicción Ambiental (National Centers for Environmental Prediction, NCEP). En este nuevo análisis, se asimilaron informaciones satelitales y observaciones de superficie y en altitud en un modelo numérico para producir la mejor estimación del estado del sistema atmósfera/océano en tres dimensiones. La primera versión del nuevo análisis (CFSRv1, Saha et al., 2010) abarca el período 19792011 y la segunda versión (CFSRv2, Saha et al., 2013) abarca el período comprendido entre enero de 2011 hasta ahora. Una ventaja importante del CFSR es su mayor resolución espacial en relación con otros reanálisis; aquí utilizamos datos de superficie y de distintos niveles de presión disponible cada 6 horas en una grilla mundial de $0,5^{\circ} \times 0,5^{\circ}$. La alta resolución de CFSR es particularmente útil cuando se examinan tormentas específicas sobre la Patagonia Occidental, en conjunto con los datos de WWLLN y las imágenes visibles (canal 1) y térmicas infrarrojas (canal 4) de los satélites GOES 12 y 13 archivadas en el NOAA Comprehensive Large Array-data Stewardship System (CLASS; http://www.class.ncdc.noaa.gov/).

Para proporcionar un contexto a nuestra climatología de la AEA se describe el campo de precipitación anual media obtenida de varias fuentes. En tierra se utilizó los valores medios de largo 
plazo (al menos 30 años de datos) obtenidos por pluviómetros operados por el Servicio Meteorológico y por la dirección de recursos hídricos de Chile. Debido a que esta red tiene una baja densidad sobre la Patagonia Occidental, también se emplearon los resultados obtenidos en una simulación de 20 año de duración del clima regional en el sur de América del Sur y los océanos adyacentes utilizando el modelo PRECIS (ver detalles y validación en Garreaud et al., 2013). Mar adentro, se utilizaron los valores medios de largo plazo del NOAA NCEP Climate Prediction Center Merged Analysis of Precipitation (CMAP, Xie y Arkin, 1996).

\section{Distribución espacial y temporal}

Comencemos nuestro análisis mostrando la densidad de descargas eléctricas $(\rho L$ ) y el número de días con descargas eléctricas (Td) (Fig. 3a, b). La densidad de descargas eléctricas se define aquí como el número de descargas en una grilla no solapada de $0,1^{\circ} \times 0,1^{\circ}$ considerando todo el periodo de datos (desde enero 2005 hasta diciembre 2012), dividido por 8 años, por lo cual tiene unidades de descargas eléctricas por $\sim 100 \mathrm{~km} 2$ por año. El número de días con descargas eléctricas es el número de días con al menos una descarga eléctrica en una grilla de $0,25^{\circ} \times 0,25^{\circ}$ considerando todo el periodo de datos, dividido por 8 años, por lo cual tiene unidades de días por año. El tamaño de la grillas son arbitrarias y no coinciden necesariamente con la definición utilizada en otros trabajos, pero nos permiten detectar la estructura detallada del $\rho \mathrm{L}$ y $\mathrm{Td}$, así como las diferencias regionales. Por otra parte, el parámetro Td se ve menos afectado por cualquier cambio temporal que puede haber afectado a la eficiencia de detección de la WWLLN (por ejemplo, Rudlosky y Shea, 2013). De todas maneras, se verificó que la estructura general del $\rho \mathrm{L}$ y $T d$ no cambia sustancialmente cuando se consideran años individuales. 
a) Densidad por descarga (WWLLN)

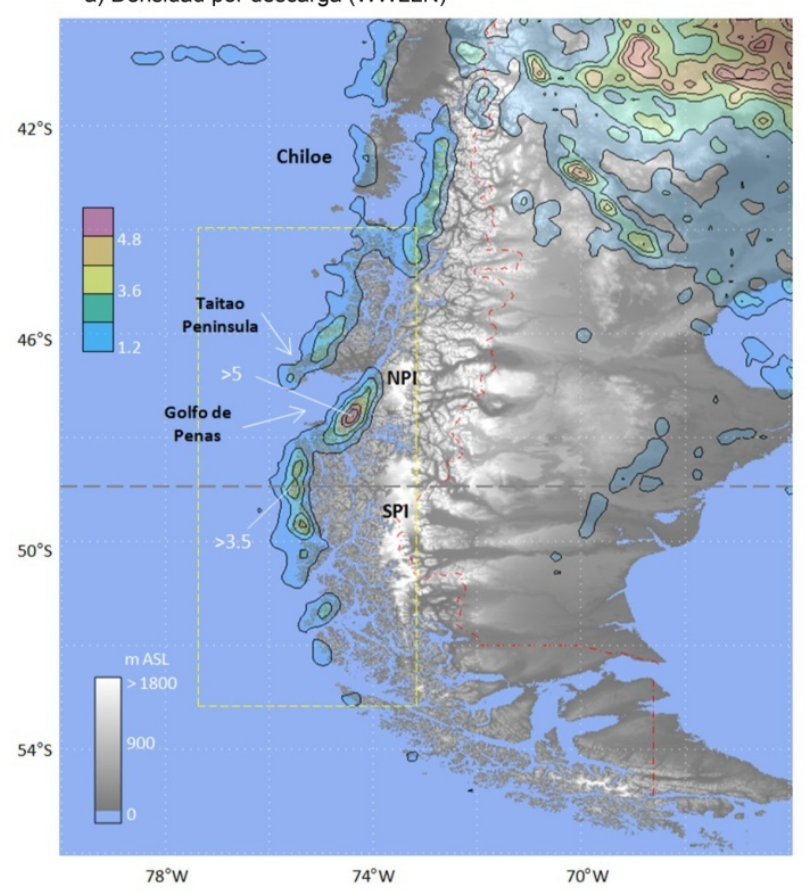

b) Numero de descargas por dia (WWLLN)

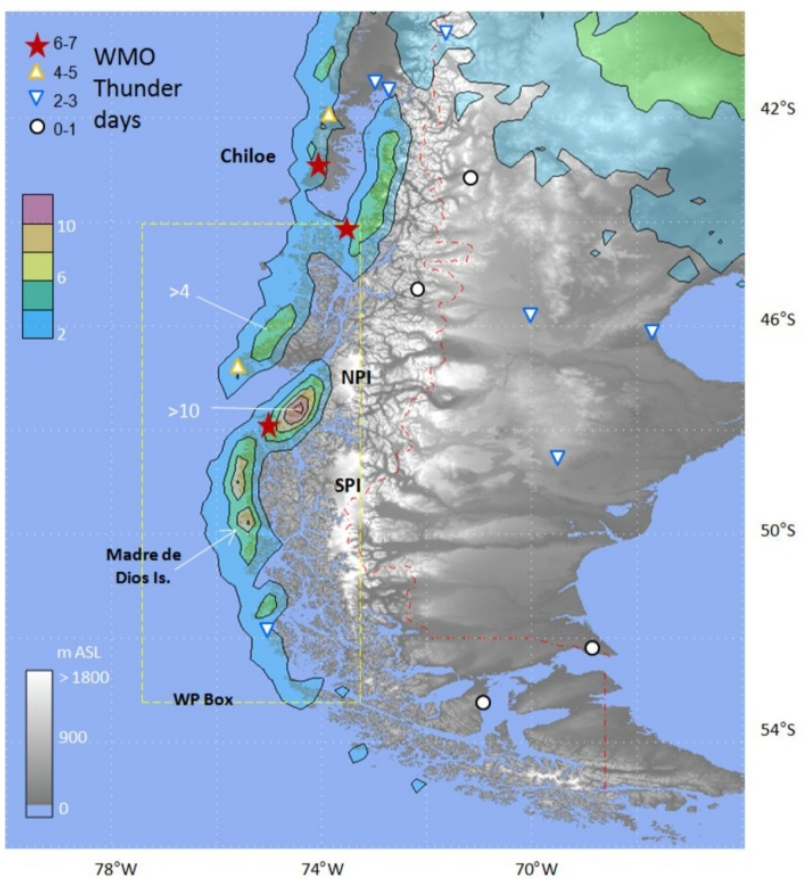

Figura 7-3a) la densidad de descargas en contornos cada 1,2 descargas en $0,1^{\circ} \times 0,1^{\circ}$ por año. (b) Número de días de tormentas (al menos un descargasen $0.25^{\circ} \times 0,25$ por año) contornea cada 2 días por año. Los datos de WWLLN, desde enero 2005 hasta diciembre del 2012

Los mapas de $\rho \mathrm{L}$ y $\mathrm{Td}$ tienen una estructura similar y bien definida, con un máximo fuerte a lo largo de la costa chilena desde $42^{\circ}$ a $52^{\circ} \mathrm{S}$ (Figura 7-3). La AEA es prácticamente inexistente en los Andes australes, incluyendo los campos de hielo patagónicos del norte y del sur el masivo. También se observa una AEA muy baja en las tierras bajas y secas al este de los Andes australes, pero los valores de $\rho L$ y $T d$ aumentan en dirección al ecuador, alcanzando valores comparables a los observados en la Patagonia Occidental, al norte de $38^{\circ} \mathrm{S}$. También se observa una baja densidad de la AEA sobre la costa al sur de Chile, pero allí se produce descargas eléctricas como se muestra en la Figura 7-4donde se observa la ubicación de las descargas eléctricas detectadas en el año 2011. Sobre el Pacífico Sur se observa una banda de descargas eléctricas dispersa centrada alrededor de $3^{\circ}$ al norte del eje de precipitación máxima, una característica que también fue observada en otras regiones con trayectorias de tormentas (Virtz et al., 2013). 


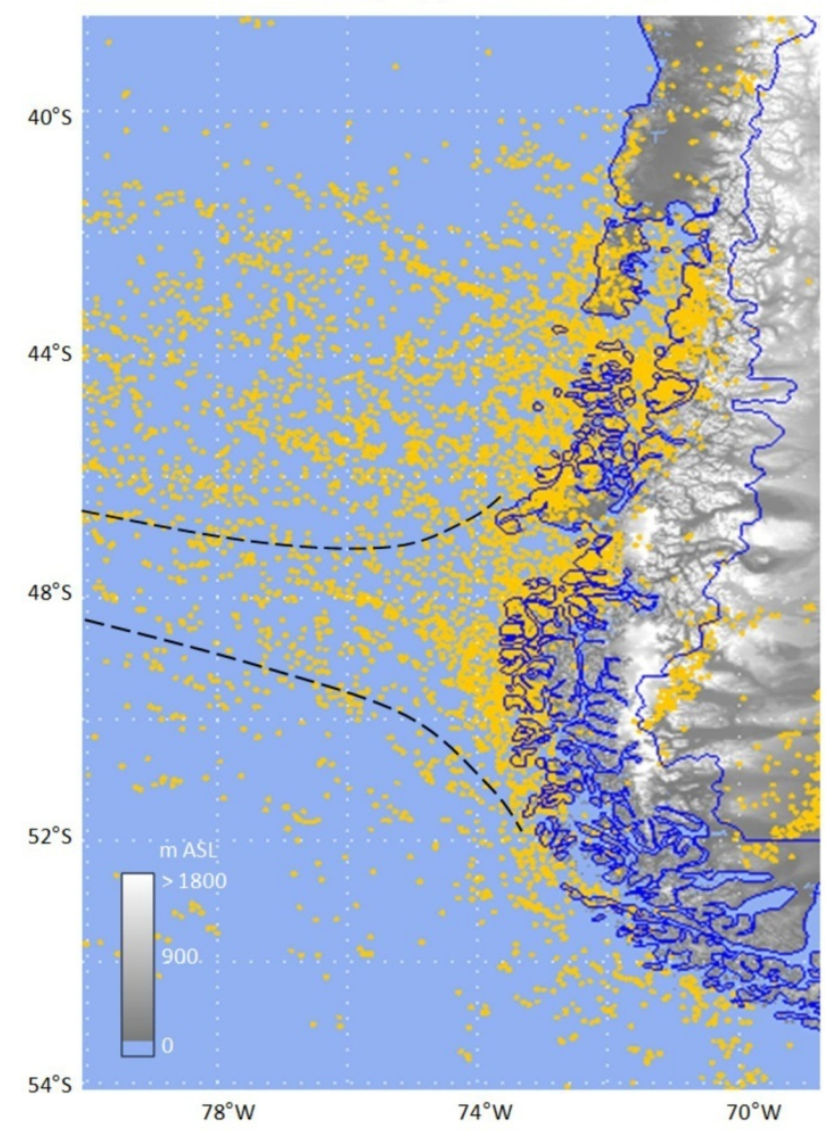

Figura 7-4I Descargas durante 2011 superpuestas a la elevación del terreno. Los datos de WWLLN.se grafican, sólo uno cada tres descargas. Las líneas discontinuas indican la banda de precipitación máxima en alta mar (de CMAP y los datos de PRECIS).

El valor máximo de la AEA a lo largo de la costa chilena es más notable teniendo en cuenta la geografía compleja de esta zona, llena de pequeñas islas, fiordos, ensenada y canales. Una inspección más cercana de la Figura 7-3a muestra un máximo localizado sobre el paseo marítimo con características geográficas complejas, que incluyen la isla de Madre de Dios $\left(50^{\circ} \mathrm{S}\right)$ y Wellington $\left(49^{\circ} \mathrm{S}\right)$, la península de Taitao $\left(46,5^{\circ} \mathrm{S}\right)$ y la costa del Golfo de Penas $\left(47,5^{\circ} \mathrm{S}\right)$. Un transecta zonal en $49^{\circ} \mathrm{S}$ (Figura $\left.7-5\right)$ confirma la preferencia de AEA por las llanuras costeras (0-100m ASL) y expuestos a los vientos de componente NO. La precipitación en estos sectores es desconocida, pero probablemente sea de alrededor de $5.000 \mathrm{~mm}$ año ${ }^{-1}$, muy por debajo de la precipitación estimada en los campos de hielo de la Patagonia ubicados 50$100 \mathrm{~km}$ hacia el interior que alcanzan más de 1,5 km de ASL. También se ha encontrado un desplazamiento espacial entre el máximo de la AEA y la máxima altura del terreno y la posición espacial del máximo de precipitación en zonas tropicales (por ejemplo, Bürgesser et al. 2013). 


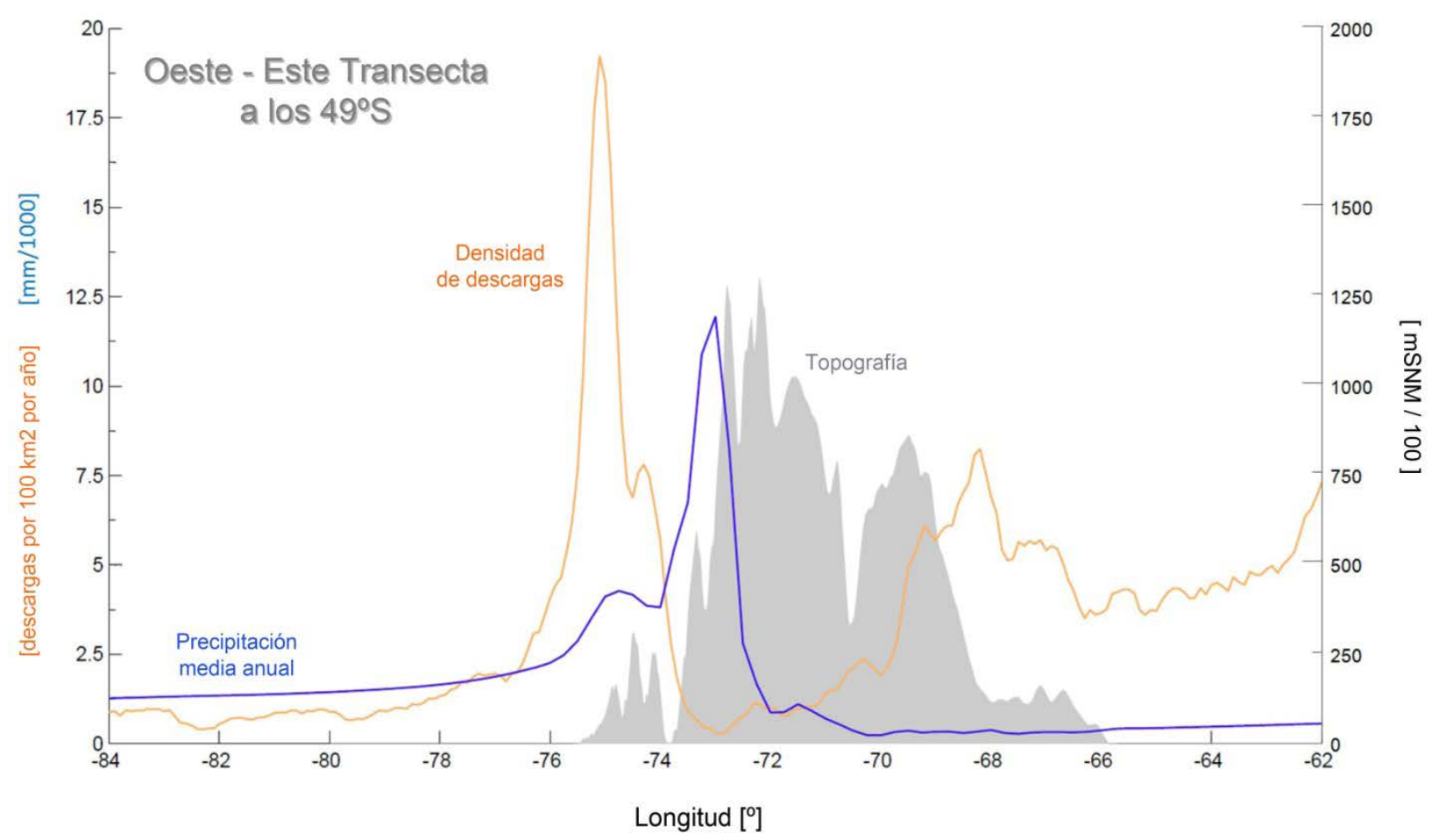

Figura 7-5 Transecta oeste-este a los $49^{\circ} S$ de la densidad de descargas(línea amarilla, a partir WWLLN), la precipitación media anual (línea azul, de PRECIS) y elevación del terreno (área gris, a partir SRTM).

El comportamiento temporal de la AEA en Chile austral se ilustra con la serie temporal de la cantidad diaria de descargas eléctricas en el área de la Patagonia Occidental $\left(42-54^{\circ} \mathrm{S} / 76-70^{\circ} \mathrm{O}\right.$, ver Figura $\left.7-3\right)$ para el año 2011 (Figura 7-6a). Debido a que las descargas están agrupadas en solo algunos puntos a lo largo de la costa, nuestros resultados no son sensibles al tamaño del área utilizada. Durante 2011, hubo 125 días de descargas eléctricas; otros años muestran un comportamiento similar (no se muestran) y el número anual de días de descargas eléctricas en el área de la Patagonia Occidental varía entre 107 en 2008 a 151 en 2012. La AEA se concentra en eventos con una duración de 1 a 4 días que ocurren un par de veces al mes; la mayoría de estos días tienen menos de 10 descargas eléctricas en el área de la Patagonia Occidental, pero el $10 \%$ de ellos presentan más de 50 descargas eléctricas. La Figura 7-6a también incluye la precipitación total CFSR sobre el área de la Patagonia Occidental, que es altamente recurrente allí (casi el $70 \%$ de los días); los episodios con descargas eléctricas están siempre acompañados de precipitaciones pero hay muchos días con precipitación y sin descargas eléctricas. 


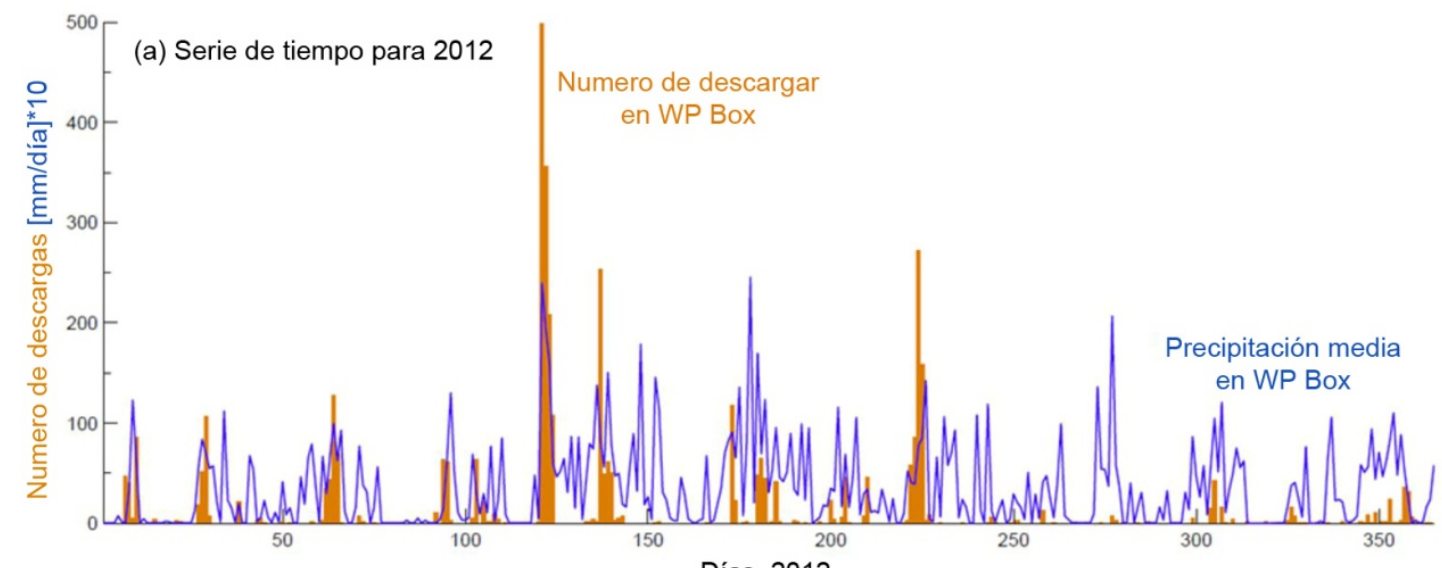

Días, 2012

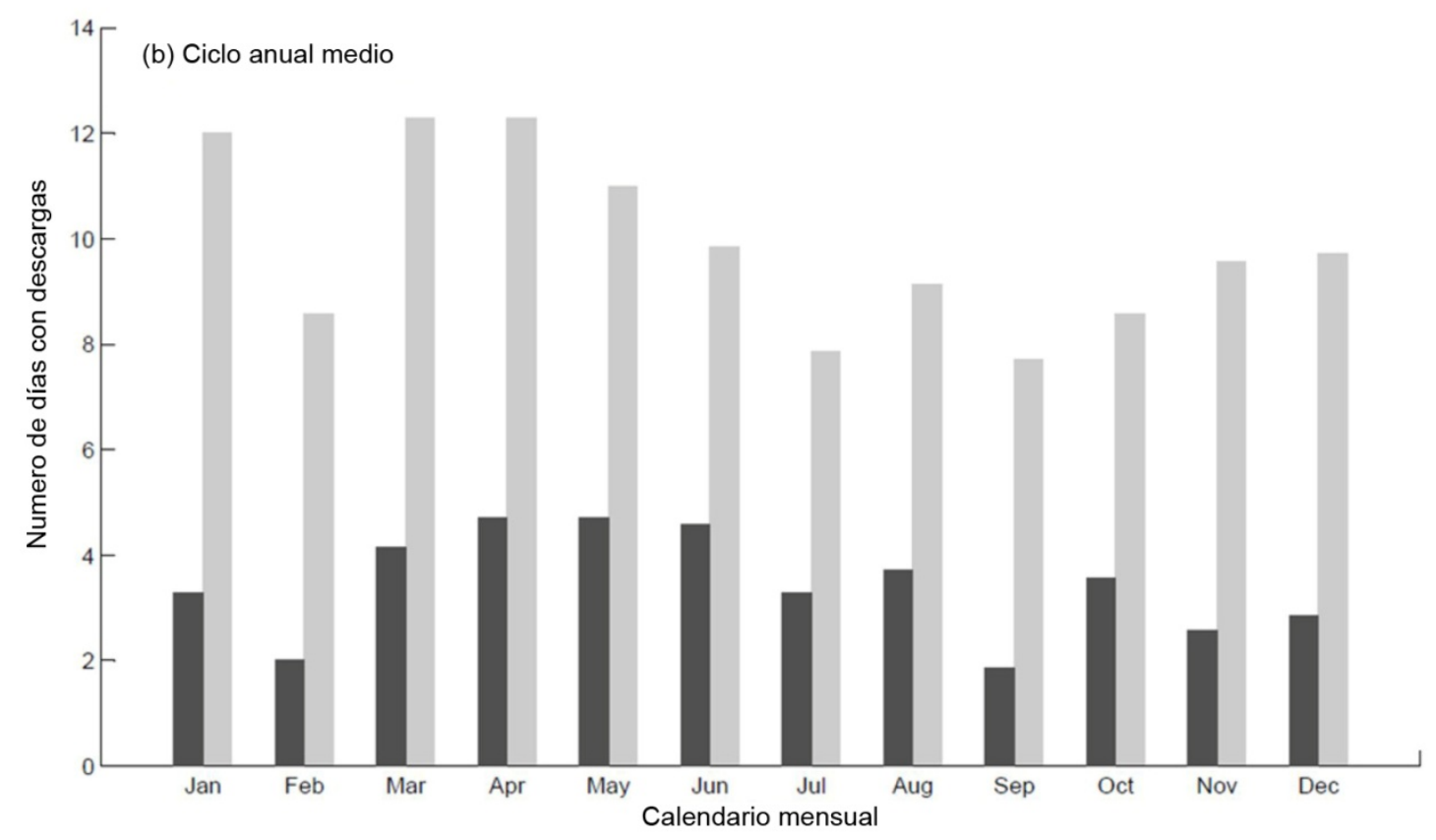

Figura 7-6(a) Series temporales del número de descargas detectadas por la WWLLN y Precipitación total CFSR en la Patagonia occidental (42-54 ${ }^{\circ} \mathrm{S} / 76-70^{\circ} \mathrm{W}$, ver. Fig.7 - 3) durante el año 2012. (b) La media de ciclo anual del número de días con al menos 1 (10) descargas sobre la Patagonia Occidental indicado por las barras (negro) de color gris. Los datos son dela WWLLN, enero 2005 a diciembre 2012.

Utilizando el periodo de 8 años, el número medio mensual de días con descargas eléctricas (así como los días con más de 10 descargas eléctricas) en el área de la Patagonia Occidental se muestra en la Figura 7-6b. La actividad eléctrica en la Patagonia occidental exhibe un ciclo anual débil en consonancia con un forzado térmico pequeño en altas latitudes. Sin embargo, la AEA tiende a ser más frecuentes desde el inicio del verano austral hasta finales del otoño, con un pico en Marzo - Abril, y algo menor a finales del invierno y durante la primavera (véase también Figura 7-6 a) También verificamos que el patrón de densidad de AEA mensual y estacional es muy similar al mapa anual (Figura 7-3), con un fuerte máximo de AEA a lo largo de la costa de la Patagonia occidental, donde se producen las descargas eléctricas en casi una tercera parte de los días. 


\section{Un caso de estudio}

Cerca de 500 descargas eléctricas se detectaron dentro del área de la Patagonia Occidental el 30 de abril 2012 (la mayoría de ellos después del mediodía), el máximo conteo diario registrado. La AEA significativa continuó hasta el 3 de mayo (Figura 7-7A) con un total de 900 descargas eléctricas durante este evento. La Figura 7-8 muestra la ubicación de las descargas eléctricas detectadas (tanto por WWLLN y por STARNET) durante el 30 de abril. La distribución de las descargas eléctricas en ese día siguieron el patrón climatológico (Figura 7-8 y Figura 7-3) con la mayoría de ellas agrupadas a lo largo de la costa del sur de Chile, con descargas eléctricas dispersas en alta mar y $\sin$ descargas eléctricas en los Andes australes o más al este. También se observó un acuerdo general en la ubicación de las descargas eléctricas de las dos bases de datos, aunque WWLLN detectado 5 veces más descargas eléctricas que STARNET.

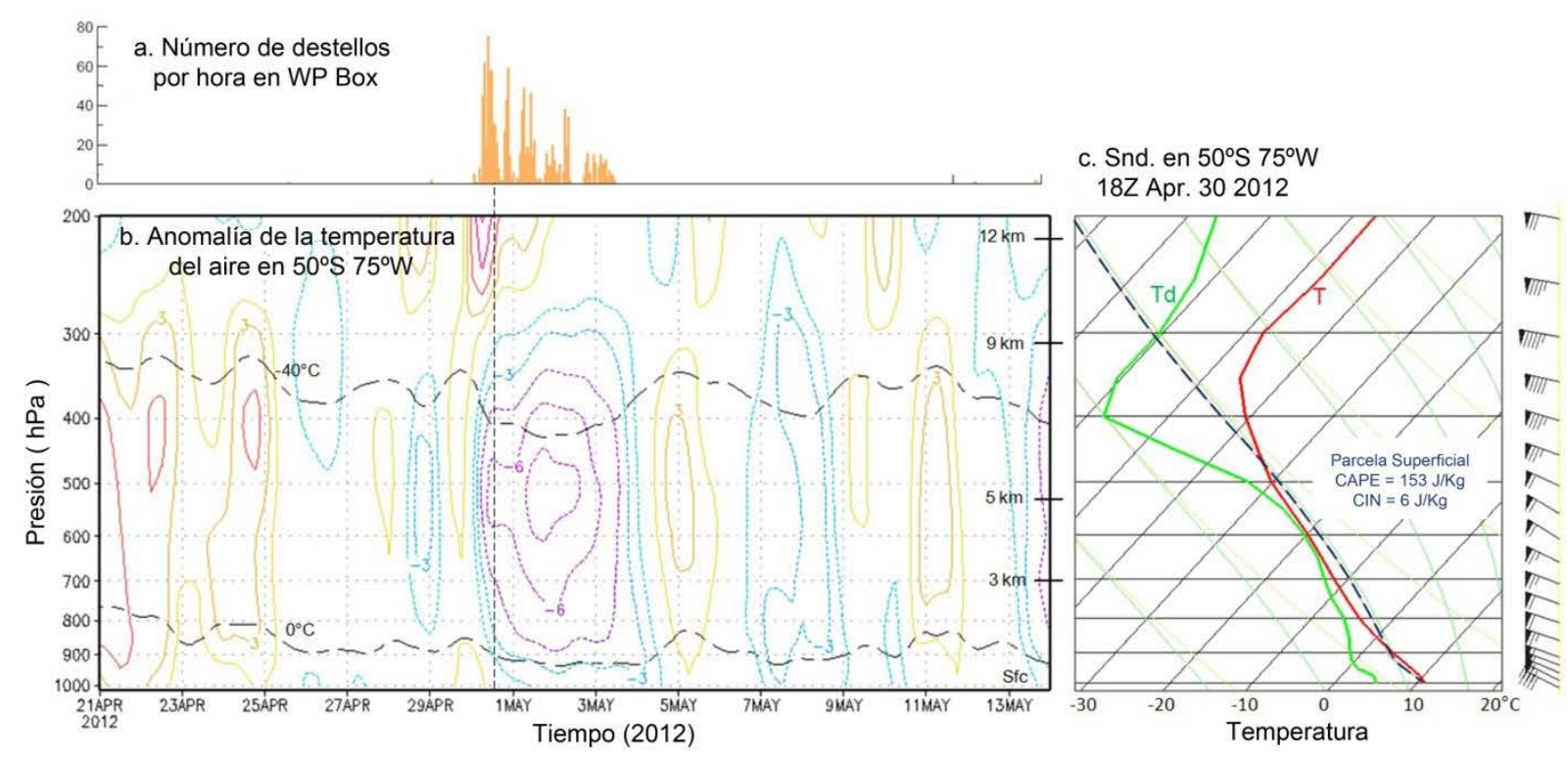

Figura 7-7Selección de variables meteorológicas durante una tormenta electrica en la Patagonia Occidental. (a) Número de descargas (WWLLN) por hora en la Patagonia Occidental del 21 de abril al 13 de mayo 201 2. Los trazos se concentraron en la tarde del 30 de abril y continuaron hasta el 3 de mayo. (b) Diagrama de tiempo y altura de la anomalía de la temperatura del aire a $50^{\circ} \mathrm{S} 75^{\circ} \mathrm{W}$ (Golfo de Penas). Se calcularon las anomalías restando la media estacional a partir de los datos de 6 horas en cada nivel. (c) Sondeo sobre el Golfo de Penas a las $18 Z 30$ de abril de 2012 (momento de máxima actividad de la AEA). Paneles (b) y (c) se construyeron utilizando los datos CFSR.

Las imágenes del GOES compuestas (1745 UTC del 30 de abril. Figura 7-8) revelan junto con el mapa meteorológico simultáneo una importante características meteorológicas de este evento (Figura 7-9). Un ingrediente clave es un ciclón profundo (con una presión en el centro $<955 \mathrm{hPa}$ ) al oeste del extremo sur del continente, generando un flujo de bajo nivel fuerte del oeste sobre el Pacífico Sur (Figura 7-10; véase también el perfil del viento en la Figura 7-7c). También se observa un mínimo cerrado a una altura geopotencial de $500 \mathrm{hPa}$ justo encima del ciclón superficial (Figura 7-9), indicando la etapa de madurez de este sistema. Las bajas temperaturas observadas en la troposfera media se movieron hacia el este 
desde el centro del Pacífico el 27 de abril para llegar a la costa oeste el 30 de abril y se mantuvo inmóvil allí durante los próximos 4 días (no se muestran).

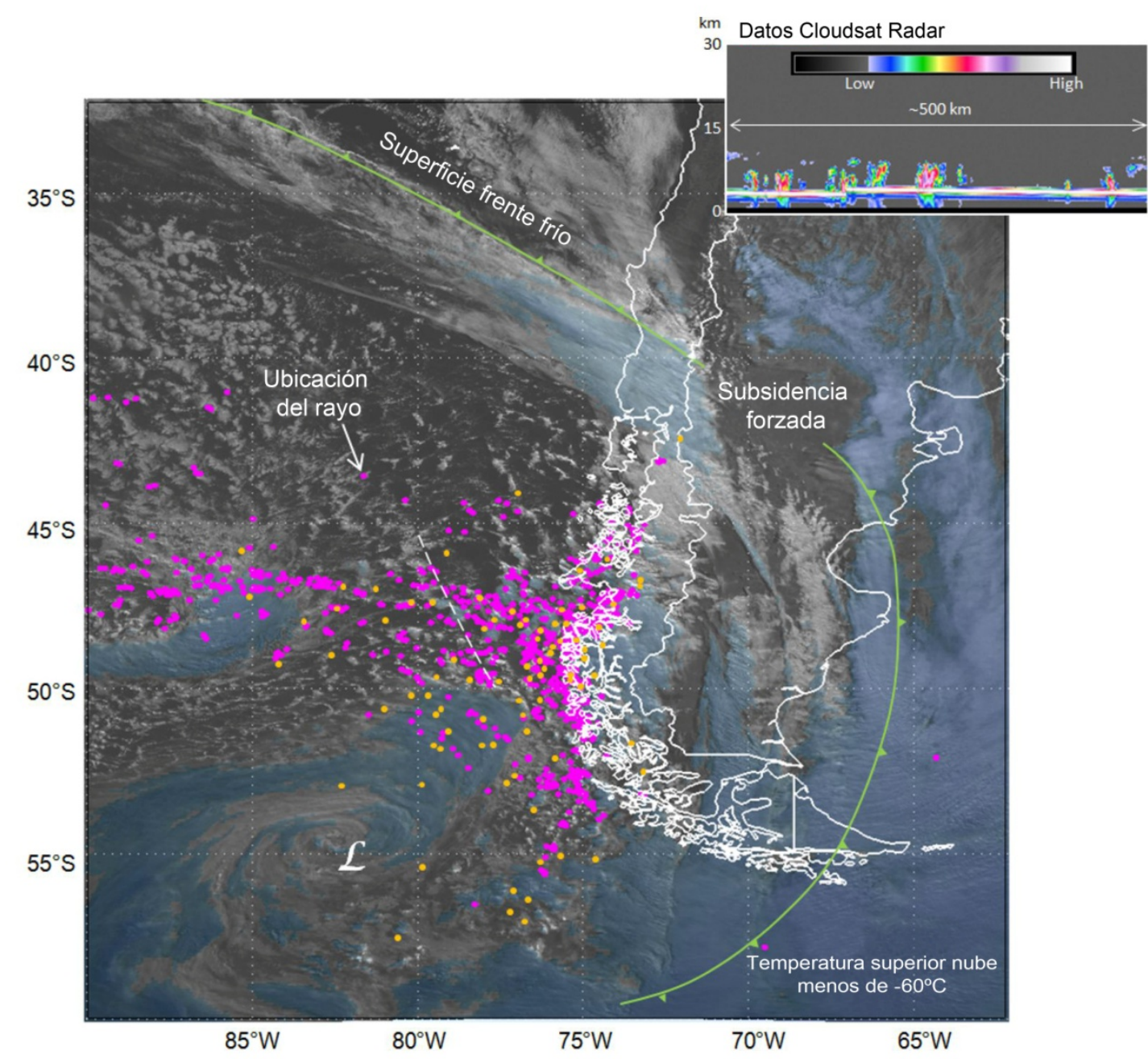

Figura 7-8Panel principal: localizaciones de descargas WWLLN (círculos de color púrpura) y StartNet (círculos de color naranja) durante la tarde del 30 de abril del 2012, se superponen a la imagen visible del GOES-13 a las 1745 UTC de ese día. EI sombreado azul débil indica temperaturas en el tope de la nube más baja de -60 ${ }^{\circ} \mathrm{C}$ derivado del GOES-13 de infrarrojos (IR2) Imagen concurrente. También se indica la posición de un frente frío que cae en el sur de Chile. Recuadro: imagen Mirada rápida de los datos de radar CloudSat a lo largo del transecta en blanco, línea punteada en el mapa de las 18 UTC 01 de mayo 2012.

La advección de aire frío mantuvo un frente frío sobre el Pacífico Sur, que se evidencia en el análisis de la temperatura e imágenes de satélite, interceptando la costa chilena a unos $38^{\circ} \mathrm{S}$. El frente se interrumpe al este de los Andes, pero se vuelve a formar cerca de la frontera con el océano Atlántico, formando una espiral hacia el centro del ciclón. La precipitación total (estable + convectiva Figura 7-10c) alcanza un máximo en el sector donde el frente frío toca tierra (hasta $25 \mathrm{~mm}$ en $6 \mathrm{~h}$ ) y también es alto sobre las montañas hasta $45^{\circ} \mathrm{S}$, debido a un ascenso orográfico marcado. Cabe destacar que la AEA no se produjo a lo largo del frente frío sino en la masa post-frontal de aire frío, que ha alcanzado la Patagonia occidental. Nubes celulares abiertas son evidentes en la imagen de satélite del sector post- 
frontal fuera de la Patagonia Occidental y hay un atisbo de desarrollo de una baja polar en el oeste lejano $\left(47^{\circ} \mathrm{S}-87^{\circ} \mathrm{O}\right)$ acompañado de algunas descargas eléctricas. La potencia del eco de retorno de una imagen rápida del CloudSat (recuadro en. Figura 7-8) revela aún más la naturaleza poco profunda de la convección post-frontal con topes de nubes por debajo de los $\sim 7 \mathrm{~km}$ ASL. También se observa que la precipitación convectiva fue un contribuyente menor sobre el sector frontal y sobre los Andes australes pero dominan sobre el sector post-frontal ( $\sim \mathrm{mm}$ en $6 \mathrm{~h}$, Figura 7-10d) donde se produce la actividad eléctrica.

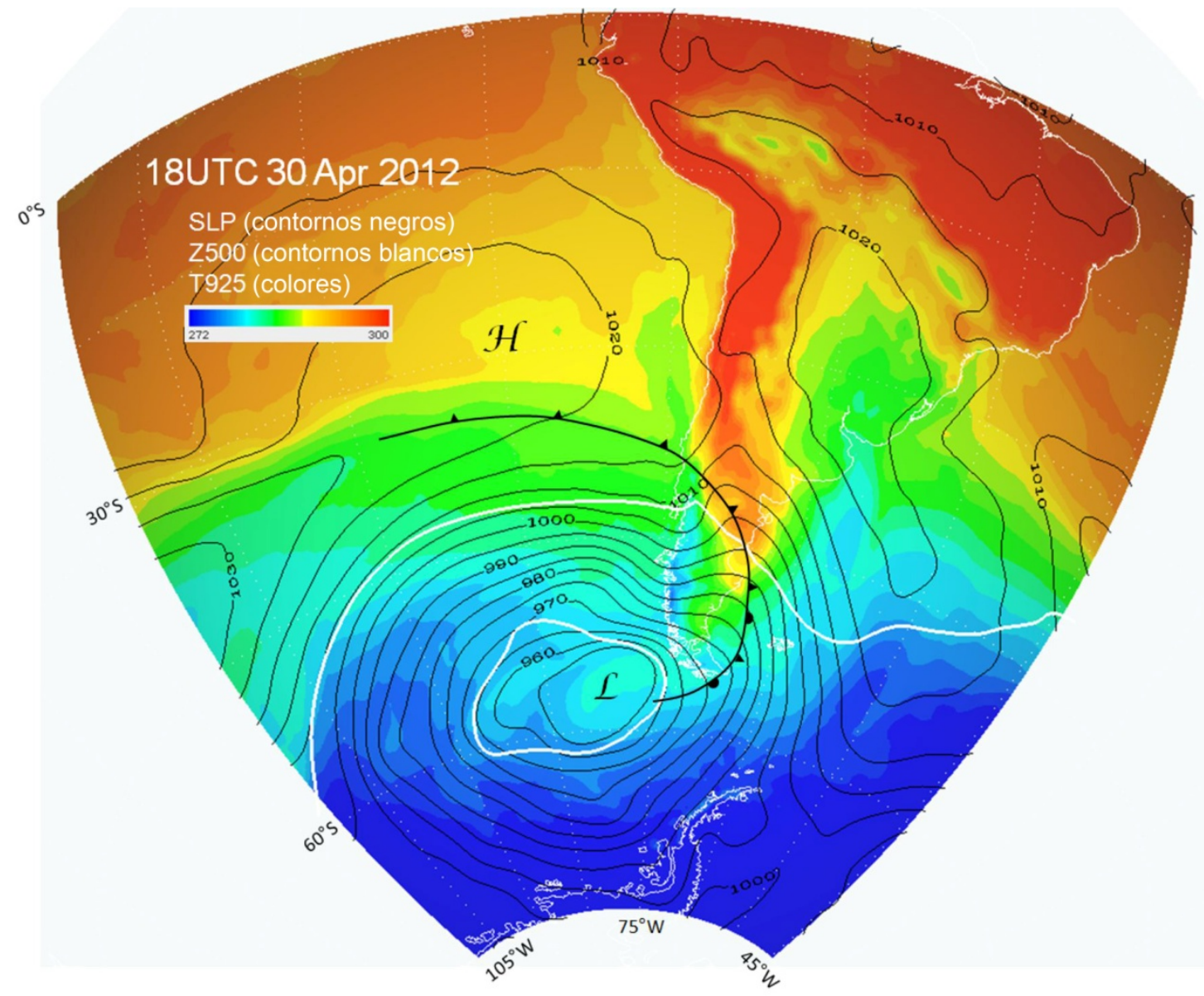

Figura 7-9Mapa del tiempo válido a las 18 UTC 30 de abril 2012, incluyendo SLP (contorneado cada 5 hPa), temperatura de 925 hPa del aire (sombreado) y $300 \mathrm{hPa}$ altura geopotencial (5600 y $5500 \mathrm{mgp}$, contornos blancos). También se indica el principal frente frío arraigado en el ciclón (L) sobre el Pacífico sur. Los datos de CFSR.

Un diagrama tiempo-altura de las anomalías de la temperatura del aire (Figura 7-7b) muestra el enfriamiento diferencial en niveles bajos y medios fuera del área de la Patagonia occidental durante el desarrollo de este evento. En la troposfera media hubo un enfriamiento rápido al inicio del evento (30 de abril), en relación con la llegada de la masa de aire post-frontal. El enfriamiento continúo hasta el 2 de mayo, cuando la temperatura del aire a $500 \mathrm{hPa}$ fue $10^{\circ} \mathrm{C}$ menor de la media estacional. El 
enfriamiento por debajo de $900 \mathrm{hPa}$ fue más débil (menos de $3^{\circ} \mathrm{C}$ ) y se llevó a cabo de manera más gradual, debido al flujo de calor $\left(\sim 80 \mathrm{Wm}^{-2}\right)$ sobre la superficie del mar. Por lo tanto, la condición más inestable en la Patagonia Occidental se produjo el 30 de abril, 12 a 24 horas después del paso del frente frío. De hecho, se observan valores de energía potencial convectiva disponible (CAPE) de alrededor de $150 \mathrm{~J} / \mathrm{kg}$ e índices de elevación negativa (ㄴ) en gran parte del sector post-frontal durante el período de intensa AEA (Figura 7-10. b).
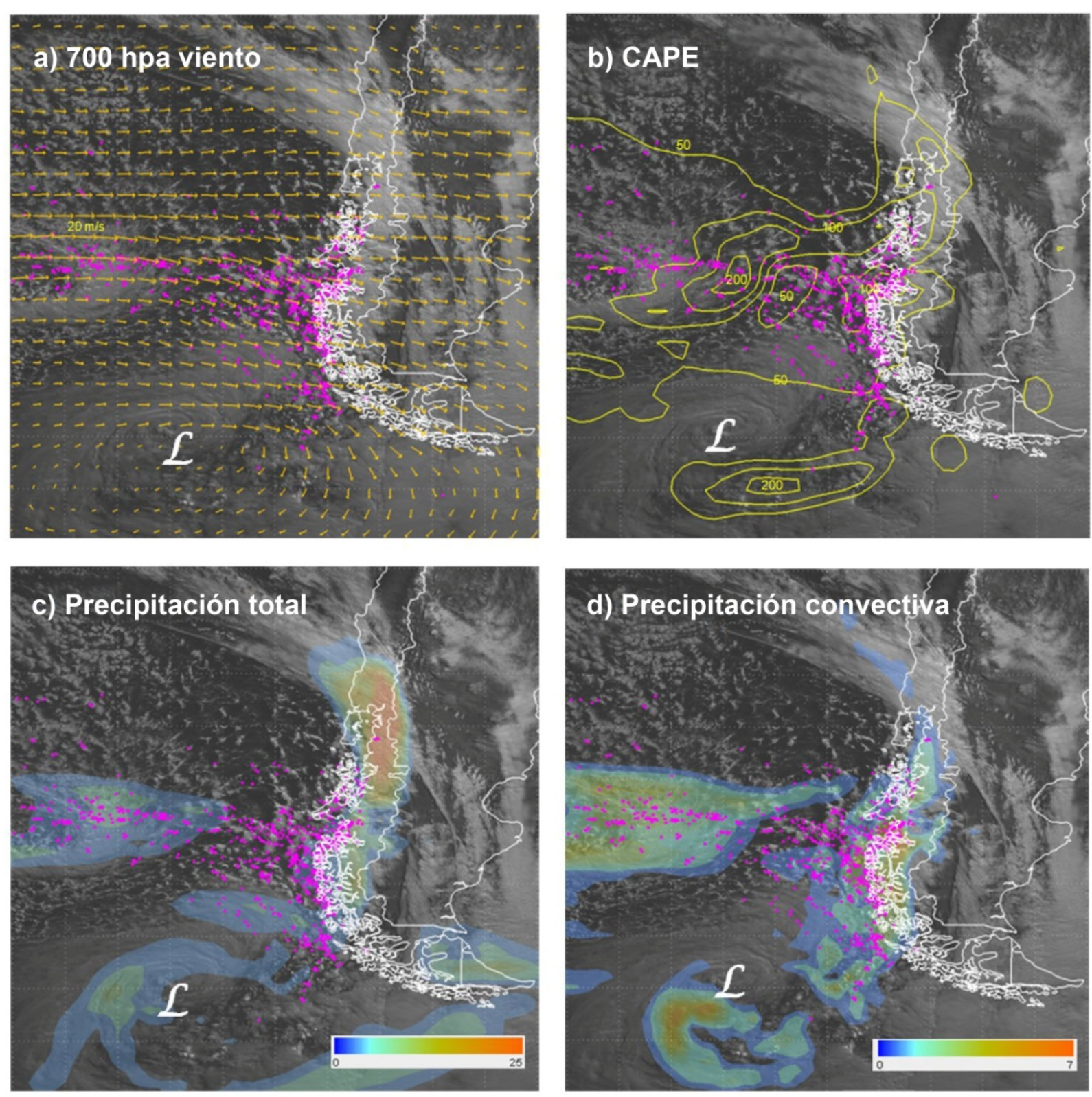

Figura 7-10Selección de campos meteorológicos CFSR de 30 de abril de 201 2, a las 18 UTC, superpuesta en el GOES-13 Imagen visible y descargas WWLLN (círculos púrpuras) durante la tarde de ese día. (A) 700 hPa vectores de viento. Las flechas más largas son de $20 \mathrm{~m} / \mathrm{s}$. (B) CAPE superficie contorneada cada $50 \mathrm{~J} / \mathrm{kg}$. (C) la precipitación total acumulado durante las últimas 6 horas (escala en la parte inferior). (D) Precipitacion convectiva acumulada durante las últimas 6 horas (escala en la parte inferior). En cada panel de la letra L indica el centro del ciclón 
Un sondeo (a partir de datos CFSR) en el Golfo de Penas $\left(50^{\circ} \mathrm{S} ; 75^{\circ} \mathrm{O}\right)$, para el momento de máxima AEA, ilustra la estructura térmica de la masa de aire post-frontal (Figura 7-7c). Cerca de la superficie la temperatura del aire fue de $\sim 10^{\circ} \mathrm{C}$, el nivel de congelación se encontraba a $\sim 1300 \mathrm{~m}$ ASL y la isoterma de $-40^{\circ} \mathrm{C}$ a $\sim 6500 \mathrm{~m}$ ASL. Se observó saturación en la baja troposfera cubierta por una capa de aire seco por encima de los $500 \mathrm{hPa}$. Más importante aún, una parcela de aire levantada de la superficie alcanza su nivel de convección libre a sólo $1000 \mathrm{~m}$ ASL y su nivel de boyancia neutra a $5500 \mathrm{~m} \mathrm{ASL}$, por lo que había un valor muy pequeño de inhibición convectiva (CIN $<10 \mathrm{~J} / \mathrm{Kg}$ ), un valor modesto del CAPE (156 $\mathrm{J} / \mathrm{Kg}$ ) y valores ligeramente negativos del $\mathrm{LI}\left(-0.2^{\circ} \mathrm{C}\right)$

\section{Análisis climatológico}

\section{a. Composición a gran escala}

Una rápida inspección de los mapas meteorológicos y de las imágenes de satélite para varios casos de AEA significativa en la Patagonia occidental revela un entorno sinóptico similar al documentado en nuestro caso de estudio. Estas condiciones se sintetizan aquí usando un análisis de composición de los campos meteorológicos seleccionados para los 90 días de la base de datos con más de 50 descargas eléctricas en el área de la Patagonia occidental. La distribución de la AEA para este sub-muestreo de días sigue el mismo patrón espacial del total de la base de datos (no se muestra).

Los mapas compuestos de presión a nivel del mar (PNM) y de temperatura del aire a $925 \mathrm{hPa}$ (Figura 7-11a) muestran un centro de baja presión al oeste del Pasaje Drake y la incursión de aire frío sobre el sureste del Pacífico que se extiende a lo largo de la costa chilena hasta $\sim 40^{\circ} \mathrm{S}$. La ubicación de la zona de baja presión compuesta (muy cerca de la posición del ciclón en el caso de estudio) refleja que casi todas las tormentas eléctricas que se producen en la Patagonia Occidental se asocian con un centro de baja presión sobre el sureste del Pacífico (observar la ubicación del centro del ciclón para los casos seleccionados). Del mismo modo, un frente frío tocando tierra al norte de la Patagonia occidental es una característica muy común de estas tormentas, evidenciado en nuestro análisis compuesto por un zona baroclínica en la temperatura del aire de bajo nivel (Figura 7-11a) y en una lengua de aire húmedo por delante del frente en el mapa de anomalías del agua precipitable (Figura 7-11d). Por lo tanto, se produce AEA significativa en la Patagonia occidental más a menudo cuando la masa de aire post-frontal ha llegado a esta región. La Figura 7-11b muestra las anomalías compuestas de PNM y a una altura geopotencial de $300 \mathrm{hPa}$. Las anomalías negativas están ubicadas justo al oeste del extremo sur del continente, indicando la estructura barotrópica y la etapa de madurez del ciclón de latitudes medias que ha flotado lentamente hacia el este. 
a) Temperatura T925 (sombreado) \& PNL (contornos)

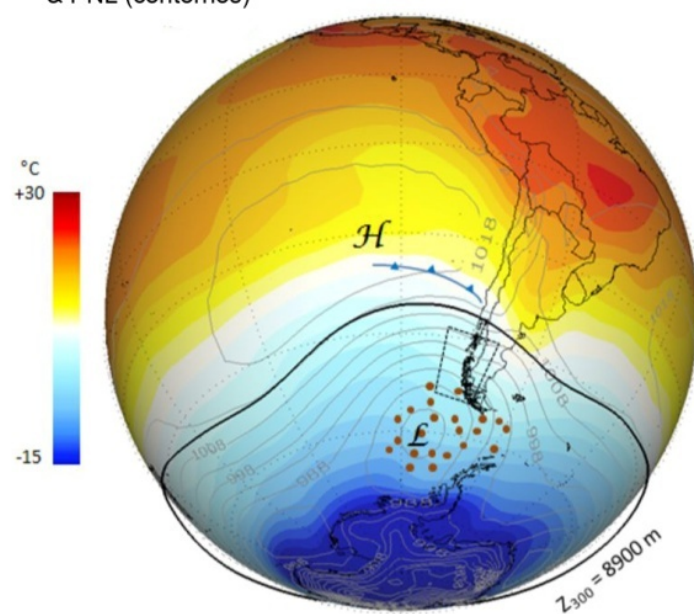

c) Anomalia T925 (sombreado) anomalia T500 (contornos)

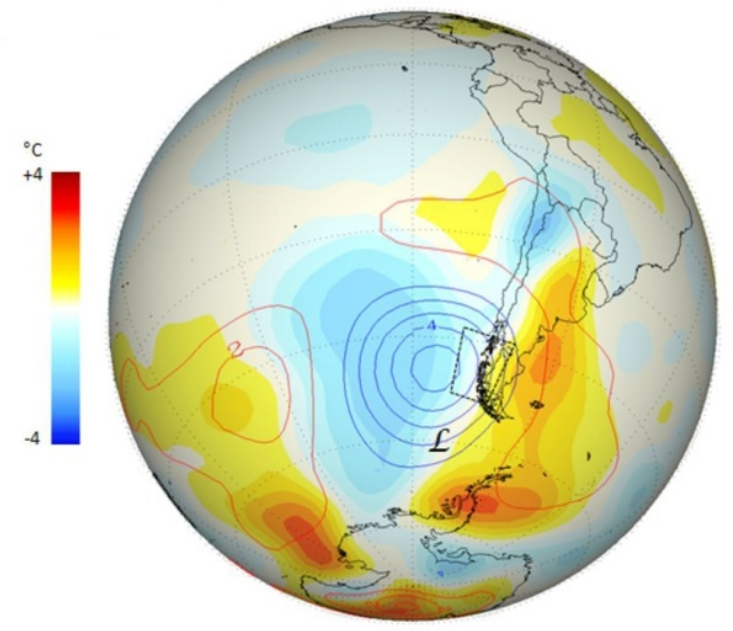

b) Anomalia PNL (sombreado) \& anomalia de $z 300$ (contornos)

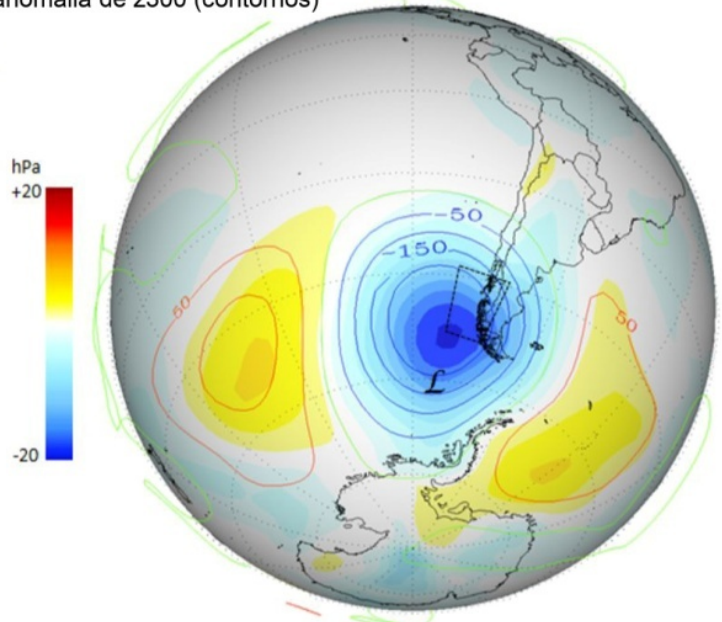

d) Lifted Index (sombreado)

anomalia de agua precipitable $>0$ (contornos)

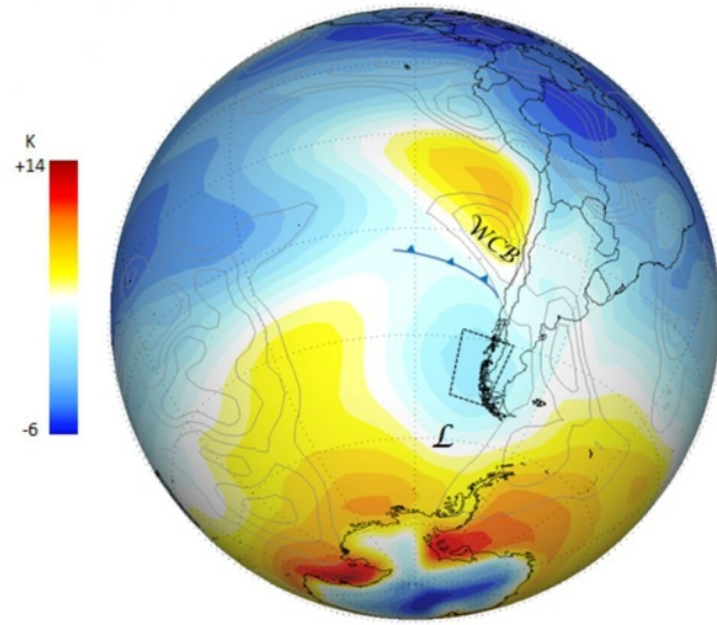

Figura 7-11mapas compuestos de campos meteorológicos CFSR seleccionados para los 90 días con más de 50 descargas en la Patagonia Occidental (cuadro de líneas discontinuas). (a) la presión a nivel del mar (SLP) contornea cada 5 hPa y 925 hPa Temperatura del aire (sombreado, escala de la izquierda). También se indica el núcleo del ciclón para casos seleccionados (puntos rojos) y la localización más frecuente del frente frío sobre el sureste del Pacífico. (b) las anomalías de SLP (sombra, escala de la izquierda) y 300 hPa anomalías altura geopotencial (contorneados cada 50 MGP). Las anomalías son calculadas como salida de largo plazo-media. (C) $925 \mathrm{hPa}$ anomalías de la temperatura del aire (sombreado, escala de la izquierda) y anomalías de la temperatura del aire en $500 \mathrm{hPa}$ (contorneados cada $1^{\circ} \mathrm{C}$ ). (d) índice de elevación (sombreado, escala de la izquierda) y la anomalía del agua precipitable (contorneada a los 5, 10, 15 y $\geq 20 \mathrm{~cm}$ ). La letra L indica el centro promedio ciclón y WCB es la ubicación media del cinturón cálido.

Las anomalías negativas de temperatura en la parte media y baja de la troposfera (Figura 7-11 c) también se encuentran fuera del área de la Patagonia Occidental. A largo de la costa del sur de Chile, el enfriamiento a $500 \mathrm{hPa}$ es mucho más grande $\left(\sim 4^{\circ} \mathrm{C}\right)$ que el enfriamiento en niveles bajos $\left(<1^{\circ} \mathrm{C}\right)$, dando lugar al desarrollo de una amplia zona de inestabilidad convectiva en la masa de aire post-frontal que abarcan a la Patagonia y al Pacífico adyacente. Para ilustrar estas condiciones inestables la Figura 7-11d muestra el mapa compuesto del índice de elevación (LI) superficial con valores cercanos a cero sobre la Patagonia occidental y mar adentro. Elegimos el índice de elevación, dada su distribución 
normal, como más adecuado para el análisis de composición, pero otros índices de estabilidad muestran un patrón similar (por ejemplo, CAPE; no se muestra). Es dentro de esta región débilmente inestable, donde se producen la mayor parte de la AEA.

\section{b. Control local}

Nuestro caso de estudio y el análisis de composición sugieren que tanto la inestabilidad débil en la troposfera inferior (por ejemplo, CAPE distinto de cero, índice de elevación cercano a cero) y el flujo de bajo nivel fuerte del oeste caracterizan el entorno local durante las tormentas eléctricas en la Patagonia occidental. Para generalizar estos resultados, vamos a examinar la distribución conjunta del índice diario de elevación (LI) y la velocidad zonal del viento a $850 \mathrm{hPa}$ (U850) promediada sobre el área de la Patagonia occidental (Figura 7-12). Cuando se considera la muestra completa (todos los días de 20052012) la distribución conjunta (mostrado por isolíneas de frecuencia) es aproximadamente binormal, aunque con un sesgo positivo para LI y U850, con valores centrales (media \pm desviación estándar) de $5 \pm$ $3,2^{\circ} \mathrm{C}$ y $11,2 \pm 3,2 \mathrm{~m} \mathrm{~s}^{-1}$, respectivamente.

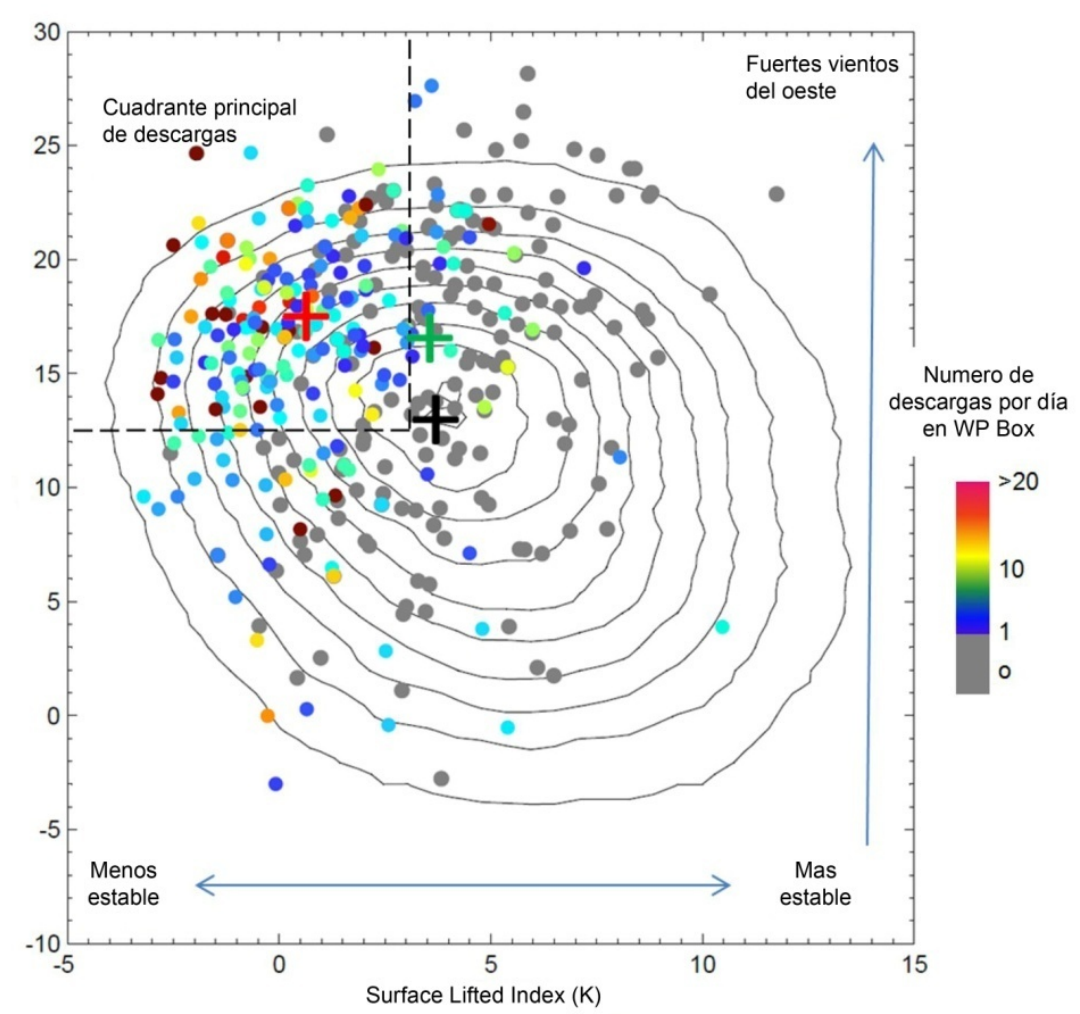

Figura 7-12. Conjunto de distribución de la superficie media diaria índice de elevación (LI, eje horizontal) y el viento zonal a los $850 \mathrm{hPa}$ (U850, eje vertical) en el cuadro de la Patagonia Occidental (véase. Figura 7-3) teniendo en cuenta todos los días a partir de enero 2005 a diciembre 2012. Las isolíneas de frecuencia son sorteados todos los $2 \%$ y el promedio de la muestra completa se indica con una cruz de color negro. Los círculos grises son los valores diarios de LI-U850 para los días con más de $10 \mathrm{~mm}$ en la caja de la Patagonia Occidental, la media submuestra se indica con una cruz verde. Los círculos de color son los 
valores diarios de LI-U850 para los días con más de 1 descarga detectada por WWLLN sobre la Patagonia Occidental, la media submuestra se indica con una cruz roja. El color de estos círculos indica el número de descargas: colores cálidos (en frío) indican más descargas (menos).

La sub-muestra de días con más de $10 \mathrm{~mm}$ de precipitación (día de lluvias) tienden a ocurrir con flujos mayores que el flujo zonal promedio $\left(16,2 \pm 2 \mathrm{~ms}^{-1}\right)$ lo cual es consistente con Garreaud et al. (2013,. su fig. 5) y evidencia una fuerte correlación entre la precipitación y el viento zonal arriba de los Andes extratropical. En contraste, los días de lluvia se producen para todo el rango de LI, y el promedio de la sub-muestra $\left(3,7 \pm 2.6^{\circ} \mathrm{C}\right)$ es sólo ligeramente inferior a la media de la muestra completa.

La sub-muestra de días de AEA (más de una descarga eléctrica en la Patagonia Occidental) se concentra en el cuadrante superior izquierdo de la distribución de frecuencia LI-U850: día con AEA tienden a ocurrir cuando los vientos del oeste de bajo nivel son más fuertes que el promedio zonal (16,5 $\left.\pm 2 \mathrm{~ms}^{-1}\right)$ y con valores $\mathrm{LI}$ mucho más bajo que el promedio $\left(0,7 \pm 1,3^{\circ} \mathrm{C}\right)$. El control de estabilidad de la actividad eléctrica es más apretado que el control de flujo zonal: alrededor del $15 \%$ de los días con descargas eléctricas ocurren con un flujo más bien débil (menos de $13 \mathrm{~m} / \mathrm{s}$ ), pero casi no hay días con descargas eléctricas cuando el valor de $\mathrm{LI}$ es mayor que $5^{\circ} \mathrm{C}$. También existe una relación logarítmica positiva, aunque débil, entre la estabilidad y el número de descargas eléctricas a escalas de tiempo diarias sobre el oeste de la Patagonia (no se muestra), en consonancia con las conclusiones de Pessi y Businger (2009a) sobre el Pacífico Norte.

El control que la estabilidad aplica sobre la AEA también se produce espacialmente. La Figura 7-13muestra la frecuencia de días con $\mathrm{LI} \leq 0.5^{\circ} \mathrm{C}$ (aproximadamente equivalente a un CAPE $\geq 50 \mathrm{~J} / \mathrm{Kg}$ ) en el sur de América del Sur, un valor modesto para la convección pero suficientemente bajo para iniciar descargas eléctricas sobre la Patagonia occidental. Las mayores frecuencias (alrededor del 30\%) en las regiones extratropicales se encuentran a lo largo de la costa del sur de Chile, decayendo gradualmente en alta mar y abruptamente hacia el interior, combinando perfectamente con la región de alta actividad de tormenta eléctrica en la Patagonia Occidental (Figura 7-3 y Figura 7-13). Recordemos que las condiciones inestables en esta región están asociadas con un enfriamiento transitorio que aumenta hacia arriba bajo las condiciones sinópticas identificadas anteriormente. 


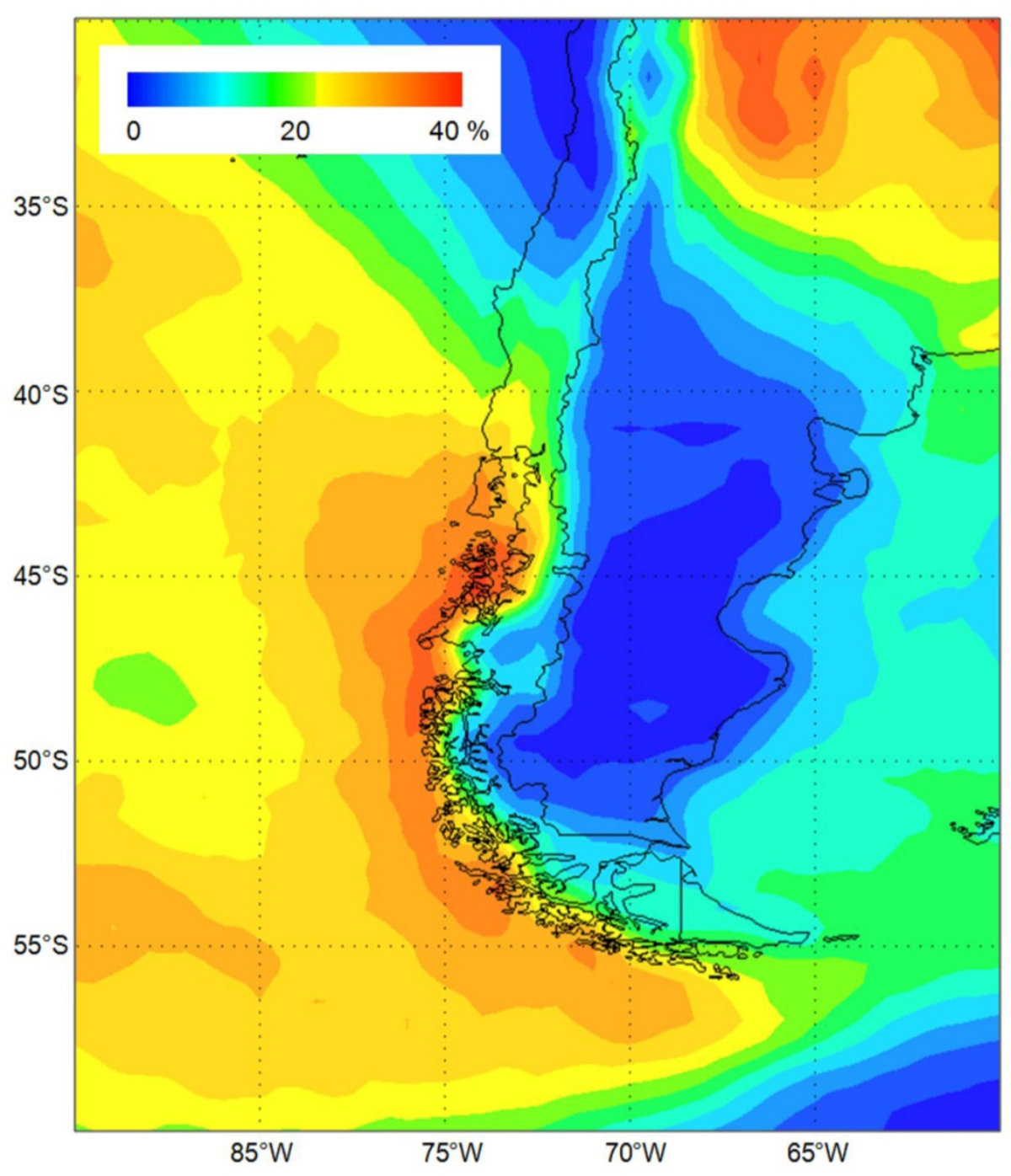

Figura 7-13 Frecuencia media anual de la superficie de índice de elevación (LI) de menos de $0,5^{\circ} \mathrm{C}$ en el sur de Sudamérica. Calculados a partir de los datos de CFSR (2005-2012).

El confinamiento en la zonas de costa con valores de $\mathrm{LI}$ frecuentemente cercanos a cero que se observa en la Figura 7-13es más bien desconcertante. La ocurrencia de anomalías frías intensas en los niveles medios debería ser tan frecuente en la zona costera como en alta mar, por lo que las condiciones cercanas a la superficie deben desempeñar un papel importante. Como se ha señalado antes, la TSM (Temperatura Superficial del Mar) frías se encuentran a lo largo de la costa occidental de América del Sur. Sin embargo, la deriva del viento del oeste, una corriente superficial en gran parte del Pacífico, intercepta al continente a los $48^{\circ} \mathrm{S}$ que conduce a una corriente en dirección al polo y a un descenso en la costa fuera de la Patagonia Occidental (Neshyba y Fonseca 1980). En consecuencia, las SST en la región cercana a la costa son $3-4^{\circ} \mathrm{C}$ más cálida que en la costa (Figura 7-14), produciendo las condiciones 
más favorables para la generación de inestabilidades que en cualquier otro lugar en el sureste del Pacífico.

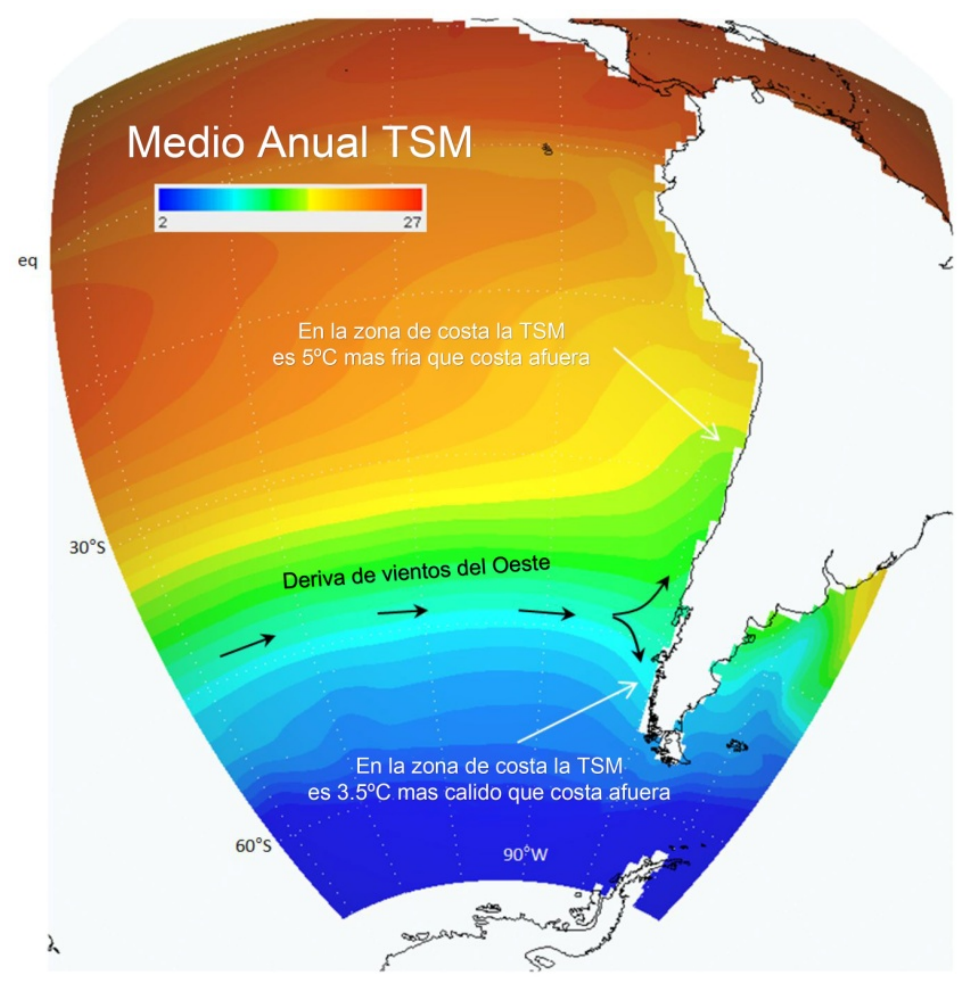

Figura 7-14NCEP Interpolación de la temperatura media anual de la superficie del mar en el Pacífico oriental. Nótese cómo la simetría zonal sobre mar abierto rompe a lo largo de la costa chilena, especialmente fuera de la Patagonia Occidental

\section{Modelo conceptual y observaciones finales}

Ocho años de detección de descargas eléctricas a nivel mundial de la WWLLN ha permitido identificar un máximo de AEA sobre la Patagonia Occidental $\left(42^{\circ}-52^{\circ} \mathrm{S}\right)$, una región fresca e híper-húmeda situada debajo de la trayectoria de las tormentas del Pacífico Sur y limita al este por los Andes australes. En esta región no es esperable la electrificación de las nubes dado el predominio de la precipitación estable y estratiforme, pero días con al menos una descarga se produce hasta un tercio del tiempo a lo largo de la costa, siendo ligeramente más frecuentes a finales del verano y durante el otoño.

Las tormentas eléctricas duran 1-3 días y se desarrollan en un entorno sinóptico recurrente identificado en un caso de estudio y generalizada por un análisis de composición de 90 eventos. Un ingrediente clave es un ciclón superficial profundo en el Pacífico Sur -Pasaje de Drake, a menudo por debajo de una baja de presión de nivel superior, indicativo de la etapa madura de la perturbación. En los días de AEA significativa, el frente frío ha alcanzado la costa en el sur de Chile a unos $40^{\circ} \mathrm{S}$ y la Patagonia Occidental se encuentra inmersa en el sector post-frontal del sistema. Durante estas incursiones de aire sub-antártico, el enfriamiento por encima del nivel de $700 \mathrm{hPa}$ se produce antes y es más pronunciado 
que el enfriamiento en los niveles bajos, lo que lleva a un medio ambiente ligeramente inestable frente a las costas del sur de Chile (CAPE $\sim 100 \mathrm{~J} / \mathrm{Kg}$; $\mathrm{LI} \sim 0^{\circ} \mathrm{C}$ ). La mayoría de las descargas eléctricas se encuentran justo en la costa y algunas descargas se producen en alta mar, donde nubes celulares abiertas poco profundos son fácilmente identificables y la lluvia convectiva domina. Por el contrario, pocas o ninguna descarga se observan a lo largo del frente frío o sobre los Andes australes donde la precipitación es máxima.

La estructura espacial visible puede interpretarse de la siguiente manera. En las condiciones débilmente inestables que prevalecen durante la masa de aire post-frontal, el ascenso a gran escala cerca del centro del ciclón puede elevar parcelas de aire superficiales sobre el océano abierto promoviendo convección poco profunda y descargas eléctricas dispersas. Cerca de la costa, un segundo ingrediente viene a ser parte del juego. El flujo del oeste moderado a fuerte incide sobre las montañas costeras que se elevan bruscamente a 300-700 MSNM, lo que obliga a una rápida elevación del aire marino, desencadenando la convección produciendo AEA significativa. El ascenso forzado continúa tierra adentro pero la superficie fría y cubierta de hielo impide el desarrollo de la convección. Claramente, mediciones in-situ (por ejemplo, radiosondas costeras) son necesarias para validar este modelo conceptual.

Además de la prominente topografía costera, el confinamiento de la AEA significativa de la Patagonia Occidental también parece estar relacionada con las condiciones de contorno de la superficie sobre el Pacífico adyacente. Aunque TSM fría $\left(<10^{\circ} \mathrm{C}\right)$ prevalece durante todo el año, estas aguas costeras son hasta $3^{\circ} \mathrm{C}$ más caliente que las de mar abierto, produciendo las condiciones más favorables para la generación de inestabilidad que en cualquier otra parte del sureste del Pacífico, cuando una anomalía fría de nivel medio pasa por allí. Las aguas costeras relativamente cálidas son debido al descenso costero y al flujo en dirección al polo generado la deriva del viento del oeste. Por lo tanto, las fluctuaciones estacional, interanuales y de mayor escala temporal de esta corriente podrían modular los cambios en la actividad eléctrica en la Patagonia occidental. 


\section{Capítulo 8 Estudio de muertes por acción de descargas}

Durante la preparación de esta Tesis, se vio la necesidad de poder fomentar conductas de protección en la población, ante las descargas eléctricas. Debido a que las muertes por rayos dependen tanto de la AEA como de factores sociológicos o de población, es que en este capítulo exploraremos ambos términos que influyen en las muertes por rayos. Para luego poder hacer un estudio cualitativo no solo a nivel nacional, sino provincia para así poder identificar las regiones más vulnerables en el país y así poder promover conductas de protección en la población. Por lo tanto basándonos en un modelo teórico propuesto por Gomes y AbKadir (2011), se realizó un mapa de vulnerabilidad de muerte por acción de rayos en la República Argentina.

Esperamos que este trabajo contribuya a mejorar el conocimiento sobre la actividad eléctrica en Argentina y en lo posible a proponer conductas de protección en la población, ya que la mayoría de las muertes por rayos son evitables y relacionadas con el desconocimiento.

Parte del material de este capítulo fue presentado bajo el título Electric Atmospheric Activity in Argentina, a Study for Estimating the Annual Death Rate by Lightning, M. Gabriela Nicora, Eduardo J. Quel, Rodrigo E. Bürgesser, Eldo E. Ávila; en el International Symposium on Lightning Protection, en Bello Horizonte - Brasil

\section{Antecedentes de trabajos}

De acuerdo a la publicación Storm Data de la US National Oceanographic and Atmospheric Administration (NOAA), de los desastres naturales (inundaciones, rayos, tornados y huracanes), los rayos son los eventos naturales que presentan la segunda mayor mortalidad en los Estados Unidos (Lopez et al., 1996).

En ese mismo trabajo se detalla que el promedio de muertes por año en USA, durante los años 1966 y 1995, fue de 85 personas muertas por año por acción de rayos. Según los datos suministrados por la Dirección de estadísticas e Información de Salud (DEIS), la tasa de la República Argentina entre 2005 y 2010 es de 15 muertes por año, teniendo un máximo de 17 muertes.

Según modelos de diferentes autores, esta estadística pareciera estar subestimada ya que algunos modelos estiman valores más cercanos a 50 muertes por año (Cardoso et al, 2011). López y Holle (2003) 
fueron los primeros en hacer una evaluación del impacto mundial de los rayos y llegaron a la conclusión de que se producen 24.000 muertes al año. Para llegar a ese valor los autores se basaron en una extrapolación muy general de seis muertes por cada millón de personas la cual aplicaron a cuatro mil millones de personas, que representan la población mundial. El problema es la verificación de estos datos ya que la estadística a nivel global es en general muy escasas (Holle, 2008).

La base subyacente de esta extrapolación es una tasa de menos de 0,3 muertes por millón de personas por año en países desarrollados y en los países no desarrollados se tomó una tasa de 6 muertes por cada millón de personas por año, la cual fue tomada para una gran parte del mundo debido a la ausencia de datos.

Cardoso et al. (2011) propusieron un modelo para calcular la tasa de muerte a nivel mundial por país en donde definieron la cantidad de muertes $L_{f}$ como el producto de densidad de descargas (D), la población (P) y un índice calculado en función de estadísticas de muertes llamado Índice de Vulnerabilidad General (V) según

$$
L_{f}=D P V
$$

Ecuación 8-1

Para el caso Sudamérica tomando una población de 300 millones de personas ( $P$ ), una densidad de $12 \mathrm{fL}^{-2}$ año ${ }^{-1}(\mathrm{D})$, y un índice de vulnerabilidad de 0.06, los autores llegan al valor de 216 muertes por año. En el mismo trabajo señalan una tasa para Argentina de $\mathbf{5 0}$ muertes por año, y el número total de muertes en el mundo ronda las 6.000 muertes por año.

Algunas estadísticas a nivel mundial señalan que en Brasil, la tasa anual de muertes fue de 0,8 por millón, con zonas de 0,5 muertes por millón (Sudeste y Nordeste) a 2,2 muertes por millón (centro) (Cardoso et al., 2011).

De los estudios y modelos evaluados, se eligió para poder hacer el primer estudio de este tipo en la Argentina, un modelo teórico propuesto por Gomes y AbKadir (2011), por parecernos a nuestro entender, un modelo que toma en cuenta a la problemática de manera global, abarcando de manera muy amplia el concepto socio económico

\section{Estudio de Descargas a Tierra}

En general uno de los parámetros sobre AEA más utilizados para el diseño de modelos de protección hacia personas e infraestructuras, ha sido la densidad de descargas eléctricas atmosféricas a suelo $\mathbf{~} \mathbf{g}$. Este parámetro se define como el número de descargas eléctricas a suelo por unidad de tiempo y por 
unidad de área. Sin embargo, este parámetro no es fácil de medir, por lo cual se han hecho esfuerzos considerables para relacionarlo con los días de tormenta.

Diferentes autores han propuesto relaciones entre la densidad de descargas eléctricas atmosféricas a suelo y el número de días de tormenta, siguiendo la mayoría de estas relaciones una dependencia exponencial como se muestra en la Ecuación 8-2donde $\mathbf{N g}$ es la densidad de descargas suelo y Td es el número anual de días con tormenta. En la Tabla 8-1 se muestra una síntesis de los parámetros que diferentes autores han presentaron (Arcioni, 2006).

La fórmula de Anderson presentada en la Ecuación8-2(Anderson et al., 1984), fue elegida para calcular la densidad de descargas eléctricas atmosféricas a suelo ya que es la utilizada por la norma IRAM 2184-1-1

$$
N g=0.04 * T d^{1,25}
$$

Ecuación 8-2

\begin{tabular}{|c|c|c|c|c|c|}
\hline Valores de $\mathrm{Ng}$ & $\begin{array}{l}\text { Campo de } \\
\text { aplicación }\end{array}$ & $\begin{array}{c}\text { Coeficiente } \\
\qquad \alpha\end{array}$ & $\begin{array}{c}\text { Exponente } \\
\beta\end{array}$ & Autores & Bibliografia \\
\hline Mediano & Universal & $8.8 .10^{-3}$ & 1.30 & $\begin{array}{l}\text { R.B. Anderson } \\
\text { y A.J. Eriksson }\end{array}$ & $\begin{array}{l}\text { CIGRA. Rev Electra } \\
\text { Na41 /79 }\end{array}$ \\
\hline $\begin{array}{l}\text { Mínimos } \\
\text { observados }\end{array}$ & Universal & $2.610^{-2}$ & 1.30 & $\begin{array}{l}\text { R.B. Anderson } \\
\text { y A.J. Eriksson }\end{array}$ & $\begin{array}{l}\text { CIGRA. Rev Electra } \\
\text { Na41 /79 }\end{array}$ \\
\hline $\begin{array}{l}\text { Medianos } \\
\text { Máximos }\end{array}$ & Universal & 0.04 & 1.25 & R.B. Anderson & Proc. IEEE/85 \\
\hline $\begin{array}{l}\text { Máximos } \\
\text { Observados }\end{array}$ & Universal & $6.1 .10^{-2}$ & 1.30 & $\begin{array}{l}\text { R.B. Anderson } \\
\text { y A.J. Eriksson }\end{array}$ & $\begin{array}{l}\text { CIGRA. Rev Electra } \\
\text { Na41 /79 }\end{array}$ \\
\hline $\begin{array}{l}\text { Medianos } \\
\text { Mínimos }\end{array}$ & $\begin{array}{c}14 \text { países en } 4 \\
\text { continentes }\end{array}$ & $8.6 .103^{2}$ & 1.45 & F. Popolansky & $\begin{array}{l}\text { Paper } 6.121- \\
\text { ICLP1992 }\end{array}$ \\
\hline
\end{tabular}

Tabla 8-1 Diferentes valores de diseño para la relacion $\mathrm{Td}-\mathrm{Ng}$

Utilizando la relación de Anderson (Ecuación8 2) y en función de los Td calculados para la República Argentina, presentados en este trabajo de Tesis, se ha diseñado el mapa de Densidad de Descargas a Tierra que se muestra en la Figura 81. 


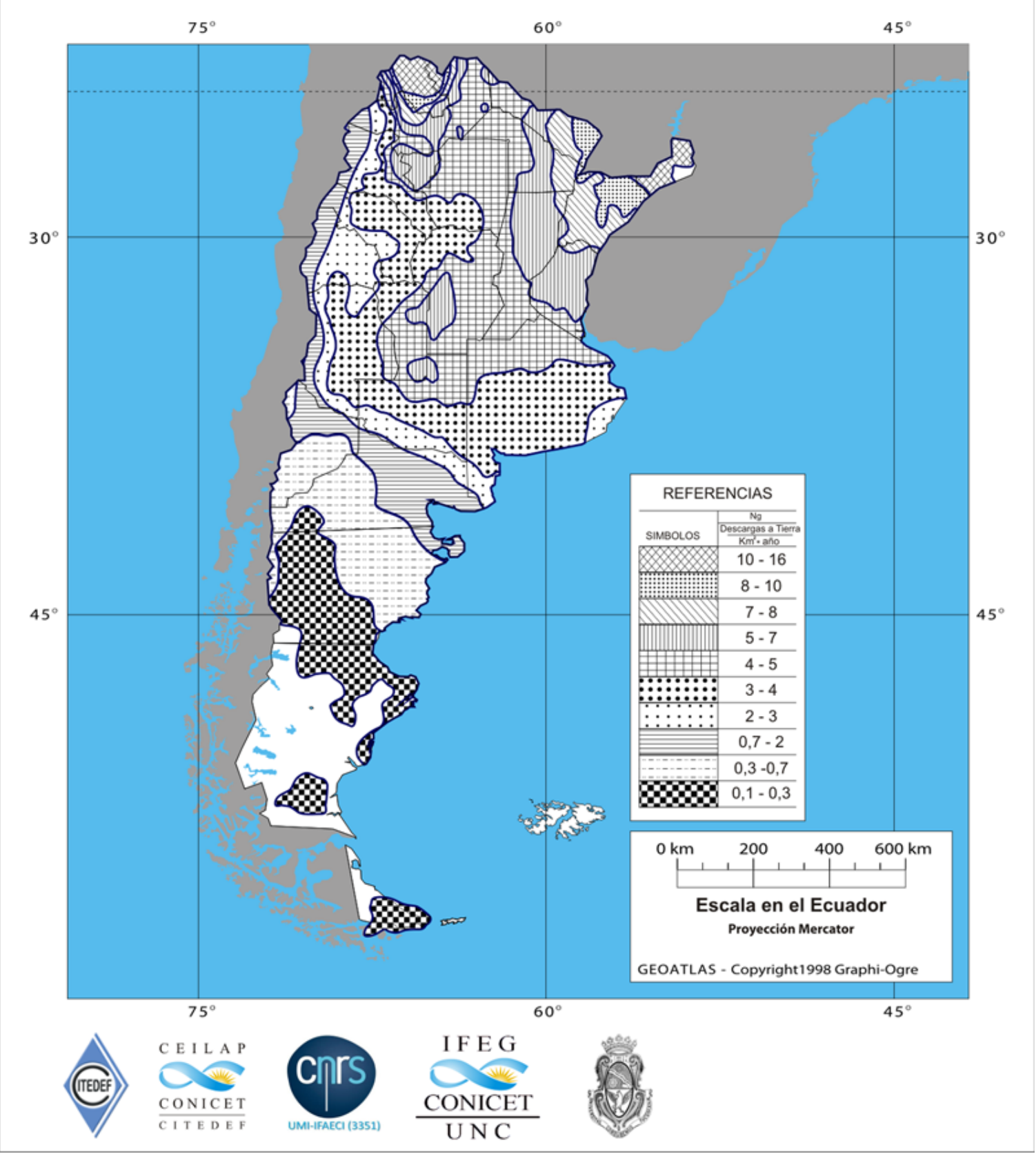

Figura 8-1Mapa de Densidad de Descargas a Tierra periodo 2005-2011. Datos de la WWLLN

\section{Factores sociológicos}

La densidad de población (PD), la tasa de alfabetización (RL) y la Fracción de Población urbana (UF) son tres factores interrelacionados que influyen fuertemente en la tasa anual de eventos relacionados con rayos en el mundo. La relación directa entre PD y el número de personas expuestas a las amenazas por rayos en una zona determinada es conocida, ya que a mayor número de personas que puede estar dentro de la distancia máxima efectiva de una descarga, mayor es la probabilidad que aparezca un siniestro. 
En el caso de la tasa de alfabetización RL, la misma influye en la tasa de víctimas debido a la falta de conciencia en las directrices de seguridad contra los rayos, también porque los grupos con menor alfabetización tienden a tener menor motivación para seguir las pautas de seguridad, y poseen falsas nociones sobre los rayos.

Los eventos relacionados con rayos en los países con bajo nivel de tasas de alfabetización, como la India (66\%), Bangladesh (54\%) y Pakistán (54\%) muestran que la mayoría de las víctimas violaron groseramente las pautas básicas de seguridad como la exposición a las tormentas eléctricas sin ningún tipo de reparo. Tal negligencia es en parte por la falta de conciencia, por no tener motivación para seguir las reglas de seguridad conocidas y muchas veces por condiciones de pobreza. Todas estas actitudes podrían atribuirse al bajo nivel de alfabetización.

Las falsas creencias que incluyen que sólo las "malas personas" son golpeados por un rayo, que portando símbolos religiosos se puede evitar la caída de rayos, que hay lugares para protegerse (especialmente de culto y cementerios de los antepasados) en los que nunca caen rayos. En el caso del norte de la Argentina hemos tenido conocimiento de dichas actitudes, por lo que luego de la caída del rayo sobre una persona la misma debe de ser "purificada".

Una de las investigaciones más famosas ya citadas es la de Lopez y Holle (1997) en la cual se refiere a una investigación hecha en las estadísticas de EE.UU. entre 1890 y1990, en la cual muestra que el porcentaje de la población rural y las muertes causadas por rayos por millón de personas en EE.UU., varían con el tiempo en un manera muy similar (Figura 8-2 b) y siguiendo una relación lineal notable entre estos parámetros.

Aunque en la Argentina los reportes por muertes suministrados por el Ministerio de salud no dicen en qué condiciones estas personas murieron, por medio de material gráfico (revistas, diarios, web) hemos podido observar que las zonas rurales experimentan un número muy elevado de fatalidades por rayos, seguido por los lugares de esparcimiento y las playas

Los factores que contribuyen a la alta tasa de muertes por rayos en zonas rurales incluyen (aparte de que ya los factores incluidos en RL son: La falta de instalaciones médicas de fácil acceso y de emergencia, la falta de acceso a la predicción del tiempo y las advertencias de tormentas, la falta de infraestructura en las viviendas, las cuales no proporcionar suficiente seguridad contra las descargas. También debido a que en las zonas rurales se realizan un gran número de actividades al aire libre para satisfacer las necesidades diarias y para encuentros sociales(bañarse, lavar, recolección de agua y alimentos al aire libre, trabajar para vivir, encuentros religiosos en lugares abierto, peregrinaciones, fiestas populares, etc.), las largas distancias entre el hogar y de otras fuentes de necesidades diarias (por ejemplo, almacenes, colegios, jardines de infantes), es que las zonas rurales son más vulnerables. 
Como hemos visto, ambos factores, tanto la densidad de población como la tasa de población rural tienen una correlación positiva con el número de muertes por descargas. Por lo tanto, Gomez el al. (2011) definieron el Factor Demográfico (DF) como la relación entre la densidad de población (PD), y la Fracción de Población urbana (UF) según.

$$
D F=\frac{P D}{U F}
$$

La cual será utilizada en la confección de un modelo de muertes de acción de rayos
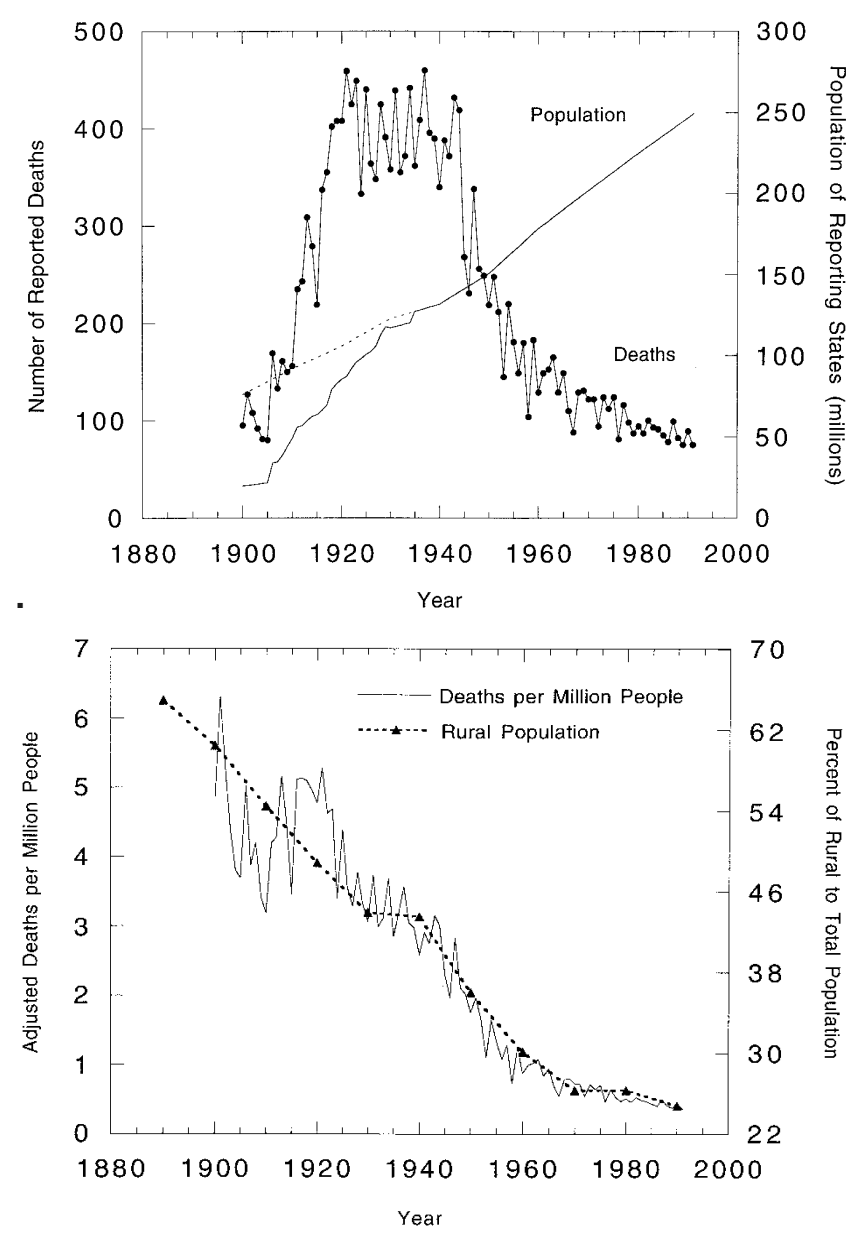

Figura 8-2 Gráficos extraídos de Lopez et al. Donde se aprecia que la cantidad de muertes por acción de rayos no depende del total de la población (a) sino de la fracción de población rural (b)

\section{Modelo de la muerte por acción de Descargas eléctricas atmosféricas a tierra (Rayos)}

Para hacer el estudio de muertes por acción de rayos, se ha utilizado la metodología presentada en el trabajo de Gomes y Ab Kadir (2011) en el cual el número de muertes se expresa en función del área (A), la tasa de descargas a tierra (Ng) y del factor demográfico (DF) (el cual es función de la fracción de 
población urbana). El número de muertes por provincias Argentinas fue calculado, según la siguiente ecuación:

$$
\sigma=\beta(A N g)^{\alpha} D
$$

Dónde:

- $\quad \sigma$ número anual de muertes en una región determinada

- $\quad \mathrm{Ng}=$ Tasa descargas a tierra $\mathrm{kms}^{-2}$ año ${ }^{-1}$

- $A=$ área de trabajo

- $\quad$ DF = Factor demográfico

- $\quad \alpha$ y $\beta$ parámetros constantes

Tomando el logaritmos natural en ambos términos de la Ecuación 8-4 , la misma se puede expresar como

$$
\ln \left[\frac{\sigma}{D F}\right]=\alpha \ln (A N g)+\ln \beta \quad \quad \text { Ecuación 8-5 }
$$

Utilizando los datos estadísticos del número anual de muertes en Argentina y Brasil, se estimaron los parámetros $\alpha$ y $\beta$. Es importante detallar que aunque el estudio se realizó para Argentina, se tomaron los datos de Argentina y Brasil para poder hacer la mejor aproximación de los valores de $\alpha$ y $\beta$ de la región.

Las estadísticas de la población de ambos países se tomaron a partir de datos oficiales publicados por el Censo Nacional de Argentina y Brasil. Las cifras anuales de mortalidad para cada región fueron presentadas por el Ministerio de Salud de Argentina y el Instituto Nacional de Investigaciones Espaciales (INPE) de Brasil.

Los valores de Ng para Brasil se tomaron de la norma ABNT NBR 5419 (2001).

La Figura 8-3 muestra la relación entre $\ln (\sigma \mathrm{DF})$ y $\ln (\mathrm{A} \mathrm{Ng}$ ) (Ecuación 8-5)con la mejor regresión lineal, que se representa por medio de la línea roja. 


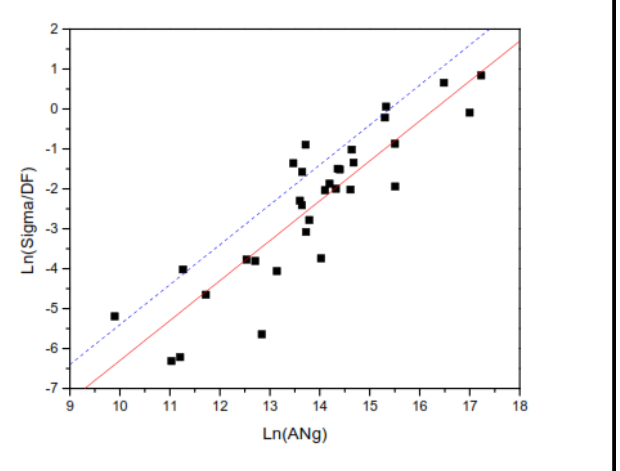

Figura 8-3Correlación entre variables para el cálculo de a y b. La linea roja representa la mejor interpolación de los datos, mientras que la línea azul representa la interpolación del modelo 2 Beta

La constante $\alpha$ se relaciona con el método de cálculo de la variable $\mathrm{Ng}$, mientras que el parámetro $\beta$ se asocia con el número de muertes registradas. Debido que, a nuestro entender, la información estadística sobre esta clase de muertes no es confiable en Argentina, es que proponemos al parámetro $\beta$ como la principal fuente de error.

Los parámetros que mejor ajustan a los datos (línea roja en Figura 8-3) son:

$$
\begin{gathered}
\beta=(1 \pm 1) \times 10^{-7} \\
\alpha=(1.0 \pm 0.1) \\
R^{2}=0.7786
\end{gathered}
$$

Para el parámetro $\beta$, el valor del error es del mismo orden de magnitud que el valor obtenido en el ajuste, por lo cual se optó por utilizar un valor de $\beta$ de $2 \times 10^{-7}$ en el modelo, y por lo tanto al modelo que utilizamos lo denominamos Modelo 2beta. La línea azul puntada de la Figura 8-3 muestra la curva de ajuste obtenidos con el modelo 2 beta según la Ecuación 8-5. Entonces, el número de muertes por provincia de la Argentina es,

$$
\sigma=2 \cdot 10^{-7}(A N g)^{1} D F
$$

Ecuación 8-6

En la Figura 8-4 se puede observar una comparación entre el número de muertes predichos por el modelo 2 beta (Ecuación 8-6) y los valores reportados por los organismos oficiales. Como era de esperar, los resultados muestran que el número de muerte predicho por el modelo es mayor que el número de muertes registradas, ya que los datos calculados por el Modelo $\mathbf{2}$ beta se encuentran por encima de la recta de relación uno a uno entre muertes calculadas por el modelo y reportadas por el sistema de salud. 


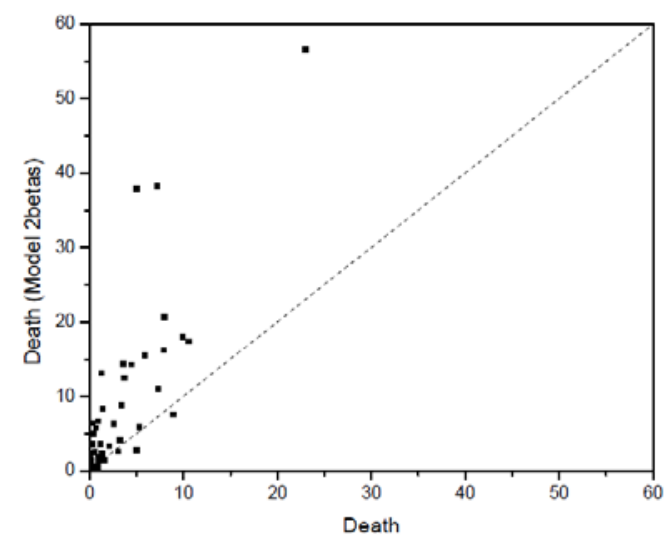

Figura 8-4Número de muerte predicho por el modelo 2beta como función de la cantidad de muerte informada

La Tabla 8-2 muestra la cantidad de muertes calculada por la Ecuación 8-6. En la misma se detalla, la población, la densidad de población, cantidad de muertes calculada por el Modelo 2beta y la cantidad de muertes por millón de personas. Según el Modelo 2 beta, el promedio de muertes por millón de habitante es de 1.3, lo que está en concordancia con los trabajos de Cardoso et al.,(2011).

Con los valores pronosticados por el modelo, se clasificaron las provincias argentinas de acuerdo al riesgo de muerte por acción de una descarga a tierra y se preparó un mapa de vulnerabilidad. La Figura 8-5 muestra las diferentes provincias argentinas clasificadas en función de su vulnerabilidad de muerte por acción de un rayo o descarga a tierra.

Para la clasificación de las provincias por su vulnerabilidad se tomó la cantidad de muertes de manera porcentual, siendo el total de muertes el calculado por el modelo en todo el país. Se tomaron los cortes en el $25 \%$ y el $75 \%$. Así que las provincias con valores de muertes entre el 0 y $25 \%$ se clasificaron como de baja vulnerabilidad, entre $25 \%$ y $50 \%$ moderada, entre $50 \%$ y $75 \%$ alta y $75 \%$ muy alta.

Este modelo se calculó como modelo de mínimo y el espíritu del trabajo no es tener el valor exacto, sino poder conocer aéreas de mayor vulnerabilidad de la población a las descargas eléctricas.

El mapa de vulnerabilidad muestra alguna diferencia significativa con el mapa Ng (Figura 8-1). Algunas regiones con baja actividad eléctrica muestran un alto riesgo, mientras que otro con alto nivel de días de tormenta muestra una menor vulnerabilidad. Esto es consecuencia de la fracción de la población urbana en el modelo. 


\begin{tabular}{|c|c|c|c|c|}
\hline Provincia & $\left(\mathrm{hab} / \mathrm{km}^{2}\right)$ & habitantes & Muertes por año & Muertes /millón \\
\hline Buenos Aires & 50,8 & 15.625 .084 & 13,05 & 0,8 \\
\hline Catamarca & 3,6 & 367.828 & 0,53 & 1,4 \\
\hline Chaco & 10,6 & 1.055 .259 & 2,15 & 2,0 \\
\hline Chubut & 2,3 & 509.108 & 0,03 & 0,1 \\
\hline $\begin{array}{l}\text { Ciudad Autónoma de Bs. } \\
\text { As }\end{array}$ & $14.450,80$ & 2.890 .151 & 2,33 & 0,8 \\
\hline Córdoba & 20 & 3.308 .876 & 4,98 & 1,5 \\
\hline Corrientes & 11,3 & 992.595 & 2,40 & 2,4 \\
\hline Entre Ríos & 15,7 & 1.235 .994 & 2,43 & 2,0 \\
\hline Formosa & 7,4 & 530.162 & 1,31 & 2,5 \\
\hline Jujuy & 12,7 & 673.307 & 2,53 & 3,8 \\
\hline La Pampa & 2,2 & 318.951 & 0,31 & 1,0 \\
\hline La Rioja & 3,7 & 333.642 & 0,32 & 1,0 \\
\hline Mendoza & 11,7 & 1.738 .929 & 1,77 & 1,0 \\
\hline Misiones & 37 & 1.101 .593 & 3,47 & 3,2 \\
\hline Neuquén & 5,9 & 551.266 & 0,09 & 0,2 \\
\hline Río Negro & 3,1 & 638.645 & 0,11 & 0,2 \\
\hline Salta & 7,8 & 1.214 .441 & 3,22 & 2,7 \\
\hline San Juan & 7,6 & 681.055 & 0,45 & 0,7 \\
\hline San Luis & 5,6 & 432.310 & 0,52 & 1,2 \\
\hline Santa Cruz & 1,1 & 273.964 & 0,01 & 0,0 \\
\hline Santa Fe & 24 & 3.194 .537 & 5,80 & 1,8 \\
\hline Santiago del Estero & 6,4 & 874.006 & 1,76 & 2,0 \\
\hline Tucumán & 64,3 & 1.448 .188 & 3,49 & 2,4 \\
\hline
\end{tabular}

Tabla 8-2Número de muerte predicho por el modelo 2beta y número de muertes por millón por provincia 


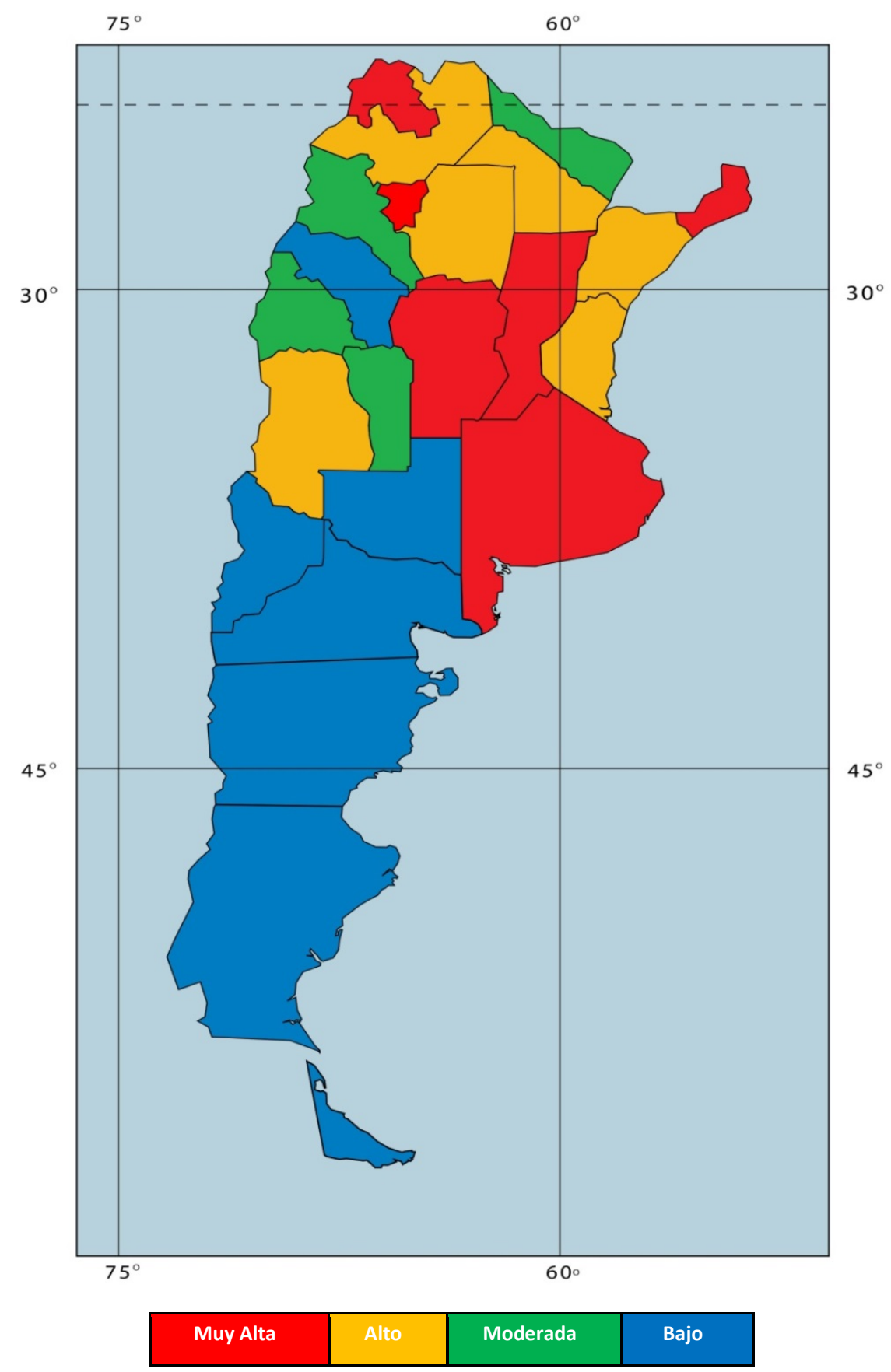

Figura 8-5. Mapa de vulnerabilidad según el modelo 2beta

\section{Rayos a tierra y sus posibles daños a personas expuestas}

Las lesiones causadas por rayos en seres "móviles" (hombres y animales) son muy diferentes de las lesiones provocadas por corrientes industriales (Goubiere, 1998).

Las corrientes de los rayos que pasan a través del cuerpo (humano o animal) son impulsos de muy corta duración y los efectos de las ondas expansivas mecánicas vinculadas a las corrientes eléctricas son muy fuertes en muchos casos. 
Según Cooray el al. (2006) existen siete formas diferentes en las que los seres humanos pueden ser afectados por el impacto de un rayo: la descarga directa, la descarga lateral, tensión por toque, tensión de paso, subsiguientes descargas, ser un canal de conexión y por ondas de choque.

En el caso de una descarga directa, el rayo termina en el cuerpo, dejándolo expuesto a la plena corriente del rayo. El canal puede terminar generalmente en la cabeza o la parte superior del cuerpo. Se cree que esto representa el mayor número de muertes (Figura 8-6).Cuando la caída de rayos, por ejemplo, se da en un árbol, la corriente inyectada en el árbol va a fluir a lo largo del tronco hasta el suelo. Si un ser humano está cerca a este árbol y, debido a un gradiente de potencial, se formara una ruta de descarga entre el árbol y el ser humano. Una porción de la corriente del rayo puede fluir a lo largo de esta ruta de descarga y a través del cuerpo a tierra. Tal evento se llama descarga lateral (Figura 8-7). Es importante señalar aquí que, más de $50 \%$ de las lesiones por rayos que tienen lugar al aire libre son causadas por este impacto, ya que en muchos casos los árboles son utilizados como refugios. Esto pone de relieve el peligro de este tipo de práctica.

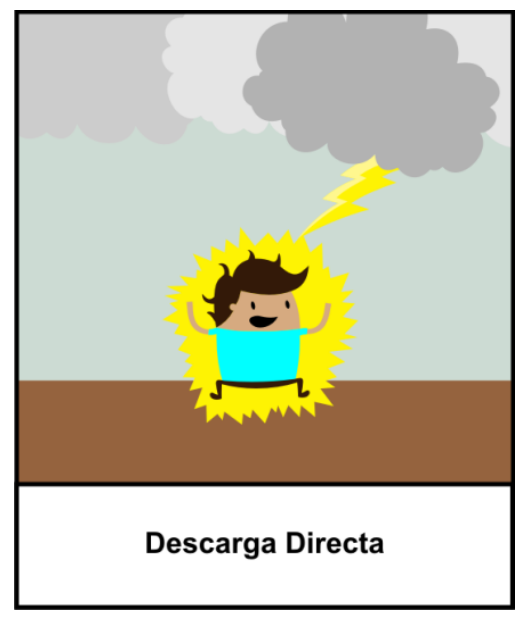

Figura 8-6

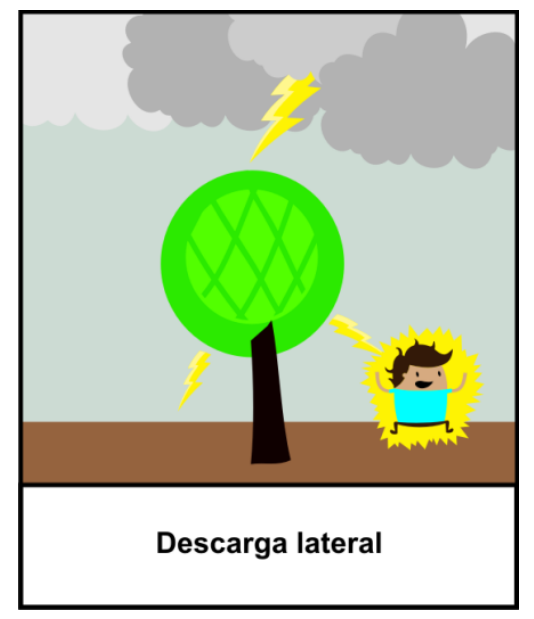

Figura 8-7

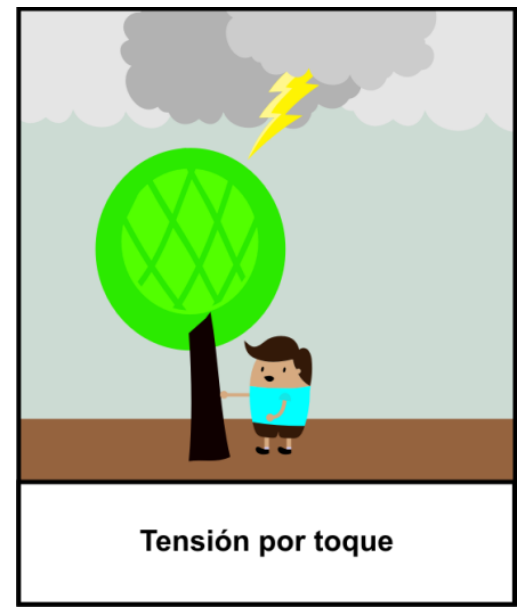

Figura 8-8

Cuando los flujos de corriente de rayo a lo largo de un objeto (un árbol o una estructura), una diferencia de potencial se crea entre el suelo y cualquier otro punto del objeto. Si una persona toca el objeto, entonces este potencial hace fluir una corriente a través de su cuerpo causando lesiones. Esto se conoce como lesiones por tensión de toque (Figura 8-8).

Durante una descarga a suelo la corriente inyectada en el punto de impacto fluirá radialmente hacia afuera. Este flujo de corriente dará lugar a una diferencia de potencial entre dos puntos situados en la dirección radial. Si una persona pasa a estar de pie cerca de un punto de descarga, la diferencia de potencial se conoce como tensión de paso, aparece entre sus dos pies que conducen a un aumento de la corriente a través de la parte inferior del cuerpo. La corriente que entra al cuerpo a través de una pierna y se descarga en la otra. En este caso, la corriente no fluye ya sea a través del corazón o el 
cerebro. Las lesiones que resultan por lo general no son graves. Sin embargo, si la persona pasa a estar sentado o acostado cerca del punto de descarga, la magnitud y la trayectoria de la corriente a través del cuerpo puede depender de la forma en que los contactos del cuerpo con el suelo. Esto es aún más importante para un animal de cuatro patas, donde la corriente puede fluir desde las piernas delanteras hacia las piernas traseras atravesando el corazón (Figura 8-9).

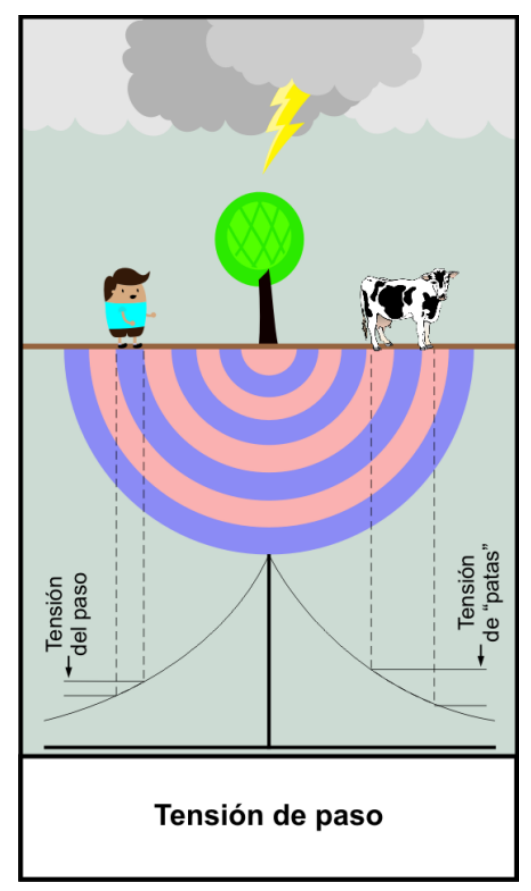

Figura 8-9

En general, un rayo se compone de varias descargas y el punto de impacto puede no ser el mismo. Es decir, la primera descarga puede golpear el suelo o cualquier otro objeto en la proximidad de una persona y las subsiguientes pueden atacar a la persona directamente. En este caso, la persona estará expuesta a la tensión de paso de la primera descargas y la subsiguiente será una descarga directa, por lo tanto la forma de ser afectada seria por descargas subsiguientes (Figura 8-10).

Otra forma en la que una persona puede recibir lesiones, aunque sólo recientemente se ha identificado en la literatura, es a través de la conexión del líder ascendente. Muchas veces en las descargas existen, varios líderes de conexión, pero puede suceder que sólo uno de estos líderes de conexión hará conexión con el suelo. Como ejemplo, en el caso de caída de un rayo a un objeto cercano, un líder de conexión puede producirse probablemente a partir de la cabeza de un persona que se encuentra en las cercanías y las lesiones a causa de las corrientes en estas descargas pueden alcanzar valores de hasta varios cientos de amperios y su duración pueden ser varias decenas de microsegundos. Esta es una corriente muy perjudicial para el cuerpo humano (Figura 8-11).

Por último, las lesiones también pueden ser causadas por ondas de choque creadas por el canal del rayo. Durante la caída de un rayo, la temperatura de canal se eleva a aproximadamente $30.000 \mathrm{~K}$ en 
unos pocos microsegundos y como resultado, la presión en el canal puede aumentar a varias atmósferas. Lo que resulta en una rápida expansión del aire que crea una onda de choque. Esta onda puede dañar a un humano que se encuentra en las proximidades de la descarga (Figura 8-12).

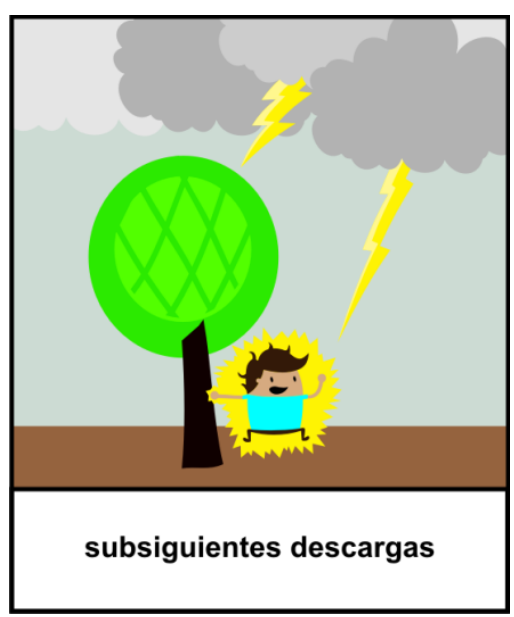

Figura 8-10

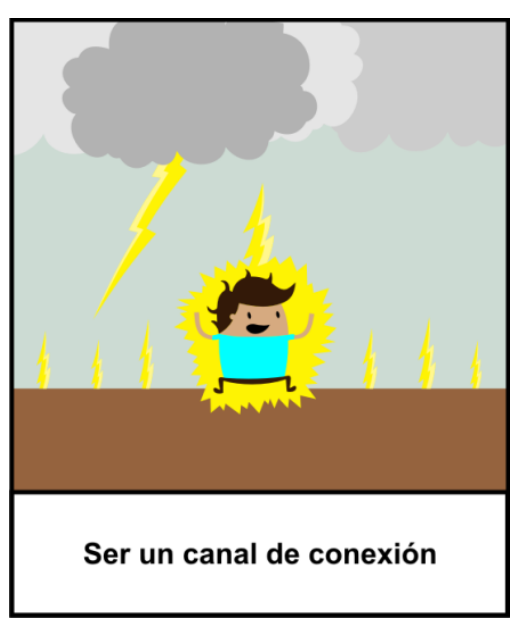

Figura 8-11

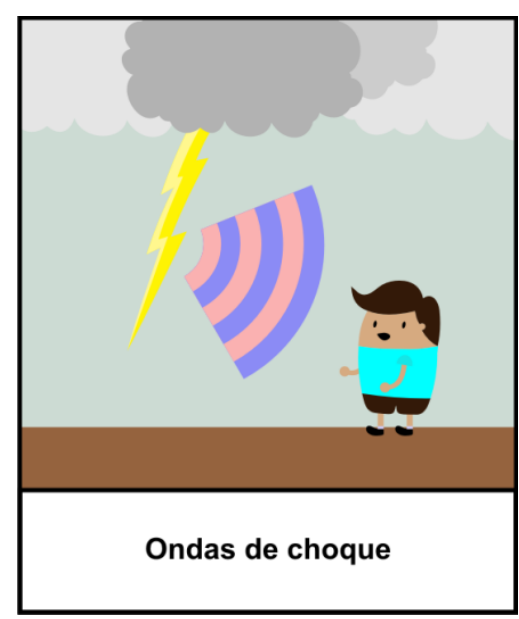

Figura 8-12

En el caso de la caída de un rayo, sólo una muy pequeña fracción de la corriente general, puede fluir a través del cuerpo y el resto fluirá sobre la superficie del cuerpo. La corriente del rayo que fluye en el interior del cuerpo, aunque pequeño, puede causar varios tipos de lesiones por calentamiento de tejido, la electrólisis y por alterar el estado eléctrico de los tejidos excitables (es decir, la despolarización). Estos efectos son controlados por la forma en que esta corriente se distribuye en el interior del cuerpo. Esto a su vez depende de la conductividad de los fluidos corporales y de los diferentes tipos de tejidos en el cuerpo. La corriente que fluye por la superficie también puede causar lesiones debido al calor generado y ondas de choque.

También es importante tener en cuenta que un solo rayo puede lesionar a varios seres humanos, al mismo tiempo.

Simplemente a manera de reseña presentaremos las lesiones más comunes provocadas por las descargas:

Lesiones al aparato circulatorio y respiratorio

Lesiones en los ojos

Lesiones en los oídos

Lesiones en el sistema nervioso

Quemaduras en la piel

Lesiones psicológicas

Traumatismos internos 


\section{Medidas de Prevención}

Como se expuso en la introducción de este capítulo, el poder ayudar a la prevención de estos tipos de muertes y accidentes ha sido una de las preocupaciones de este equipo.

Por lo tanto durante la preparación de esta tesis hemos participado en numerosas notas periodísticas, radiales televisivas y graficas en los cuales reforzábamos la idea de la prevención.

Como ejemplo de este trabajo se presenta el folleto explicativo "Protección contra Rayos" preparado en el marco de esta tesis (Figura 8-13). 


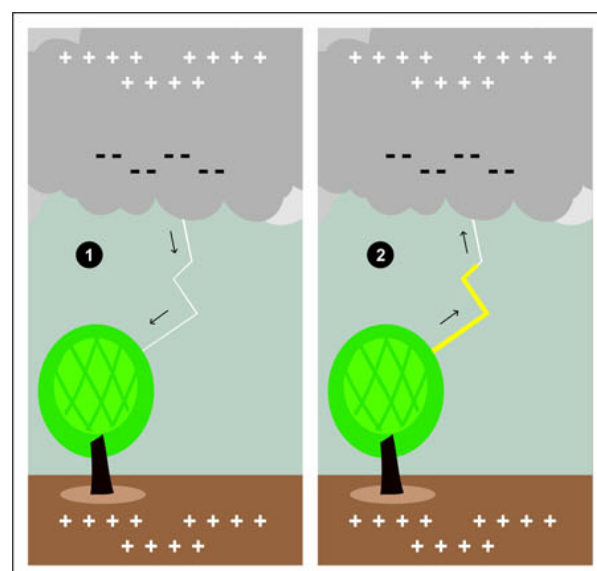

¿QUE ES UN RAYO Y COMO SE FORMA?

Los rayos no solo impactan en regiones debajo de una tormenta
sino que también pueden impactar a distancias de hasta $16 \mathrm{~km}$ alejadas de los bordes de la tormenta, es decir en regiones

El lugar de contacto entre el rayo y tierra se decide cuando el ugar optimo para que la carga se deposite. EI rayo no necesariamente impacta sobre el objeto mas alto que se

Cuando el rayo impacta sobre la superficie se produce un enorme potencial electrico en la tierra que producen que cargas fluye puede producir daños y victimas hasta distancias de $40 \mathrm{~m}$ del punto de impacto.

Por el mismo canal que desciende la carga de la nube y hace contacto con la superficie, se produce un flujo de carga desde a positiva en varias etapas, con baja carga negativa y sube carga p ps
una duración de no mas de 0.5 seg

La velocidad del sonido en el aire es de $320 \mathrm{~m} / \mathrm{s}$. si se ve un rayo y se escucha el trueno después de
$10 \mathrm{seg} \rightarrow 3,2 \mathrm{~km} / 20 \mathrm{seg} \rightarrow 6,4 \mathrm{~km} / 30 \mathrm{seg} \rightarrow 10 \mathrm{~km}$

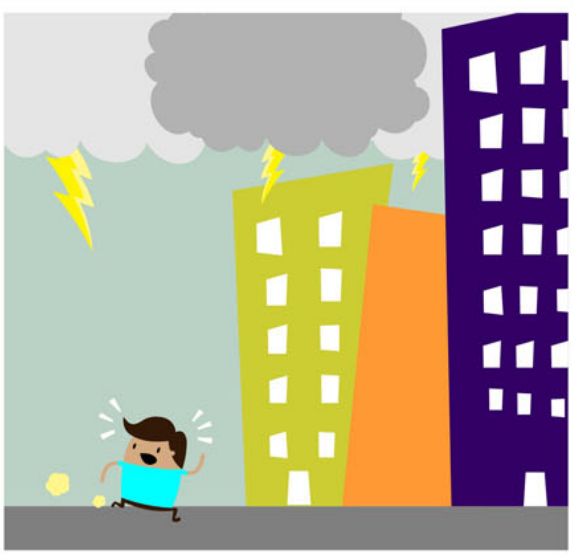

¿QUE HACER EN CASO DE TORMENTA? Si siente que el cabello y los bellos del cuerpo se erizan, o que algunos metales livianos comienzan a vibrar o se escucha el presencia un chisporroteo en objetos metalilcas, usted está en personas juntas se deben separar varios cuerpos de distancia pabeza abajo y taparse los oídos. Una vez que la amenaza de rayo haya
pasado se debe continuar con la búsqueda de un lugar seguro. Regla del $30-30$

aue si se ve un rayo y se escucha el trueno antes de transcurrir $30 \mathrm{seg}$, significa que están cayendo rayos a a distancia menor de $1 \mathrm{~km}$, entonces se debe buscar un menos 30 minutos después de haber escuchado la ultima descarga. ¿Cual son los lugares mas seguros?:
Las construcciones de mamposteria cerradas, tales como casas, escuelas, edificios público. Una vez adentro se debe mantener
lejos de aberturas metálicas, conexiones elécticas cañeriss metálicas y cualquier tipo de conductor metálico que este conectado a la construcción. no usar teléfonos con conexión con de uso.

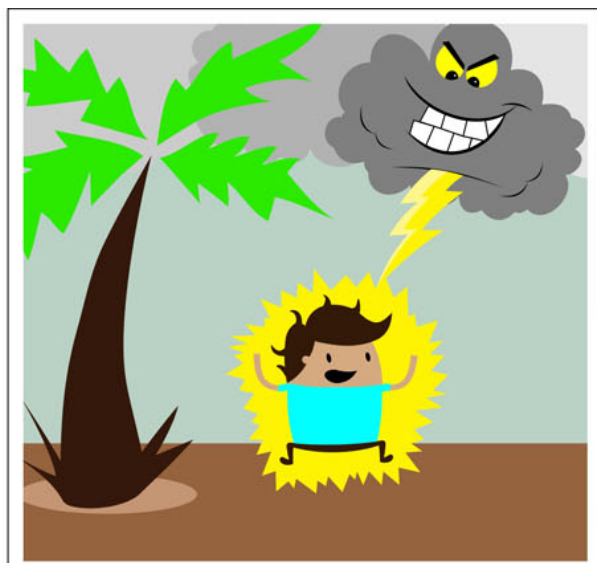

¿QUE NO HACER EN CASO DE TORMENTA? Lugares no adecuados para protegerse de los rayos son: - Autos descapotables o con techos no metálicos.
vehiculos abiertos sin ventanillas (tractores). - Carpas.

- Refugios de parada de colectivos.

Evite:

Areas abientas como campos de deportes, canchas de - golf, playa, piletas, mar. aislados tales como un - Estar dentro del agua o cerca de piletas, rios, lagos o - Contacto con vallas metálicas u otras estructuras de - Contacto co
metal largas

\begin{tabular}{|c|c|c|}
\hline $\begin{array}{lll}I & F \quad E \quad G \\
\end{array}$ & UNIDEF & CEILAP \\
\hline$\frac{\text { CONICET }}{\mathrm{U} N \mathrm{~N}}$ & & $\begin{array}{l}\text { CONICET } \\
\text { CIED }\end{array}$ \\
\hline
\end{tabular}

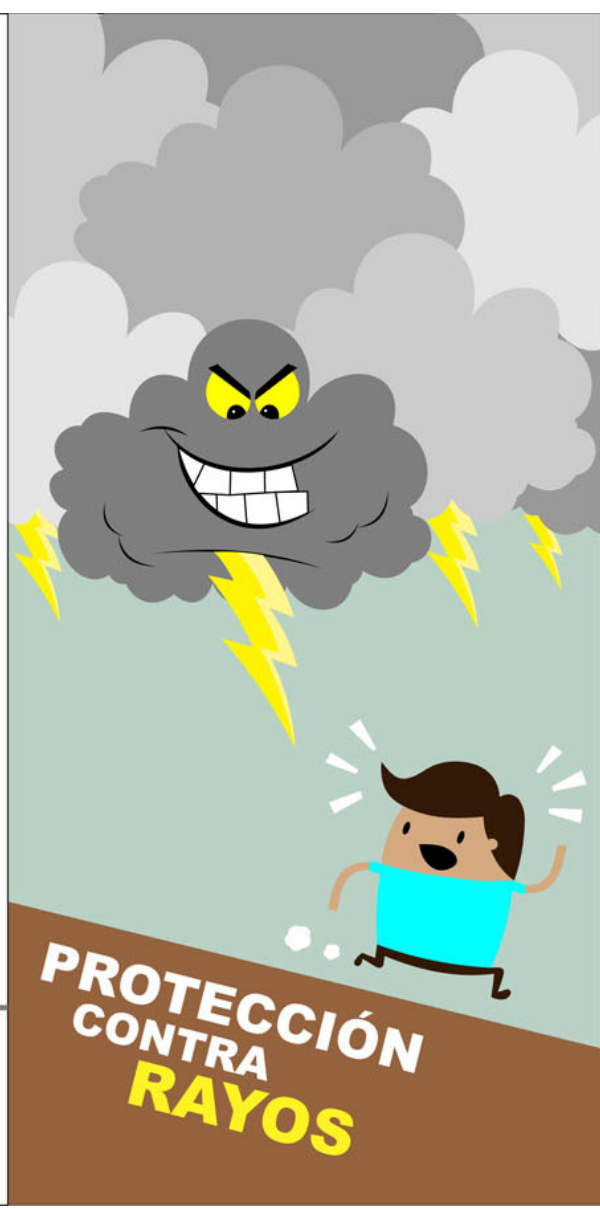

Figura 8-13 Folleto de Protección ante tormentas eléctricas 


\title{
Capítulo 9 Descargas eléctricas como marcadores de eventos severos
}

\begin{abstract}
Como se ha desarrollado a lo largo de esta tesis, la AEA en las tormentas está fuertemente ligada a la microfísica y dinámica de las mismas y, por lo tanto, los cambios en la actividad eléctrica pueden indicarnos cambios en los procesos internos de las tormentas eléctricas. Distintos estudios han propuestos modelos estadísticos para utilizar las descargas eléctricas como indicadores de la severidad y tipo de evento (tornado, granizo, etc.) yque estas pueden ser utilizadas para emitir un alerta temprana de estos eventos severos. Sin embargo, la utilización de las descargas eléctricas como marcadores de eventos severos todavía no es una práctica usual ya que es necesario realizar estudios a largo plazo para obtener correlaciones entre estos fenómenos. En este capítulo se presenta un estudio sobre la factibilidad de utilizar las AEA detectada por la WWLLN como marcador de eventos severos utilizando como caso de estudio una tormenta severa ocurrida en Buenos Aires en Abril de 2010.
\end{abstract}

\section{Descargas y Eventos Severos}

Según distintos estudios (Williams, 1994; 1989,2001, 2013; Price, 2013; Avila et al., 2010), que han sido presentados a lo largo de esta Tesis, la AEA está asociada a la dinámica y microfísica de las nubes de tormentas y puede ser correlacionada con distintos parámetros meteorológicos y climáticos. Por ejemplo, Yoshida et al. (2009) examinaron la correlación entre el número de descargas eléctricas por segundo por nube convectiva y la altura entre la isoterma de 0 o $\mathrm{C}$ y el tope de la nube. Estos autores encontraron que la tasa de descargas es proporcional a la quinta potencia de dicha altura.

Los cambios en la actividad eléctrica pueden indicarnos cambios en los procesos internos de las tormentas eléctricas. Tanto la tasa de las descargas, así como la polaridad de las mismas, se encuentran asociados con eventos severos específicos (Williams 2001; Dotzek y Praice 2009). La tasa de descargas pareciera estar relacionado con la intensidad de las corrientes ascendentes, que afecta la tasa de transferencia de carga y separación de las mismas. En cuanto a la polaridad de los CGs, pareciera depender más directamente ya sea al cambio de 
temperatura en la región de carga o por cambios en el contenido de agua líquida (LWC) en la zona de carga (Takahashi 1978; Saunders et al. 1991)

Por ejemplo, a continuación se presentan las variaciones en la AEA asociada a algunos eventos severos.

Las TORMENTAS DE GRANIZO han sido estudiadas en muchos países debido a los daños causados, tanto a la agricultura, como a los daños en las propiedades, automóviles, etc. Debido a que el tamaño de granizo es directamente proporcional a la velocidad de la corriente ascendente, un granizo del tamaño de un garbanzo necesita corrientes ascendentes de $35 \mathrm{~km}$ $\mathrm{h}^{-1}$, mientras que granizos del tamaño de pomelos necesita corrientes ascendentes de $160 \mathrm{~km}$ h-1.

El granizo se forma por múltiples ascensos y descensos dentro de la tormenta, durante los cuales crece por acreción con gotas de agua sobreenfriada, construyendo distintas capas (como en una cebolla) en el granizo. Con el tiempo, el granizo va a ser demasiado pesado para que las corrientes soporten su peso, y por lo tanto, saldrá de la corriente ascendente y caerá de la nube. Numerosos estudios han mostrado una relación entre la AEA y la ocurrencia de granizo (MacGorman y Burgess, 1994; Carey y Rutledge, 1998; Emeršič et al., 2011). Por ejemplo, Chagnon (1992) y Montanya et al. (2009) han demostrado que la AEA aumenta rápidamente en el momento de ocurrencia de caída de granizo. Liu et al. (2009) han mostrado que la polaridad de los CGs cambia a positivo (+CG) durante la caída de granizo en la tormenta. Por lo general, las tormentas no severas tienen CGs de polaridad predominantemente negativa.

Los TORNADOS también se asocian con ciertas características de AEA. Se han observado dos tipos de características que se pueden asociar a los tornados. La primera es lo que se llama el "salto" en el número total de descargas (IC+IG) 10-20 minutos antes del contacto de un tornado con tierra (Kane, 1991, Pérez et al., 1997; Weber et al., 1998; Williams et al., 1999; Schultz et al., 2009; Gatlin y Goodman, 2010), este salto es un parámetro que se define en relación al cambio de la tasa de las descargas (que se observa como un cambio brusco en la pendiente de la curva). La Figura 9-1de Williams et al. (1999) muestra esta característica del pico de AEA antes de la máxima severidad. La otra característica que muestran numerosos estudios, es un cambio en la polaridad de CG de negativa a positiva alrededor del tiempo de avistamientos del tornado. Carey et al. (2003) mostraron que durante un episodio de 5 tornados en un período de $1 \mathrm{~h}$, la fracción +CG aumento hasta aproximadamente el $60 \%$ del total de AEA detectada. 


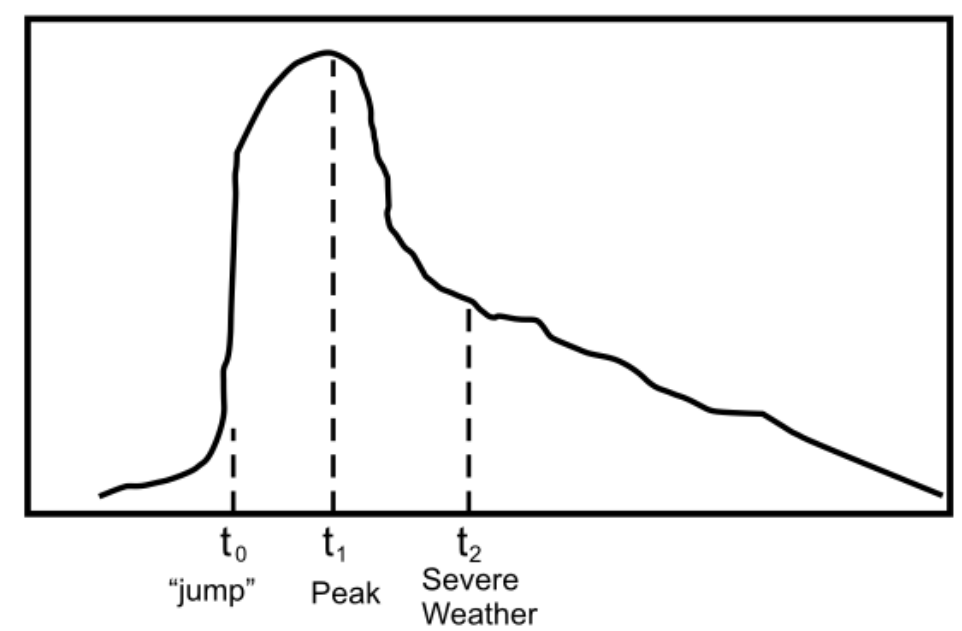

Figura 9-1 Grafico extraído de Williams et.al. 1999, en donde se puede observar el "jump" y el cambio de pendiente, asi como el pico máximo que se adelanta a la máxima severidad de la tormenta

Las TORMENTAS TROPICALES, HURACANES Y TIFONES conllevan tormentas de una severidad máxima. En los últimos años, se han comenzado a estudiar estas tormentas oceánicas mediante redes globales de detección de AEA (Price et al., 2009). Dado que estas tormentas tienen una vida media de 1 a 2 semanas, y que migran miles de kilómetros, fue necesario contar con redes globales como la WWLLN, para poder rastrearlos y estudiarlos. Se ha demostrado recientemente que la AEA de huracanes presenta picos 24 horas antes de la intensidad máxima de la tormenta (vientos máximos) como se observa en Figura 9-2 (Price et al., 2009). Pareciera que la AEA parece actuar como el pulso de la tormenta y puede permitirnos pronosticar mejor la intensificación de estas grandes tormentas. 

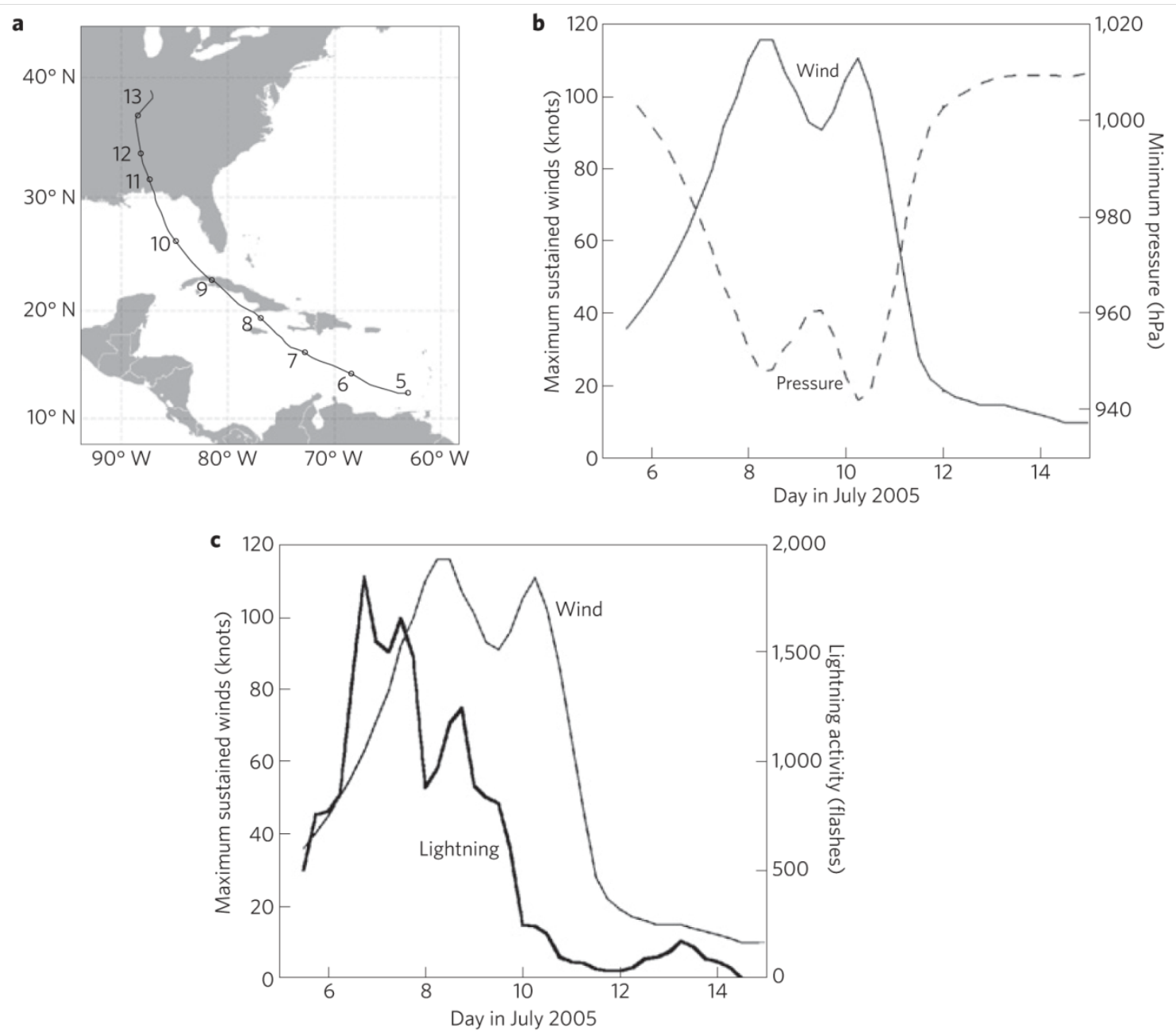

Figura 9-2(extraída de Price 2009)donde se observa el traqueo del huracán (a), en el panel b se ve la relación entre el máximo viento y la presión y el panel c muestra el pico de descargas que se adelantan aprox. 24 hs del pico de máxima intensidad del viento

Por otro lado, la AEA también está relacionada con otros tipos de eventos a los detallados anteriormente como son, por ejemplo, los incendios forestales y las erupciones volcánicas.

En el caso de los INCENDIOS FORESTALES, se ha detallado que, en las latitudes medias, una de las causas principales de estos eventos son las descargas CG. Solo en Canadá, cada año, se queman más de 1,5 millones de hectáreas (Stocks et al., 2003) donde las descargas +CG parecen ser clave. En Argentina no tenemos estadísticas ciertas sobre incendios generados por rayo, pero en el trabajo realizado sobre AEA en la Patagonia (Garreau et al 2014), y que presentamos en el Capítulo 7, una de las líneas de evidencia de la AEA en esa zona de la Patagonia fueron los trabajos palio climatológicos donde se evidencia incendios forestales generados por estas. 
Por otro lado, distintos estudios (Thomas et al, 2007, 2010; Bennett et al, 2010; Harrison et al., 2010; Behnke et al, 2012; entre otros) han mostrado que las ERUPCIONES VOLCÁNICAS pueden generar descargas eléctricas, y en muchos casos son indicadoras de la severidad de la erupción y, al igual que en los casos de las tormentas, la AEA puede ser utilizada para emitir una como alerta temprana de la misma. Sobre este tema hemos presentado una publicación, Nicora et al., (2013), en donde se realizó el estudio de la actividad eléctrica generada por la erupción del complejo volcánico Cordón Caulle en junio de 2011 utilizando datos de descargas eléctricas detectadas por la WWLLN, que se detallará más adelante.

\section{Estudio de las posibilidades de detección y pronóstico de eventos severos en Argentina - Tormenta del 18 de Abril del 2010}

Se presenta un caso de estudio de una gran tormenta de granizo ocurrida en la zona norte de la ciudad de Buenos Aires. En este caso hemos utilizado la metodología presentada por Schultz et al. (2011) con el objetivo principal de demostrar la factibilidad de utilizar los datos de la WWLLN para realizar estudios de eventos severos, para luego poder hacer, en un futuro cercano, una metodología de pronostico a corto plazo de este tipo de eventos.

\section{a. Características meteorológicas del día en estudio}

La característica principal de la tormenta a estudiar fue la caída de granizo, con un diámetro que alcanzaron los cinco centímetros, entre las 19:30 y las 20:15 (hora local) del día 18 de abril del 2010, sumado a una intensa lluvia en diferentes localidades del norte y oeste del conurbano bonaerense, y distintos barrios de la ciudad de Buenos Aires.

Entre las localidades bonaerenses más afectadas se encontraron Vicente López, San Isidro, Olivos, San Martín, San Fernando, San Miguel y Luján. En tanto, en la ciudad de Buenos Aires, los barrios de Colegiales, Saavedra, Núñez, Villa Devoto, Chacarita, Villa Urquiza y Belgrano sufrieron las mayores consecuencias del granizo.

Los voceros del SMN destacaron, además, que en territorio porteño cayeron 15 milímetros de lluvia en un lapso de 30 minutos, lo que causó anegaciones en algunas esquinas debido a la imposibilidad de desagote por los sumideros. 
El médico Carlos Martínez, jefe de Emergencia del Hospital de Vicente López, declaró al canal Todo Noticias que "entre 20 y 30 personas" fueron atendidas por las heridas que causaron los golpes de granizo, principalmente en el cuero cabelludo.

En la Figura 9-3 se puede observar el tamaño de los granizos caídos en la zona de Martínez.

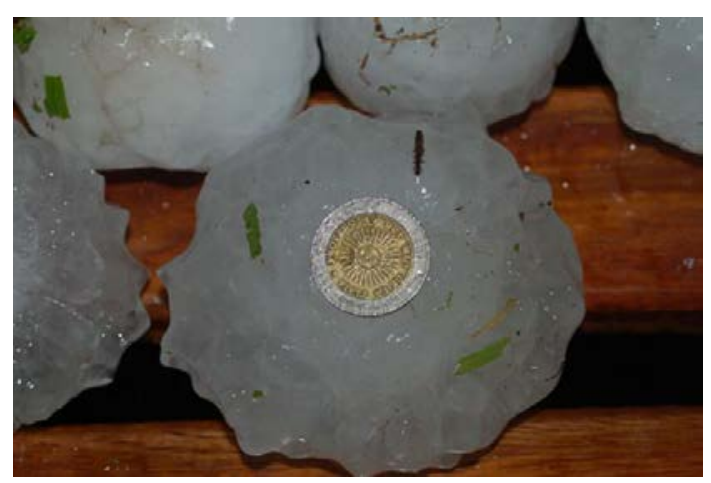

Figura 9-3 Foto de un granizo del día de la tormenta. Foto: Diego Calderon

\section{b. Fuentes y bases de datos}

Se trabajaron con datos de la WWLLN con una resolución espacial de $0,05^{\circ} \times 0,05^{\circ}(5 \mathrm{~km} \times 5$ $\mathrm{km}$ ), ya que era importante tener la mayor precisión posible en la distribución de la AEA, y 5 km es la precisión espacial esperable para la WWLLN. Para los análisis horarios, se realizó un gráfico suavizado en donde a los valores de cada grilla se lo promedió con los valores de las grillas de su alrededor, esto permite poder suavizar los datos y darle un formato "óptico" más volumétrico. Se utilizaron también los datos del radar de Ezeiza, y los datos de las estaciones en la zona de la tormenta, ambos datos provistos por el Servicio Meteorológico Nacional. También se compararon las mediciones de tierra con datos satelitales del GOES 13, e información de sitios web meteorológicos.

\section{c. Metodología: de comparación entre descargas totales y eventos severosC. Schultz et. al. (2011) - Universidad de Alabama}

Schultz et al. (2011) proponen que la tasa total de las descargas eléctricas está fuertemente correlacionada con la ocurrencia de eventos severos, y que esta correlación se observa en el rápido incremento de las AEA totales minutos antes de la ocurrencia del evento severo. En su trabajo, Schultz et al. (2011) plantea el uso de las AEA totales ya que a nivel microfísico no existe diferencia entre la generación de CG e IC. 
Para el trabajo, Schultz et al. (2011) realizaron el estudio de 711 tormentas en todo el territorio de Estados Unidos donde compararon la tasa de AEA totales y las tasas de CG generadas. Los resultados muestran un aumento de la AEA total y CG antes de la aparición de los eventos severos, aunque las AEA totales mostraron ser más eficaces para la detección temprana de dichos eventos.

La Figura 9-4 explica gráficamente cuales son los pasos en la metodología utilizada para pronóstico de eventos severos utilizada por Schultz et al. (2011) y que se detalla a continuación,

Calculo de la tasa de AEA total cada 2 minutos (ya que 2 minutos permite filtran ruido), (FRavg). Si FRavg es mayor o igual a $\mathbf{1 0} \mathrm{fl} \mathrm{min}^{-1}$ se activa el algoritmo. Este valor umbral de $\mathbf{1 0}$ fl min $^{-1}$ fue obtenido como valor estadístico de los estudios realizados por el grupo en este y anteriores trabajos.

Una vez que se activa el algoritmo, se toman 6 periodos consecutivos anteriores de FRavg. Se realiza la resta de los valores de FRavg consecutivos para obtener DFRDT, que es proporcional a la derivada en el tiempo de la tasa de descargas. De lo anterior se obtienen 5 valores de DFRDT y se calcula la desviación estándar $\boldsymbol{\sigma}$ (sigma) de la misma.

Si para el tiempo que FRavg supero los $10 \mathrm{fl} \mathrm{min}^{-1}$, el valore de DFRDT supera el valor igual a2* $\boldsymbol{\sigma}$ se denomina que ocurrió un "salto" (jump) y se emite una alarma (warning) durante 45 minutos para esa tormenta. 


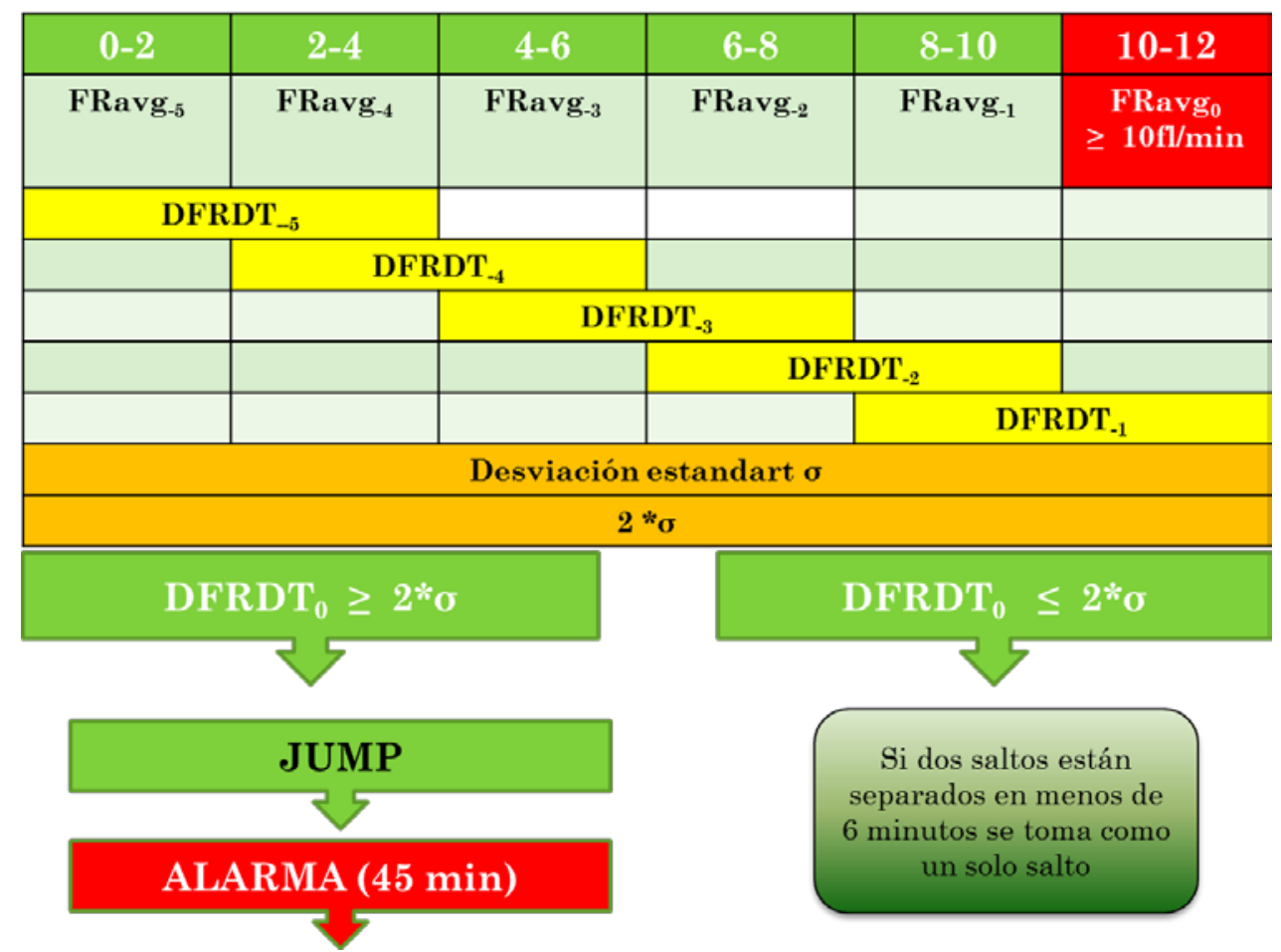

Figura 9-4 Diagrama explicativo del algoritmos de Schultz et.al

Del trabajo, los autores encontraron que, en promedio, la alarma fue emitida $(20,65 \pm$ $15,05)$ min antes de la caída de granizo y de $(21,32 \pm 15,15)$ min para tornados. Además, concluyeron que la AEA totales es la mejor herramienta para realizar pronósticos a corto plazo por lo cual es necesario contar con sistemas de detección de AEA totales (provista por redes de tierra y/o por satélites geoestacionarios).

\section{d. Caso de estudio}

Los pasos para realizar el estudio fueron:

\section{Verificar la posibilidad de trabajar con las bases de datos existentes en la Argentina.}

Se verifico la validez de las bases de datos de la WWLLN para el uso de la metodología propuesta por Schultz et al. (2011), ya que en su trabajo utilizaron datos de la National Lightning Detection Network (NLDN) la cual es una red de detección de alta eficiencia.

Por ello, primero se observó el total de descargas durante el 18 de Abril detectado por la Red WWLLN y se comparó con los datos integrados de satélite del sitio meteorológico Wether Undergroun (http://www.wunderground.com/), que se observa en la Figura 9-6. De la comparación, se pudo observar una alta correspondencia espacial entre las descargas detectadas por la WWLLN y la nubosidad detectada por el satélite. 


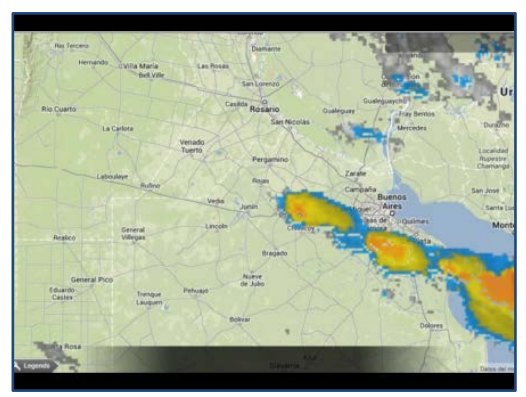

a Datos Satelitales

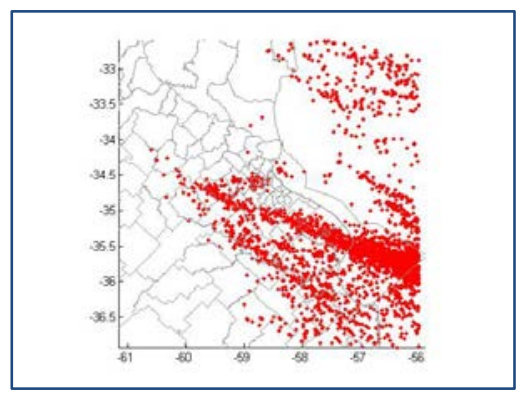

b Descargas totales durante el dia detectadas por la WWLLN

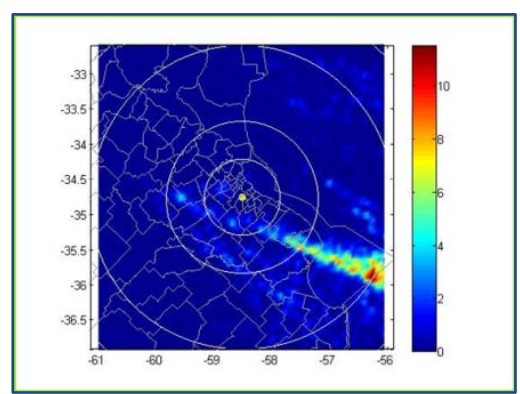

C Datos suavizados de la WWLLN

Figura 9-5 Detalle de la actividad detectada por la WWLLN en el área de estudio $(b, c)$ e imagen satelital

\section{Evaluación de los datos de las estaciones del SMN en la zona de la tormenta}

Por medio de los datos de las estaciones del SMN se observaron los datos horarios, para toda la zona de influencia del sistema.

En la Tabla 1-1 se pueden observar los datos para las estaciones de Ezeiza, Punta Indio, La Plata, Buenos Aires, Aeroparque y El Palomar. De los códigos que figuran en la tabla, los que corresponden a eventos severos con actividad eléctrica son:

95 Tormenta eléctrica sin granizo con precipitación

96 Tormenta eléctrica con granizo con precipitación

99 Tormenta eléctrica fuerte con granizo

17 Tormenta eléctrica sin precipitación al momento de la toma

29 Tormenta eléctrica con o sin precipitación

Como se puede observar en los datos horarios de la Tabla 9-1 aunque el granizo a analizar sobre la zona de Martínez ocurrió entre las 19:30 y las 20:15, al analizar todas las estaciones se observó que durante el día de estudio, en horas de la mañana, las estaciones del sur (en referencia a la Ciudad de B., As.) mostraron presencia de tormenta eléctrica con y sin granizo. A su vez, a la hora de la tormenta sobre el norte de Buenos Aires, las estaciones no detectaron la caída de granizo ni de actividad eléctrica. Esto se pudo deber a lo puntual (geográficamente) de la tormenta en hora de la tarde. 


\begin{tabular}{|c|c|c|c|c|c|c|}
\hline & Ezeiza & Punta Indio & La Plata & Bs As & Aeroparque & Palomar \\
\hline 0 & 0. & 0. & 0. & 0. & 10. & 0. \\
\hline 1 & 0. & -99. & 0. & 0. & 0. & -99. \\
\hline 2 & 10. & -99. & 0. & 0. & 0. & -99. \\
\hline 3 & 10. & 0. & 0. & 0. & 0. & 10. \\
\hline 4 & 10. & -99. & 0. & 0. & 0. & -99. \\
\hline 5 & 10. & -99. & 0. & 0. & 0. & -99. \\
\hline 6 & 10. & 0. & 0. & 0. & 0. & 10. \\
\hline 7 & 10. & -99. & 0. & 0. & 0. & -99. \\
\hline 8 & 10. & -99. & 0. & 0. & 0. & -99. \\
\hline 9 & 13. & 0. & 0. & 0. & 13. & 10. \\
\hline 10 & 95. & 95. & 13. & 0. & 13. & 29. \\
\hline 11 & 95. & 96. & 95. & 0. & 0. & 10. \\
\hline 12 & 29. & 17. & 17. & 0. & 0. & 3. \\
\hline 13 & 10. & 17. & 95. & 0. & 0. & 0. \\
\hline 14 & 10. & 95. & 17. & 0. & 0. & 0. \\
\hline 15 & 0. & 17. & 17. & 0. & 0. & 0. \\
\hline 16 & 0. & 96. & 29. & 0. & 0. & 0. \\
\hline 17 & 0. & 29. & 1. & 0. & 0. & 0. \\
\hline 18 & 0. & 10. & 3. & 0. & 0. & 0. \\
\hline 19 & 0. & 10. & 0. & 0. & 0. & 0. \\
\hline 20 & 0. & 10. & 0. & 0. & 0. & 0. \\
\hline 21 & 0. & 10. & 0. & 0. & 0. & 0. \\
\hline 22 & 13. & 10. & 13. & 0. & 17. & 17. \\
\hline 23 & 95. & 17. & 95. & 96. & 99. & 95. \\
\hline
\end{tabular}

Tabla 9-1 Datos de las estaciones del SMN durante el dia de estudio. Datos en hora local

\section{Análisis de las descargas detectadas por la WWLLN}

En la Figura 9-6 se han graficado todas las descargas detectadas por la WWLLN para el 18 de Abril del 2010 por minuto en una caja limitada por [ $32^{\circ}$ y-37 $] \mathrm{S}$ y longitud $\left[56^{\circ}\right.$ y $61^{\circ}$ ] S. Los datos de la WWLLN son en UTC. Como se puede observar en la figura 6, se detectan claramente los dos aumentos en la AEA, uno ocurrido entre las 13 y 17 UTC (10 a 14 hs local), y un segundo episodio ocurrido entre las 21 y 24 UTC (18 a 21 hora local), donde el evento de horas de la mañana se corresponde con los datos del SMN en las zonas sur de Buenos Aires. 


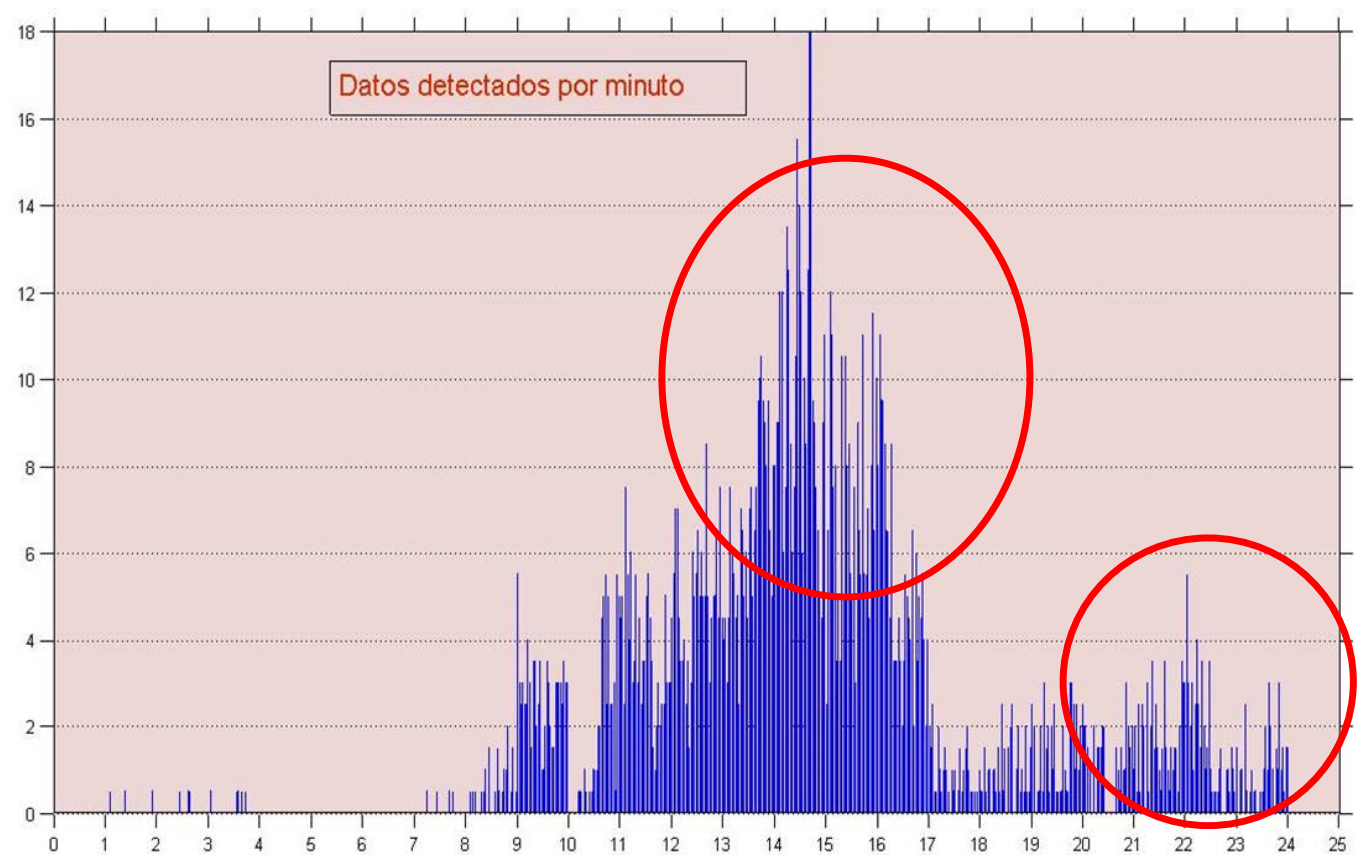

Figura 9-6 Descargas totales detectadas por la WWLLN, en donde se pueden obsevar los dos eventos. Abscisas en hora local

\section{a. Análisis horario de descargas del primer evento}

En la Figura 9-7 se graficó para periodos de una hora, la imagen del satélite GOES procesado por el SMN, los datos del radar de Ezeiza y la densidad de datos detectados por la WWLLN en una grilla de $0,05^{\circ} \times 0,05^{\circ}(5 \mathrm{~km} \times 5 \mathrm{Km})$ suavizada. Es importante detallar que, como se había visto por medio de la tabla de los observadores meteorológicos, la celda de tormenta paso por la zona Sur, sobre las localidades de La Plata y Punta Indio, y luego siguió su recorrido sobre el Rio de la Plata

Lo primero que se observa es la muy buena correlación espacial de la densidad de descargas detectadas por la WWLLN, y los datos del radar y satelital. Este indicaría que es factible utilizar los datos de AEA para hacer un pronóstico. También hemos detectado, que los máximos de reflectividad también se correlacionan con los lugares con más alta tasa de descargas. Por lo tanto utilizando la metodología de Schultz et al. (2011) realizamos el estudio de alerta de eventos severos por medio de la actividad eléctrica. 


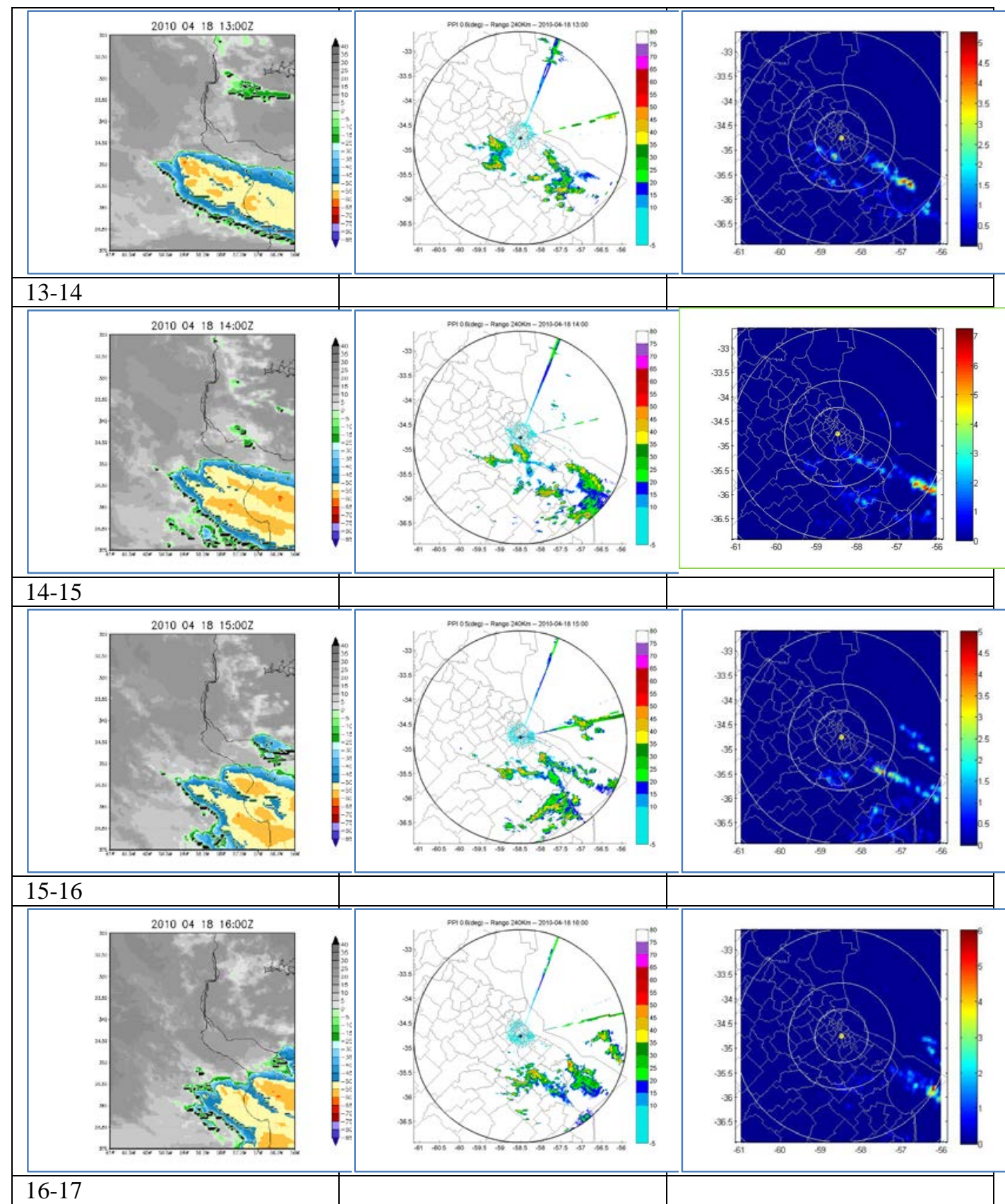

Figura 9-7 Gráficos horarios del primer evento detectando una celda de tormenta por la zona Sur de Buenos Aires, Los paneles izquierdos son la imágenes satelitales, los centrales el radar de Ezeiza y los paneles derechos muestran la densidad de descargas para cada celda

El panel superior de la Figura 9-8 muestra las descargas totales por minuto dentro de la caja de estudio. En el panel intermedio se graficó DFRDT, junto con la desviación estándar ( $\sigma)$. En este punto hemos realizado un cambio respecto al algoritmo propuesto por Schultz et al. (2011), ya que el uso de $2 \sigma$ como valor umbral para el caso de nuestros datos eran muy alto, por lo que decidimos utilizar un valor umbral de un $\sigma$. Por último en el panel inferior, se graficó los eventos con DFRDT $\geq \sigma$, que representan los saltos junto con los datos suministrados por el SMN. 


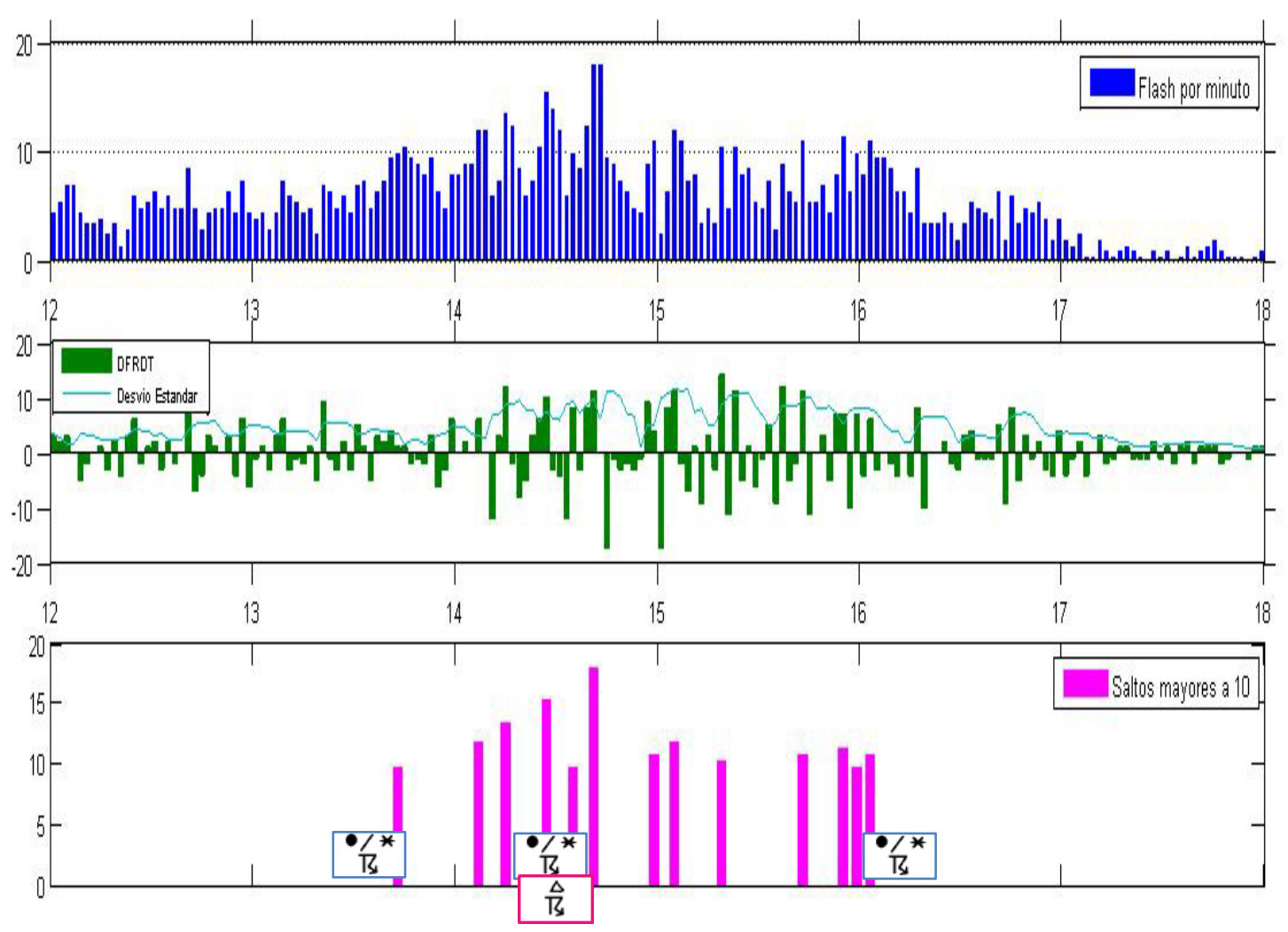

Figura 9-8En el panel superior están graficados las descargas totales por minuto dentro de la caja de estudio. En el panel intermedio se graficó DFRDT, junto con la desviación standart ( $\sigma$ ), el panel inferior, se graficó DFRDT $\geq \sigma$, que representan los saltos y se comparó con los datos suministrados por el SMN.

$\stackrel{\bullet \text { K }}{*} 9_{95}$ - Tormenta eléctrica sin granizo con precipitación reporte de Punta Indio, La Plata, Ezeiza

$\vec{B} 96$ - Tormenta eléctrica con granizo reporte de Punta Indio

De la Figura 9-9 se observa que existe una correlación entre los saltos de AEA y los eventos registrados por el SMN. Sin embargo, no se tiene información acerca del tiempo de ocurrencia ni de la intensidad de dichos eventos (en este caso, pareciera que el evento principal es la caída de granizo)por lo cual no se puede determinar el plazo de la alarma en este caso.

\section{b. Análisis de descargas del segundo evento}

Se realizó el estudio similar al del primer evento entre las 21 y 24 UTC. Se observan las mismas similitudes que en el primer evento entre los datos del radar, el satélite y la densidad de descargas de la WWLLN. Figura 9-9 


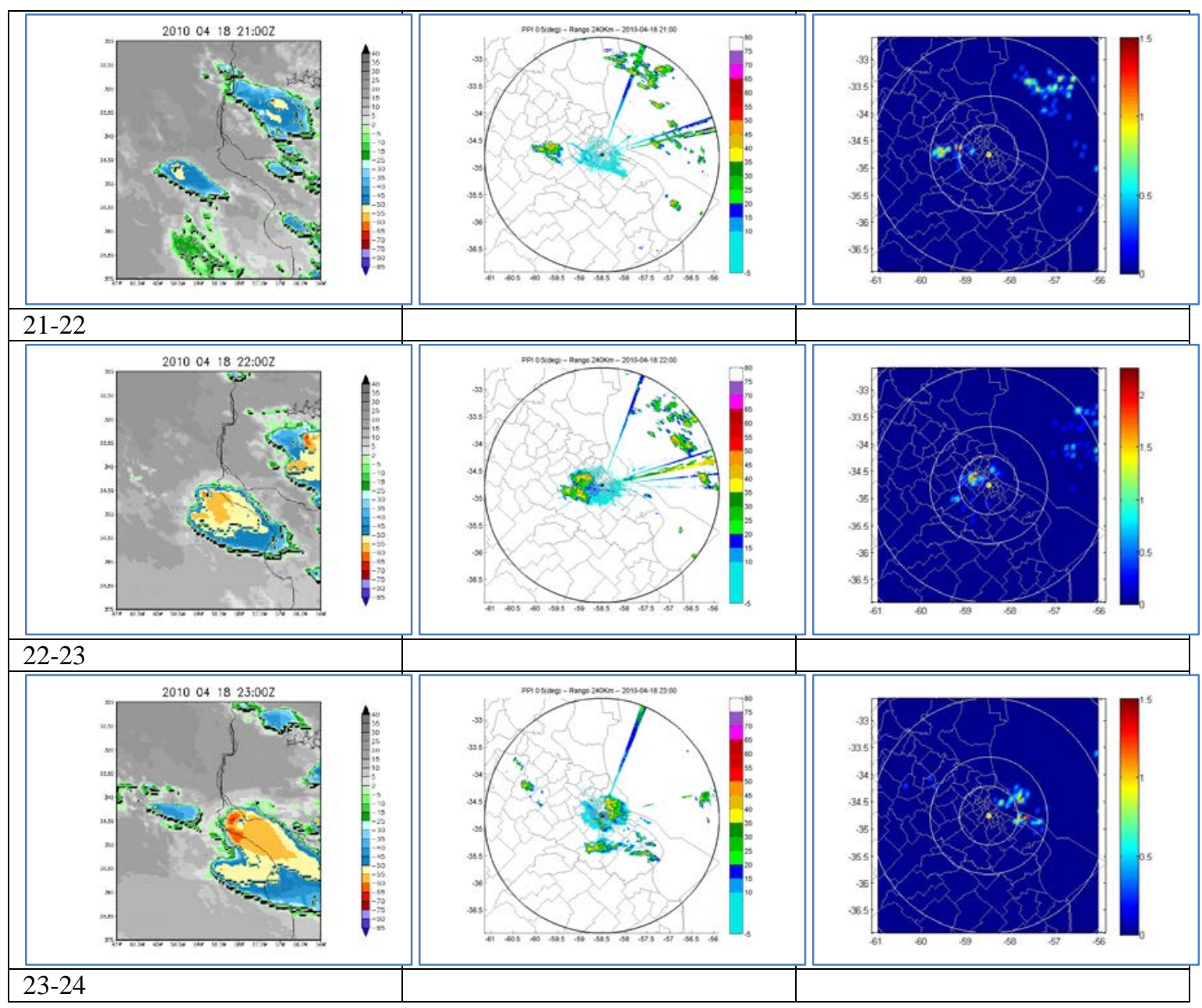

Figura 9-9 referencia similares a Figura 9-8

La Figura 9-9 es similar a la Figura 9-8 pero entre las 18 y 23 horas. Si nos centralizamos en el evento del fuerte granizo en la zona norte de Bs. As como Martínez, este evento fue reportado entre las 19.30 y las 20.15 . Se puede observar que entre las 22 y 22:30 hs UTC (19 a 19:30 hora local) hubo 4 saltos (jump). En promedio podríamos decir que la alerta se encuentra en el plazo de la media hora (aproximado) y concuerda con el plazo el plazo de alarma promedio según Schultz et al. (2011) de 20,65 min +/- 15,05 para eventos severos. 


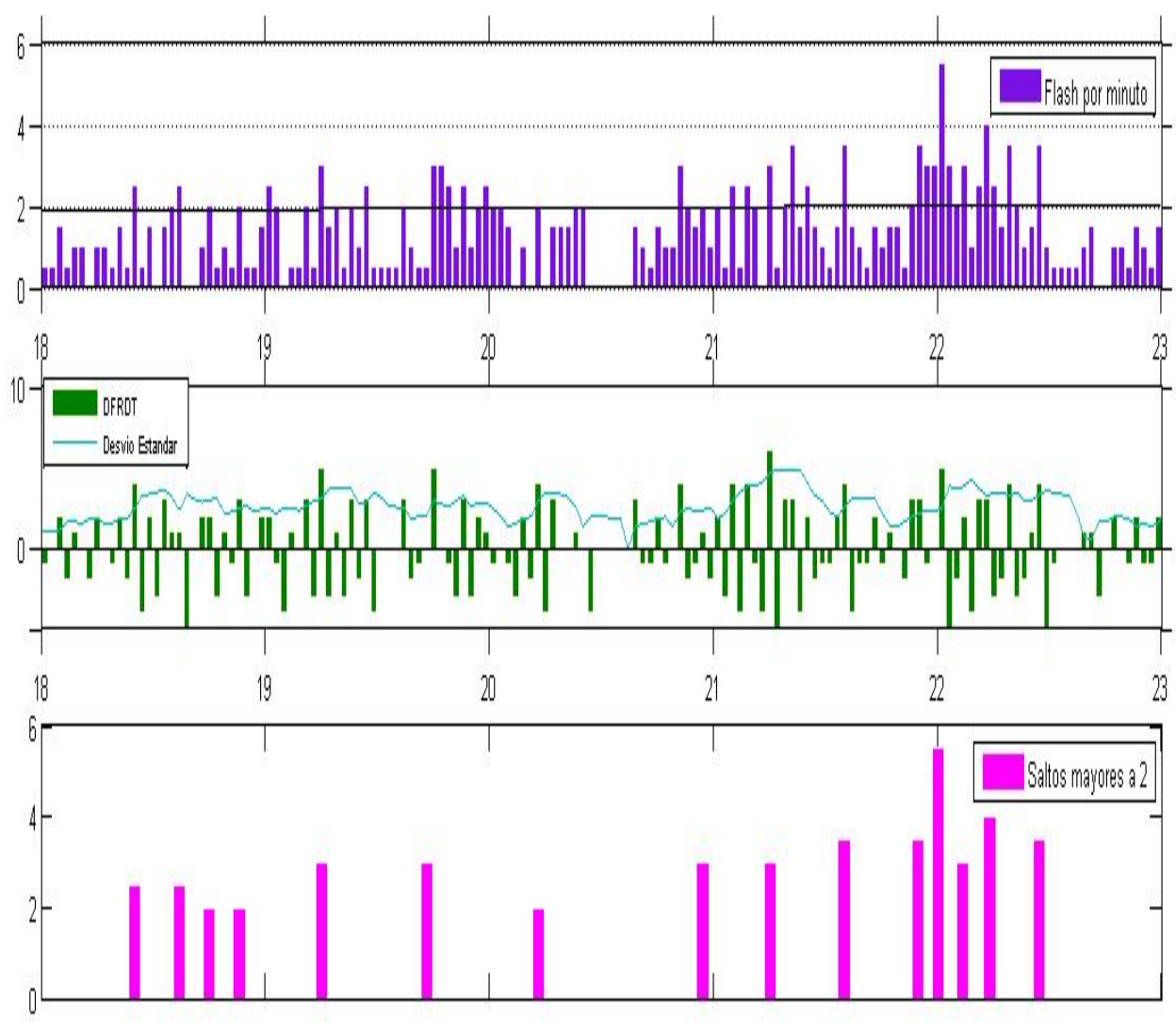

Figura 9-10 referencias similares a Figura 8-9

\section{Consideraciones finales}

Creemos que este trabajo es muy importante, ya que demostramos la factibilidad de utilizar los datos de AEA, provistos por la WWLLN, y el algoritmo presentado por Schults et al. (2011) para realizar pronóstico de corto plazo en la Argentina. Sin embargo, es necesario realizar mayores estudios para obtener modelos estadísticos que representen las condiciones locales. Igualmente es una rama de trabajo que nuestro grupo de investigación sigue trabajando para poder ayudar al país a contar con una herramienta para el pronóstico de corto plazo. 


\section{Capítulo 10 Actividad Eléctrica asociada a erupciones volcánicas - Un caso de estudio}

En este capítulo presentaremos un estudio sobre la actividad eléctrica asociada a erupciones volcánicas y en particular a la erupción del 4 de junio del 2011 del Complejo Volcánico Cordón Caulle. Este estudio fue publicado bajo el título Actividad eléctrica asociada a la erupción del complejo volcánico Cordón Caulle durante 2011 María Gabriela Nicora, Rodrigo E Búrgesser, Alejandro Rosales, Eduardo J Quel, Eldo E Ávila. Meteorológica 12/2013; 38(2):121-131.

Se realizó un estudio de la actividad eléctrica generada por la erupción del complejo volcánico Cordón Caulle en junio de 2011 utilizando datos de descargas eléctricas detectadas por la red World Wide Lightning Location Network. La actividad eléctrica observada se corresponde a descargas eléctricas generadas en la pluma volcánica con una buena correlación entre la cantidad de descargas y la altura de la misma. Aunque la actividad eléctrica detectada fue baja, los resultados están de acuerdo con los obtenidos por estudios previos y muestran que puede ser usada como un indicador de la actividad volcánica. Además muestra la factibilidad de utilizar la red para una detección temprana de erupciones volcánicas.

\section{Introducción}

El complejo volcánico Cordón Caulle está ubicado aproximadamente a los 40,5900 de latitud sur y $72,1170^{\circ}$ de longitud oeste y está constituido por una serie de centros volcánicos de tipo fisural asociados a dos fracturas paralelas principales de orientación NO-SE que constituyen una estructura de rift. El complejo hizo erupción mediante la apertura de un nuevo aparato volcánico identificado por Collini et al. (2012) como We Pillan, el 4 de junio del 2011. La erupción comenzó en junio de 2011, con un evento mayor entre el 4 y el 7 de junio y un evento de menor intensidad entre el 11 y el 14 de junio continuando con emisiones de lava y pequeñas columnas eruptivas hasta al menos mayo del 2012. La erupción fue catalogada de nivel 6, lo cual representa un Índice de Explosividad Volcánica (Volcanic Explosivity Index, VEI) de clase 3 , y presentó una columna eruptiva con una altura entre los 7 y $12 \mathrm{~km}$ para el evento mayor. La erupción presentó magmas evolucionados con una erupción inicial pliniana o subpliniana con una fase explosiva, seguida por otras más efusivas con duración de varios 
meses (Collini et al., 2012). Del análisis de las cenizas tomadas en diferentes localidades se sugiere la presencia de al menos dos diferentes materiales juveniles de tipo basálticoandesítica (55-60\% SiO2) y riolítica (71-73\% SiO2), con composiciones intermedias que podría representar un tipo híbrido, posiblemente de un proceso de mezcla de magma incipientes (Collini et al., 2012).

Distintos estudios (Thomas et al., 2007, 2010; Bennett et al., 2010; Harrison y otros., 2010; Behnke et al., 2012; entre otros) han mostrado que las erupciones volcánicas pueden generar descargas eléctricas. McNutt and Williams (2010) presentaron una base de datos sobre descargas eléctricas producidas por distintas erupciones volcánicas. La base de datos muestra que 212 erupciones, debidas a 80 volcanes, han sido documentadas como productoras de descargas eléctricas.

Thomas et al., $(2007,2010)$ estudiaron la actividad eléctrica generada por la erupción del volcán Augustine durante 2006. Estos autores encontraron dos etapas en la actividad eléctrica. Una primera etapa que se corresponde con la erupción del volcán y que está caracterizada por una alta tasa de descargas de corta extensión, con pocas ramificaciones y con longitudes típicas de pocos cientos de metros (Por ejemplo: National Geographic, Sept. 2007, p. 14-15) y tiempos de 10ms (Thomas et al., 2010); y una segunda etapa que se corresponde con el desarrollo de la columna eruptiva y pluma volcánica. Las descargas eléctricas en esta segunda etapa son similares a las descargas intranube observadas en las nubes de tormentas, con duración de entre 30-600 ms.

La generación de descargas eléctricas se debe a que las partículas generadas durante la erupción volcánica pueden resultar cargadas como resultado de su proceso de formación o por la interacción entre ellas. Si el proceso de cargado es mayor al proceso de disipación de carga (debido a la conductividad del aire y a la neutralización de cargas por colisiones entre partículas con carga opuesta), el campo eléctrico generado por las cargas eléctricas aumenta hasta alcanzar un valor suficiente para que ocurra la ruptura dieléctrica del aire y se produce la descarga eléctrica.

Existen diferentes teorías sobre los procesos que generan la electrificación de las nubes volcánicas (volcanic clouds o eruption clouds). Dentro de los procesos asociados a la primera etapa en la actividad eléctrica, se pueden señalar:

Electrificación de cenizas debido a las interacciones con agua. Este proceso fue descripto a partir de las observaciones de la erupción tipo freática del volcán Surtsey en Islandia durante 1963. Estas observaciones mostraron una electrificación de la pluma $\left(10^{5}-10^{6}\right.$ cargas 
elementales positiva $\mathrm{cm}^{-3}$ ) durante los períodos cuando el vapor de agua y el material piroclástico entraban en contacto (Anderson et al., 1965). Pounder (1972) sugirió que la separación de carga se produce durante la pulverización del agua cuando esta se evapora. También se observó separación de carga cuando la lava fluía hacia el mar, lo cual podría producirse cuando la roca caliente volatiliza partículas de sal marina, las cuales transportan carga positiva (Björnsson et al., 1967).

Electrificación de cenizas a través de mecanismos de fragmentación. Gilbert et al. (1991) midieron la carga en partículas de cenizas en la columna eruptiva del volcán Sakurajima en Japón y sugirieron dos mecanismos para la carga de las mismas, que no implicaban explícitamente la presencia de agua: (i) triboelectrical o cargado por fricción, que es debido al contacto entre materiales con características diferentes; (ii) fractoemission o fractocharging, en el cual los electrones, los iones positivos y negativos, los átomos neutros y las radiaciones electromagnéticas son expulsados de las superficies agrietadas del material fresco dando como resultado una carga residual. Estos mecanismos se apoyan en diversos experimentos de laboratorio en el cual se midió la electrificación de partículas por medio de fricción (Hatakeyama et al., 1952; Kikuchi et al., 1982; James et al., 2000). En el trabajo de James et al. (2008), sobre electrificación de plumas volcánicas ricas en silicato plantean que, a su entender, el mecanismo más importante es el de fractoemission, el cual confiere a la partícula una carga neta opuesta a la del gas y del aerosol circundante. Este último mecanismo se concibe dentro y en las cercanías del conducto eruptivo.

Dentro de los procesos asociados a la segunda etapa, que se corresponde con el desarrollo de la columna eruptiva y de la pluma volcánica, se pueden señalar:

Separación de carga dependiente del tamaño de las cenizas. Durante esta etapa el proceso fractoemission parece dominar. Sin embargo, no existe un proceso físico conocido por el cual este proceso de electrificación dependa del tamaño de las partícula (Mather et al., 2006). James et al. (2000) sugirieron que la dependencia de la electrificación con el tamaño de las partículas puede resultar como un proceso secundario de la captura de iones, que es a la vez función del tamaño de las partículas y de la velocidad de caída asociada. Miura et al. (2002) realizaron estudios durante la erupción del Volcán Sakurajima en Japón, entre el 28 y 29 de octubre de 1995, y propusieron un modelo "PNP" (Positivo - Negativo - Positivo) para la distribución de carga dentro de la nube volcánica, el cual depende del tamaño de las partículas. Este modelo propone que la parte superior de la nube está formada mayoritariamente por gas y pequeños aerosoles, los cuales llevan una carga positiva; la existencia de una capa intermedia de ceniza fina con carga neta negativa y la parte inferior 
formada por cenizas de mayor tamaño cargadas positivamente (Figura 10-1). La recopilación de los resultados actuales y anteriores a la erupción del volcán Sakurajima y de otros volcanes, indica que distribución de la carga negativa en la parte media de la nube es predominante en la mayoría de los casos observados.

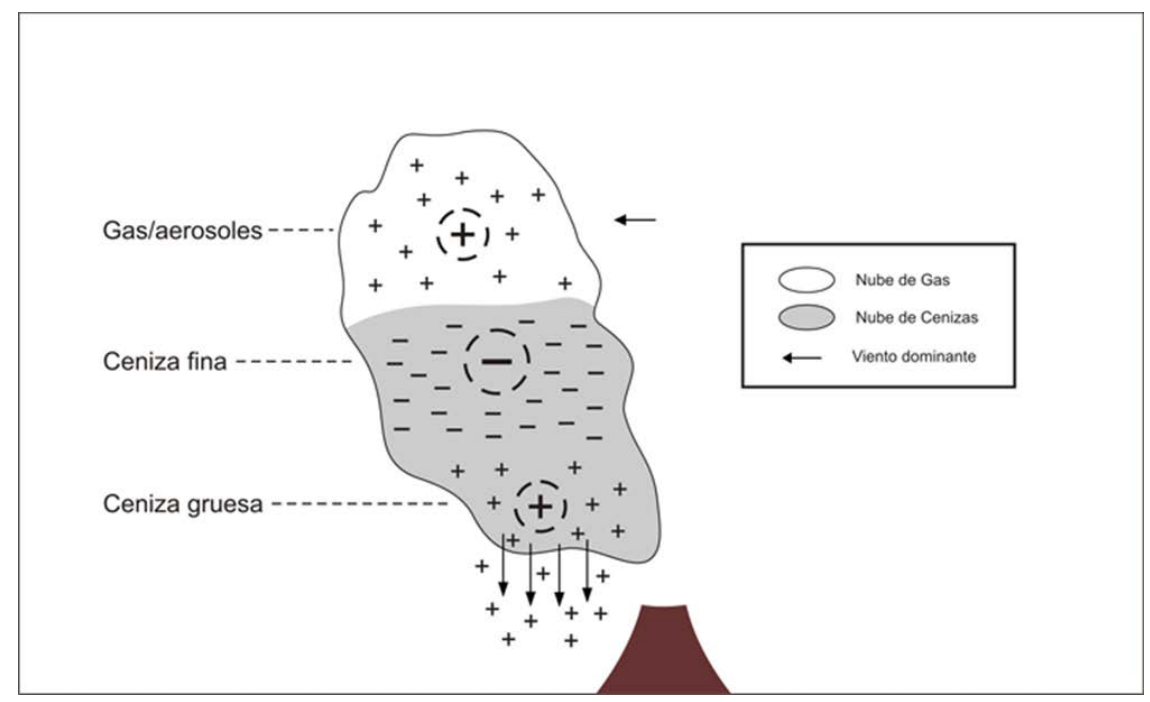

Figura 10-1Modelo de separación de cargas basada de mediciones en el volcán Sakurajima. Adaptado de Miura y otros, 2002

Mecanismo de electrificación análogo al de nubes de tormenta. McNutt y Williams (2010) sugirieron que cuando la columna eruptiva alcanza una altura de $7 \mathrm{~km}$, el mecanismo para la generación de descargas eléctricas es similar al mecanismo de electrificación de las nubes de tormentas.

En el caso de las nubes volcánicas, las partículas de cenizas volcánicas sirven como núcleos de condensación de agua y de hielo. Duran et al. (2008), basados en experimentos de laboratorio, encontraron que la nucleación de partículas de hielo sobre cenizas volcánicas ocurre a temperaturas entre -10 y $-20^{\circ} \mathrm{C}$. Debido a la alta concentración de estos núcleos, en comparación con los núcleos encontrados naturalmente en la atmosfera, las gotas de nube y cristales de hielo son más pequeños que los presentes en las nubes de tormentas, y por lo tanto, el proceso de precipitación es suprimido (Williams et al., 2005). Sin embargo, Sparks et al. (1997) mostraron que las cenizas volcánicas presentan una distribución bimodal con modas de $10 \mu \mathrm{m}$ y de $200 \mu \mathrm{m}$, siendo dominante la moda menor a medida que aumenta la distancia al cráter del volcán. Por otra parte, las fuerzas electrostáticas y las diferentes velocidades de caída permite que el proceso de agregado de las partículas sea muy eficiente, alcanzando los agregados tamaños de hasta $800 \mu \mathrm{m}$ (James et al., 2002). Por lo tanto, aunque el proceso de 
precipitación es suprimido, debido a la dispersión en el espectro de tamaños de las cenizas volcánicas, las partículas nucleadas o acrecidas sobre la misma presentan una distribución de tamaños que permiten diferentes velocidades de caída y por lo tanto, la colisión entre las mismas. Además, en nubes volcánicas las corrientes de aire ascendentes son sustancialmente mayores que las presentes en las nubes de tormentas, y por lo tanto, la acreción de los cristales de hielo y de las cenizas volcánicas debería ocurrir en un tiempo menor y con una mayor eficiencia que en las nubes de tormentas (Williams et al., 2005).

McNutt y Williams (2010) presentaron una correlación entre el índice de explosividad volcánica (VEI) con el porcentaje de volcanes que presentaron electrificación. Estos autores encontraron que alrededor de una 10\% de las erupciones con valores de VEI entre 3 y 6 presentaron actividad eléctrica, y solo el $2 \%$ lo hicieron para valores de VEI entre 1 y 2 . Esta correlación es coherente con el hecho de que las grandes erupciones, con valores altos de VEI, tienen asociadas nubes volcánicas con un desarrollo vertical similar a los sistemas de convección profunda.

Para el mecanismo de electrificación análogo al de nubes de tormenta, el papel del agua, en todas sus formas, parece tener un rol fundamental (Williams y otros, 2005). Por ello la composición del magma es un parámetro relevante ya que, según su composición, se puede determinar aproximadamente el contenido de agua disuelto (Mc Nutt y otros, 2010) , y a la vez conocer el estilo eruptivo (Estromboliana, Pliniano, etc.), el cual da una característica de la explosividad del evento.

Entonces, tanto el índice de explosividad volcánica como la composición del magma son parámetros fundamentales para las teorías expuestas anteriormente ya que los mismos se relacionan con la altura de la columna eruptiva y con el contenido de agua de la misma.

El objetivo de este trabajo es estudiar la actividad eléctrica generada por la erupción del complejo volcánico Cordón Caulle (1507-15) durante el mes de Junio de 2011 usando datos de actividad eléctrica detectada por la red de detección mundial World Wide Lightning Location Network (WWLLN), y en base a los informes sobre dicha actividad volcánica, estudiar la relación de ésta con distintos parámetros relevantes de la erupción.

\section{Datos y metodología}

Para realizar el estudio sobre la actividad eléctrica producida por la erupción del complejo volcánico Cordón Caulle, se utilizó una ventana espacial ubicada entre $40^{\circ}$ y $42^{\circ}$ de latitud sur y entre $73^{\circ}$ y $71^{\circ}$ de longitud oeste con una resolución espacial de $0,1^{\circ} \times 0,1^{\circ}$. La actividad 
eléctrica se monitoreo durante los meses de mayo a julio. Se recopilaron los informes sobre la actividad volcánica y parámetros meteorológicos generados por distintos organismos (Servicio Geológico y Minero de Chile, Servicio Geológico Minero Argentino, Centro de avisos de Cenizas Volcánicas Buenos Aires VAAC Buenos Aires SMN-SHN, Proyecto CYTED-CENIZA).

\section{Resultados y discusión}

En la ventana espacial considerada, la red WWLLN detectó 115 eventos entre el 4 y el 7 de junio, mientras que para los días anteriores se detectó solo un evento. Para los días posteriores se detectaron 4 eventos entre el 11 y 14 de junio, y solo un evento durante el mes de julio.

Es bien conocido que la actividad eléctrica debido a descargas por tormentas eléctricas, disminuye cuando aumenta la latitud; en particular, la actividad eléctrica en la ubicación del complejo volcánico Cordón Caulle es usualmente muy baja, en especial durante los meses de invierno. Esto fue corroborado ya que la actividad eléctrica detectada fue muy baja o nula para los días anteriores y posteriores a la erupción volcánica. Esto indicaría que la actividad eléctrica detectada entre el 4 y el 7 , y entre el 11 y el 14 de junio se corresponde con actividad eléctrica generada por la erupción del volcán.

El Reporte Especial de Actividad Volcánica No 28 - Región de Los Ríos - Complejo Volcánico Puyehue - Cordón Caulle con fecha del 4 de junio de 2011 indica que la erupción se inició a las 14:45 (hora local) del día 4 de junio. A su vez, el primer evento detectado por la red WWLLN ocurrió a las 14:41 (hora local) del mismo día ( http://www.sernageomin.cl/volcan.php?ild=38).

El hecho que la red WWLLN detectará el primer evento al momento de la erupción indicaría que, a pesar de la tendencia a detectar eventos de alta intensidad, las descargas detectadas inicialmente se corresponden a descargas generadas en la fase explosiva. Sin embargo, durante esta etapa no es posible determinar que mecanismo (electrificación de la ceniza debido a la interacción con agua o por fragmentación) domina o si actúan de manera combinada.

La Figura 10-2 muestra la actividad eléctrica detectada entre el 4 y 7 de Junio, la cual presenta una distribución espacial con una dirección preferencial sudeste. Los informes para estos días indican que se observó una columna de gas de $10 \mathrm{~km}$ de altura y $5 \mathrm{~km}$ de ancho, vientos con dirección sur a $5 \mathrm{~km}$ de altura y con una dirección sudeste-este a $10 \mathrm{~km}$ de altura. 
Por lo tanto, la ubicación de las descargas detectadas es consistente con estos informes y con la pluma observada en distintas imágenes satelitales. En la Figura 10-2, también se observa que se detectaron cuatro eventos ubicados al noroeste del volcán que no pueden ser relacionados con la pluma volcánica y que podrían deberse a errores en la ubicación dado por la red WWLLN.

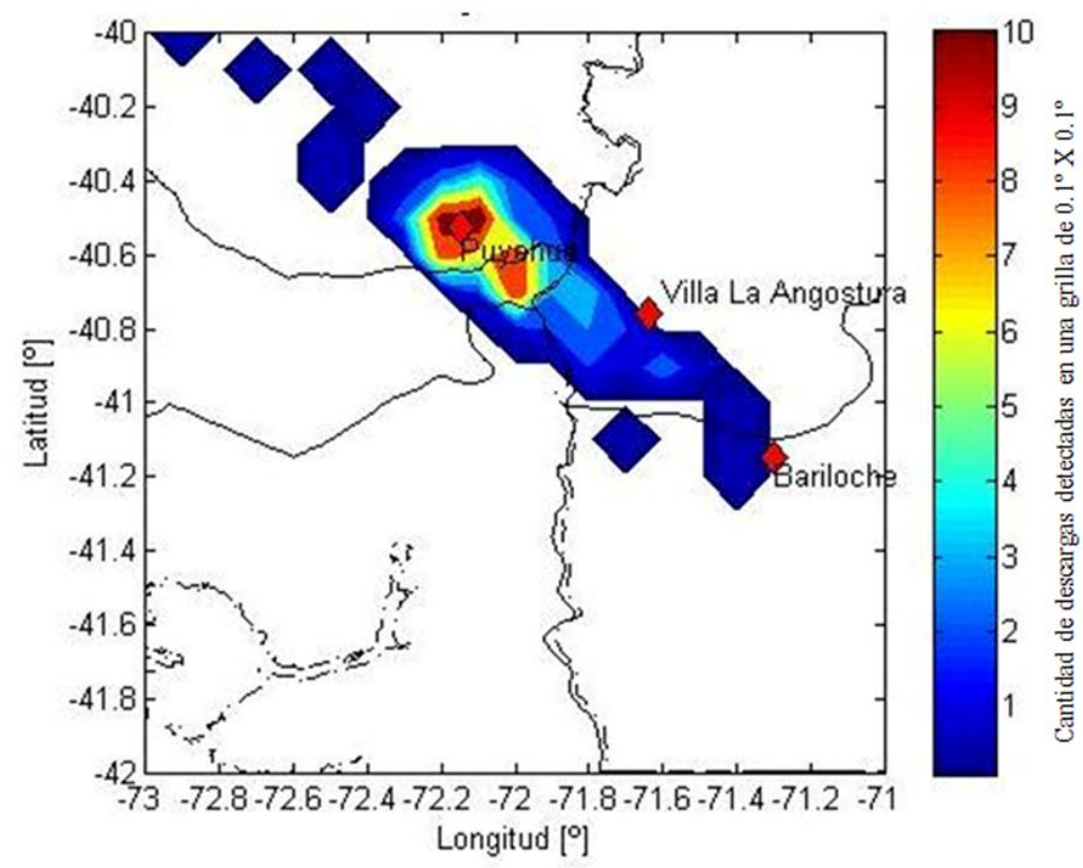

Figura 10-2Actividad eléctrica detectada por la red WWLLN entre el 4 y 7 de junio de 2011 y la ubicación del volcán Puyehue

En la Figura 10-3 se muestra el histograma de las descargas detectadas en función de la distancia al volcán. Se puede observar que la mayoría de las descargas detectadas (>60\%) ocurrieron entre los 5 y $20 \mathrm{~km}$ del volcán. Esto indicaría que la mayoría de las descargas eléctricas detectadas se produjeron en la pluma volcánica ya que presentan una distribución espacial y temporal consistente con la misma.

La Figura 10-4 muestra la altura de la pluma reportada por el Observatorio Vulcanológico de los Andes del Sur (OVDAS) y la cantidad de descargas eléctrica detectada por la WWLLN en la ventana espacial considerada para los días entre el 1 y el 18 de junio. Se puede observar que existe una buena correlación, con un coeficiente de Pearson mayor a $0.8\left(p<10^{-4}\right)$, entre la altura y la cantidad de descargas detectadas por la red. 


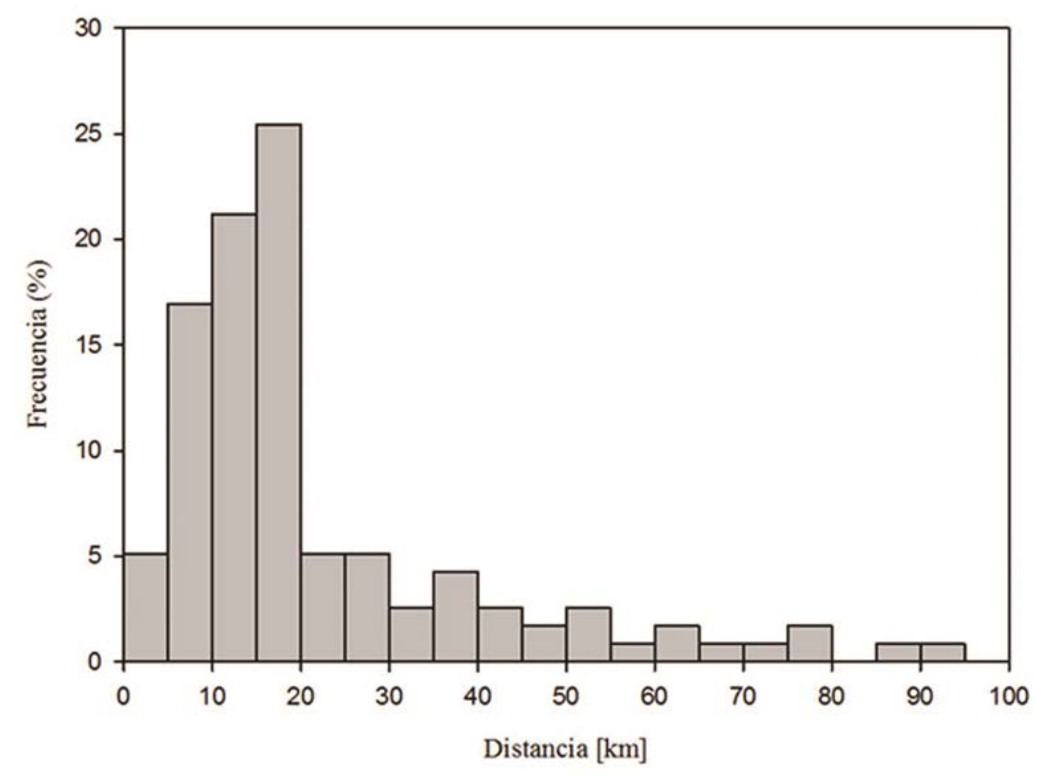

Figura 10-3Histograma de la distancia entre la ubicación de las descargas eléctricas y la posición del cráter del volcán Puyehue

Se observa que la red WWLLN detecta actividad eléctrica cuando la altura de la pluma es superior a $7 \mathrm{~km}$, que se corresponde a una temperatura de la atmósfera de aproximadamente $-20^{\circ} \mathrm{C}$. Es plausible asumir que la temperatura de la pluma es mayor a la de su entorno y que a esta altura se produce la nucleación de partículas de hielo sobre las cenizas volcánicas (Duran y otros, 2008). Además, la composición química del magma, de tipo basáltico a riolíticos (48$77 \% \mathrm{SiO} 2$ ), tiene un contenido de agua entre 0,1 al 6,5 por ciento de la masa, lo cual provee del agua para que el proceso de nucleación y de acreción pueda realizarse. Esto sugiere que en la nube volcánica estaría operando el mecanismo de electrificación análogo al de nubes de tormentas. Sin embargo, no es posible descartar al mecanismo de fractoemission sino asumir que estos mecanismos pueden operar de manera simultánea. 


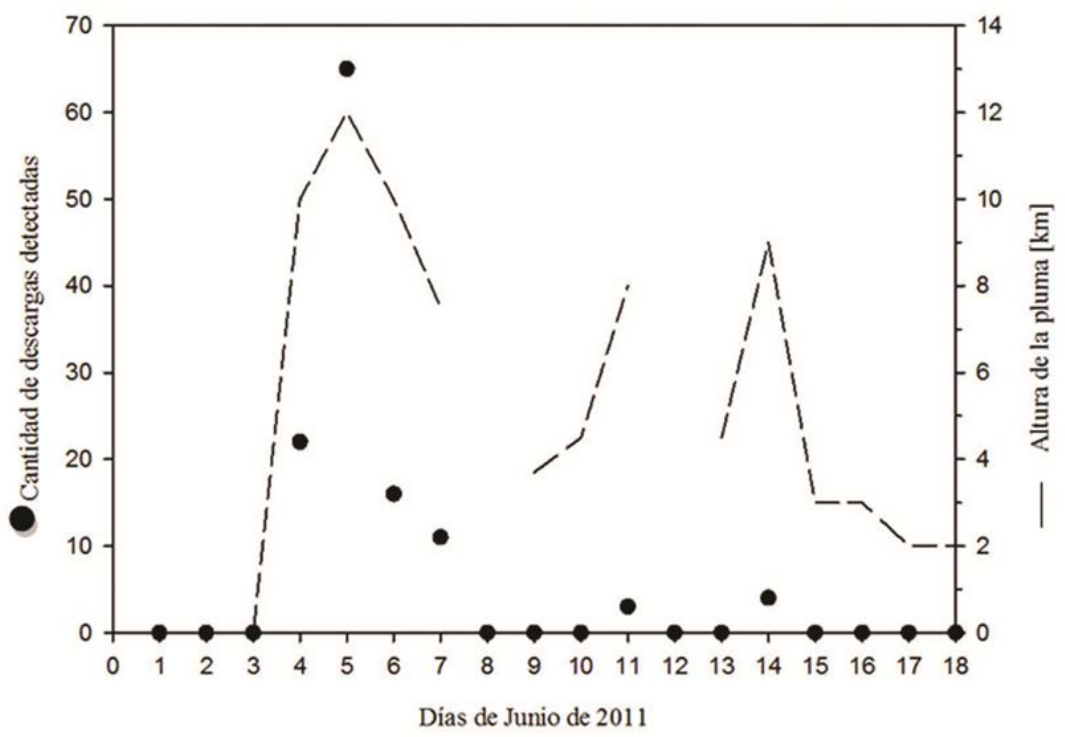

Figura 10-4Cantidad de descargas eléctricas detectadas (círculos negros) y altura de la pluma (línea quebrada) por día entre el 1 y el 18 de junio

La red WWLLN posee un proyecto de investigación experimental para la detección temprana de erupción de volcanes denominado Monitoreo Global de Actividad Eléctrica Volcánica (Global Volcanic Lightning Monitor, http://wwlln.net/volcanoMonitor.html), el cual se basa en la detección de la actividad eléctrica en la cercanía de la caldera del volcán. Este sistema emitió un alerta sobre le erupción del complejo volcánico Cordón Caulle a las 14:43 (hora local), con la detección del primer rayo a las 14:41 (hora local). Esta alerta fue enviada 30 minutos antes de la primera alerta sobre la erupción del volcán dada por el Servicio Nacional de Geología y Minería (SERNAGEOMIN) - Observatorio Volcanológico de los Andes del Sur (OVDAS).

\section{Conclusión}

La actividad eléctrica observada es consistente espacial y temporalmente con la pluma volcánica generada por la erupción del complejo volcánico Cordón Caulle. La ubicación de la mayoría de las descargas detectadas en dirección sureste del volcán está de acuerdo con la dirección del viento dominante y la pluma observada.

Aunque se observó un aumento en los eventos detectados por la WWLLN, esto no implica necesariamente un aumento en la actividad eléctrica sino una mayor cantidad de descargas de 
gran intensidad. Sin embargo, no existe otro sistema que pueda detectar actividad eléctrica en las latitudes donde se ubica el complejo volcánico Cordón Caulle.

Es importante señalar la coincidencia temporal entre la erupción volcánica con los primeros datos de electrificación de la pluma y de la columna eruptiva. Esto pereciera deberse al tipo explosivo de la erupción con una fase inicial pliniana, la cual eyectó una columna eruptiva entre los 10 y $12 \mathrm{~km}$ (Collini et al., 2012). Este tipo de erupción de muy alta energía provocó una electrificación muy efectiva de la columna eruptiva por alguno o varios de los procesos de electrificación descriptos.

Tanto la composición química del magma, como el tipo de erupción del volcán en estudio, son característicos de erupciones que pueden tener asociados actividad eléctrica (McNutt et al., 2010). Esto fue observado en el estudio realizado, ya que la erupción estuvo asociada a descargas eléctricas generadas tanto en la etapa explosiva como en la pluma y en la columna eruptiva. Estas descargas fueron observadas desde diversos sitios y fueron, desde los primeros momentos, una de las principales características visuales de la erupción.

Por primera vez se detectó la actividad eléctrica generada por una erupción volcánica en Suramérica. Aunque la actividad eléctrica detectada fue baja y se corresponde principalmente a la electrificación de la pluma, los resultados encontrados están de acuerdo con los obtenidos en estudios previos y muestran que la actividad eléctrica puede ser usada como indicador de actividad volcánica.

La alerta del Monitoreo Global de Actividad Eléctrica Volcánica de la red WWLLN fue anterior al reporte del Servicio Nacional de Geología y Minería (SERNAGEOMIN) de Chile, demostrando la relevancia del sistema como herramienta de alerta temprana, apoyando a los sistemas nacionales de alerta (en el caso de que existieran) y en los casos que no existan monitoreo continuo de sistemas eruptivos, esta técnica podría servir como alertas tempranas de erupciones en lugares remotos del Cono Sur. 


\section{Capítulo 11 Conclusiones generales de la Tesis}

En este Capítulo se resumen los resultados más relevantes del trabajo de Tesis, resaltando aquellos que constituyen aportes originales a los temas abordados.

En la presente tesis se realizaron importantes avances en la investigación de la actividad eléctrica atmosférica en América del Sur y, en particular, en la caracterización de la actividad eléctrica atmosférica en el territorio argentino y su relación con distintos eventos climáticos. Los avances están reflejados en distintas publicaciones en revistas internacionales y nacionales así como en numerosas presentaciones en congresos.

Este trabajo de tesis presenta información inédita para el país sobre la actividad eléctrica atmosférica en el territorio argentino, en distintas escalas temporales, información que no existían previamente más allá de la información del número de días con tormenta provista por la red de estaciones meteorológicas del Servicio Meteorológico Nacional (SMN), información que solo era recabada en ciertos sitios del país.

Dentro de la Tesis realizada es importante recalcar la confección de los mapas isoceráunicos del territorio argentino para la actualización de las normas IRAM de protección contra descargas eléctricas atmosféricas en el país (IRAM 2184-11/AEA 92305-11). Estos mapas confeccionados en base a los datos de la World Wide Lightning Location Network (WWLLN) fueron validados con los mapas confeccionados con los datos provistos por el SMN y mostraron la versatilidad y confiabilidad del algoritmo implementado y de la base de datos utilizada. Los mapas confeccionados revelaron ciertas características, como el máximo encontrado en la región noroeste del país y cierta actividad ceráunica observada en la región patagónica de Chile, que no habían sido reportadas anteriormente. Estos estudios sientan las bases para futuros estudios de la variabilidad de la actividad ceráunica debido a cambios climáticos.

En el caso de Sud América, si bien existen algunos trabajos previos en base a información de redes regionales, los trabajos realizados en esta Tesis presentan información novedosa en cuanto a la caracterización de la actividad eléctrica atmosférica en toda la extensión del continente. En particular es interesante remarcar el estudio del ciclo diario de la actividad eléctrica observado en el continente, siendo este estudio novedoso en cuanto no existía una caracterización completa del ciclo y, si bien existían algunos indicios, los resultados 
encontrados muestran una relación entre la AEA y la convección profunda en la atmósfera asociada a los sistemas convectivos de mesoescala.

Además, si bien en la Tesis se presenta un estudio preliminar, se muestra que la actividad eléctrica atmosférica es un indicador factible de utilizar para emitir un alerta temprano de eventos meteorológicos severos como por ejemplo las tormentas productoras de granizo. Si bien la relación entre la AEA y la ocurrencia de granizo se utiliza en aquellos países que poseen una red propia de detección de actividad eléctrica atmosférica nacional (por ejemplo: Estados Unidos, Brasil, países de Europa), este estudio es inédito en el país y muestra que, si bien Argentina no posee una red propia, los datos provistos por la red WWLLN son suficientemente confiables para realizar pronósticos a corto plazo. Por lo cual, la Tesis sienta la base para realizar este tipo de pronóstico, a tiempo real, en todo el territorio argentino.

Otro resultado relevante presentado en la Tesis es el estudio sobre muertes debido a la acción de rayos. A partir de estos resultados se elaboró un mapa de vulnerabilidad de la población ante esta amenaza, constituyendo una herramienta de gran utilidad para los tomadores de decisiones en materia de prevención.

La relevancia de los resultados obtenidos en la tesis ha hecho posible su publicación en artículos de revistas nacionales e internacionales de la especialidad, los cuales se listan a continuación,

Characterization of the lightning activity of "Relámpago del Catatumbo", Rodrigo E. Bürgesser, María G. Nicora, Eldo E. Ávila, 2012. Journal of Atmospheric and Solar-Terrestrial Physics77, 241-247.

Spatial and time distribution of the flash rate over tropical África, Rodrigo E. Bürgesser, María G. Nicora, Eldo E. Ávila 2013.Journal of Atmospheric and Solar-Terrestrial Physics, 94, 41-48.

Actividad eléctrica asociada a la erupción del complejo volcánico Cordón Caulle durante 2011, María Gabriela Nicora, Rodrigo E Bürgesser, Alejandro Rosales, Eduardo J Quel, Eldo E Ávila,2013. Meteorológica 12/2013; 38(2):121-131.

Lightning in Western Patagonia, Garreaud, René, Nicora, M. Gabriela, Bürgesser, Rodrigo E., Ávila, Eldo E, 2014. Journal of Geophysical Research: Atmospheres, 119, DOI: 10.1002/2013JD021160.

Las dos primeras publicaciones, fueron realizadas en el inicio de la Tesis, estos trabajos sirvieron para familiarizarse con la utilización de las distintas bases de datos de actividad 
eléctrica atmosférica, y en los algoritmos y métodos de análisis para realizar este tipo de estudios.

La tercera publicación fue la primera investigación sobre la actividad eléctrica debido a una erupción volcánica en el hemisferio sur. En este trabajo también se verificó que la actividad eléctrica atmosférica puede ser utilizada para emitir una alerta temprana de estos tipos de eventos utilizando las herramientas con las que se contaban y se cuentan en este momento.

La cuarta publicación, tiene como originalidad el análisis de la actividad eléctrica observada en una región que, en los conocimientos previos, se tenía como irrelevante. Este tema de estudio surgió del hecho que la red WWLLN emitía alertas de erupción en esas zonas que eran descartadas por ser falsos positivos. Esto muestra la iniciativa en este trabajo de tesis de afrontar nuevos desafíos y a cuestionar ciertos hechos ya aceptados. También queremos reforzar la importancia de contactar e interactuar con investigadores especializados en la climatología del lugar de estudio para llevar a cabo la investigación realizada.

Por todo esto, consideramos que la presente Tesis, presenta resultados novedosos sobre la actividad eléctrica atmosférica y su relación con distintos eventos climáticos, sus posibles aplicaciones y su relevancia para la seguridad de la población. Además, de la Tesis se desprenden distintas aplicaciones y trabajos futuros, dando lugar a un área de investigación nueva y relevante para el país. 


\section{Referencias}

Abarca, S. F., Corbosiero, K. L. and Galarneau Jr., T.J., 2010. An evaluation of the Worldwide Lightning Location Network (WWLLN) using the National Lightning Detection Network (NLDN) as ground truth. J. Geophys. Res. 115, D18206, doi:10.1029/2009JD013411.

Abreu, D., Chandan, D., Holzworth, R. H. y Strong, K., 2010. A performance assessment of the World Wide Lightning Location Network (WWLLN) via comparison with the Canadian Lightning Detection Network (CLDN).Atmos. Meas. Tech., 3, 1143-1153.

Albrecht, R.I., Goodman, S.J., Petersen, W.A., Buechler, D.E., Bruning, E.C., Blakeslee, R.J. and Christian, H.J., 2011. The 13 years of TRMM Lightning Imaging Sensor: From individual flash characteristics to decadal tendencies, XIV International Conference on Atmospheric Electricity, August 08-12, 2011, Rio de Janeiro, Brazil.

Amador, J. A., 2008. The Intra-Americas Sea Low-level Jet, Annals of the New York Academy of Sciences, 1146, 153-188

Anderson R.B., Eriksson A.J., Kroninger H., Meal D.V. and Smith M.A. 1984, Lightning and thunderstorm parameters IEE Conference Publication No. 236, "Lightning and Power Systems", London, June 1984

Angelis, C. de and McGregor, G.R. and Kidd, C., 2004. Diurnal cycle of rainfall over the Brazilian Amazon. Climate Research, 26 . pp. 139-149. ISSN 0936-577X

Arcioni, J.C.,2006. La actividad eléctrica atmosférica media anual ("AEAMA") en la Argentina, Ingeniería Eléctrica,Pages. 130-139,

Arcioni J. C., Giménez J.F, 2014. Los rayos a tierra y las probabilidades de Poisson, Ingeniería Eléctrica, Abril 2014

Asnani, G.C., 1993. Tropical meteorology, Indian Institute of Tropical Meteorology, Pune.

Aumann, H.H., Broberg, S.D., Elliott, Gaiser, S., Gregorich, D., 2006. Three years of atmospheric infrared sounder radiometric calibration validation using sea surface temperatures. J. Geophys. Res.-Atmos., 111, D16S90.doi:10.1029/2005JD006822.

Aumann, H.H.,Gregorich, D.T., Broberg, S.E., Elliott, D.A., 2007. Seasonal correlations of SST, water vapor, and convective activity in tropical oceans: a new hyperspectral data set for climate model testing. Geophys.Res. Letters 34,L15813.doi:10.1029/2006GL029191.

Avila, E.E. and Caranti, G.M., 1994. A laboratory study of static charging by fracture in ice growing by riming. Journal of Geophysical Research-Atmospheres 99, 10611-10620.

Avila, E. E., Aguirre Varela, G. G. and Caranti, G. M.: Temperature dependence of charging in ice growing by riming, J. Atmos. Sci., 52, 4515-4522, 1995.

Avila, E. E., Aguirre Varela, G. G. and Caranti, G. M.: Charging in ice-ice collisions as a funof the ambient temperature and the larger particle average temperature, J. Geophys101, 2960929614, 1996.

Avila, E. E., Caranti, G. M., Castellano, N. E. and Saunders C. P. R.: Laboratory studies of influence of cloud droplet size on charge transfer during crystal-graupel collisions, J. GeophRes., 103, 8985- 8996, 1998.

Ávila, E. E., and Pereyra, R. G.: Charge transfer during crystal graupel collisions for twodifferent cloud droplet size distributions, Geophys. Res. Lett., 27, 3837-3840, 2000.

Ávila, E. E., Bürgesser, R. E., Castellano, N. E., Campagnucci, R. H., Collier, A. y Hugh"Relación entre la tasa de descargas eléctricas globales y las nubes de convección profXIII 
Congreso Latinoamericano e Ibérico de Meteorología (CLIMET XIII) y el X CoArgentino de Meteorología (CONGREMET X), 2009. Buenos Aires, Argentina.

Ávila, E.E., Bürgesser, R.E., Castellano, N.E., Collier, A.B., Compagnucci, R.H., Hughes, A.R.W, 2010. Correlations between deep convection and lightning activity on a global scale.J. Atmos. Sol. Terr. Phys. 72 (14-15), 1114-1121,

Ávila, E. E., Bürgesser, R. E., Castellano, N. E., Pereyra, R. G., and Saunders, C. P., 2011. Charge separation in low-temperature ice cloud regions. Journal of Geophysical Research: Atmospheres (1984-2012) 116.D14.

Ávila, EE, RA Lighezzolo, NE Castellano, RG Pereyra, y RE Bürgesser, 2013. Laboratory measurements of charge separation in low liquid watercontent conditions and low impact velocity, J. Geophys.Res..Atmos., 118 ,doi: 10.1002/jgrd.50555.

Ba, M.B. and Nicholson, S.E., 1998: Analysis of Convective Activity and Its Relationship to the Rainfall over the Rift Valley Lakes of East Africa during 1983-90 Using the Meteosat Infrared Channel. J. Appl. Meteor., 37, 1250-1264.

Baker, Marcia B., Hugh J. Christian, and John Latham, 1995. A computational study of the relationships linking lightning frequency and other thundercloud parameters. Quarterly Journal of the Royal Meteorological Society 121.527: 1525-1548.

Baker, M. B., Blyth, A. M., Christian, H. J., Latham, J., Miller, K. A., \& Gadian, A. M., 1999. Relationships between lightning activity and various thundercloud parameters: Satellite and modelling studies. Atmospheric research, 51(3), 221-236.

Bateman M.G., T.M. Marshall, M. Stolzenburg, and Rust W.D.,1999, Precipitation charge and size measurements inside a New Mexico mountain thunderstorm, J. Geophys. Res. 104 pp.96439653.

Beebe, R. G. and Bates, F.C., 1955. A mechanism for assisting in the release of convective instability. Mon. Wea. Rev., 83, 1-10, doi: 10.1175/1520-0493.

Behnke, S.A., Thomas, R.J., McNutt, S.R., Schneider D.J., Krehbiel, P.R., William, R. y Edens, H.E., 2012 Observations of volcanic lightning during the 2009 eruption of Redoubt Volcano, J. Volcanol. Geotherm.Res. (2012), doi:10.1016/j.jvolgeores.2011.12.010.

Bennett, A.J., Odams, P., Edwards, D. y Arason, P., 2010. Monitoring of lightning from the April-May 2010 Eyjafjallaj okull volcanic eruption using a very low frequency lightning location network, Environ. Res. Lett. 5, 044013 (8pp).

Betz, Hans Dieter, Ulrich Schumann, and Pierre Laroche, eds. Lightning: principles, instruments and applications: review of modern lightning research. Springer, 2009.

Björnsson, S., Blanchard, D.C., y Spencer, A.T., 1967.Charge generation due to contact of saline waters with Molten Lava. J Geophys Res 72, 1311-1323.

Blakeslee, R. J., Mach, D. M., Bateman, M. G., \& Bailey, J. C. , 2012. Seasonal variations in the lightning diurnal cycle and implications for the global electric circuit. Atmospheric Research, 135-136228-243.

Boccippio, D.J., Goodman, S.J., Heckman, S., 2000. Regional differences in tropical lightning distributions. J. Appl. Met. 39, 2231- 2248.

Boccippio, D. J., Koshak, W. J., and Blakeslee, R. J., 2002.Performance assessment of the Optical Transient Detector and Lightning Imaging Sensor. Part I: Predicted diurnal variability. J. Atmos. Oceanic Thechnol., 19, 1318-1332.

Bonner, W.D., 1966. Case study of thunderstorm activity in relation to the Low-Level Jet. Mon. Wea. Rev., 94, 167-178, doi: 10.1175/1520-0493 
Bovalo, C., Barthe, C. y Bègue, N., 2012. A lightning climatology of the South-West Indian Ocean, Nat. Hazards Earth Syst. Sci., 12, 2659-2670.

Silvia Bordón, Ricardo M. Garrido, Martín I. Pucciano Iserte: "CURVAS DE NIVEL ISOCERAUNICO EN LA REPUBLICA ARGENTINA" X Congreso Argentino de Meteorología, BsAs, 2009

Borucki, W. J. and Chameides, W. L, 1984, Lightning: Estimates of the rates of energy dissipation and nitrogen fixation, Rev. Geophys. Space Phys., 22, 363-372.

Brooks, C.E.P., 1925. The distribution of thunderstorms over the globe.Geophys.Mem.London 24, 147- 164.

Brooks, H.E., Leeb, J.W., Cravenc, J.P., 2003. The spatial distribution of severe thunderstorm and tornado environments from global reanalysis data. Atmospheric Research, 67-68, 73-94.

Browning, K. A. , 1986, Conceptual models of precipitation systems. Weather and Forecasting, 1(1), 23-41.

Bürgesser, R. E., Pereyra, R. G. and Avila, E. E., 2000, Charge separation in updraft of converegions of thunderstorm, Geophys. Res. Lett., 33, L03808, doi:10.1029/2005GL023993

Bürgesser, R.E., Nicora, M.G., Ávila, E.E., 2012. Characterization of the lightning activity of "Relámpago del Catatumbo". Journal of Atmospheric and Solar-Terrestrial Physics77, 241-247

Bürgesser, RE, MG Nicora, y EE Ávila, 2013: la distribución espacial y temporal de la tasa de desarrollo rápido sobre África tropical. Journal of Atmospheric and Solar-TerrestrialFísica , 94, 41-48.

Carey, L. D., and Rutledge, S. A., 1996. A multiparameter radar case study of the microphysical and kinematic evolution of a lightning producing storm. Meteorology and Atmospheric Physics, 59(1-2), 33-64.

Carey LDS, Rutledge A, 1998, Electrical and multiparameter radar observations of a severe hailstorm.J Geophys Res 103(12):13979-14000 doi:10.1029/97JD02626

Carey LD, Petersen WA, Rutledge SA, 2003, Evolution of cloud-to-ground lightning and storm structure inthe Spencer, South Dakota, tornadic super cell of 30 May 1998. Mon Weather Rev 131:1811-1831

Carey, L. D., and Buffalo, K. M., 2007. Environmental Control of Cloud-to-Ground Lightning Polarity in Severe Storms. Monthly weather review, 135(4).

Cardoso, I; Pinto Jr; Pinto R.C; Holle R.A new approach estimate the annual number of global lightning fatalities. ICAE, 2011, Rio de Janeiro, Brasil

Carpenter, D. L., U. S. Inan, M. L. Trimpi, R. A. Helliwell, and J. P. Katsufrakis, 1984, Perturbations ofSubionospheric LF and MF Signals Due to Whistler-Induced Electron Precipitation Burst. J.Geophys. Res., 89: 9857.

Carvalho, L. Jones, C. and Liebmann, B., 2002. Extreme Precipitation Events in Southeastern South America and Large-Scale Convective Patterns in the South Atlantic Convergence Zone. Journal Of Climate,15(17), 2377.

Cecil, D. J., Buechler, D.E., Blakeslee, R.J., 2012. Gridded lightning climatology from TRMMLIS and OTD: Dataset description, Atmospheric Research, ISSN 0169-8095, http://dx.doi.org/10.1016/j.atmosres.2012.06.028.

Chagnon SA, 1992 Temporal and spatial relations between hail and lightning. J Appl Met 31(6):587-604 
Chahine, M.T., et al., 2006. The atmospheric infrared sounder (AIRS): improving weather forecasting and providing new data on greenhouse gases. Bulletin of the American Meteorological Society 87, 911-926.

Chahine, M.T. ,et al., 2006.The atmospheric infrared sounder (AIRS): improving weather forecasting and providing new data on greenhouse gases. Bulletin of the American Meteorological Society 87,911-926.

Chameides, W. L., Stedman, D. H., Dickerson, R. R., Rusch, D. W., and Cicerone, R. J.: NOx production in lightning, J. Atmos. Sci., 34, 143-149, 1977.

Christian, H., Blakeslee, R., Goodman, S., Mach, D., Stewart, M., Buechler, D., Koshak, W.J., Hall, J. M., Boeck, W., Driscoll, K. T. and Bocippio, D. J., 1999. The lightning imaging sensor. NASA conference publication. NASA

Christian, H. J., R. J. Blakeslee, D. J. Boccippio, W. L. Boeck, D. E. Buechler, K. T. Driscoll, S. J. Goodman, J. M. Hall, W. J. Koshak, and D. M. Mach, 2003, Global frequency and distribution of lightning as observed from space by the Optical Transient Detector. J. Geophys. Res., 108, 4005, doi:10.1029/2002JD002347

Collier, A.B., and Hughes, A.R.W., 2011a. A harmonic model for the temporal variation of lightning activity over Africa, J. Geophys.Res., 116.

Collier, A.B. and Hughes, A.R.W., 2011b. Lightning and the African ITCZ, J Atmos. Sol-Terr. Phy., 73, 16, 2392-2398.

Collier, A. B., Bürgesser, R. E. and Ávila, E. E., 2013. Suitable regions for assessing long term trends in lightning activity. Journal of Atmospheric and Solar-Terrestrial Physics 92, 100-104.

Collini, E., Osores, M. S., Folch, A., Viramonte, J. G., Villarosa, G., \& Salmuni, G. ,2013. Volcanic ash forecast during the June 2011 Cordón Caulle eruption. Natural hazards, 66(2), 389-412.

Cooray, V., Cooray, C., \& Andrews, C. J.,2007. Lightning caused injuries in humans. Journal of Electrostatics, 65(5), 386-394.

Dai, A., Giorgi, F., and Trenberth, K. E., 1999. Observed and model-simulated diurnal cycles of precipitation over the contiguous United States. Journal of Geophysical Research: Atmospheres (1984-2012), 104(D6), 6377-6402.

Dai A., 2001. Global Precipitation and Thunderstorm Frequencies. Part II: Diurnal Variations. Journal Of Climate,14(6), 1112.

de Angelis, C. F., Mcgregor, G. R. and Kidd, C., 2004. A 3 year climatology of rainfall characteristics over tropical and subtropical South America based on tropical rainfall measuring mission precipitation radar data. Int. J. Climatol., 24: 385-399. doi: 10.1002/joc.998

Demetriades, N. W. and R. L. Holle, 2005, Lightning produced by cold season extratropical cyclones: observations related to nowcasting storm development, intensity and precipitation amounts, Conference on Meteorological Applications of Lightning Data; AMS; Tucson, AR.

Dowden, R.L., Brundell, J.B. and Rodger, C.J., 2002. VLF lightning location by time of group arrival (TOGA) at multiple sites Source. J. Atmos. Sol -Terr. Phy., 817-30.

Dowden, R. L., Holzworth, R. H., Rodger, C. J., Lichtenberger, J., Thomson, N. R., Jacobson, A. R., Lay, E. H., Brundell, J. B., Lyons, T. J., O'Keefe, S., Kawasaki, Z., Price, C., Prior, V., Ortega, P., Weinman, J., Mikhailov, Y., Woodman, R., Qie, X., Burns, G., Collier, A. B., Pinto Jr, O., Diaz, R., Adamo, C., Williams, E. R., Kumar, S., Raga, G. B., Rosado, J. M., Ávila, E. E., Clilverd, M. A., Ulich, T., Gorham, P., Shanahan, T. J. G., Osipowicz, T., Cook, G., Zhao, Y., Oct. 2008. World- 
Wide Lightning Location Using VLF Propagation in the Earth-lonosphere Waveguide. IEEE Antennas and Propagation Magazine, 50 (5), 40-60.

Dotzek N, Price C, 2009 Lightning characteristics in severe weather. In: Betz HD, Schumann $\mathrm{U}$, Laroche $\mathrm{P}$ (eds) Lightning principles, instruments and applications. Springer, Berlin, pp 487508

Drapcho, D. L., Sisterson, D., and Kumar, R.: Nitrogen fixation by lightning activity in a thunderstorm. Atmos. Environ., 17, 729-734, 1983.

Duran, A.J., R.A. Shaw, W.I. Rose, Y. Mi y Ernst, G.G.J., 2008. Ice nucleation and overseeding of ice in volcanic clouds.J.Geophys. Res., 113:D09206. Doi:10.1029/2007JD009064.

Durkee J, Mote T, Shepherd J., 2009. The Contribution of Mesoscale Convective Complexes to Rainfall across Subtropical South America. Journal Of Climate, 22(17), 4590-4605.

Emersic C, Heinselman PL, MacGorman DR, Bruning EC, 2011 Lightning activity in a hailproducingstorm observed with phased-array radar. Mon Weather Rev 139:1809-1825

Falcón, N., Williams, P., Muñoz, A. and Nader, D., 2000. Microfísica del relámpago del Catatumbo. Ingeniería UC, Junio, año/vol. 7, número 001, Universidad de Carabobo, Valencia, Venezuela.

Falvey, M. and R. Garreaud, 2007, Wintertime precipitation episodes in central Chile: Associated meteorological conditions and orographic influences. Journal of Hydrometeorology, 8, 171-193

Fraedrich, K., 1972. A simple climatological model of the dynamics and energetics of the nocturnal circulation at Lake Victoria. Q.J.R. Meteorol. Soc., 98: 322-335. doi: 10.1002/qj.49709841606

Gan, M. A.; Rao, V. B., 1991. Surface cyclogenesis over South America. Monthly Weather Review, 1991, vol. 119, no 5, p. 1293-1302.

Garreaud, R., P. Lopez, M. Minvielle, and M. Rojas, 2013, Large-Scale Control on the Patagonian Climate, Journal of Climate, 26, 215-230.

Garreaud, René, Nicora, M. Gabriela, Bürgesser, Rodrigo E., Ávila, Eldo E, 2014, Lightning in Western Patagonia Journal of Geophysical Research: Atmospheres, DOI: 10.1002/2013JD021160

Gan, M. A. ; Rao V. B., 1998. Surface cyclogenesis over South America. Monthly Weather Review, v.19, p.1293-1302.

Gan, M. A.; V. E. Kousky ;. Ropelewski, C. F., 2004. The South America monsoon circulation and its relationships to rainfall over westcentralBrazil. J. Climate, v.17, p.47-66.

Gatlin PN, Goodman SJ, 2010 A total lightning trending algorithm to identify severe thunderstorms. J Atmos Ocean Tech 27:3-22

Goldberg, R. A., J. R. Barcus, L. C. Hale, and S. A. Curtis, 1986., Direct Observation of Magnetostatic Electron Precipitation Stimulated by Lightning. J. Atmos. Terr. Phys., 48:293300 ,

Gomes, Chandima, M.Z.A. Ab Kadir,2011, A theoretical approach to estimate the annual lightning hazards on human beings, Atmospheric Research, Volume 101, Issue 3, August 2011, Pages 719-725

Gourbière, E., 1998: Lightning injury to human beings in France. 24th Intl. Conf. on Lightning Protection, Staffordshire Univ., Birmingham, United Kingdom, 814-819 
Gray, W. M. and Jacobson, R. W., 1977. Diurnal Variation of Deep Cumulus Convection. Mon. Wea. Rev., 105, 1171-1188.

Griffing, G. W. 1977, Ozone and oxides of nitrogen production during thunderstorms, J. GeophysRes., 82, 943-950,.

Harrison, R.G., Nicoll, K.A, Ulanowski, Z. y Mather, T.A., 2010. Self-charging of the Eyjafjallaj okull volcanic ash plume.Enviromental Research Letters, 5024004 (4pp).

Hartigan, John A., 1975."Clustering algorithms.".

Heckman, S., Williams, E. and Boldi, B., 1998. Total global lightning inferred from Schumann resonance measurements, J. Geophys. Res., 103, 31775-31779.

Helliwell, R. A., J. P. Katsufrakis, and M. L. Trimpi: Whistler-Induced Amplitude Perturbations inVLF Propagation. J. Geophys. Res., 78: 4679-4688, 1973.

Hill, R.D., Rinker, R.G., and Wilson, H.D. 1980, Atmospheric nitrogen fixation by lightning, J.Atmos.Sci., 37, 179-192,.

Hill, R.D., Rinker, R.G., and Coucouvinos, A.: 1984.Nitrous oxide production by lightning, J. Geophys.Res., 89, 1411-1421,

Holle, R.L., Lightning-caused deaths and injuries in the vicinity of vehicles. 3rd Conf. on Meteorological Applications of Lightning Data, New Orleans, LA, Amer. Meteor. Soc., 10 pp., 2008.

Holle, R.L., 2012. Diurnal variations of NLDN cloud-to-ground lightning in the United State. 22nd International Lightning Detection Conference, 2-3 April and 4th International Lightning Meteorology Conference, 4-5 April, Broomfield, Colorado, USA

Holz, A. and T. T. Veblen, 2011a, The amplifying effects of humans on fire regimes in temperate rainforests in Western Patagonia, Palaeogeography, Palaeoclimatology, Palaeoecology, 311, 82-92.

Holz, A. and T. T. Veblen, 2011b, Variability in the Southern Annular Mode determines wildfire activity in Patagonia, Geophysical Research Letters, 38.

Hordij H., Bordón S., Candurra, C.,1996, Análisis de lamarcha anual de las cartas isoceráunicas en la Rep. Argentina, VII Congreso Argentino de Meteorología, BsAs,

Hoskins, B. J. and K. I. Hodges, 2002, New perspectives on the Northern Hemisphere winter storm tracks, Journal of the Atmospheric Sciences, 59, 1041-1061.

Hoskins, B. J. and K. I. Hodges, 2005, A new perspective on Southern Hemisphere storm tracks, Journal of Climate, 18, 4108-4129.

Houze Jr, R. A., 1994: Cloud dynamics. Vol. 53, Elsevier, 523 pp.

Hutchins, M., R. Holzworth, J. Brundell, and C. Rodger, 2012, Relative detection efficiency of the world wide lightning location network, Radio Science, 47, doi 10.1029/2012RS005049.

Huschke, R. E., (Ed.) 1959. Glossary of Meteorology, 638 pp., Am. Meteorol. Soc., Boston, Mass.

http://www.inpe.br

http://www.comservicefire.com.br/docs/Para-raios/NBR\%205419\%20-\%20Para-raios.pdf

http://www.deis.gov.ar/. 
Inan, U. S., D. L. Carpenter, R. A. Helliwell, and J. P. Katsufrakis, 1985, Sub ionospheric VLF /LF PhasePeturbations Produced by Lightning-Whistler Induced Particle Precipitation. J. Geophys. Res.,90:7457-7469.

Israel, H.: "Atmospheric Electricity," Vols. I and 2. U.S. Dept of Commerce, Clearinghouse forFederal Scientific and Technical Information, TT67-51394/I, 197!. Translation of 2 Ed. of"Atmospharische Electrizitat ."Israel Program for Scientific Translation, IPST Catalog No. 1995, Jerusalem, 1971.

Jacobson, A.R., Holzworth, R.H., Harlin, J., Dowden, R.L. and Lay E.H., 2006.Performance assessment of the World Wide Lightning Location Network (WWLLN), using the Los Alamos Sferic Array (LASA) array as ground-truth.J.Atmos. Ocean. Tech., 23, 1082-92.

James, M.R., Gilbert, J.S. y Lane, S.J., 2002. Experimental investigation of a volcanic particle aggregation in the absence of a liquid phase. J Geophys Res 107:2191, doi:10.1029/2001JB000950.

James, M. M., Wilson, L. L., Lane, S. S., Gilbert, J. J., Mather, T. T., Harrison, R. R., \& Martin, R. R., 2008. Electrical Charging of Volcanic Plumes. Space Science Reviews, 137(1-4), 399-418. doi:10.1007/s11214-008-9362-z

Jayaratne E.R., C.P.R. Saunders, and J. Hallet, 1983, Laboratory studies of the charging of soft-hail during ice crystal interactions, Q. J. R. Meteorol. Soc. 109 pp.609_630.

Jorgensen, David P., and Margaret A. LeMone, 1989, Vertically velocity characteristics of oceanic convection. Journal of the atmospheric sciences 46.5 621-640.

Kane RJ. , 1991 Correlating lightning to severe local storms in the Northern United States. Weather Forecast6(1):3-12

Kartalev, M.D., M.J. Rycroft, M. Fuellekrug, V.O. Papitashvili, V.I. Keremidarska ., 2006. A possible explanation for the dominant effect of South American thunderstorms on the Carnegie curve. Journal of Atmospheric and Solar-Terrestrial Physics, 68, 457-468.

Keith,W. D., and Saunders, C. P. R.1990, Further laboratory studies of the charging of graupel duringice crystal interactions, Atmos. Res., 25(5), 445-464,

Kelley, M. C., D. T. Farley, E. Kudeki, and C. L. Siefring, 1984, A Model for Equatorial Explosive SpreadF. Geophys. Res. Lett., 11:1168-1171,.

Ko, M.K.W., 1986, Ligtning: a possible source of strastospheric odd nitrogen, J. Geophys. Res., 91, 5395-5404,.

Koshak, W. J., Stewart, M. F., Christian, H. J., Bergstrom, J. W., Hall, J. M., \& Solakiewicz, R. J. (2000). Laboratory calibration of the optical transient detector and the lightning imaging sensor. Journal of Atmospheric and Oceanic Technology, 17(7), 905-915.

Kummerow, C., Barnes, W., Kozu, T., Shiue, J., \& Simpson, J., 1998. The Tropical Rainfall Measuring Mission (TRMM) sensor package. Journal of Atmospheric \& Oceanic Technology, 15(3).

Laurent, H., Machado, L. A., Morales, C. A., and Durieux, L., 2002. Characteristics of the Amazonian mesoscale convective systems observed from satellite and radar during the WETAMC/LBA experiment. Journal of Geophysical Research: Atmospheres (1984-2012), 107(D20), LBA-21.

LAING, A. G. ; FRITSCH, J. M. 2000. The large-scale environments of the global populations of mesoscale convective complexes. Mon.Wea. Rev., v.128, p.2756-2776. 
Lay, E.H., Holzworth, R.H., Rodger, C.J., Thomas, J.N., Pinto, O. Jr. and Dowden, R.L.,2004, WWLLN global lightning detection system: Regional validation study in Brazil, Geophysical Research Letters, Vol. 31, L03102, doi:10.1029/2003GL018882.

LeMone, Margaret A., and Edward J. Zipser, 1980, Cumulonimbus vertical velocity events in GATE. Part I: Diameter, intensity and mass flux. Journal of the Atmospheric Sciences 37.11 (1980): 2444-2457.

Lenters, J. D. and Cook, K. H., 1995: Simulation and Diagnosis of the Regional Summertime Precipitation Climatology of South America. J. Climate, 8, 2988-3005.

Lenters J, Cook K., 1999. Summertime Precipitation Variability over South America: Role of the Large-Scale Circulation. Monthly Weather Review,127(3), 409.

Levine, J. S. and Shaw Jr., E. F.: 1983, In situ aircraft measurements of enhanced levels of $\mathrm{N}$ $2 \mathrm{O}$ associated with thunderstorm lightning, Nature, 303, 312-314,.

Lhermitte, R., and Williams E., 1985. Thunderstorm electrification: A case study, J. Geophys. Res., 90 (D4), 6071-6078, doi:10.1029/JD090iD04p06071.

Liebman B., Kiladis G., Marengo J., Ambrizzi T., and Glick J., 1999. Submonthly Convective Variability over South America and the South Atlantic Convergence Zone. Journal Of Climate, 12(7), 1877.

Liebmann B., Kiladis G., Vera C., Saulo A., and Carvalho L., 2004. Subseasonal Variations of Rainfall in South America in the Vicinity of the Low-Level Jet East of the Andes and Comparison to Those in the South Atlantic Convergence Zone. Journal Of Climate, 17(19), 3829-3842.

Liu D, Feng G, Wu S. ,2009, The characteristics of cloud-to-ground lightning activity in hailstorms overnorthern China. Atmos Res 91:459-465

Liu, C., Williams, E. R., Zipser, E. J., and Burns, G., 2010. Diurnal Variations of Global Thunderstorms and Electrified Shower Clouds and Their Contribution to the Global Electrical Circuit. Journal of the atmospheric sciences 67.2.

López, Raúl E., and Ronald L. Holle, 1996,"Fluctuations of lightning casualties in the United States: 1959-1990." Journal of Climate 9.3 , 608-615.

Lòpez, Raú E., and Ronald L. Holle, 1998. Changes in the Number of Lightning Deaths in the United States during the Twentieth Century. Journal Of Climate 11, no. 8: 2070.

Lyons, W. A., Nelson, T. E., Williams, E. R., Cramer, J. A., and Turner, T. R., 1998. Enhanced positive cloud-to-ground lightning in thunderstorms ingesting smoke from fires. Science, 282(5386), 77-80.

Lyons, W. A., Stanley, M. A., Nelson, T. E., Cummer, S. A., Huffines, G. R., and Wiens, K. C., 2008. Supercells and sprites. Bulletin of the American Meteorological Society, 89(8), 11651174.

Machado L, Rossow W, Guedes R, Walker A., 1998. Life Cycle Variations of Mesoscale Convective Systems over the Americas. Monthly Weather Review, 126(6), 1630.

MacGorman DR, Burgess DW, 1994, Positive cloud-to-ground lightning in tornadic storms and hailstorms.Mon Weather Rev 122:1671-1697

MacGorman, D. R., Rust, W., Krehbiel, P., Rison, W., Bruning, E., \& Wiens, K., 2005. The Electrical Structure of Two Supercell Storms during STEPS. Monthly Weather Review, 133(9), 2583. 
Mäkelä, A., E. Saltikoff, J. Julkunen, I. Juga, E. Gregow, and S. Niemelä , 2013, Cold-Season Thunderstorms in Finland and Their Effect on Aviation Safety, Bulletin of the American Meteorological Society, 94, 847-858.

Mäkelä, A., P. Rossi, and D. M. Schultz, 2011, The daily cloud-to-ground lightning flash density in the contiguous United States and Finland. Monthly Weather Review, 139, 13231337.

Machado L, Rossow W, Guedes R, Walker A., 1998. Life Cycle Variations of Mesoscale Convective Systems over the Americas. Monthly Weather Review, 126(6), 1630.

Mapes, Brian E., Thomas T. Warner, Mei Xu, Andrew J. Negri, 2003. Diurnal patterns of rainfall in northwestern South Smerica. Part I: Observations and context. Mon. Wea. Rev., 131, 799-812.

Market, P. S., C. E. Halcomb, and R. L. Ebert , 2002, A climatology of thundersnow events over the contiguous United States, Weather and forecasting, 17, 1290-1295.

Markson, R., and Price, C., 1999. Ionospheric potential as a proxy index for global temperatures,Atmos. Res., 51, 309-314

Markson, Ralph, 2007, The global circuit intensity: Its measurement and variation over the last 50 years. Bulletin of the American Meteorological Society 88.2 (2007): 223-241.

Marengo, J. A., Liebmann, B., Vera, C. S., Nogués-Paegle, J., and Báez, J., 2004. Lowfrequency variability of the SALLJ. CLivAR exchanges, 9(1), 26-27

Marino, M., 2007: "Variabilidad de la precipitación en la Argentina en diferentes escalas temporales relacionada con actividad convectiva observada" Tesis Doctoral, Universidad de Buenos Aires

Markgraf, V. and L. Anderson, 1994, Fire history of Patagonia: clima te versus human cause, Revista do Instituto Geológico, 15, 35-47.

Markson, R., and Price, C., 1999. Ionospheric potential as a proxy index for global temperatures, Atmos. Res., 51, 309-314.

Martínez, M., Ramírez, J. and Montaño, R., 2003. Actividad de Rayos en Venezuela Utilizando la Data del Sensor Óptico (LIS) del proyecto TRMM de la NASA. Revista Científica, Facultad de Ingeniería Universidad del Zulia, No. 2.

Mason B., A, 1953, critical examination of theories of charge generation in thunderstorms, Tellus 5 (1953), pp.446460.

Mather, T.A. y Harrison, R.G, 2006. Electrification of volcanic plumes. Surv Geophys 27:387432, doi: 10.1007/s10712-006-9007-2

Matsudo, C. M., and Salio, P. V., 2011. Severe weather reports and proximity to deep convection over Northern Argentina. Atmospheric Research 100.4, 523-537

McNutt, S.R. y Williams, E.R., 2010. Volcanic lightning: global observations and constraints on source mechanisms, Bulletin of Volcanology, Vol. 72 Issue 10, p1153-1167.

Miura, T., Koyaguchi, T. y Tanaka, Y., 2002. Measurements of electric charge distribution in volcanic plumes at Sakurajima Volcano, Japan, Bulletin of Volcanology, Vol. 64 Issue 2, p75-93,

Montanya J, Soula S, Pineda N, van der Velde O, Clapers P, Sola G, Bech J, Romero D, 2009 Study of the total lightning activity in a hailstorm. Atmos Res 91:430-437

Moore C.B.and B. Vonnegut, 1977, The thundercloud, Golde, R.H. (Ed.): Lightning, vol. 1: Physics of lightning (Academic Press, San Diego, CA). 
Muñoz, E., Busalacchi, A.J., Nigam, S., and Ruiz-Barradas, A., 2008. Winter and Summer Structure of the Caribbean Low-Level Jet. J. Climate, 21, 1260-1276, doi: 10.1175/2007JCLI1855.1

Naccarato, K. P., Pinto, O. and Pinto, I. R. C. A., 2003. Evidence of thermal and aerosol effects on the cloud-to-ground lightning density and polarity over large urban areas of Southeastern Brazil. Geophysical Research Letters 30.13

Negri, A.J., Anagnostou, E.N. and Adler, R.F., 2000. A 10-yr Climatology of Amazonian Rainfall Derived from Passive Microwave Satellite Observations. J. Applied Meteo., 39, 42-56.

Negri, A., T. Bell, and L. Xu, 2002. Sampling of the Diurnal Cycle of Precipitation Using TRMM. Journal of Atmospheric and Oceanic Technology, 19 (9), 1333-1344

Natl Geogr, 2007, (photo) Sept issue, National Geographic magazine, 212, 14-15

Nesbitt, S.W., Zipser, E.J. and Cecil, D.J., 2000. A Census of Precipitation Features in the Tropics Using TRMM: Radar, Ice Scattering, and Lightning Observations. J. Climate, 13, 40874106.

Nesbitt S. and Zipser E., 2003. The Diurnal Cycle of Rainfall and Convective Intensity according to Three Years of TRMM Measurements. Journal Of Climate, 16(10),1456.

Neshyba, S. and T. R. Fonseca, 1980, Evidence for counterflow to the west wind drift off South America. Journal of Geophysical Research: Oceans (1978-2012), 85, 4888-4892.

Nicholson, S.E., 2000. The nature of rainfall variability over Africa on time scales of decades to millenia, Global and Planetary Change, 26, 1-3, 137-158.

Nicholson, S.E., 2001. Climatic and environmental change in Africa during the last two centuries.Climate Research, 17.

Nicolini, M., and Saulo, A. C., 2006. Modeled Chaco low-level jets and related precipitation patterns during the 1997-1998 warm season. Meteorology and Atmospheric Physics 94.1-4, 129-143.

Nicora M. Gabriela, Quel Eduardo, Bürgesser Rodrigo, Ávila Eldo, 2013. Electric Atmospheric Activity in Argentina, a Study for Estimating the Annual Death Rate by Lightning,; International Symposium on Lightning Protection, Bello Horizonte - Brasil

Nicora, M. G., Búrgesser, R. E., Rosales, A., Quel, E. J., \& Ávila, E. E. ,2013. Actividad electrica asociada a la erupción del complejo volcánico Cordón Caulle durante 2011. Meteorologica, 38(2), 121-131.

Nicora, M. Gabriela, Eduardo J. Quel, Rodrigo E. Bürgesser, Eldo E. Ávila trabajo Electric Atmospheric Activity in Argentina, a Study for Estimating the Annual Death Rate by Lightning Lightning Protection (XII SIPDA), 2013 International Symposium on. IEEE, 2013.

Nieto Ferreira, R., Rickenbach, T. M., Herdies, D. L., and Carvalho, L. M. V., 2003. Variability of South American convective cloud systems and tropospheric circulation during JanuaryMarch 1998 and 1999. Mon. Wea. Rev., 131, 961-973.

Noxon, J. F. 1976, Atmospheric nitrogen fixation by lightning, Geophys. Res. Lett., 3, 463465.

Oki, T. and Musiake, K., 1994. Seasonal Change of the Diurnal Cycle of Precipitation over Japan and Malaysia. J. Appl. Meteor., 33, 1445-1463.

Ogawa, T., and Komatsu, M., 2009. Q-bursts from various distances on the Earth. Atmospheric Research, 91(2), 538-545. 
Paltridge and Platt, 1976. Radiative Processes in Meteorology and Climatology, Elsevier, 6263.

Pereyra, R. G., Avila, E. E., Castellano, N. E. and Saunders, C. P. R., 2000. A laboratory study of graupel charging. J. Geophys. Res., 105, 20803-20812.

Pereira, L. G. and Rutledge, S. A., 2006. Diurnal Cycle of Shallow and Deep Convection for a Tropical Land and an Ocean Environment and Its Relationship to Synoptic Wind Regimes. Monthly Weather Review 134:10, 2688-2701.

Pereyra, R. G., Bürgesser, R. E. and Ávila, E. E., 2008, Charge separation in thunderstorm conditions,J. Geophys. Res., 113, D17203, doi:10.1029/2007JD009720.

Perez AH, Wicker LJ, Orville RE, 1997 Characteristics of cloud-to-ground lightning associated with violent tornadoes, Wea. Forecasting 12:428-437

Petersen, W. A., and Rutledge, S. A., 1992. Some characteristics of cloud-to-ground lightning in tropical northern Australia. Journal of Geophysical Research: Atmospheres (1984-2012), 97(D11), 11553-11560.

Petersen, W. A., Carey, L. D., Rutledge, S. A., Knievel, J. C., Johnson, R. H., Doesken, N. J., McKee, T. B., Vonder Haar, T., and Weaver, J. F., 1999. Mesoscale and radar observations of the Fort Collins flash flood of 28 July 1997. Bulletin of the American Meteorological Society, 80(2), 191-216.

Petersen, W. A., Nesbitt, S. W., Blakeslee, R. J., Cifelli, R., Hein, P., Rutledge, S. A., 2002. TRMM Observations of Intraseasonal Variability in Convective Regimes over the Amazon. Journal of Climate 15:11, 1278-1294.

Petersen, W. A., Christian, H. J. and Rutledge, S. A. 2005., "TRMM observations of the global relationship between ice water content and lightning", Geophys. Res. Lett., 32, L14819, doi:10.1029/2005GL023236,

Pessi, A. T. and S. Businger (2009a), Relationships among lightning, precipitation, and hydrometeor characteristics over the North Pacific Ocean. Journal of Applied Meteorology and Climatology, 48, 833-848.

Pessi, A. T. and S. Businger (2009b), The Impact of Lightning Data Assimilation on a Winter Storm Simulation over the North Pacific Ocean. Monthly Weather Review, 137, 3177-3195.

Pessi, A. T., S. Businger, K. Cummins, N. Demetriades, M. Murphy, and B. Pifer (2009), Development of a Long-Range Lightning Detection Network for the Pacific: Construction, Calibration, and Performance* . Journal of Atmospheric and Oceanic Technology, 26, 145-166.

Pierce, E. T, 1974, Atmospheric Electricity-Some Themes. Bull. Am. Meteorol. Soc., 55:11861194,

Pilipenko V., "New physical phenomena in the atmospheric lightning discharges: observations from microsatellites and ground," FP7-SPACE-2010-1,

Pinto Jr. O., Pinto, I.R.C.A. and Naccarato, K.P., 2007. Maimum cloud-to-ground lightning flash densities observed by lightning location systems in the tropical region: A review. Atmospheric Research 84, 189-200.

Pounder, C., 1972.Electrification from salt water on heated metals. J Phys D Appl Phys 5, 753-755.

Price, C. and Rind, D., 1992. A simple lightning parameterization for calculating global lightning distributions. J. Geophys. Res., 9919-9933. 
Price, C., 1993. Global surface temperatures and the atmospheric electrical circuit, Geophys. Res. Lett., 20, 1363-1366.

Price, C., 2000, Evidence for a link between global lightning activity and upper tropospheric watervapour, NATURE, Vol406, July 2000.

Price, C. and Asfur, M., 2006. Can lightning observations be used as an indicator of uppertropospheric water vapor variability? Bull. Amer. Meteor. Soc., 87, 291-298.

Price C, Asfur M, Yair Y, 2009, Maximum hurricane intensity preceded by increase in lightning frequency. Nat Geosci 2:329-332. doi:10.1038/NGEO477

Price, C. 2013,Lightning Applications in Weather and Climate, Surv Geophys

Pulwarty, R., Barry, R., and Riehl, H., 1992. Annual and seasonal patterns of rainfall variability over Venezuela. Erdkunde, 46:273-289.

Ramírez, J. and Martínez, M., 1997. Influencia de las sobretensiones por descargas atmosféricas y comportamiento de los sistemas de puesta a tierra en líneas aéreas de transmisión y distribución. Apuntes curso tutorial III. Jornadas Latinoamericanas en alta tensión y aislamiento eléctrico. Caracas, Venezuela, pp. 138-143.

Rakov, V. A., \& Uman, M. A. (2003). Lightning : physics and effects / Vladimir A. Rakov and Martin A. Uman. Cambridge, UK ; New York : Cambridge University Press, c2003.

Rao, V. B.; Cavalcanti, I., Hada, K. 1996. Annual variation of rainfall over Brazil and water vapor characteristics over South America.J. Geophys. Res. ,v.101 ,p.2539-2551.

Rasmussen, K.L., and Houze Jr, R.A., 2011. Orogenic convection in subtropical Southa merica as seen by the TRMM satellite. Monthly Weather Review 139.8, 2399-2420.

Rickenbach, T. M., Ferreira, R. N., Halverson, J. B., Herdies, D. L., and Silva Dias, M. A., 2002. Modulation of convection in the southwestern Amazon basin by extratropical stationary fronts. Journal of Geophysical Research: Atmospheres (1984-2012), 107(D20), LBA-7.

Reynolds, S.E., Brook, M. and Gourley, M.F., 1957. Thunderstorm charge separation. Journal of Meteorology 14, 426-436.

Rickenbach, T. M., 2004. Nocturnal Cloud Systems and the Diurnal Variation of Clouds and Rainfall in Southwestern Amazonia. Monthly Weather Review 132:5, 1201-1219.

Reeve, N., and Toumi, R.1999, Lightning activity as an indicator of climate change, Q. J. R.Meteorol. Soc., 125, 893-903,.

Reynolds, S. E., Brook, M. y Gourley, M. F., 1957: Thunderstorm charge separation. J. Meteor., 14, 426-436.

Roble, Raymond G., and I. S. R. A. E. L. Tzur, 1986, The global atmospheric-electrical circuit. The Earth's Electrical Environment: 206-231.

Rodger, C. J., Brundell, J. B. and Dowden, R. L., 2005. Location accuracy of VLF World Wide Lightning Location (WWLL) network: Post-algorithm upgrade. Ann. Geophys., 23, 277-290.

Rodger, C. J., Werner, S., Brundell, J. B., Lay, E. H., Thomson, N. R. Holzworth, R. H., and Dowden, R. L., 2006. Detection efficiency of the VLF World-Wide Lightning Location Network (WWLLN): initial case study. Ann. Geophys., 24, 3197-3214, doi:10.5194/angeo-24-3197-2006.

Rodger, C. J., Brundell, J. B., Holzworth, R. H., and Lay, E. H., 2009.Growing detection efficiency of the World Wide Lightning Location Network. Am. Inst. Phys. Conf. Proc., Coupling of thunderstorms and lightning discharges to near-Earth space: Proceedings of the Workshop, 23-27 June 2008, Corte, France, 1118, 15-20, doi:10.1063/1.3137706. 
Romatschke U, Houze Jr. R.A., 2010. Extreme Summer Convection in South America. Journal Of Climate, 23(14), 3761-3791.

Romatschke, U. and Houze Jr, R.A., 2013. Characteristics of Precipitating Convective Systems Accounting for the Summer Rainfall of Tropical and Subtropical South America. Journal of Hydrometeorology 14.1, 25-46.

Rudlosky, S. D., andD. T. Shea, 2013, Evaluating WWLLN Performance Relative to TRMM/LIS. Geophys. Res. Lett.,40,2344-2348, doi:10.1002/grl.50428

Rycroft, M. J.,1973, Enhanced Energetic Electron Intensities at $100 \mathrm{~km}$ Altitude and a WhistlerPropagating through the Plasmasphere. Planet. Space Sci., 21: 239-251,

Saha, S., S. Moorthi, H.-L. Pan, X. Wu, J. Wang, S. Nadiga, P. Tripp, R. Kistler, J. Woollen, and D. Behringer, 2010, The NCEP climate forecast system reanalysis, Bulletin of the American Meteorological Society, 91, 1015-1057.

Saha, S., S. Moorthi, X. Wu, J. Wang, S. Nadiga, P. Tripp, H.-L. Pan, D. Behringer, Y.-T.Hou, and H.-y. Chuang, 2012, The NCEP climate forecast system version 2. Journal of Climate.In press.doi: http://dx.doi.org/10.1175/JCLI-D-12-00823.1

Salio, P., Nicolini, M., Zipser, E.J., 2007. Mesoscale Convective Systems over Southeastern South America and Their Relationship with the South American Low-Level Jet. Monthly Weather Review, doi: 10.1175/MWR3305.1.

São Sabbas, F. T., Sentman, D. D., Wescott, E. M., Pinto Jr, O., Mendes Jr, O., and Taylor, M. J., 2003. Statistical analysis of space-time relationships between sprites and lightning. Journal of Atmospheric and Solar-Terrestrial Physics, 65(5), 525-535.

Saravia, J. B., and P. L. Silva Dias., 1996, "Ciclogênese no litoral sur do Brasil: Estudo de Caso." IX Congresso Brasileiro de Meteorologia, Campos do Jordão. Vol. 6. 1996.

Satyamurti P.; Ferreira, C., Gan M. A. 1990: Cyclonic Vortices over South America. Tellus , v. 42A, p.194-201.

Saulo, C., Ruiz, J. and García Skabar, Y. 2007. Synergism between the low-level jet and organized convection at its exit region. Monthly Weather Review 135.4.

Saunders, C.P.R, Keith, W.D. and Mitzeva, R.P., 1991. The effect of liquid water on thunderstorm charging. Journal of Geophysical Research 96, 11007-11017.

Saunders, C.P.R., Avila, E.E., Peck, S.L., Castellano, N.E. and Aguirre Varela, G.G, 1999, A laboratorystudy of the effects of rime ice accretion and heating on charge transfer during icecrystal/graupel collisions, Atmos. Res. 51, 99-117,

Saunders, C. P. R., Peck, S. L., Aguirre Varela, G. G., Avila, E.E. and Castellano, N.E, 2001, A laboratorystudy of the influence of the water vapour and mixing on the charge transfer process duringcollisions between ice crystals and graupel, Atmos. Res., 58, 187-203.

Saunders, C. P. R., Bax-norman, H., Emersic, C., Avila, E. E. and Castellano, N. E., 2006. Laboratory studies of the effect of cloud conditions on graupel/crystal charge transfer in thunderstorm electrification. Quarterly Journal of the Royal Meteorological Society, 132: 2653-2673. doi: 10.1256/qj.05.218.

Schultz, D. M. ,1999, Lake-effect snowstorms in northern Utah and Western New York with and without lightning, Weather and forecasting, 14, 1023-1031.

Schultz CJ, Petersen WA, Carey LD ,2009, Preliminary development and evaluation of lightning jumpalgorithms for the real-time detection of severe weather. J Appl Met Clim 48:2543-2563 
Schultz, Christopher J., Walter A. Petersen, and Lawrence D. Carey, 2011, Lightning and Severe Weather: A Comparison between Total and Cloud-to-Ground Lightning Trends. Weather \& Forecasting 26.5.

Schumann, U. and Huntrieser, H.,2007, The global lightning-induced nitrogen oxides source, Atmos.Chem. Phys. Discuss., 7, 2623-2818,

Seluchi, M. E., and A. C. Saulo, 1998: Possible mechanisms yieldingan explosive coastal cyclogenesis over South America: Experimentsusing a limited area model. Aust. Meteor. Mag., 47, 309- 320 .

Silva Días, M. A. F. ,1987, Sistemas de mesoescala y previsão de tempo a curto prazo. Rev. Bras. Meteorologia, v.2, p.133-150

Simpson G.C, On the electricity of rain and its origins in thunderstorms, Philos. Trans. A 209 (1909), pp.379_413.

Simpson G.C. and G.D. Robinson, 1941, The distribution of electricity in thundercloudsll, Proc. R. Soc. London, Ser. A 161 , pp.281329.

Simpson G.C. and F.J. Scrase, 1937, The distribution of electricity in thunderclouds,Proc. R. Soc. London, Ser. A 161 , pp.309352.

Siqueira, J. R., and Machado, L. A. T., 2004. Influence of the frontal systems on the day-today convection variability over South America. Journal of Climate, 17(9).

Siqueira, J. R., Rossow, W. B., Machado, L. A. T., and Pearl, C., 2005. Structural Characteristics of Convective Systems over South America Related to Cold-Frontal Incursions. Monthly weather review, 133(5).

Servicio Nacional de Geología y Minería - SERNAGEOMIN Observatorio Volcanológico de los Andes del Sur - OVDAS - Red Nacional de Vigilancia Volcánica - RNVV http://www.sernageomin.cl/

Smith, R. and J. Evans (2007) Orographic precipitation and water vapor fractionation over the southern Andes, Journal of Hydrometeorology, 8, 3-19.

Song, Y., Semazzi, F. H. M., Xie, L. and Ogallo, L. J., 2004.A coupled regional climate model for the Lake Victoria basin of East Africa. Int. J. Climatol., 24: 57-75. doi: 10.1002/joc.983

Sparks, R.S.J., Bursik, M.I., Carey, S.N., Gilbert, J.S., Glaze, L.S., Sigurdsson, H., y Woods, A.W., 1997.Volcanic Plumes. John Wiley \& Sons, Chichester.

Spencer, J.W., 1971, Fourier series representation of the position of the sun, Search, 2, No 5 .

Stensrud, D., 1996. Importance of Low-Level Jets to Climate: J. Climate, 9:1698-1711.

Sterling, D. R., Robinson, P. J., 1985. The diurnal variation of thunderstorm activity in the United States. Journal of Climate and Applied Meteorology, 24, 1048-1058.

Stocks, B. J., Mason, J. A., Todd, J. B., Bosch, E. M., Wotton, B. M., Amiro, B. D., ... \& Skinner, W. R. ,2002,. Large forest fires in Canada, 1959-1997. Journal of Geophysical Research: Atmospheres (1984-2012), 107(D1), FFR-5.

Stolzenburg, M., Rust, W., Smull, B. F., \& Marshall, T. C., 1998, Electrical structure in thunderstorm convective regions: 1 . Mesoscale convective systems. Journal Of Geophysical Research. Atmospheres, 103(D12), 14059. doi:10.1029/97JD03546

Stolzenburg, M., Rust, W., \& Marshall, T. C.,1998, Electrical structure in thunderstorm convective regions: 2. Isolated storms. Journal Of Geophysical Research. Atmospheres, 103(D12), 14079. doi:10.1029/97JD03547 
Stolzenburg, M., Rust, W., \& Marshall, T. C. (1998). Electrical structure in thunderstorm convective regions: 3. Synthesis. Journal Of Geophysical Research. Atmospheres, 103(D12), 14097. doi:10.1029/97JD03545

Stolzenburg, M., Marshall, T. C., Rust, W., \& Bartels, D. L.,2002, Two simultaneous charge structures in thunderstorm convection. Journal Of Geophysical Research. Atmospheres, 107(D18), ACL 5-1. doi:10.1029/2001JD000904

Takahashi, T., 1978, .Riming electrification as a charge generation mechanism in thunderstorms. J. Atmos. Sci., 35, 1536-1548.

T. Takahashi, T. Tajiri and Y. Sonoi, 1999, Charges on graupel and snow crystals and the electrical structure of winter thunderstorms, J. Atmos. Sci., 56, 1561-1578.

Tarazona J., Ferro C. and Urdaneta, A.J.,2006, Cartographic representation of the Venezuelan keraunic activity. International Council on Large Electrics Systems, August 28September 1, 2006, Paris, France.

Thomas, R.J., Krehbiel, P.R., Rison, W., Edens, H.E., Aulich, G.D., Winn, W.P., McNutt, S.R., Tytgat, G., Clark, E., 2007. Electrical activity during the 2006 Mount St. Augustine volcanic eruptions.Science 315, 1097.

Thomas, R.J., McNutt, S.R., Krehbiel, P.R., Rison, W., Aulich, G., Edens, H.E., Tytgat, G., Clark, E., 2010. Lightning and electrical activity during the 2006 eruption of Augustine Volcano. In: Powers, J., Coombs, M., Freymueller, J. (Eds.), The 2006 Eruption of Augustine Volcano: Alaska. U.S. Geological Survey Professional Paper 1769, pp. 579-608.

Torres-Sánchez H., 2010, ¿Qué rayos sabemos? Rev. Acad. Colomb. Cienc. 34 (131): 193208, 2010. ISSN 0370-3908.

Ushio, T., Heckman, S.J., Boccippio, D.J., Christian, H.J. and Kawasaki, Z.I., 2001. A survey of thunderstorm flash rates compared to cloud top height using TRMM satellite data. J. Geophys. Res. 106 (D20), 24, 089-24, 095.

Velasco, I. Y., and Fritsch, J. M., 1987. Mesoscale convective complexes in the Americas. J. Geophys. Res., 92, 9591-9613.

Velásquez, R., 2000. Mecanismos Físicos de Variabilidad Climática y de eventos extremos en Venezuela. Tesis de grado para optar al título de Licenciado en Meteorología. Universidad de Costa Rica. San José de Costa Rica. 118 pp.

Vera, C. ; Vigliarolo, P. 2000. a diagnostic study of cold-air outbreaks over South America. Mon. Wea. Rev., v.128, p.3-24.

Vera, C. S., P. K. Vigiarolo, and E. H. Berbery, 2001: Cold seasonsynoptic-scale waves over subtropical South America. Mon.Wea. Rev., 130, 684-699.

Vera, C. S.; Viguarolo, P. K.; Berbery, E. H. 2002. Cold season synoptic scale waves over subtropical South America. Mon. Wea.Rev. v.30, p.684-699.

Vera, C., Silvestri, G., Barros, V. Y Carril, A. ,2004: Differences in El Niño response over the Southern Hemisphere. J. Climate,v.17, p.1741-1753.

Villarini, G., and Smith, J. A., 2013. Spatial and temporal variability of cloud-to-ground lightning over the continental US during the period 1995-2010. Atmospheric Research, 124, 137-148.

Virts, Katrina S., Joel A. Thornton, John M. Wallace, Michael L. Hutchins, Robert H. Holzworth, and Abram R. Jacobson, 2011,Daily, seasonal, and intraseasonal relationships between lightning and NO2 over the Maritime Continent, Geophys. Res. Lett., 
Virts, K. S., J. M. Wallace, M. L. Hutchins, and R. H. Holzworth, 2013, Highlights of a new ground-based, hourly global lightning climatology. Bulletin of the American Meteorological Society. 94, 1381-1391.doi: http://dx.doi.org/10.1175/BAMS-D-12-00082.1

Vonnegut B., Possible mechanism for the formation of thunderstorm electricity , 1953,Bull. Am. Meteorol. Soc. 34 (1953), pp.378381.

Wallace, John M., and Peter V. Hobbs., 2006, Atmospheric science: an introductory survey. Vol. 92. Academic press, 2006.

Wallace, John M., 1975, Diurnal variations in precipitation and thunderstorm frequency over the conterminous United States. Monthly Weather Review 103.5 (1975): 406-419.

Wang, C. and Enfield, D.B., 2001. The tropical Western Hemisphere Warm Pool, Geophysical Research Letters, Vol. 28, 1635-1638.

Wang, C. and Enfield, D.B., 2002. A further study of the tropical Western Hemisphere Warm Pool, J. Climate, 16, 1476-1493.

Weber ME, Williams ER, Wolfson MM, Goodman SJ ,1998, An assessment of the operational utility of aGOES lightning mapping sensor. Project Report NOAA-18, MIT Lincoln Laboratory, Lexington, MA

Whitlock, C., P. I. Moreno, and P. Bartlein, 2007, Climatic controls of Holocene fire patterns in southern South America. Quaternary Research, 68, 28-36.

Whipple, F.J.W., 1929. On the association of the diurnal variation of electric potential gradient in fine weather with the distribution of thunderstorms over the globe. Quarterly Journal of Royal Meteorological Society 55, 1-17.

Williams, E.R., 1985. Large-scale charge separation in thunderclouds. J. Geophys. Res. 90, 6013-6025.

Williams ER, Weber ME, Orville RE, 1989, The relationship between lightning type and convective state ofthunderstorms. J Geophys Res 94:13213-13220

Williams, E.R., 1994. Global circuit response to seasonal variations in global surface air temperature. Monthly Weather Review 172, 1917-1929.

Williams ER et al, 1999, The behavior of total lightning activity in severe Florida thunderstorms. AtmosRes 51:245-265

Williams, E.R., Rothkin, K., Stevenson, D., Boccippio, D., 2000. Global Lightning Variations Caused by Changes in Thunderstorm Flash Rate and by Changes in the Number of Thunderstorms. J. Appl. Meteor., 39, 2223-2230.doi: 10.1175/1520-0450.

Williams ER (2001) The electrification of severe storms. In C. A. Dowswell III (ed) Severe ConvectiveStorms. American Meteorological Society, AMS Monographs, Boston, pp 527-561

Williams, E., Rosenfeld, D., Madden, N., Gerlach, J., Gears, N., Atkinson, L., Dunnemann, N., Frostrom, G., Antonio, M., Biazon, B., Camargo, R., Franca, H., Gomes, A., Lima, M., Machado, R., Manhaes, S., Nachtigall, L., Piva, H., Quintiliano, W., Machado, L., Artaxo, P., Roberts, G., Renno, N., Blakeslee, R., Bailey, J., Boccippio, D., Betts, A., Wolff, D., Roy, B., Halverson, J., Rickenbach, T., Fuentes J., and Avelino, E., 2002. Contrasting convective regimes over the Amazon: Implications for cloud electrification. Journal of Geophysical Research: Atmospheres (1984-2012), 107(D20), LBA-50

Williams, E.R., Satori, G., 2004. Lightning, thermodynamic and hydrological comparison of the two tropical continental chimneys.J. Atmos. Sol.-Terr. Phys. 66, 1213-1231. 
Williams, E.R. y McNutt, S.R., 2005. Total water contents in volcanic eruption clouds and implications for electrification and lightning, Recent Progress in Lightning Physics.

Williams, Earle R. , 2009,The global electrical circuit: A review. Atmospheric Research 91.2 : 140-152.

Williams, Earle, Mareev, Eugene, 2013, RecentProgress on the Global Electrical Circuit, Atmospheric Research, doi:10.1016/j.atmosres.2013.05.015

Wilson C.T.R., 1916, On same determinations of the sign and magnitude of electricdischarges in lightning ashes, Proc. R. Soc. London 92 , p.555.

Wilson C.T.R, 1920, Investigations on lightning discharges and the electric field of thunderstorms,Philos. Trans. A 221 , pp.73115.

Wilson C.T.R, 1929, Some thundercloud problems, J. Franklin Inst. 208 , pp.112.

World Meteorological Organization [WMO] (1953), World distribution of thunderstorm days. Part I: Tables. Geneve, 213 pp.

World Meteorological Organization, 1953. World distribution of thunderstorm days. Part 1: Tables, WMO Publ. 21, TP 6, Geneva, Switzerland.

WMO, World distribution of thunderstorm days, Part 2, WMO - No 21.TP 21, 1956

Xie, P. and P. A. Arkin, 1997, Global precipitation: A 17-year monthly analysis based on gauge observations, satellite estimates, and numerical model outputs, Bulletin of the American Meteorological Society, 78, 2539-2558.

Yair, Yoav. "New results on planetary lightning.2012, Advances in Space Research 50.3 : 293-310.

Yoshida, S., Morimoto, T., Ushio, T., Kawasaki, Z., 2009. A fifth-power relationship forlightning activity from Tropical Rainfall Measuring Mission satellite observations. J. Geophys.Res. 114, D09104, doi:10.1029/2008JD010370

Zajac, B.A., and Rutledge, S.A., 2001. Cloud-to-Ground Lightning Activity in the Contiguous United States from 1995 to 1999. Monthly Weather Review, 129, 999-1019.

Zamboni L,, Mechoso C, and Kucharski F., 2010. Relationships between Upper-Level Circulation over South America and Rainfall over Southeastern South America: A Physical Base for Seasonal Predictions. Journal Of Climate, 23(12), 3300-3315.

Zipser, E. J., Cecil, D. J., Liu, C., Nesbitt, S. W., \& Yorty, D. P. ,2006,. Where are the most intense thunderstorms on Earth?. Bulletin of the American Meteorological Society, 87(8).). 


\section{Glosario}

Actividad Eléctrica Atmosférica (AEA): Se utiliza para describir todos los procesos de intercambio de carga dentro de la troposfera

Descarga, sinónimo de Flash

Destello, sinónimo de Flash

Flash, lightning flash: Proceso de neutralización de cargas completa que involucre uno o varios eventos de descargas eléctricas (leaders, strokes, etc.) en un intervalo de aproximadamente 1s en las descargas CG. En el caso de las bases de datos de LIS su definición es diferentes y y se define en el punto $3 b$

Leader: canal conductor cargado formado tras el proceso de iniciación.

Líder, sinónimo de Leader

Lightning Es una descarga electroestática entre zonas de cargas de diferentes polaridad dentro de la nube (IC intra cloud), entre nubes (Cloud to cloud CC) o entre la nube y la tierra (cloud to ground CG). En español existen dos palabras diferentes, los IC y CC se los llama Relámpagos y los CG son Rayos Esta descarga se encuentra acompañada por el ruido del trueno

Lightning Strokes: Cada una de los intercambios de carga entre la nube y la tierra

Multiplicidad, número de strockes durante una descarga CG.

Polaridad CG strokes, pueden ser negativos o positivos de acuerdo con el signo de la carga signo de la carga eléctrica que baja de la nube al suelo

Precursor, sinónimo de Leader

Precursor escalonado descendente: Sinónimo de Leadear

Rayos: Descarga electrostática entre zonas de cargas de diferentes polaridad entre la nube y la tierra (cloud to ground $C G$ )

Relámpago: Descarga electrostática entre zonas de cargas de diferentes polaridad dentro de la nube (IC intra cloud), entre nubes (Cloud to cloud CC)

Return stroke (CG): stroke that connects to ground (see: cloud-to-ground stroke).

Sferic, o atmospheric: Señal de radio generado por un lightning stroke.

Stroke: Similar a Lightning Stroke 
Time-of-arrival (TOGA):procedimiento de localización de un strock que utiliza el tiempo de llegada medida con un conjunto de receptores. 